\title{
Designing for Learning in Use of Everyday Artefacts
}



Ph.D. Thesis

Marianne Graves Petersen

University of Aarhus, October 2002 



\section{Danish Abstract}

Et nyt Bang \& Olufsen system bliver installeret hos Paul og Sarah. B\&O sælgerne ordner den tekniske installation, demonstrerer det nye systems funktionalitet og forlader Paul og Sarah, så de kan udforske det nye vidunder. Dette er ikke en usædvanlig situation, men er alligevel en situation der vækker til eftertanke hos B\&O og bestemt også i forhold til forskningsfeltet menneske maskin interaktion. B\&O overvejer hvordan de kan sikre, at deres produkter er intuitive at bruge, og at kunderne med tiden lærer at bruge systemerne. I forhold til Menneske-Maskin interaktions området rejser denne situation flere spørgsmål end der umiddelbart kan besvares. Det er disse spørgsmål, der er drivkraften bag denne afhandling.

Denne afhandling tager fat på tre generelle udfordringer for Menneske-Maskin området. For det første undersøges konsekvenserne af computerens bevægelse fra arbejdspladsen til dens indtrængen i vores hverdagsliv. For det andet udforskes de teoretiske og praktiske implikationer af at forstå læring i brug, i modsætning til opfattelser af brug af teknologi som mere statisk. Endelig unders $\varnothing$ ges det hvordan vi kan designe for læring i brug af hverdagsartefakter, dvs. de første udfordringer angribes fra et design perspektiv.

Arbejdet, der præsenteres i det følgende, udspringer af en tradition for aktions forskning. Problemstillingerne der arbejdes med, er således resultatet af et samarbejde med interaktionsdesign gruppen på Bang \& Olufsen. Den empiriske del af afhandlingen udgøres af et langtidsstudium af B\&O TV brug i to familiers hjem. Ydermere afholdtes designworkshops med familier i private hjem, og sammen med $\mathrm{B} \& \mathrm{O}$ eksperimenteredes med forskellige former for organisering af designarbejde. Teoretisk, udforskes virksomhedsteorien som forståelsesramme for læring-i-brug. På baggrund heraf, udvikles forståelsen af artefakter som "lærings artefakter" og dette arbejde danner baggrund for en analyse af langtidsbrug af B\&O TV.

Hovedbidragene udgøres af læringsartefakt konceptet samt et sæt af design principper for hverdagsartefakter, der er udviklet på basis heraf. Ydermere præsenteres en videreudvikling af perspektivet på design og brug som stærkt sammenvævede aktiviteter, og der gives et eksempel på, hvordan forståelsen af artefakter som læringsartefakter, kan danne baggrund for en evaluering af design, ikke kun i forhold til brug, men også i forhold til den design praksis, som stod bag. Endeligt præsenteres en metodisk cyclus for design for læring i brug og de metoder og teknikker, der er udviklet i denne afhandling præsenteres i sammenhængen af denne cyklus. 


\section{Abstract}

A new Bang and Olufsen system is installed in the living room of Paul and Sarah. The $\mathrm{B} \& \mathrm{O}$ sales people do the technical set-up, demonstrate the functionality of the new system for Paul and Sarah, and leave them to explore their new wonder. Not an unusual situation, but nevertheless a situation which fosters a set of concerns at $\mathrm{B} \& \mathrm{O}$ and indeed also for the field of Human Computer Interaction. B\&O is concerned with making sure that their customers find $\mathrm{B} \& \mathrm{O}$ systems intuitive to use and over time learn to use the facilities offered by the system. Looking to the field of HumanComputer Interaction, this situation raises more questions than can be answered. These questions drive the work reported in this thesis.

The thesis deals with three general challenges for the area of HumanComputer Interaction. First, it investigates the consequences of the proliferation of computers from the workplace into our everyday lives. Secondly it examines the theoretical and practical implications of considering learning-in-use, as opposed to more static views on technology use. Finally, it examines how we can come to design for learning in use of everyday artefacts, i.e.it aims at approaching the first challenges from a design perspective.

The work presented in the following comes out of a tradition of actionoriented research. Thus the above problems emerged through collaboration with the interaction design group at Bang \& Olufsen. The empirical part of the thesis consists of a long-term study of Bang \& Olufsen television use in the home of two families. Furthermore, design workshops have been held with families in their homes, and experiments with design practice have been organised together with Bang \& Olufsen. Theoretically, activity theory is explored as a basis for understanding learning-in-use. On this basis, a framework of learning artefacts is developed, and this framework is used to analyse the long-term study of $\mathrm{B} \& \mathrm{O}$ use.

The main contributions of this thesis is the framework of learning artefacts and a set of design principles for everyday artefacts, developed on the basis of this framework. In addition, it presents a further development of the perspective of design and use as strongly related and provides an example of how the framework of learning artefacts allow us to evaluate design, not only against use but also aga inst the design practice, which produced it. Finally, the thesis offers a methodological cycle for designing for learning in use and the methods and techniques developed as part of this thesis are framed herein. 


\section{Table of Contents}

\section{PART I-SUmmary}

DANISH ABSTRACT.

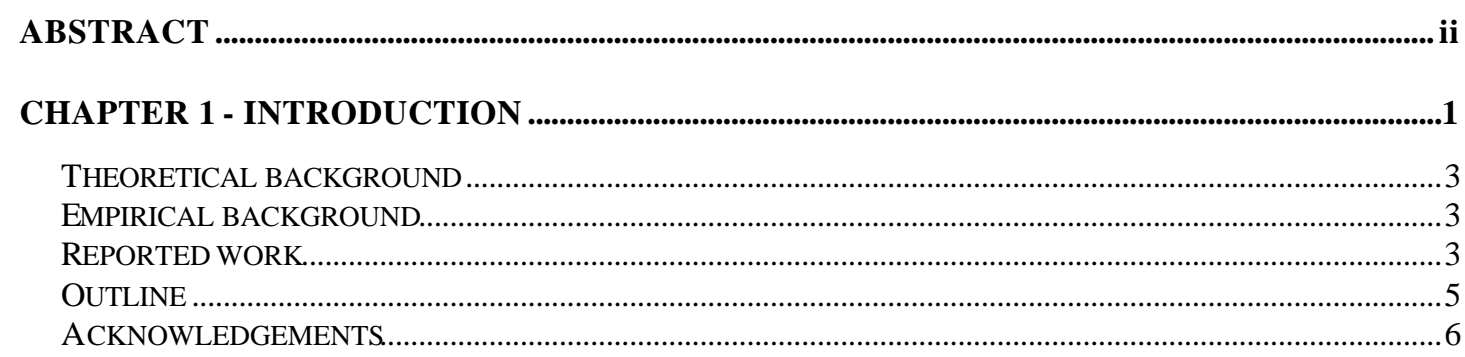

CHAPTER 2 - LIVING WITH EVERYDAY ARTEFACTS ...................................................................

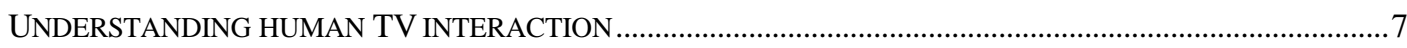

EVERYDAY ARTEFACTS IN AN ACTIVITY THEORETICAL PERSPECTIVE ...................................................12

METHODOLOGICAL EXPERIENCES FROM STUDYING TV USE IN THE HOME ……………........................

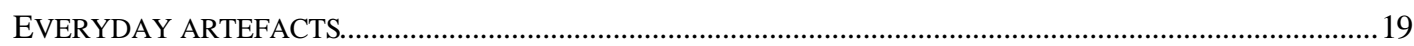

CHAPTER 3 - LEARNING IN USE OF EVERYDAY ARTEFACTS .................................................21

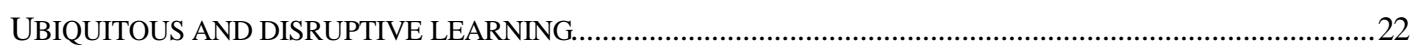

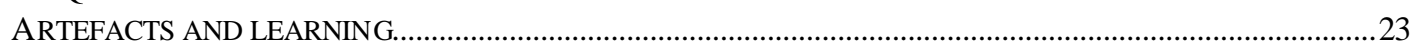

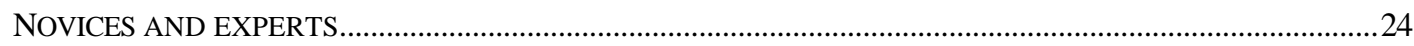

MOTIVES AND THE DYNAMICS OF LEARNING...……………………………………………....2

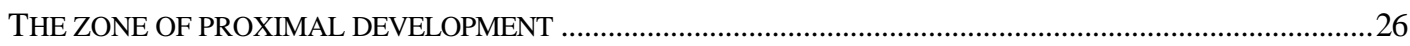

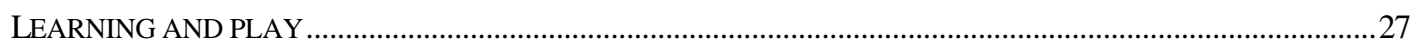

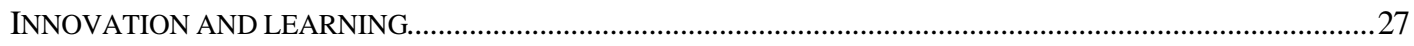

LEARNING IN USE OF EVERYDAY ARTEFACTS..................................................................................2

LEARNING IN USE OF EVERYDAY ARTEFACTS......................................................................................

CHAPTER 4 - FROM MENTAL MODELS TO LEARNING ARTEFACTS ......................................31

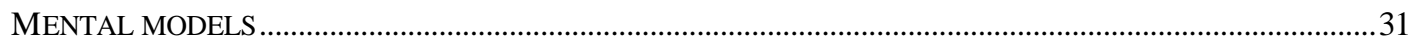

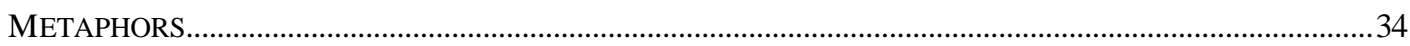

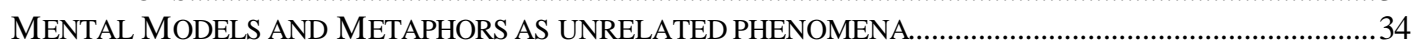

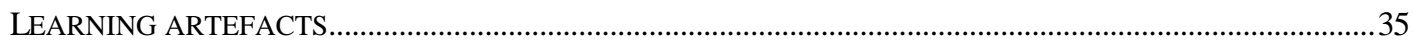

LEARNING ARTEFACTS - DEFINITION ………………………………………………………….....

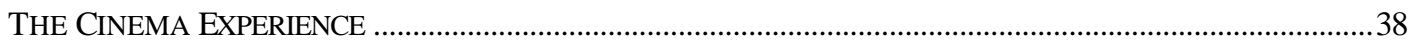

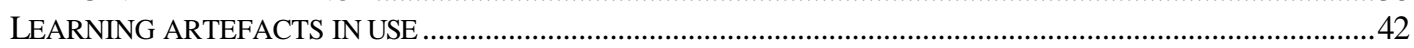

LEARNING ARTEFACTS AND DESIGN............................................................................................. 46

FROM MENTAL MODELS TO LEARNING ARTEFACTS...............................................................................4

CHAPTER 5 - DESIGNING FOR LEARNING IN USE OF EVERYDAY ARTEFACTS .............49

ARTEFACTS AS CRYSTALLISED DESIGN PRACTICE....................................................................................49

TOWARDS RE-DESIGNING THE CINEMA EXPERIENCE ……………………………………………......

SUPPORTING COLLABORATION IN A MULTIDISCIP LINARY DESIGN TEAM ..................................................54

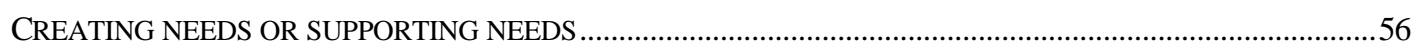

DESIGNING EVERYDAY ARTEFACTS WITH FAMILIES AT HOME .............................................................56

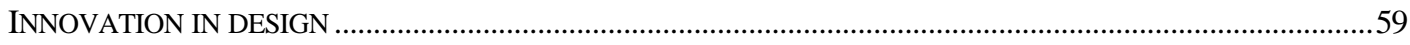

A DESIGN CYCLE FOR LEARNING AND LIVING WITH EVERYDAY ARTEFACT S...............................................59

DESIGNING FOR LEARNING IN USE OF EVERYDAY ARTEFACTS................................................................61

CHAPTER SIX - RESEARCH METHODOLOGY ..........................................................................................63

CHAPTER 7 - CONCLUSION............................................................................................................................................67

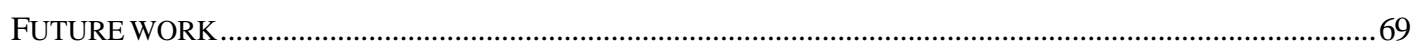




\section{PART II - Papers included in the thesis}

[P1] Bødker, S. \& Petersen, M. G. (2000) DESIGN FOR LEARNING IN USE In Scandinavian Journal of Information Systems, vol. 12, pp. 61-80..

[P2]Petersen, M. G., Madsen, K. H. and Kjær, A. (2002) USABILITY OF EVERYDAY

TECHNOLOGY - EMERGING AND FADING OPPORTUNITIES. In ACM Transactions.

on Computer-Human Interaction, Vol. 9, No. 2, June 2002, pp. 74-105.

[P3]Kjær, A., Madsen, K. H. \& Petersen, M. G. (2000) METHODOLOGICAL CHALLENGES IN THE STUDY OF TECHNOLOGY USE AT HOME. In Home Informatics and Telematics: Information, Technology and Society, Sloane, A. and van Rijn, F. (Eds.) Boston: Klüwer Academic Publishers, pp.45-60.

[P4]Baillie, L. and Petersen, M. G. (2001) EMERGING THEMES IN DESIGNING

HOUSEHOLD ENVIRONMENTS. In Proceedings of the OIKOS2001 Workshop, Aarhus

University Press, pp. 44-46...

[P5]Petersen, M. G. and Baillie, L. (2001) METHODOLOGIES FOR DESIGNING FUTURE HOUSEHOLD TECHNOLOGIES . In Proceedings of the OIKOS2001 Workshop, Aarhus University Press, pp. 47-49.

[P6]Petersen, M. G. \& Madsen, K. H. (1999)SUPPORTING COLLABORATION IN MULTIMEDIA DESIGN. In Brewster, S., Cawsey, A. \& Cockton, G. (eds.) Human-Computer Interaction - INTERACT'99 (Volume II), pp. 185-190

[P7]Bødker, S., Nielsen, C. \& Petersen, M. G. (2000) CREATIVITY, COOPERATION AND INTERACTIVE DESIGN. In DIS'00 Designing Interactive Systems, New York, 17 - 19 August 2000, ACM Press, pp. 252-262. 


\section{Chapter 1}

\section{Introduction}

A new Bang \& Olufsen television is installed in the home of Sarah and Paul. The Bang \& Olufsen sales person demonstrates the effect of the cinema experience in Paul and Sarah's living room, through connecting the four speakers in the living room and widening the format of the television. Sarah is very excited about the cinema experience. She has tried it at her sister's house and seen it demonstrated in the shop where they bought the television. In fact the cinema effect was one of the major reasons for buying the system in the first case. Despite this motivation, it takes four months before Sarah is able to set up the cinema experience on her own. As she succeeds, she realises that she does not like the effect after all. It is too dramatic for her taste. Instead she finds out how to set up their system in a way that she can enjoy her favourite music played out loudly through the four speakers in the living room. She invents the concert experience.

The above case illustrates the challenges that are taken up in this thesis, namely that of how to design for learning in use of everyday artefacts. Starting with learning in use, from a perspective of activity theory, this work insists on taking seriously that use of technology develops and changes over time in a dialectical relation with the material surroundings. As it happened in the above example where Sarah explored the cinema experience offered by her new Bang \& Olufsen TV but finally abandoned it, and instead invented the concert experience. This ongoing learning in use is for instance not captured in traditional HCI studies (Bannon 1991) nor usability tests held in usability laboratories [P2] (Bødker \& Petersen 2000), which often forms the basis of usability work (Borgholm \& Madsen 1999). This thesis seeks to establish a foundation, both theoretically and methodologically, for moving beyond the traditional snapshots of use to focus on learning in use.

Secondly, focusing on an everyday artefact like a Bang \& Olufsen appliance is different from dealing with more traditional, work-oriented technologies. Such 
artefacts are unaccompanied by any direct training and there is no immediate community of practice (Lave \& Wenger 1991) surrounding their use as we normally find it in work settings. Thus everyday artefacts are characterised by the need for them to stand on their own in use situations, they need to be self-explanatory, and they need to appeal and reveal their opportunities. Moreover, we face further challenges with respect to the everyday artefacts that are positioned in private homes. Studying technologies like a Bang \& Olufsen Television implies dealing with privacy issues and sporadic use [P5] (Kjær et al. 2000). To put it more broadly, designing domestic technologies implies a concern for the special order of the household (O'Brien et al. 1997) and for the values and interests of the households, i.e. we need to design for the domestication of technologies (Silverstone 1992).

The two themes of learning in use and everyday artefacts are also interconnected. First of all, everyday artefacts, like other artefacts are developed through use and in turn changes use. Secondly, everyday artefacts very much stand on their own, thus they need to be self-contained and support users in gradually explore the potentials of the artefacts, with respect to their practice and daily life. The $\mathrm{B} \& \mathrm{O}$ case points to some of the resources we have in dealing with these challenges. The cinema experience, which triggered and motivated Sarah's exploration of the Bang \& Olufsen Television, was formulated and demonstrated already in the shop where Sarah and her husband bought the TV. Thus the TV does not stand completely on it's own. In this example we see how the sales process had a role in motivating Sarah's exploration of the television and how it supported the move from the cinema experience to the concert experience. This is well in line with the perspective of Henderson (1991), who sees salespeople, service, and repair folks etc. as co-designers of a continuing design and with Grudin (1990b) who argues that field support, documentation and training form part of the interface. Thus in the context of everyday artefacts the process of buying and choosing the technology can act as a resource for the later exploration of the technology.

Last but certainly not least, the design process is a resource in dealing with the challenges of learning use and everyday artefacts. In a classic paper, Floyd (1987) advocates for the need to maintain both a product and a process perspective in the design of interactive technologies. Further, coming from the tradition of cooperative design (Greenbaum \& Kyng, 1991), a focus on the design process follows naturally from the interest in finding means for involving users actively in the design of future products (Grønbæk et al. 1993). Moreover, Bødker describes how the processes of use and design are connected, since they both in turn develop and constrain computer artifacts (Bødker 1999). Engeström describes the relation between use and design as cycles, which mirror each other (Engeström 1987). Since a developmental perspective on use implies an interest in the process of use, the process of design also becomes a potential resource in designing for development in use. Thus this thesis looks more specifically at how we can support learning in use through focusing on the underlying design process.

Although at first, an integrated television and video recorder may seem a rather simple technology to study, it is interesting for several reasons. With its hierarchy of menu-structures, its integration with other products (in a link-system) and the distribution of the input/output devices between the screen, the remote control, the operation panel on the television and the lights on the loudspeakers, it actually turns out to be more complex than at first sight. Further it encompasses nontrivial facilities like advanced programming of the video, but still it is small enough to enable a systematic evaluation of the patterns of use. Secondly, the trend of more and 
more advanced interactive technology, being built into mundane, everyday technologies like a TV, coffee machine, washing machine etc. confirms that this is an area that needs to be dealt with within the area of HCI (Thomas and Macredie 2002). Sheer numbers also illustrate the trend. In 1998, only 2,5\% of all microprocessors, which were sold, were for PCs, the rest "went everywhere, like cockroaches - only smarter" (Thackara 2001). Thus our everyday technologies turn interactive and penetrate our lives in a way unseen before. Kuutti name them 'babyfaces' and argue that these are the blind spot of HCI community (Kuutti 1999). Moreover, the overwhelming problems people have in using apparently simple technologies like VCRs and the like (Negroponte 1995, Norman 1988, Kuuttii 1999, [P4] Baillie and Petersen. 2001), confirm that there is room for improvement in this area.

\section{Theoretical background}

The work of this thesis represents a continuation of a longstanding effort in developing activity theory as a framework for Human-Computer Interaction (Bødker $1991 \& 1999$, Bertelsen 1998, Nardi 1996). More specifically, this thesis takes as its starting point the view on use and artefacts as developing in a dialectical relationship (Bødker 1991). Further, it draws upon the work of Bødker (1999) and Engeström (1987) in viewing use and design as interconnected. The perspective on learning is adopted from Bødker (1991 \& 1999) Engeström (1987 \& 1990) and Bateson (1972), with inspiration from others (Brown \& Duguid 1996, Lave \& Wenger 1991, Lave 1996). This work also draws upon the concepts of primary secondary tertiary artefacts as proposed by Wartofsky (1973) and further developed by Engeström (1990), Cole (1996) and Bertelsen (1998). In considering the characteristics of everyday artefacts, inspiration is sought from the design community as represented by Dunne (1999) and Gaver et al. (1999). With further respect to design, the work of Schön (1983) also provides a basis for this thesis.

\section{Empirical background}

Reflecting the fundamental view on use and design as interrelated, the empirical part of this work has a foot in both camps. On the use side, a study of the adoption and long-term use of a Bang \& Olufsen integrated television and video recorder (B\&O AVANT) has been conducted in the homes of two families and over a period of 4-6 months. With respect to design, the BIDI project (Usability Work in Danish Industry) provided an interesting frame for developing usability practices. BIDI was a collaboration between researchers in computer science, information and media science plus the three first industrial usability groups established in Denmark at Danfoss, Kommunedata and Bang \& Olufsen. The focus of BIDI was to move usability work from the predominant evaluations towards more design-oriented practises, focusing on collaboration and creativity in design. Particularly the collaboration with the usability group at Bang \& Olufsen (one of the partners in the BIDI project) provided the opportunity to mirror the studies of the long-term use of the B\&O AVANT in the design practice, which produced it. Moreover, with the experiences from the above studies and activities in mind, a sequence of design workshops has been held in the homes of three families.

\section{Reported work}

During the course of working on this thesis, findings have been published as described below. In the following, the main focus of the papers are indicated and 
small descriptions of their contributions are provided. This collection of papers makes up the second half of the thesis.

\section{Learning in use}

[P1] Bødker, S. \& Petersen, M. G. (2000) Design for Learning in Use. In Scandinavian Journal of Information Systems, vol. 12, pp. 61-80.

In this article, we set out to understand learning in use of computer artefacts from an activity theoretical perspective. Based on Engeström's work in particular (Engeström 1987, 1990), this lead us to construct a combined design cycle and checklist for designing "the learnable artefact". Secondly, we report on the early findings from the empirical study of television use in terms of Engestöm's levels of artefacts (Engeström 1990). Finally, the proposed design cycle is considered in light of the empirical findings.

[P2] Petersen, M. G., Madsen, K. H. and Kjær, A. (2002) Usability of Everyday Technology - Emerging and Fading opportunities. In ACM Transactions on Computer-Human Interaction, Vol. 9, No. 2, June 2002, pp. 74-105.

This paper further elaborates on Engeström's levels of artefacts. It applies his framework to analyse a long-term study of Bang \& Olufsen television use in the homes of two families. Engeström's artefacts are developed into the idea of learning artefacts and design principles are developed of how to design for learning in use. It establishes the need to design learning artefacts supporting motive formation, e.g. through overall product concepts, and to link these concepts to the means of interaction as well as the physical appearance of the product.

\section{Everyday artefacts}

[P3] Kjær, A., Madsen, K. H. \& Petersen, M. G. (2000) Methodological Challenges in the Study of Technology Use at Home. In Home Informatics and Telematics: Information, Technology and Society, Sloane, A. and van Rijn, F. (Eds.) Boston: Klüwer Academic Publishers, pp.45-60.

In planning and conducting the long-term study of television use, we faced some methodological challenges with respect to capturing the development of the sporadic use of television in users' private homes. These are analysed and discussed in this paper. We unsuccessfully constructed an incident diary as a means of capturing the sporadic and developing use. We were more successful, however, in constructing iterative investigations emphasising hands-on use as part of the discussions of the present state of use. We also experimented with role play as a way of entering the situation with an open mind, letting the users describe and demonstrate in their own words, rather than having us forming their expectations.

[P4] Baillie, L. and Petersen, M. G. (2001) Emerging Themes in Designing Household Environments. In Proceedings of the OIKOS2001 Workshop, Aarhus University Press, pp. 44-46.

Based on interviews with people in their homes about problems and experiences with present household technologies, this short-paper outlines emerging themes in designing household environments. This includes the need to design for use-life cycle, to avoid functionality cramming, to take into account the often surprising uses of technology in the household.

[P5] Petersen, M. G. and Baillie, L. (2001) Methodologies for Designing Future Household Technologies. In Proceedings of the OIKOS2001 Workshop, Aarhus University Press, pp. 47-49.

This short paper discusses some of the methodological opportunities and challenges in designing future household technologies. It discusses the "Technology Tour" as a means of 
eliciting the stories of technology use in the household and how living with representations of future technologies also provoked discussions and ideas for future household technologies.

\section{Design}

[P6] Petersen, M. G. \& Madsen, K. H. (1999) Supporting Collaboration in Multimedia Design. In Brewster, S., Cawsey, A. \& Cockton, G. (eds.) HumanComputer Interaction - INTERACT'99 (Volume II), pp. 185-190.

As part of the BIDI project we experimented with design workshops to support collaboration in multimedia design at Bang \& Olufsen. In the article, we contrast this form with the traditional work practice in particular regarding the use of materials in design and the layout of the design room with respect to supporting collaboration among the different disciplines in design work. We conclude with a set of guidelines for issues to consider in planning a design session.

[P7] Bødker, S., Nielsen, C. \& Petersen, M. G. (2000) Creativity, Cooperation and Interactive Design. In DIS'00 Designing Interactive Systems, New York, 17 19 August 2000, ACM Press, pp. 252-262.

In wrapping up the BIDI project, we found that a number of activities had addressed ways of supporting creativity in design work. With a focus on history, multi-voicedness, contrasting perspectives and springboards, this work again draws upon the insights gained from activity theory. With respect to this Ph.D. project, aspects of a design workshop with Bang \& Olufsen, as well as a project with user involvement in the design of a Bang \& Olufsen television called "Talk to your TV" formed the contributions to the article.

[P8] Bødker, S., Krogh, P. G. and Petersen, M. G. (2001) Interactive Design Collaboratorium. In Proceedings of Interact2001. ACM Press, pp. 51-58.

This paper develops concepts for how to support design work with pervasive technologies. Following on from the BIDI project, it concretises how usability work can be moved towards more design oriented activities, supported by the physical and technological environments. Grounded in the design practice at $\mathrm{B} \& \mathrm{O}$ a prototype is constructed that integrates wall-, table , and mobile technologies. The experiences from experimental use of this are reported.

In the following, these papers are referred to as [PX] authors (year), e.g. the last paper is referenced as [P8] Bødker et al. (2001).

\section{Outline}

This thesis is constituted by two parts. Part one consists of the following chapters, which ties together the years of work reported in this thesis. The second part consists of a collection of papers published during this period of time, as outlined above. To give an overview of the chapters of the summary, this first chapter provides an introduction to the thesis. The following chapter two discusses the characteristics of everyday artefacts and of how they challenge our well-established design criteria in HCI. Chapter three moves on to discuss what characterises learning in use of everyday artefacts. Chapter four provides an activity theoretically informed framework for analysing learning in use of everyday artefacts, and a case of $\mathrm{B} \& \mathrm{O}$ television use over a period of six months is analysed in terms of this framework. Chapter five focuses on how we can come to design for learning in use of everyday artefacts. Chapter six provides some reflections on research methodology and finally chapter seven holds the conclusion. Part two of this thesis consists of the papers as outlined above [P1-8]. 


\section{Acknowledgements}

This thesis would never have come through if it had not been for the collaboration and support from a number of people. To name some of them: First and foremost I thank Susanne Bødker for suggesting this project in the first place and for provoking and backing me up along the way. CIT provided the financial support and encouraged the collaboration with industry, which made this project an engaging and challenging experience.

Thanks to all the partners in BIDI project, at Danfoss, Kommunedata and in particular the interaction design group at B\&O: Henning Slavensky, Karsten Moesgaard, Janne Flanding, Klaus Bærentsen, Anette, Annemette Sonnichsen and the research group in Århus: Susanne Bødker, Kim Halskov Madsen, Thea Borgholm, Pernille Markquardsen, and Christina Nielsen.

I much appreciate the patience and the kindness of all the families who volunteered to have some odd researchers hanging around in their homes and I thank Kim Halskov Madsen and Arne Kjær, who went out there, with me. Also thanks to Lynne Baillie, David Benyon and Catriona Mackaulay at Edinburgh University for nice experiences and stimulating cooperation, and to Jon von $\mathrm{S}$ Therkildsen for answering strange questions and for moral support.

The following people provided constructive comments on earlier drafts of this thesis: Olav Bertelsen, Susanne Bødker, Torkild Clemmensen, Kaj Grønbæk, Kasper Hornbæk, Ole Iversen, Kim Halskov Madsen, and Christina Nielsen. Working on this thesis would have been much less fun if it had not been for Christina Nielsen, Niels Olof Bouvin, Peter Krogh, Olav Bertelsen, "Pigernes" Frokostklub, Åbogade and SIGCHI.dk. Last but not least, I thank my family Simon, Anders and Jesper for keeping me both on and off track in the course of conducting the work reported in this thesis. 


\section{Chapter 2}

\section{Living with everyday artefacts}

In a historical perspective, the computer interface can be seen as reaching out (Grudin 1990a). While in 1950s, the focus on interface design stopped at the hardware level, in 1990, concerns for the interface comprised the work setting (ibid). Today we see how computers continue their pervasion into most aspects of our everyday life, including our homes. They are becoming everyday artefacts. Taking the specific case of long term use of $\mathrm{B} \& \mathrm{O}$ TV as a starting point, this chapter discusses how the move of interactive technology into our everyday lives challenges existing HCI theories and practices. It pushes ahead a number of questions, which are discussed in this chapter such as: How do we understand the nature of human action, when relaxation in front of the television forms part of the motive of use? How do people learn to use the ever changing technology when training is not an opportunity? What are the consequences of a domestic setting for understanding use and designing for use? Is transparency a design ideal in this case? Following this pragmatic approach, activity theory is consulted to identify means of addressing these challenges from a theoretical perspective. Finally, a set of methodological concerns and experiences from studying technology use in the home are reported.

\section{Understanding human TV interaction}

According to most HCI theories, including activity theory, humans form goals, which are realised through performing actions, accordingly (Card et al. 1983, Norman 1988, Polson \& Lewis 1990, Bødker 1991). However, falling asleep in front of the television, having it on to feel less lonely, or choosing the product for the show-off effect represent different kind of "uses" that cannot easily be modelled in terms of tasks and goals. But they are nonetheless important for understanding humancomputer interaction in the case of everyday artefacts. Monk (2000) elaborates on this, considering the nature of tasks in the context of the home: 
"Some of what we do in the home is very much like work and may be described as productive (e.g.
cleaning and shopping) or personal maintenance (e.g. sleeping, eating and grooming). Other activities,
however, have no obvious purpose, they are "leisure activities". What are the "tasks" involved in
reading a novel or watching TV? Even when we are doing work-like tasks at home our motivation and
concerns may be quite different from when we are at work being paid to do something" (Monk 2000, p.
186).

Suggesting provocative technological concepts like The (De) Tour Guide and The Dream Communicator, Gaver and Martin (2000) elaborates on Monk's view arguing that

"Rather than pursuing clear and precise goals, we often find enjoyment and meaning in experiencing the world in novel or surprising ways" (Gaver and Martin 2000, p. 211).

The cases of long term use of Bang \& Olufsen TV, in particular the approach taken by Paul also illustrates a type of use, which is not exactly driven by productive needs. In some respects the new B\&O TV is most of all a hobby for Paul. After it had been installed in their house, Paul kept the manuals by his bed for bedtime reading. On and off he experimented with the possibilities of the television, not driven by any particular need nor problem but rather to investigate and play with the technology for its own sake. Moreover, the Bang \& Olufsen TV often works in the periphery of human attention. In one of the families, the television is most often turned on after dinner, and stays on for the rest of the evening. The family members then wanders on and off from it, intertwining with their other activities. Other types of everyday artefacts are emerging which also support shifting degrees of attention. Go et al. (2000) have developed a concept of family ware, which are small personalised interaction devices embedded in everyday things, supporting affective communication among family members and lovers. For instance a couple may each wear a necklace with a stone in, where the one's stone turns warm as the partner holds his stone in the hand. In this way lovers may give a delicate sign that they are thinking of each other (or not!). The success of such artefacts relies exactly upon their ability to operate in the periphery of human attention, they are made explicitly to be non-obtrusive and to not disturb users at work while performing some other "primary" tasks. This type of use, is not well understood within the area of HCI and it is certainly not easy to evaluate in a usability lab since time and emotions are inherently important aspects of this type of use.

Another characteristic that distinguishes Bang \& Olufsen technology use from the use of more work-oriented artefacts is that no training can be assumed. Thus the technologies are met with what ever preconditions people have, and the room for setting expectations and providing support is limited to conventions, the sales and marketing process, and in the case of the Bang \& Olufsen products also the installation in the home by $\mathrm{B} \& \mathrm{O}$ technicians. Furthermore, the immediate community of practice (Lave \& Wenger 1991) is in daily life also limited to the people who live together. Thus access to more capable peers is rather limited in the case of Bang \& Olufsen appliances. This sets demands for the technology to be self-explanatory and for identifying new means of supporting learning in use. This is discussed further in chapters three and four.

Moreover, the $\mathrm{B} \& \mathrm{O}$ customers we visited were very excited to own $\mathrm{B} \& \mathrm{O}$ products. One of the families are members of the $\mathrm{B} \& \mathrm{O}$ club, meaning that they are invited to special events in the $\mathrm{B} \& \mathrm{O}$ boutique, when, for instance, new products are launched. Thus part of the role of a Bang \& Olufsen product is to signal a certain lifestyle, and provide a certain feeling of identity from such everyday technologies. A Bang \& Olufsen system is a point in case of Norman's (1999) third design axiom for Information appliances: "Pleasurability - Products should be pleasurable, fun, 
enjoyable. A joy to use and a joy to own" (ibid, p. 67, own emphasis MGP). This is in compliance with others who have pointed to the life style aspect (Blyth 1999) as well as the aesthetic appearance (Silverstone et al. 1992) as some of the prime motivations for purchasing technology. In the extreme cases, this type of technology may never be used, but still a pleasure to own. This discussion takes us into the area of marketing, and it certainly raises problems, which we are not used to address within the area of HCI. Importantly, this thesis is concerned with the usability of everyday artefacts as opposed to the marketing of these, that is satisfaction after purchase rather than purchase alone (Siegel and Dray 2001).

\section{Aesthetics and everyday artefacts}

Bang \& Olufsen explicitly strives for aesthetically pleasing user interfaces (Bærentsen 1998a). However, the ideal of aesthetics is not captured in established principles like transparency (Winograd and Flores 1986, Bødker 1991), consistency (Nielsen and Molich 1990, Reisner 1990, Shneiderman 1998) nor the ISO standard for usability, which includes efficiency, learnability and satisfaction (ISO 9241-11, 1998). But the field of HCI is starting to see that we need to move beyond traditional usability in terms of effectiveness and efficiency and look seriously at other factors including aesthetics (Kurosu and Kashimura 1995, Tractinsky 1997, Dunne 1999, Hassenzahl et al. 2000, Karvonen 2000, Bertelsen 2001). Surprisingly, much of the effort on aesthetics in the HCI community consists of constructing experiments in controlled and contrived settings establishing correlation factors between aesthetics and usability (e.g. Kurosu and Kashimura 1995, Tractinsky 1997, Hassenzahl et al. 2000). The argument goes that in the interest of selling products, there should be more focus on apparent usability, which appears to be correlated with aesthetics (Kurosu and Kashimura 1995, Tractinsky 1997) or appeal (Hassenzahl et al. 2000), but not with actual usability. This work serves mainly to maintain the gap between aesthetics and usability or between the rational and emotional (Karvonen 2000). This work maintain the old saying (e.g. Norman 1988) that aesthetics serve to hide bad interaction design and therefore most often become associated with lack of usability (Karvonen 2000).

Karvonen however emphasises the important observation that judgements on aesthetic is highly context dependent and that it requires a maturity of media before they have an aesthetics of their own (ibid). In Bertelsen's terms (2001) the above work represents a classical understanding of aesthetics viewing it as catharsis, pleasure and balance. Referring to the notion of tertiary artefacts (Wartofsky 1979), Bertelsen recommends adopting modern aesthetics (aiming for disturbance, excitement and dynamics) in interface design (Bertelsen 2001). This is also in line with Dunne (1999) who sees aesthetic experiences as one of the means for providing the gentle provocations in the design of electronic objects. This idea is elaborated in the following chapters.

\section{Questioning transparency as design ideal}

While transparency is a well-established principle in interactive systems design (Winograd \& Flores 1986, Bødker 1991), Dunne (1999) has argued that in "less utalitarian areas of our lives" transparency is a problematic ideal for interaction design.

"In design, the main aim of interactivity has become user-friendliness. Although this ideal is accepted in the workplace as improving productivity and efficiency, its main assumption, that the way to humanise technology is to close the gap between people and machines by designing 'transparent' interfaces, is problematic,..(...).. This enslavement is not, strictly speaking, to machines, nor to the 
people who build and own them, but to the conceptual models, values, and systems of thought the machines embody. User friendliness helps to naturalise electronic objects and the values they embody.. (...) .. We unwittingly adopt roles created by the Human Factors specialists of large corporations. For instance, camcorders have many built -in features that encourage generic usage; a warning light flashes whenever there is a risk of 'spoiling' a picture, as if to remind the user that they are about to become creative and should immediately return to the norm" (ibid, p.30).

Dunne sees the solution as to poetise the distance between people and electronic objects and acknowledge that the "values and ideals about life embodied in designed objects are not natural, objective or fixed, but man-made artificial and mutable" (ibid, p. 30). While Dunne pinpoints the need to move beyond the ideal of transparency and consider embedded values and provocative experiences as resources in designing for "less utilitarian areas of our lives", at times the approach he proposes run the risk of throwing the baby out with the bath water. For instance the underlying ideals and values of cooperative design (Greenbaum and Kyng (1991), Ehn (1993)), is to give future users the chance to influence their future work practice through democratic participation in the development of new work technologies. And not, as Dunne (1999) sees it as supporting seduction by machines (ibid). While his provocations are welcome, in light of the previous discussions, most of the exemplar designs he discusses seem to be created from divine inspiration of the industrial designer, whose foremost priority is to make something provocative enough to have their own names exposed. Thus we should not turn to the other extreme and have seduction by designers. Instead we can lean on to the visions of cooperative design, which indeed seems applicable in the area of everday artefacts. But notably, as discussed in chapter six, the area of everyday artefacts has fundamentally different conditions for user participation than work-oriented technologies have (in Scandinavia). However, the need to take seriously the role of personal expression and values in the home is important and is pursued in the research of this thesis through conducting design workshops with families, situated in actual private homes. Thus continuing the tradition of cooperative design, the question is not whether to involve the users or not, but how to identify means and methods, which allows users to cooperate in the construction of disruptive (Norman 1999a), innovative, and creative everyday artefacts.

\section{Creating needs or supporting needs}

The following quotes from the interviews with families in their homes suggest that it is indeed not always needs and problems in everyday life, which determine peoples' choice of everyday technologies.

John: and THIS is the apple of my eye (about his home-computer)

Sue: I thought that was me! [laughs]

John: It got delayed. [It is part of the] standard home-pc agreement. I ordered the biggest I could get. Sue: And so did all the others. The contractor was taken by surprise

John: This one is a printer, copy machine and Fax duplex

Sue: It isn't duplex

John: No, but it will be, they delivered the wrong thing... and a scanner. It can do everything. The only thing we use it for is to print, but then it came with $60 \%$ discount.

Sue: Fax! It is damned rare that you need that.

Interviewer: Have you used it?

Sue: No, we haven't.

Sue: There are things you want, which you don't need (about her own wish for a new toaster, and her boyfriend's wish for a joystick)

[The interviews are translated from Danish] 
Analogously, in the case of the cinema experience, we saw how it successfully motivated Sarah in her exploration of the new B\&O system during a long period of time. Arguably, the cinema experience does not resolve a deep-rooted problem in Sarah's life, to say the least. Indeed Bang \& Olufsen do not make reference to the problems of their customers as drivers in the design process.

"At B\&O the aim is to provide the best of two worlds, aesthetic-emotional experiences and technical functions.(...). This calls for transparent and aesthetically pleasing user interfaces" (Bærentsen 1998a, p.1).

This is in contrast to much of the present understanding of how we design interactive systems in general. As discussed by Kaptelinin, "Computer tools are used by people to reach meaningful goals that usually exist beyond the situation of human-computer interaction" (Kaptelinin 1996, p. 47-48). Consequently books on methods for designing interactive systems, often describe how the design process starts out with identifying a problem situation (Bisgaard et al 1989, Mathiassen et al. 1997). The overall task is described as adapting systems to the needs of people (Mathiassen et al 1997). This is also well in line with the tradition of cooperative design which takes a work practice as the starting point and then seeks to develop technology to address problems and conflicts in current practice (Greenbaum and Kyng 1991). Being a bit more pragmatic, Newman and Lamming (1995) argues that apart from resolving problem situations in a context of use, the problem we address is often rather to plug a gap in the company's product line. Indeed, as pointed out by several, many of the everyday technologies of today are by and large technology-driven (Negroponte 1995, Norman 1999a, Thackara 2001). Norman (1999a) and Thackara (2001) point to the established lesson of making the technology user-centred, as a way to resolve this situation. However that is a short description of a very complex process. As argued by Bertelsen (2001)

"the problem is that paradoxical one of meeting needs that don't yet exist, supporting the development of practise that we cannot yet imagine" (ibid, p. 19).

Or as worded by Dunne (1999) Hertzian Tales is concerned with

\footnotetext{
"assessing the development of objects not against whether they fit into how things are now, but the desirability of the changes they encourage (own emphasis, MGP) (ibid, p. 19).
}

Thus we cannot necessarily start with a well-defined problem in the case of designing everyday artefacts. Then what do we do? A start could be to look into related disciplines. In talking about industrial design, which can be seen as the design of everyday objects, possibly embedded with computer technology, Engholm and Michelsen (2000) argue that a design problem can originate in a diverse sets of concerns ranging from technique, production, materials, environment, market, user tests to aesthetics, prestige and identity. Engholm and Michelsen (ibid) do not mention social structures, which by others are seen as an important resource for the design of domestic technology (Harper 2001, O'Brien et al. 1999). In a recent trend on marketing, i.e. the idea of value proposition (Lanning 1998), it is suggested that a product supply focus should be replaced by a value delivery focus. Lanning suggests that value brought to the actual users through providing experiences, should drive the invention of new products. The idea is that through becoming a customer, as opposed to looking at other companies, or just asking customers what they want, a focus on value delivery can be established. Thus, while the idea behind value proposition seems interesting from the perspective of designing everyday artefacts, the methodologies referred in Lanning's approach seems to be hopelessly lacking compared to the way of understanding use praxis as developed within the area of HCI. 
One of the exemplar situations of "becomming a customer" as referred by Lanning is when a group of Honda employees at a distance videotape consumers loading groceries in the trunk of their cars in a parking lot. In contrast, in the tradition of activity theory and in our way of working with cooperative design (Greenbaum and Kyng 1991) and usability (Buur and Bødker 2000), we have found it fruitful to tear down the walls in the usability labs and engage closely with the future users. Further, the approach of value proposition assumes that users adopt predefined, static values, it holds no notion of how these values may be developed in use over time by the users, as it happened for Sarah in the case of the cinema experience.

Then how do we understand what drives the design of everyday artefacts? First, we can acknowledge that this is indeed a complex matter, and that a lot of competencies need to be represented in the design process. Apart from supporting the design process, it is also important to acknowledge that, as argued by Kaptelinin (1996) that the values and goals intended by the developers can influence users who may not even be aware of these influences.

Since this thesis is anchored in a cooperative design tradition, the question becomes one of identifying means and processes allowing future users to co-construct the values and goals inherent in future technology. Delimiting the focus to one of everyday artefacts, this thesis represents a number of approaches to this problem

- Pursuing a focus on learning in use can support users in relating to the potentials of a given technology, and judge and adapt it according to their own wishes and life context (Discussed in chapters three and four and in [P2] Petersen et al. (2002)).

- Identifying approaches for moving cooperative design traditions into the context of the home sphere (Discussed in the final section of this chapter, in chapter five on design, in Baillie et al. (in press), and [P5] Petersen and Baillie (2001)).

- Supporting collaboration in design work enabling multiple and diverse parties to cooperate in the design process, ranging from marketing, industrial designers, engineers, users etc. (Discussed in chapter five, in [P6] Petersen and Madsen (1999), [P7] Bødker et al. (2000), and [P8] Bødker et al. (2001)).

\section{Everyday artefacts in an activity theoretical perspective}

Taking about these problems in activity theoretical terms helps sort out some of the issues outlined above. From the point of view of activity theory, everyday artefacts mediate our everyday activities. Human activity is understood in terms of activity, action and operation. Activity is the why of human activity it is the motivation and emotions underlying human action, i.e. what gives meaning to our actions. Activities are most often collective and they represent the smallest unit of analysis in the framework of activity theory. Activities are realised through a series of conscious, goal-directed, individual actions. Actions in turn are accomplished through a series of unconscious operations, which are framed by the specific material conditions of the activity. While activities are the smallest possible unit of analysis in activity theory, it is also important to look beyond single activities and see how they form parts of webs of activities. 


\begin{tabular}{|c|c|c|}
\hline Human activity & Directed/guided by & Characteristics \\
\hline Activity - Why & Motive, object & Collective \\
\hline Action - What & Goal & Individual, conscious \\
\hline Operation - How & Conditions & Individual, unconscious \\
\hline
\end{tabular}

Figure 2.1 The nature of Human Activity

Ideally, artefacts allow subjects to act "through" them (Bødker 1991), they are transparent and allow us to focus on the object of our activity. When we turn on the TV to watch the news, we wish to focus on what is happening of interest in the world, and we do not want to investigate the details of the remote control, nor the technicalities of the TV. We may be forced, however, to focus on the layout of the remote control, if, for instance, the remote is new to us, if we demonstrate it to someone else or if the batteries need to be changed. In these types of situations breakdowns occur and we shift our focus from the object of our activity, i.e. events in the world, to the artefact, i.e. the television itself. Thus the use of artefacts is changing as we meet new conditions and as we gain experience in the use of the artefact and in the domain in which we operate. A consequence of this nature of artefacts is that artefacts can only be understood in use (Bannon \& Bødker 1991). Equally, the ideal of transparency is not a static feature of the interface, but evolves through use (Bardram \& Bertelsen 1995). Our way of use of the artefact in turn transform the artefact and the unanticipated use is often incorporated or crystallised in later generations of the artefact (Bærentsen 1989). This is further discussed in the following chapter three.

The level of activity is one of the distinguishing features of activity theory (Kaptelinin 1996). In contrast, cognitive, task analysis-based approaches to HCI understand human action in terms of goals and actions, e.g. GOMS (Card et al. 1983), Cognitive Walkthrough (Lewis and Wharton 1997), Perceptual Control Theory / Layered Protocols (Farrell et al. 1999). An activity theoretical perspective views actions and goals in their wider context of activities and motives. Thus the mediation between subject and object is only the "tip of the iceberg" (Engeström 1987). As illustrated in figure 2.2, use inevitably develops in a complex interplay between the acting subject, the object of the activity, and the context of use in terms of the norms and rules, the community and the division of labour.

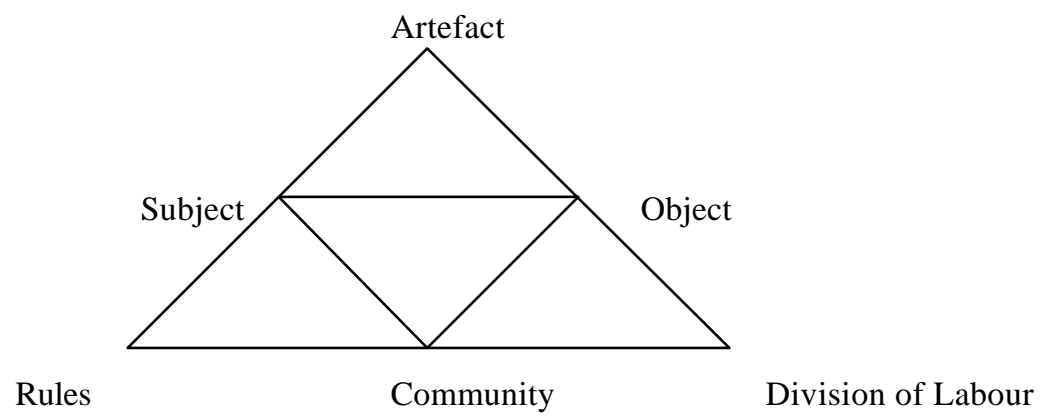

Figure 2.2 The mediated nature of human activity (cf. Engeström 1987)

In line with this, Bærentsen (1998b) points out how motives are formed with respect to societal praxis and norms. He uses a collage by Prüstel as a rather extreme example. It shows Spanish traders trying to sell a modern washing machine to native people in the New World, who do not wear any clothes at all. Bærentsen (ibid) argues that this situation is hopeless, since the people who are supposed to buy this technical 
wonder have no praxis, norms nor rules for washing clothes. They have no conceptual knowledge, making the functionality and interface of the washing machine understandable in the first place. Nor do they have any operational competencies in the area of wash. Thus societal praxis and norms are preconditions for motive formation and thus for understanding activities. While the situation referred by Bærentsen is rather extreme and far off from most meetings between Bang \& Olufsen products and customers, it is interesting for the area of everyday artefacts anyway. As interactive technology constantly seeks its way into new aspects of everyday life it challenges our assumptions and expectations as we no longer know what functionality to expect from our refrigerator, our television, our car, our heating control system etc. [P2] Petersen et al. (2002). On the other hand everyday artefacts need to find their form with respect to people's life practice. A mundane example of a conflict between existing life-practice and the visions of a new everyday artefact, is Holtzblatt's (1999) vivid description of how the picture phone conflicts with the 'drop in culture' of telephone conversations of today where people talk while cooking, doing laundry and even while in the bathroom. Holtzblatt (ibid) argues that a live picture connection would lock people back into a formal relation while talking, being dressed up and locked to a physical place. In conclusion activity theory holds a conceptual system for understanding culture, values, motivations, emotions, personality, however, without providing a full description of these phenomena (Kaptelinin 1996), nor has this broad and holistic perspective on human activity been operationalised in the context of HCI yet.

The cases discussed above suggest that it is exactly the level of activity and motivation, which help us understand the special nature of some of the above mentioned aspects of human television interaction. As suggested by Monk, we are used to deal with production-oriented tasks in HCI. However, for instance Paul's initial approach to his new television is of a more play-full character, where he investigates the possibilities and limitations of the television using the manual as a frame of reference. Understanding him as a member of the B\&O community, helps to see why Paul has an interest in the technology for the sake of the technology itself, thus Paul is interested in generally mastering the facilities of his new TV system. Another example is that of Karen who in turn finds motivation in envisioning a new division of labor in the family as she now expects to be able to program the video on her own using the teletext programming facility of the new TV. Her criterion for success becomes to master the video programming her self [P2] Petersen et al. (2002).

\section{Everyday artefacts and play}

In understanding the nature of the cinema experience, as pursued by Sarah, we may seek inspiration in Vygotsky's thoughts on the nature of play activity (Vygotsky 1979). Vygotsky sees an imaginary situation as the defining characteristic of play. Notably the imaginary situation also sets out rules for action (ibid). Like a game of chess, which comprises the universe of king, queen, knight etc. including rules for how they can move. Vygotsky argues that it is incorrect to conceive of play as activity without purpose. On children's play he notes that simply running around without purpose or rules is boring and does not appeal to children. On the contrary, the imaginary situation and the according rules, rule out a number of possibilities for action (ibid).

In play, a child "adopts the line of least resistance - she does what she most feel like doing because play is connected with pleasure - and at the same time she learns to follow the line of greatest resistance by subordinating herself to rules and thereby renouncing what she wants, since subjection to 
rules and renunciation of implusive action constitute the path to maximum pleasure in play" (ibid p. 99).

In the case of the cinema experience we saw how the imaginary situation of the cinema experience as supported in the design of the product and through demonstrations and marketing motivated Sarah's exploration of the TV. It also ruled out the possible actions of setting up surround sound and wide screen format in the living room, which Sarah set out to pursue. Thus understanding the use of everyday artefacts in terms of play in this situation help us identify the imaginary situation and how it ruled out a set of possible actions for Sarah. This perspective suggests that use is not just goal-less, headless behavior, which is hard to understand and indeed design for. Another feature of a perspective of play on the interaction with everyday artefacts is that play is a leading factor in development (ibid) and thus may serve as a resource in learning to use an everyday artefact.

\section{Methodological experiences from studying TV use in the home}

Several have addressed the problem of domestic technology use through constructing special theoretical frameworks. Venkatesh (1999) suggest a concept of Home as Living Space, which is seen as constituted by Social, Physical and Technological Spaces. Junestrand and Keijer (2001) in turn focus on Space, Time and Technology, acknowledging other relevant perspectives. In some respects, it is hard to see what makes these frameworks particularly suited for the domestic environment, as they seem more generally applicable. On the other hand, there seems to be a consistent focus on the role of the integration of technology into the physical space of the home (O’Brien and Rodden 1997, Venkatesh 1999, Junestrand and Keijer 2001). This is not an interest, which is confined to technology in a domestic setting (Bødker and Madsen 1998, Streitz et al. 1998, Bødker et al. 2001), moreover the power of the physical framing of technology is also reflected in the recent trend of pervasive computing (Mark 1999). However in the following, we discuss how such a perspective can be pursued in a domestic setting.

A first consequence of the importance of the actual physical context of technology use is the need to move evaluation and design activities into actual homes of people. Having identified ideas on what to look for, we need to develop means of doing this under the specific limitations set by the home setting e.g. the issue of privacy. The home setting challenges the ethnographic tradition, which has often provided the basis for interactive systems design (O'brien and Rodden 1997), since the issue of privacy implies that extended periods of observation is not normally possible. Thus as discussed in [P3] Kjær et al. (2000), and in line with O'brien and Rodden (1997) we conducted a series of visits ranging a couple of hours in the homes of families. We experimented with means of capturing interaction outside of our time of visit and developed the technology tour as a means of entering a home, given the special character of the home setting.

\section{The Technology Tour}

Given the limitations in terms of access to the home and inspired by the role of physical space, as discussed above, and the idea of object biography (Silverstone et al. 1992), we devised the technology tour of the home. While the term Technology Tour signals a focus on the technology itself, the idea of object biography is that it can act as a tracer of the changing social and cultural contexts of objects (ibid). It thereby provides a way to understand everyday artefacts in the broader context of their use activity, cf. discussion above. The Tour consists of asking the householders to give a 
round of their house going through each technology and tell its story triggered by questions posed by the investigator. The idea of object biography is not elaborated much by Silverstone et al. (1992), since they have an interest in understanding technology as media, rather than as tools. Therefore we developed it as described in [P5] Petersen \& Baillie (2001) for our interest in understanding present technology use, to provide a basis for developing new technology. On the tour we focus explicitly on

The role of the physical space (Silverstone et al. 1992, O'brien and Rodden 1997, Venkatesh 1996)

- how the technology is situated in the physical space, motivations for this organisation

- the stability of the physical organisation - is it changed in special situations

- possible conflicts of ownership of space

- the history of the physical organisation - how was it organised before, why was it changed

- satisfaction / dissatisfaction with the present organisation

Rules and ownership of space and technology (Engeström 1987, O'brien and Rodden 1997)

- Who has the right to do what and when

- Who has the right over whom and in what situations

- Possible conflicts, when and why

History of the technology (Engeström 1987, Bødker 1996, Silverstone et al. 1992)

- Who acquired it when and why

- Describe problematic situations you have had during times of use

Present use of the technology (Bødker and Grønbæk 1991)

- Create hands on situations based on scenarios constructed from the stories told by the members of the household

- What is favoured/disliked about it

Our experiences from the Technology Tour suggest it has the following characteristics

- It is a good start up activity. People find it quite easy to get started and you start to get a feeling of the home. At best, the whole family shows around, making discussions on possible conflicts and rules more easy going and interesting, providing a less idealised picture of use practices.

- It gives the householders the ownership of the situation, making them show the way around, and set the limits as to how far around they want to go. Some view the bedroom as a very private space. Others do not care so much.

- We got particularly interesting accounts in this way, when people started to tell stories (Brown \& Duguid, 1996). The stories are records of particular incidents, and "they are built in response to the particulars of breakdown" (ibid, p. 65). For example John's story about the first time they used the stove. John and Susanne were about to cook dinner, but they could not work out how to turn on the stove. Puzzled by the complexity of this apparently simple operation, they finally gave up, called the previous owner of the flat, and got him to tell them how to turn on 
the oven. Subsequently, they have several times used this as a "party trick", asking people to turn on the stove, having a laugh as it turns out each time that people cannot accomplish this on their own. The stories are valuable in that they "are repositories of accumulated wisdom" (ibid, p. 66) or in Venkatesh and Mazumdar's (1999) terms they provide accounts of both the social, physical and technological space of the situation, thus providing holistic accounts of the event.

\section{Questionnaires and Post-its}

Further when studying technology use in the home, we face methodological challenges in how to capture sporadic use (Kjær et al. 2000). Though for instance a TV may be on for a long time, the interaction is most often rather sporadic. Indeed the incidents, which are interesting from an evaluation or design perspective, e.g. when people try out something new, have problems, are surprised, learn from each other etc. are even more sporadic. In response to this, we experimented with a form of incident diaries (Baxter 1991) in the study of long-term use of Bang \& Olufsen TV. However, as discussed in [P3] Kjær et al. (2000), the diaries did not come to work in the setting we investigated. In total, one got filled in. While incident diaries have worked in other more work- oriented settings (Baxter 1991, Rieman 1996), for a number of reasons, they did not come to work in the study of B\&O TV use. Our hypothesis is that tired parents who relax in the sofa, when the kids have fallen asleep are just not very motivated to fill in anything. Further the frequency of our visits (approximately one month) possibly were too infrequent to remind people that we were interested in their use process and to resolve questions regarding the diaries. E.g. in the study by Rieman (1996), daily round up meetings were hold with the participants, where questions could be resolved. Rieman found that during the first days users had questions as to what constituted critical incidents. Further in this approach, we did not consider how to get feedback from all members in the families, especially the children.

\section{Engaging families in design and evaluation activities}

The users of Bang \& Olufsen TV are families, thus one of the challenges and opportunities of everyday artefact is that of dealing with a broader group of users instead of just adult workers (Venkatesh 1996), in this case with families ([P5] Petersen and Baillie 2001). While there have been few reflections on how to involve families in design and evaluation of domestic technologies, ideas are emerging on how to engage with special groups of future users. Druin (1999) in particular has taken up the challenge of working with children as partners in designing technologies for children, adopting contextual and participatory design techniques. And Gaver et al. (1999) have involved elderly in design activities using cultural probes, in the form disposable cameras, photo alb ums, and pre-stamped post cards with provocative questions such as "why do we have politicians?" etc. While in the long-term study of Bang \& Olufsen television usage, we did not focus on this issue initially however, it became more and more inevitable. Several have pointed to the issue of conflicts of ownership of space and technology between the family members (O'brien and Rodden 1997, Junestrand and Keijer 2001), however, as discussed in [P1] Bødker and Petersen (2000), the technology uses between the family members is deeply inter twined, also in more positive ways. We see how they learn from each other and help each other in the use of this type of technology. For instance as John explained how his eight year old son made him aware of the facility of storing frequently accesses teletext pages. As Paul explained, how he asked his son to make back-up copies of his 
own attempts at video recordings using their new B\&O system. And as Sarah explained how she knew she had to use the LIST button on the remote control to set up the cinema experience, from discussions among her husband and son.

Asking the whole family to take us on a technology tour of the home, as discussed above is one approach to engage with the whole family. Further, in line with Druin (1999), we also had very positive experiences with bringing flexible materials known from participatory design into design workshops in the homes of people. We supplemented paper, post-its, card-board etc. with kids dough, lego bricks, balloons etc that are materials which normally appeal to children and indeed these materials engaged the children. When bringing in the workshop toolbox to the home, the children immediately started to play around with the dough. Thus the task was to frame their play. Our experiences are in line with Druin et al. (1999) who claim that techniques from participatory design is indeed applicable for engaging with children. However our lack of success with the questionnaires also point to the old, but often neglected principle that participation in design activities should be fun (Ehn 1993). In this respect the cultural probes approach by Gaver and Dunne (1999) has something to offer. However, their approach suffers from lack of close involvement with the users, as users send post cards and picture albums to the designers who then interpret these in a setting where no users are directly involved. Thus this issue certainly requires more investigation and experimentation as we still need to identify means for supporting the collaboration among family members and how to make the activities of evaluation and design compelling and interesting for all parties. 


\section{Everyday artefacts}

In conclusion, the characteristics, challenges and opportunities for understanding everyday artefacts are summarised in the following.

The use of everyday artefacts are characterised by

- No training can be assumed

- The artefacts need to be self-explanatory

- They shift between being in focus, acted through, and operating in the periphery

- There are some fundamental but not yet completely understood differences to the use of work oriented artefacts.

- A broader picture on use is required. Aesthetics is important. Play may also be a useful perspective on the interaction between people and everyday artefacts.

- Focus should include motivations for use, not only on possible goals and actions.

Methodologically, - evaluation and design

- Move into the home in the case of domestic technologies

- Engage all users e.g. families in the design of everyday artefacts used by families

- Stimulate discussions and collaboration among the family members

- Focus on the physical organisation of the home and on the biography of objects in the home

- The activities should be fun and engaging

- Supply materials appealing to all groups of participants, e.g. kids dough, lego bricks, disposable cameras

\section{Actual techniques}

- Technology Tour

- Little success with incident diaries in the context of the home 


\section{Chapter 3}

\section{Learning in use of everyday artefacts}

One of the ideals for interaction design at Bang \& Olufsen is that of intuitive user interfaces (Bærentsen 1998a, 2000). At the same time, Bang \& Olufsen has the ambition that each of their products shall have its own identity, for it to stand out and be self-contained. An example of the consequences of these ideals is that two strongly related and contemporary products, the B\&O AVANT (integrated television and video system) and the B\&O AV5 (integrated television and CD player) have each their menu structure and accordingly each their visual presentation of the menu hierarchy. They also have different procedures for doing the same thing such as tuning TV channels. The problems facing Bang \& Olufsen in meeting these ideals are at the heart of designing for learning in use of everyday artefacts. On the one hand, these technologies need to stand out in the crowd, be appealing and unique, but on the other hand, they must be intuitive and self-explanatory, since no training can be assumed. Moreover, as discussed in the previous chapter, technology use in the home often happens in relative isolation from the community of practice (Lave and Wenger 1991), e.g. from other users of the same domestic technologies. Thus, somehow learning to use the artefact shall happen in or close to the use of the artefact itself, that is, we need to design for learning in use of everyday artefacts. This chapter provides a theoretical investigation into how we can understand learning in use of everyday artefacts and it seeks to relate the theoretical endeavours to the cases of long-term use of Bang \& Olufsen TV. 


\section{Ubiquitous and disruptive learning}

Focusing on learning in use makes the debate on whether learning can happen separately from work- or life-activity obsolete. By definition learning in use is learning which takes place through everyday actions. This perspective is well in line with the practice-based view on learning as legitimate peripheral participation, as expressed by Lave and Wenger (1991). Lave (1993) argues that learning is ubiquitous in ongoing activity. She outlines some of the premises of learning in practice as

"Learning is an integral aspect of activity in and with the world at all times. That learning occurs is not problematic. What is learned is always complexly problematic" (Lave 1993, p. 8).

However, in challenging the theory of learning as legitimate peripheral participation, Engeström argues that

"The theory of legitimate peripheral participation depicts learning and development primarily as a oneway movement from the periphery, occupied by novices, to the center, inhabited by experienced masters of the given practice. What seems to be missing is movement outward and in unexpected directions: questioning of authority, criticism, innovation, initiation of change" (Engeström, 1999, p. 12).

"The challenge to developmental theory is to account for the negative, destructive and explosive elements in developmental processes without patronising and reducing them to safe formulas at the outset" Engeström (1996, p. 29).

Engeström (1996) bases his argument on the novel "The Borderliners" by Peter Høgh, where three children grow up in a children's home under very distressing conditions, ultimately leading to one of the children committing suicide. As is evident from the Bang \& Olufsen case, there are also destructive elements of learning in the use of everyday appliances, however in this case the consequences are less disastrous and dramatic. But in line with Engeström's argument, the case of long-term use of a Bang \& Olufsen television illustrates that learning in use of an everyday artefact is not always ubiquitous. As Sarah and Paul have theirs integrated television and video installed in their home, they are introduced to the new remote control by the B\&O technicians, who installs the TV. Being a bit surprised and concerned Paul asks the $\mathrm{B} \& \mathrm{O}$ person, whether it is possible to control the new system with their old $\mathrm{B} \& \mathrm{O}$ remote control. He is told that this is possible to some extend, however only a limited subset of the functionality of the new television can be accessed with the old remote.

Figure 3.1 Bente uses the new remote control to operate the TV
After one month of use Sarah primarily uses the old remote control, severely restricting her means of operating the new television set. After another month, she has started to use the new remote control however, it is still by no means transparent to her, as evident from the very way she holds it. First she needs to take on her reading-glasses and she holds it carefully with both hands, as can be seen on the picture. 
She explains how she previously saw the new remote control as her enemy, but now is beginning to become familiarised with it. Paul jumps into using the new remote control from the beginning. An additional situation from the Bang \& Olufsen world illustrates why it is important to be aware of the cases where learning does not happen as a one-way movement from the periphery to the centre. In [P1] Bødker and Petersen (2000), a case is described where a user expects the navigation in a menu hierarchy to be similar to that of a computer, because of the look and feel of the menu structure on the TV. However, the situation breaks down repeatedly, since the user cannot identify a go-back mechanism on the remote control, because the interaction mechanisms on the remote are very different from that of a computer. In this case it could potentially have been more beneficial to consider signalling that this product is not a computer and thus cannot be operated in the same way.

\section{Artefacts and learning}

In [P1] Bødker and Petersen (2000) we discuss how learning both happens in use, between users and in the transfer of experiences between artefacts. Learning in use happens as transformations between the different levels of human activity (Bødker 1991) and in this way the use of artefacts changes in the history of use of the individual. Learning between users of e.g. Bang \& Olufsen products is challenged by the limited access to the community of practice of other Bang \& Olufsen technology owners. Moreover, artefacts also crystallise the historical, collective history of use, from one generation of artefacts to another (Bærentsen 1989). Using the case of the historical development of handguns, Bærentsen (ibid) illustrates how transformations happen historically from activities to actions and onto operations, and externalisation happens when human operations are transformed into machine operations. In the case of handguns, means of igniting the guns evolve to be built into the gun itself as fuses are added to the weapons eliminating the need for a fire, over to cartridges packaged with bursting. Thus artefacts transfer experiences, practices and inventions.

\footnotetext{
"The computer application constrains or disciplines use through what kinds of operations it allows the user to form, through the kinds of uses that it lends itself to, physically, handlingwise and with regard to the foci that the user is "offered" in or through the computer application" (Bødker 1999, p. 23).
}

But on the other hand, the shape of an artefact or a tool never predetermines use.

"A tool always implies more possible uses than the original operations that gave birth to it...(...)... Thus, the presence of a tool in an activity system does not mechanically determine the way it is actually used and conceived of by the subjects" (Engeström 1990, p. 174).

Suchman (1987) elaborates on this view, arguing that

"The inherent difficulty of conveying the use of a technology directly through its design is well known to archaeologists, who have learned that while the attribution of design intent is a requirement for an artifact's intelligibility, the artifact's design as such does not convey unequivocally either its actual or its intended use. While this problem in construing the purpose of artifacts can be alleviated, it can never fully be resolved, and it defines the essential problem that the novice user of the tool confronts. Insofar as the goal of a tool's design is that use of the tool should be self-evident, therefore, the problem of deciphering an artifact defines the problem of the designer as well" (Suchman 1987 p.18)

Since everyday technologies like Bang \& Olufsen products need to stand on their own and be self-evident, as argued by Suchman (ibid), the deciphering of the purpose of interactive technologies, defines the problem of both users and designers. She also points to this duality in distinguishing between actual and intended use, where actual use is performed by users, and the intended use represents the designers' expectations and ideals. In line with Engeström (1987), Suchman (1987) sees this problem as one, which can never fully be resolved. She sees the problem of construing the purpose of 
a technology as a problem for novice users. While this is certainly true, the problem reaches beyond this. From a developmental perspective, use and design are not static entities but are constantly transformed in a dialectical relationship with the material surroundings, where use shapes and develops the technologies at hand and design in turns frames and transforms use. This implies that the problem of conveying the use of a technology reaches beyond novice use, and is a fundamental premise for the use of technology and thus for the design of technology. To put it differently, in this perspective, learning is seen as an inseparable part of use.

\title{
Novices and experts
}

A lot of work on learning within HCI focuses on either experts or novices. E.g. GOMS models error free expert performance (Card et al. 1983), Cognitive Walkthrough (Lewis et al. 1990) focuses on the first exploratory learning of walk up and use interfaces. Here, the evaluator is asked to make judgements as to what is obvious to the user. The dichotomy between novice and expert suffer from the implicit assumption that learning is a one-way movement from noviceness to expertness. This one-dimensional understanding of learning has been critiqued by a number of people (Bannon 1991, Laufer and Glick 1996, Davis 1997, Engeström 1999). An obvious question is what happens in between, and how the development of different forms of expertise, e.g. tool, technology, domain etc. can be supported

\begin{abstract}
"the paucity of studies that are concerned with the process of development of expertise with a computer application is remarkable. The issue is not simply that expert performance needs further examination, but that we need to pay greater attention to how users become skilled in the use of the computer application (Bannon 1991, p. 36).
\end{abstract}

Clanton words this in terms of the design challenges of the game tradition

"Great games do not focus on the beginner or on the expert but on the path from one to the other and how to create challenges without exceeding the player's threshold for tolerable frustrations, how to reward success while engaging the player in the next challenge" (Clanton 2000, p. 310).

Game applications are also designed very deliberately for learning in terms of ascending levels, which the player can go through, where the line of progression corresponds to increasing levels (Clanton 2000). However in the case of home appliances, identifying one right path of progression seems too dangerous as people of very diverse backgrounds use these and for different purposes. Laufer and Glick (1996) have studied expert and novice differences from an activity theoretical perspective. They conclude that

"expert/novice differences is not exhausted by looking solely at qualitative and quantitative differences
or the organisation of knowledge, customarily associated with a logical/rationalist model of
thinking...(...)... Therefore, expertness and noviceness cannot be isolated from the individual who is the
expert or novice. To be an expert one must participate in a particular work activity and transform it and
in the process be transformed oneself" (ibid, p. 196).

It is exactly this path of learning, as it happens in actual situations of real life, that this thesis seeks to investigate. In the long term study of Bang \& Olufsen customers, we valued the ecological validity and picked a set of people who were not classified in terms of noviceness and expertness, but were $\mathrm{B} \& \mathrm{O}$ customers with their experiences, expectations and motivations. We followed them over periods of four and six monthts to investigate their learning processes, as reported in [P2] Petersen et al. (2002) and the following chapter. 


\section{Motives and the dynamics of learning}

In the perspective of activity theory, learning in use can be understood as formation of activity. Often the formations happen as transitions between the different levels of activity, e.g. actions turn into unconscious operations as the subject get experience with performing certain actions, i.e. actions become operationalised.

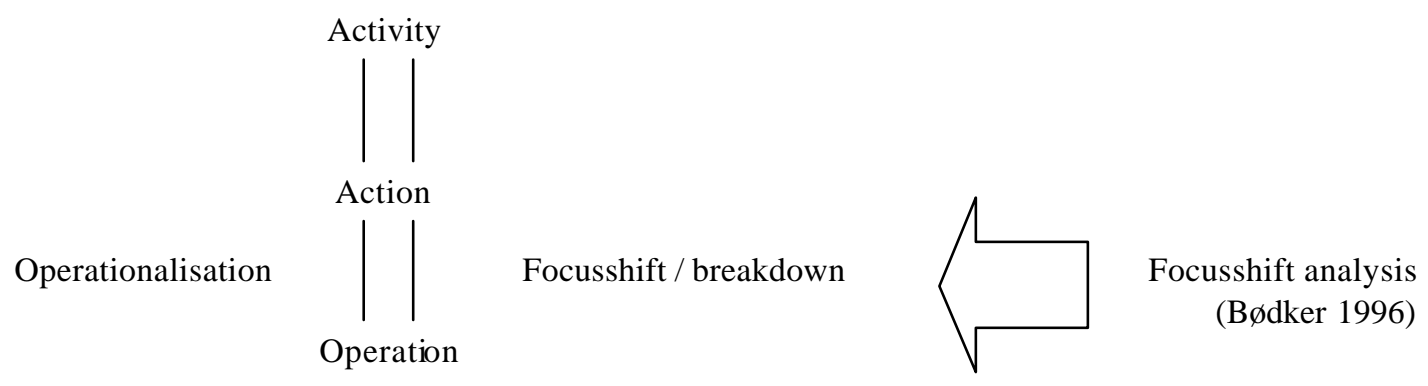

Figure 3.2 Transitions between kinds of human activity

"When operationalisation takes place, it is first very situation specific, but as the human being meets new conditions the variation of situations that can be handled by operation grows" (Bødker 1991, p. 32). However, breakdowns or deliberate focus shifts may also occur where unconscious operations are turned into conscious actions. For instance, if we get a new television, many of the things we did before without thinking consciously about them e.g. shifting between different channels suddenly become conscious actions to us, as we try to get familiar with the new television and remote control. The transformations between actions and operations in technology use is well understood both theoretically (Bødker 1991), as well as empirically and methodologically (Bødker 1996). However, as argued by Bardram \& Pedersen (1994) our understanding of the formations and transformations of activities and actions is less developed and less well understood in the context of HCI. This issue is explored in the following.

\section{Activity and motive}

Activity has to do with motive-formation and it is the motive that drives the activity and provides meaning for the activity. The level of activity is a distinguishing feature of activity theory (Kaptelinin 1996). In contrast in the cognitive science tradition, there is most often no frame of reference to the context of use, to the motive behind the activity, to the cultural norms and history of the activity nor to how these may influence the motive formation and thus the goal setting. Here analyses often proceed on the level of button presses (e.g. Card et al. 1980, Haakma 1999). An activity theoretical perspective views actions and goals in their wider context of activities and motives. In principle, activity theory holds a conceptual system for understanding culture, values, motivations, emotions, personality, however, without providing a full description of these phenomena (Kaptelinin 1996), nor has this broad and holistic perspective on human activity been operationalised in the context of HCI yet. So what characterises activities and how are they formed? The concept of activity should be understood quite literally. In the perspective of activity theory, it is a fundamental characteristic that living organisms are inherently active (Bærentsen 2000). This is in line with Engeström (1987), who challenges the reactive forms of learning typically inherent in a cognitive science approach to learning. He argues against such a patronising approach, which excludes the possibility for users to find or creat new contexts (ibid). 
In the long-term studies of Bang \& Olufsen television use, we saw some examples of how people were indeed motivated to start use and explore their new television, triggered by some overall product concepts and facilities. As discussed earlier, the concept of the cinema experience motivated Sarah's exploration and use over a long period of time. Moreover, after seeing a demonstration of a new "direct manipulation approach" to video programming, Karen was very excited as she envisioned that she now could programme the video on her own. She previously had to rely on her husband for this. As described in [P2] Petersen et al. (2002) it actually turned out to be one of the "fading opportunities", since by the time Karen needed this facility, she had forgotten how to get into the mode of "direct programming. Thus an important part of motivating initial exploration of everyday artefacts is not just hook people up to do anything, but to create a sense of potential use and let users judge and adapt according to their specific needs and life situation. The concept of the zone of proximal development provides a starting point for this endeavour.

\section{The zone of proximal development}

In considering learning within the framework of activity theory, Vygotsky (1978) emphasises the need to look beyond the present competence of users, and consider prospective development, through investigating the zone of proximal development. The zone of proximal development

"is the distance between the actual developmental level as determined by independent problem solving and the level of potential development as determined through problem solving under adult guidance or in collaboration with more capable peers" (ibid, p. 86).

Vygotsky (1978) further distinguishes between learning and development. Focusing on the case of a learning child, Vygotsky argues that learning creates the zone of proximal development, whereas development reflects the actual path of mental development. Interpreting this perspective onto practical evaluation and design of interactive technology has a number of implications. For instance in the traditional set-up of usability testing, focus is exactly on the present competence of users and not on the prospective development, i.e. how the design of the technology creates a zone of proximal development. In traditional usability testing users are taken into a lab, given a scenario or use-case and are then asked to perform a task as described in the scenario (Borgholm and Madsen 1999). The focus here is then on whether the user can accomplish the task and where she has problems. Throughout the test, the testleader should not interfere with the test (Tognazzini 1992) and has traditionally been placed in a seperate room with one-way mirrors into the test-room (Buur and Bagger 1999).

Looking into the zone of proximal development in usability work requires a different approach than the currently predominant. We have developed an explorative inquiry approach [P3] Kjær et al. (2000), which attempts to create a set- up allowing us to look into how design supports the creation of a zone of proximal development. Instead of being isolated from users, we sit down with them in their natural context. Without revealing the functionality of the product, we ask questions, which focus on the new experiences people have had with the technology. We ask about the things they would like to try out in the future, which functionality and opportunities they expect from the product and how they have become aware of these opportunities. Similarly, designing for the zone of proximal development means focussing on means for supporting people's expectations and visions of future possibilities. As discussed in the following chapter, the use of metaphors in design is one approach to accomplish this. 


\section{Learning and play}

Play can be seen to take on a number of roles in human activity (Hakkarainen 1996). However, having identified play as an interesting perspective on the interaction between human and everyday artefacts, in the previous chapter, it is interesting that several have identified the role of play in supporting learning and development (Vygotsky 1978, Hakkarainen 1996). Where Vygotsky (1978) Hakkarainen (1996) focus primarily on childhood, this perspective can potentially be a resource in the case of everyday appliances due to the lack of more capable peers, teaching etc. in this case.

"Though the play-development relationship can be compared to the instruction-development relationship, play provides a much wider background for changes in needs and consciuosness" (ibid, p.102). "It is the essence of play that a new relation is created between the field of meaning and the visual field - that is, between situations in thought and real situations (ibid. p. 104).

Again this is in line with what metaphors can do to interface design. This is further discussed in the following chapter.

\section{Innovation and learning}

As argued by Brown and Duguid (1996) working, learning and innovation are often seen as conflicting factors in work practices. This trend is also represented in some of the work, which tries to broaden up concerns for usability to cover learning and innovation. As argued by Hassenzahl et al. (2000)

\footnotetext{
"Mainly contradictory to usability is the principle to foster curiosity by designing a system that is novel and surprising (but not completely incomprehensible). In order to work, novelty and surprise must impair at least the external consistency of the software, a core principle of usability. In usability design, this might conflict with the task-related efficiency and effectiveness of the software system" (ibid, p. 202).
}

In contrast, Engeström (1987) argues that conflicting situations constitute openings for learning. In his view, the result of learning is new expanded activities. Thus he sees learning and innovation as intimately connected. Part of the reason for the different viewpoints here can be attributed to the time scale and level of activity. Hassenzahl et al. (2000) base their conclusions on a controlled experiment where people interact for two minutes with 7 different prototypes in a laboratory context. Engeström in turn discusses life-conflicts, which in the long run lead to new and improved activities. A second characteristic of the Hassenzahl et al. (2000) study is that it studies use and innovation in a laboratory situation. As argued by Brown and Duguid (1996), when studying work as it unfolds in actual practice in organisations, innovation and learning are inherently inseparable from human work practice. Acknowledging this provides a resource for supporting further innovation and learning in human work practice.

\section{Learning in use of everyday artefacts}

Being categorical, one of the differences between work technologies and everyday artefacts is that people are not forced to use everyday artefacts in the same way as they are with work technologies. There are exceptions to this of course in example of how workers work around new technologies (e.g. Bowers et al. 1995). However, if for instance a new case record system is introduced at a hospital, if a new flight control system is introduced in an air traffic control room, there is no way that the employees can avoid using these systems. They may be able to avoid aspects of the systems and they may not be happy with them, but in many cases they are unavoidable. In our 
studies on the use of existing domestic technologies, it was also striking how many items were never used at all [P4] (Baillie and Petersen 2001). Thus the challenge of everyday artefacts is in some respects more mundane. "The fundamental trick in relation to the user's learning of the device must be to get the user to do something with the equipment" (Bærentsen 2000, p. 43, original emphasis). Lessons from game design may be one way to open up the design space in this respect. Clanton (2000) explains how it is important that the player gets hooked within the first ten minutes of the game, and he emphasises the importance of the player having a positive first experience. However, where one of the criteria for success in game design, i.e. one of the measures of fun, is that people get so addicted, that they forget to stop playing (Clanton 2000), this is hardly a goal more generally for the design of everyday artefacts. That takes us more into the area of pursuasive technologies (Fogg 2000), that deliberately seeks to change user attitude and behaviour.

A second strand of work, which touches upon how users learn in use, is the theory of affordances, originally suggested by Gibson (1986) in his ecological approach to visual perception

"The affordances of the environment are what it offers the animal, what it provides or furnishes, either for good or ill" (Gibson p. 127).

In Gibson's view, affordances are not just abstract, physical properties, but they need to be seen relative to the animal. While this may sound very promising, the work on affordances by Gibson and others hold a set of severe limitations with respect to understanding learning in use of everyday artefacts. Norman (1999b) and Gaver (1991) applied Gibson's work onto the area of HCI. However in their interpretration, affordances become rather static constructs, which are there in the environment once and for all (Albrechtsen et al. 2001). This is in conflict with an activity theoretical based understanding of artefacts as evolving through use. Secondly, as discussed by Bærentsen and Trettvik (in press) and Albrechtsen et al. (2001), Gibson's framework suffers from a limited understanding of human activity. In activity theoretical terms, Gibson's concept of affordances concerns the level of operations and does not encompass notions of goals and motives (Albrechtsen et al. 2001, Bærentsen and Trettvik (in press). As saluted by Bærentsen and Tretvikk

"unless we understand what motivates people to use something, we cannot even begin to understand why they succeed or fail to realise it" (ibid, p. 9).

That is the challenge taken up in this thesis and further discussed in the following chapter.

\section{Pre-use learning}

Several have pointed out the need to look at pre-use learning (Kurosu and Kashimura 1995, Hassenzahl et al. 2000) in terms of how users perceive the quality of a product even before starting to use it. According to their argument this determine whether people will actually buy the technology at hand. The work of this thesis also focuses on pre-use learning, however with a different underlying intention. In line with Bærentsen's example of how native people look astonished on a modern washing machine (Bærentsen 1998b), we expect motives and expectations to be formed even before people lay hand on the technology, i.e. right from their first encounter with it or even from just hearing rumours about it (cf. the case of WAP technology). Clearly, seeing a Bang \& Olufsen television in a shop, most potential Bang \& Olufsen customers will immediately form a rich set of expectations as to what they can accomplish using such a product. Notably the interest pursued in this thesis is not to 
identify ways for selling more technology as seems to underlie some of the other works in this area (Kurosu and Kashimura 1995, Hassenzahl et al. 2000). As discussed earlier, this interest may stop as soon as people have bought the gadget. Rather this work investigates how the experiences formed through pre- use may support or hinder the long-term use of everyday artefacts like a Bang \& Olufsen TV. Accordingly, our own long-term study of television use started by the time of installation of the TV in the homes of two families ([P3] Kjær et al. (2000), [P2] Petersen et al. (2002)). The Bang \& Olufsen customers were first interviewed about their expectations even before they had laid their hands on the remote control. We then returned to their expectations on each of the subsequent visits, to see how their use developed with respect to the motives and expectations set out at the beginning. We investigated this through iterative investigation [P3] Kjær et al (2000). We found that for instance the concept of the cinema experience, helped Sarah insist on exploring the technology to obtain this experience, despite a number of obstacles and problems on the way. It had been conveyed through a combination of factors coming into play before she actually started using the TV, that is through sales, marketing, installation as well as the physical appearance of the product.

With respect to everyday artefacts more generally, users will often recognise product types, were cultural norms and practises are already well-established, e.g. televisions, mobile phones, internet etc. However, it is also the case that these technologies develop a very fast rate and thus the need to convey the zone of proximal development is important in these cases.

\section{A case study of learning in use of a domestic, everyday artefact}

The case study of the installation and subsequent long-term use of Bang \& Olufsen integrated television and video provides an example of how a study of learning in use of existing domestic, everyday artefacts can be conducted [P2] Petersen et al. (2002). The study captured pre-use learning from the time of the installation, and it followed two families over periods of 4-6 months. We used exploratory inquiry as a way to ask open ended question focusing not only on what the users could do now, but also to elicit expectations of their future competence [P3] Kjær et al. (2000), i.e. to investigate the zone of proximal development supported by the technology. We followed their development process and saw how their expectations in some cases stranded and in others turned out to be successful motivators, which both motivated exploration and modification of the initial expectations [P2] Petersen et al. (2002). We further saw how resources both in and around the artefact acted as resources for learning in use. In this case the sale, installation and marketing process supported the users in motivating their future use and in relating the potentials of the new product to their own life activity. One approach to address the issues discussed in this chapter is in the framework of learning artefacts, which is developed in the following chapter. However first a summary of the conclusions with respect to designing for learning in use of everyday artefacts at this point. 


\section{Learning in use of everyday artefacts}

This chapter has developed a thesis of what characterises learning in use of everyday artefacts. The characteristics are summarised in the following.

\section{Theoretical conclusions}

- Learning and innovation in are not necessarily conflicting purposes

- Learning is both ubiquitous and dis ruptive

- Play may be a fruitful perspective on the relation between people and everyday artefacts

- Learning in use starts with motive formation even before people lay their hand on the artefact

- Positive first time experiences are important. Getting people started is a big part of the trick.

- Time is an important factor in studying learning in use

\section{Practical conclusions}

Looking into the zone of proximal development means asking different questions in the lab and in the field than what is most often done now, whe re the execution of predefined tasks are often evaluated. New approaches are needed to allow for a focus on exploratory learning and future competence and how this can be supported by the design of everyday artefacts. We suggest the following approaches to evaluating learning in use and the zone of proximal development, as discussed in [P3] Kjær et al. (2000).

- Exploratory investigation. Asking what people want to do or expect to do in the future rather than asking them to do what the technology can already do.

- Iterative inquiry. Pursuing expectations in later sessions.

- Focus on pre-use and initial familiarity 


\section{Chapter 4}

\section{From Mental Models to Learning Artefacts}

So what are the tools for understanding and designing for learning in use? Within the area of HCI, metaphors and mental models are hard to avoid, when talking about learning to use computer systems. A range of literature has pointed to the positive learning effect of using metaphors (Erickson 1990, Madsen 1994, Liddle 1996, Carroll \& Mack 1999). Equally, mental models have been the predominant way of talking about how users' knowledge and learning guide their actions in the area of HCI (Norman 1983, Lewis 1986, Carroll \& Olson 1988, Preece et al. 1994, Carroll \& Mack 1999). However, work on mental models hold some fundamental limitations with respect to understanding learning in use of everyday artefacts and notably to design for it. These limitations are discussed in the following. As an alternative to the perspective of mental models, the framework of learning artefacts is developed in this chapter. Learning artefacts are based on activity theory, and seek to meet some of the inherent limitations in the existing perspectives. This chapter provides a theoretical explanation of learning artefacts as well as a case study analysed in these terms.

\section{Mental models}

In line with Fein et al. (1993), Carroll and Olson (1988) define mental models as users'

\footnotetext{
"knowledge of how the system works, what its components are, how they are related, what the internal processes are, and how they affect the components" (Carroll and Olson, p. 47).
}

Allen (1997) outlines the characteristics of mental models as allowing users to predict how a system reacts to a certain input, to explain the causes of an event, to diagnose reasons for malfunctions of the system, and to support training through providing 
users with a coherent account of the system. The interests driving research into mental models in HCI have been varied. One strand represents an interest arising from the area of psychology to develop the best possible model of human knowledge and learning, and various architectures have been developed for this purpose. Others strive for practical applicability in HCI and have constructed models allowing for predictions on aspects of usability of systems. E.g a Keystroke-level analysis (Card et al. 1980) enables time-predictions of error-free expert performance. Task-Action Grammar (Payne and Green 1986) in turn models an ideal user's mental model of a command language and support evaluation of consistency and complexity of a command language through analysing the complexity of the language.

Closer to the interest pursued in this thesis, some have sought to document that mental models support learning in use of interactive technologies (Fein et al. 1993, Kieras and Bovair 1984). In these studies, mental models are explicitly taught users through training material before the users conduct some tasks in a laboratory context. Subsequently, the correlation between models and performance are studied. The studies confirm that users with a device model perform tasks faster and retrieve them better than those who learns the device by rote training. While these studies are important in pointing to the potential role of mental models in supporting use, they do not reveal how models emerge through daily life, and how we can affect these through the design of artefacts. What furthermore characterises most work on mental models in Human Computer Interaction research is that it does not consider how the situated nature of human technology use influences the models people actually form of their tasks and the technology at hand. E.g. GOMS and TAG are predictive models that are constructed detached from naturally occurring event, and they both focus on idealised, error free performance. One exception though is when Norman states that mental models are evolving, unstable, incomplete, have no firm boundaries, are unscientific and that people have messy, sloppy, incomplete and indistinct structures (Norman, 1983).

\section{De-contextualised, low level interactions modelled}

The low level of the actions typically modelled in the area of mental models is problematic. An example of the typical level of analysis is the following.

\footnotetext{
"The user wants to listen to track 12 on a CD player, the user sees a button with label '12', the user wants to press that button, the user presses this button with finger, the user hears the button click, the user hears music of track 12", (Haakma 1999).
}

Because of the low level of the interactions modelled, the cognitive approach to mental models offers really only one instrument in designing interactive technology. There is no support for e.g. designing what Norman has termed "disruptive technologies" (Norman 1999a). That is technologies that are revolutionary changes, "the ones that changes people's lives" as opposed to incremental technologies, which are better technologies for doing the same work within the old paradigm (ibid, p. 232). But Carroll \& Olson (1988) argue that system's purpose and form should not be part of the users' mental models as this information "seems 'shallow' and unhelpful in a performance context" (ibid. p. 47). This assumption seems to impede much of the research into mental models. Presumably goals arise inside the head of users regardless of the specifics of the context and system. Given a certain goal, mental models are assumed to support the generation of the actions required in reaching the goal. In most approaches, this happens in a rational and mechanistic way, where "errors" are avoided and goals determine the actions. In contrast, as worded from the perspective of an industrial designer on the challenge of designing interactive 
technology: Hertzian tales is concerned with "assessing the development of objects not against whether they fit into how things are now, but the desirability of the changes they encourage (Dunne 1999, p. 19, own emphasis, MGP).

This problem relates to the lack of overall motive of the activity. While it may never have been the intention of the research into mental models to include understanding of motive formation, this theoretical basis makes it hard to understand how users recognise the potentials of new everyday technologies and how this may be supported through the models people form of the technologies at hand. As argued by Allen (1997) the roles of mental models are merely to predict and explain relations between input and output and to diagnose reasons for malfunctioning. Thus the potential of models in encouraging certain changes in human action and practice is not considered. The ideal is rather to perform tasks faster and better through for instance simplifying inefficient procedures (e.g. Kieras and Bovair 1984).

\section{Assume passive learning}

As pointed out and criticised by several (Carroll \& Mack 1995, Engeström 1987), cognitive mental models assume learning to happen in a passive manner, where models are "slowly renewed objects of consumption" (Engeström, p. 250). The possibilities for mental models to be actively acquired, and developed by creative and enterprising users are ignored by the majority of the work on mental models. As expressed by Norman (1988) the user should adopt the model produced by the designer, otherwise the user will obtain a wrong model.

“the designer expects the user's model to be identical to the design model. But the designer doesn't talk directly with the user - all communication takes place through the system image. If the system image does not make the design model clear and consistent, then the user will end up with the wrong mental model" (Norman 1988, p. 16).

Yet a consequence of the "passive consumption" perspective is that mental models become deterministic accounts of human action (Suchman 1987, Robinson and Bannon 1991). Instead, Suchman (1987) proposes to view plans or models as resources for action, rather than viewing them as determining the courses of action.

\section{Vague relation to design:}

Most of the work on mental models in HCI does not focus on how models transform over time and thus on how we can design for them. Some of the exceptions to this are discussed in the following. Carroll and Olson (1988) outline a range of relevant and still only vaguely answered questions:

"Do we build the user interface to reflect a consistent mental model? If so, What does the input and presentation look like? Should we tell the learner what model to build?" (1988, pp. 56-57).

In agreement with Norman (1999a), Liddle (1996) describes the importance of designing to support the models invoked by the user

\footnotetext{
“The most important thing to design properly is the user's conceptual model. Everything else should be subordinated to making that model clear, obvious, and substantial. That is almost the exactly opposite of how most software is designed" (Liddle, p. 21).
}

Ehn and Kyng (1984) emphasises that the conceptual model of technology design should come out of the existing labour process thus point to the need for grounding the conceptual model in the world of the users

\footnotetext{
"a user model is user oriented conceptual model lin king concepts of a specific labour process to their technical realisation. It serves a s a basis for education as well as implementation” (ibid p.220).
} 
Interestingly, in 1999, Norman has also changed his conception of a successful conceptual model from that of Norman (1988), now arguing that a mental model

"is successful if the users can tell a story, can explain to others how it all works. It is successful if the users can then use the system in ways the developers never imagined" (Norman 1999a, p.179).

Thus acknowledging that users are inherently creative and active creatures. While work on mental models typically make weak references, if any, to the underlying design, the area of metaphors normally directly inform HCI design.

\section{Metaphors}

"The essence of metaphor is understanding and experiencing one kind of thing in terms of another" (Lakoff and Johnson 1980, p. 5). Lakoff and Johnson emphasises how metaphors not only affect the way we talk about things but also structure the way we act in our everyday life, e.g. an argument is often both talked and felt about in terms of war. E.g. you can win or loose an argument and become very frustrated when loosing. However, the lack of systematic use of metaphors in interface design and the lack of understanding exactly how they work have been identified (Erickson 1990, Madsen 1994, Carroll \& Mack 1999). Part of the explanation may well be that research into metaphors has often been of a very general nature, ignoring the specific goals, motives and use context (Carroll and Mack 1999). Suggestions on how to apply metaphors in practical design are often pragmatic and sporadic. For instance, on the issue of how to represent a metaphor in the design, Erickson (1990) argues that ideal interface metaphors have distinctive vis ual and auditory representations, as well as specific words associated with them. On the other hand, we find Madsen's recommendation as to "not necessarily explicitly incorporate the metaphor in the final design" (Madsen 1994, p. 60, italics original).

Allen (1997) emphasises the potential counter-productiveness of metaphors in generating mental models due to imperfect matches and generalisations, and Norman (1999a) makes the radical claim that metaphors most certainly should be avoided. They only have a role in the initial stages of learning, he claims, and only get in the way afterwards. However, Carroll and Olson (1988) provide the interesting observation that

\footnotetext{
"metaphors are useful not only when they provide familiar descriptions of novel experiences, but also when they provoke thought by failing to accord perfectly with the target of the metaphor comparison" (ibid, p. 58).
}

And on the other hand, we have the success of the desktop metaphor. Commenting on the role of this classic metaphor in supporting use, Liddle (1996) argues that

\footnotetext{
"It is a mistake to think that either spreadsheets or desktops were intended to imitate accounting pads, office furniture, or other physical objects. The critically important role of these metaphors was as abstractions that users could then relate to their jobs. The purpose of computer metaphors, in general, and in particular of graphical or icon-oriented ones, is to let people use recognition rather than recall" (ibid, p. 21).
}

Thus there are diverse views on the role of metaphors, however, in general, there is a lack of understanding how metaphors in design affect the models we hold of artefacts.

\section{Mental Models and Metaphors as unrelated phenomena}

With some notable exceptions (Liddle 1996, Carroll and Mack 1999), most of the work on mental models and metaphors ignore the existence of the other. Part of the explanation behind this is that the two areas come from different traditions. The area of mental models is born out of cognitive science and motivated by an interest in 
understanding human cognition. The idea of metaphor originates in a literary tradition that has been interpreted onto the challenge of designing interactive systems. Few studies come all the way around and the purpose of each is most often implicit and rarely spelled out. In the area of mental models, the least cognitive processing is often seen as the ideal, whereas the area of metaphors seek to exploit our inherent ability to understand the world in terms of metaphors and transfer experiences from one area to the other (Lakoff and Johnson 1980). However, suggesting a connection between mental models and metaphors Carroll and Mack (1999) argue that

\footnotetext{
"the learning outcome we ..(..).. imagine, is that a relatively complete, explicit and valid model of the target domain is attained.... we suggest that metaphor can stimulate the learner to actively self-generate a model" (ibid, p. 400).
}

In line with their idea, viewing use and design as inseparable activities (Bødker 1999) metaphors in the design of everyday artefacts only qualify to the extent that they make a positive difference in the way users understand and use interactive technology. It is exactly this relation that is investigated in the remainder of this chapter through the perspective of learning artefacts, which offers an alternative, activity theoretically grounded perspective on the connection between metaphors and the models people form of the artefacts in use.

\section{Learning artefacts}

"The essential instruments of learning activity are models" (Engeström 1987, p. 126). Thus focusing on how people learn to use interactive technologies, it comes naturally to dwell into the role of models. As discussed above, the idea of models is not new to the area of HCI, but there seems to be room for improvement. The framework of learning artefacts provides an alternative perspective on the modelling that takes place in use and design of everyday artefacts. The perspective of learning artefacts is tied up on the notion that artefacts are both material and ideal (Wartofsky 1978, Engeström 1987, Cole 1996). That is beyond the material object, artefacts comprise models of use and praxis, which serve to "preserve and transmit skills" (Wartofsky 1978, p. 201). Not only do the models hold the present understanding of current practice, as is the case in the majority of the work on mental models. Learning artefacts are "representations to ourselves of what we do, of what we want, and what we hope for" (Wartofsky 1979, p. xv). Thus they also represent a future, prospective practise. They contain an element of change and can help understand how zones of proximal development are created in technology use and design.

Wartofsky (1979) originally formulated the idea of primary, secondary and tertiary artefacts, which in this thesis is elaborated into the idea of learning artefacts, via the work of Engeström (1987, 1990). As suggested by (Engeström 1987) and illustrated in table 4.1, the three types of artefacts are intimately connected with the three types of activity, and with Bateson's categories of learning (Bateson 1972).

\begin{tabular}{|l|l|l|l|}
\hline Leont'ev (1978) & Bateson (1972) & Wartofsky (1979) & Engeström (1987, 1990) \\
\hline Activity / Motive & Learning III & Tertiary artefacts & Where-to artefacts \\
\hline Action / Goal & Learning II & Secondary artefacts & Why- and How artefacts \\
\hline Operation / Condition & Learning I & Primary artefacts & What artefacts \\
\hline
\end{tabular}

Table 4.1 Connections between levels of Human activity, learning and artefacts as suggested in Engeström $(1987,1990)$ 
At the bottom level, we have primary artefacts supporting learning I. Primary artefacts are the artefacts proper, i.e. the actual, physical artefacts with theirs conditions and limitations framing our operations. In Learning I both the object/outcome and the (primary) artefact are given. Learning happens as subconscious repetitive corrections that are framed by the primary artefact, i.e. the artefact proper (Engeström 1987). Secondary artefacts are the representations embodied in the primary artefact, which serve to "preserve and transmit skills in the production and use of the primary artefacts" (Wartofsky 1979, p. 201). These representations are understood as functional and material entities, they hold both elements of 'natural resemblance' and conventions. They are not directly visible, except from their externalisation through practical actions, gestures, words and symbols (ibid, Engeström, 1990). Secondary artefacts are a result of learning II and Learning II happens as a response to a problem situation. Engeström (1987) expands Bateson's (1972) notion of learning II arguing that the models preserving and transmitting skills may be formed in two ways. The subconscious reproductive learning IIa or the conscious, productive learning IIb. In learning IIa, the object/outcome is given and the instruments/models are formed subconsciously through trial and error and blind search among previously known means. Empirical generalisations are obtained in this way. Learning IIb is conscious hypothesis testing. Here the object/outcome is given and the secondary artefact is found or invented through experimentation that is through hypothesis testing. Theoretical generalisations are thus obtained. Correspondingly, Engeström (1990) distinguishes between two types of secondary artefacts. He argues that there are both 'how artefacts' which are ad-hoc models for how to handle a primary artefact in a specific situation with a specific object, generated though practical experience. 'Why artefacts' in turn are more general understandings of the way of functioning of the primary artefact, that is models of why the artefact behaves as it does.

Whereas Learning II is a response to a problem situation, in learning III, the problem of the task itself must be created. The instruments of learning III are tertiary artefacts. "Wartofsky's tertiary artefacts are visions or world outlooks which serve as guidelines in the
production and application of secondary artefacts, i.e. models" (Engestrom 1990 p. 152).

Tertiary artefacts are imaginative artefacts, which support transcendence of current conventions and praxis. They

"constitute a relatively autonomous 'world', in which the rules, conventions and outcomes no longer appear directly practical, or which, indeed, seem to constitute an arena of non-practical, or 'free' play or game activity. ... So called 'disinterested' perception, or aesthetic perception, or sheer contemplation then becomes a possibility; but not in the sense that it has no use. Rather in the sense that the original role of the representation has been, so to speak, suspended or bracketed" (Wartofsky p. 208).

"That is to say, just as in dreams our imagery is derived from our ordinary perception, but transcends or violates the usual constraints, so too in imaginative praxis" (ibid, p. 209).

Neither Wartofsky (1979) nor Engeström (1990) use the specific term of learning artefacts. Wartofsky's mission was to develop a new understanding of human perception, viewing perception as situated in a changing historical praxis, and as an active outward process, which is mediated by representations or artefacts, and which transforms these. Engeström (1987) in turn seeks to develop an understanding of a historically new form of learning, namely expansive learning. Engeström has analysed at a set of cases ranging from overcoming deep personal crisis (Engeström 1996) to the development of academic theories (1987) and developmental work 
research (Engeström 1990, 1999). In the latter, the aim is to develop the organisations and activities of work in cooperation with the practitioners.

In this thesis, Wartofsky's primary, secondary and tertiary artefacts, as further developed by Engeström $(1987,1990)$ are applied to understand how users approach technology and how they learn to use the technology through use, over time. Applying these ideas onto the situation of learning in use of everyday artefacts obviously implies a matter of interpretation. Studying the introduction of a new television is arguably a very different matter of less radical consequences than e.g. some of Engeström's studies. However, this is attempted done in the spirit of activity theory, where the conceptual tools must be concretised according to the specific nature of the object under scrutiny (Engeström 1987). The perspective and terminology of learning artefacts has been developed based on the works of Wartofsky (1979) and Engeström $(1987,1990)$, and through a number of analyses of long-term use of Bang \& Olufsen television set, as reported and discussed in [P2] Petersen et al. (2002). In the following, an extract is provided from one of the central cases, to illustrate the applicability of learning artefacts in this context and to provide a basis for discussions on the implications of a perspective of learning artefacts in HCI, both theoretically and practically. However, before moving to the case, first a definition is provided of learning artefacts. In order to operationalise the concepts in this context, and to mark, that they are used in a different area than that of Engeström's (1990), a new terminology has been developed.

\section{Learning artefacts - definition}

In line with Wartofsky's and Engeström's artefacts, learning artefacts are closely related with the different levels of activity, i.e. they mediate the different types of activity.

\begin{tabular}{|l|l|l|}
\hline Human activity & Learning artefacts & Characteristics \\
\hline Activity (motive) & Transformation artefacts & $\begin{array}{l}\text { Visions of future use experiences / } \\
\text { changed activities }\end{array}$ \\
\hline Action (goal) & Interaction artefacts Principles & $\begin{array}{l}\text { General principles and hypotheses } \\
\text { for interaction }\end{array}$ \\
\hline Operation (conditions) & Condition artefacts & Ad hoc models of interaction \\
\hline
\end{tabular}

Table 4.2 Learning artefacts

\section{Transformation artefacts}

Transformation artefacts mediate visions and projections of future use practises that allow users to relate to these and form motivations in the meeting between the artefact and their specific context, situation and preferences. Transformation artefacts can refer to changed activities, to experiences and feelings, like the cinema experience. They are transformative by nature, signaling new possibilities and new roles, i.e. transformed activities. 


\section{Interaction artefact}

Interaction artefacts support the interaction necessary to meet the goals formed by the motivation. These artefacts may be both general principles of functioning that mediate across artefacts or situations of use and in addition more vague ad-hoc understandings that fade away unless they form part of repeated use. Interaction artefacts may be perceived as basic conditions as they turn unconscious with increased experience.

\section{Condition artefacts}

Condition artefacts provide the basic conditions of our operations and they serve to contextualise interaction and transformation artefacts. They have an important role as reminders of possibilities, as visible triggers in our everyday activities.

Importantly, learning artefacts form, transform, fade away, become molded in specific use situations in specific contexts over time. Like other artefacts, learning artefacts must be understood in specific cases as they unfolds in use. Such a case is analysed in the following.

\section{The Cinema Experience ${ }^{1}$}

Sarah is a member of a family that has recently bought an integrated television and video recorder from Bang \& Olufsen. The family previously owned a 10-year-old Bang \& Olufsen television, so they are familiar with the brand. We analyse how Sarah came to use the new television over a period of six months with special focus on how she pursued the cinema experience offered by the new system.

\section{By the time of installation: Forming the cinema experience}

Sarah and her husband Paul explain excitedly how they look forward to obtain the cinema experience in their living room. Technically, this experience refers to the possibility of wide screen format on the television and of connecting multiple loudspeakers to obtain surround sound. The cinema experience was one of their prime motives for buying the new television set. Several mediating artefacts play a role in forming both Sarah's and Paul's expectations with respect to the cinema experience at this time, when neither yet has any experience with using the product on their own. Sarah refers to her visit to the cinema to see "Titanic", as an event that has served to form her expectations regarding the new product. Moreover, she has experienced the same system at her sister's house and in the special Bang \& Olufsen boutique where they bought the television. By using the term cinema experience in their sales brochures and in the sales situation, Bang \& Olufsen introduces the analogy between the television and the cinema, thus making visits to the cinema a point of reference in the encounter with the Bang \& Olufsen television. This analogy is followed up in the design of the actual television. As illustrated in figure 4.1, electronic curtains rise and fall as the television is turned on and off, thereby daily encounters with the television feature a direct reference to the cine ma experience.

In terms of learning artefacts, the cinema experience as used by Bang \& Olufsen in the sales situation and the sales brochures acts as a transformation artefact

\footnotetext{
${ }^{1}$ This section is a revision of a sub-section in [P2] Petersen et al. (2002), which was written jointly with Kim Halskov Madsen and Arne Kjær.
} 
for Sarah and Paul in that it helps them to envision a new kind of experience offered by the new television set.
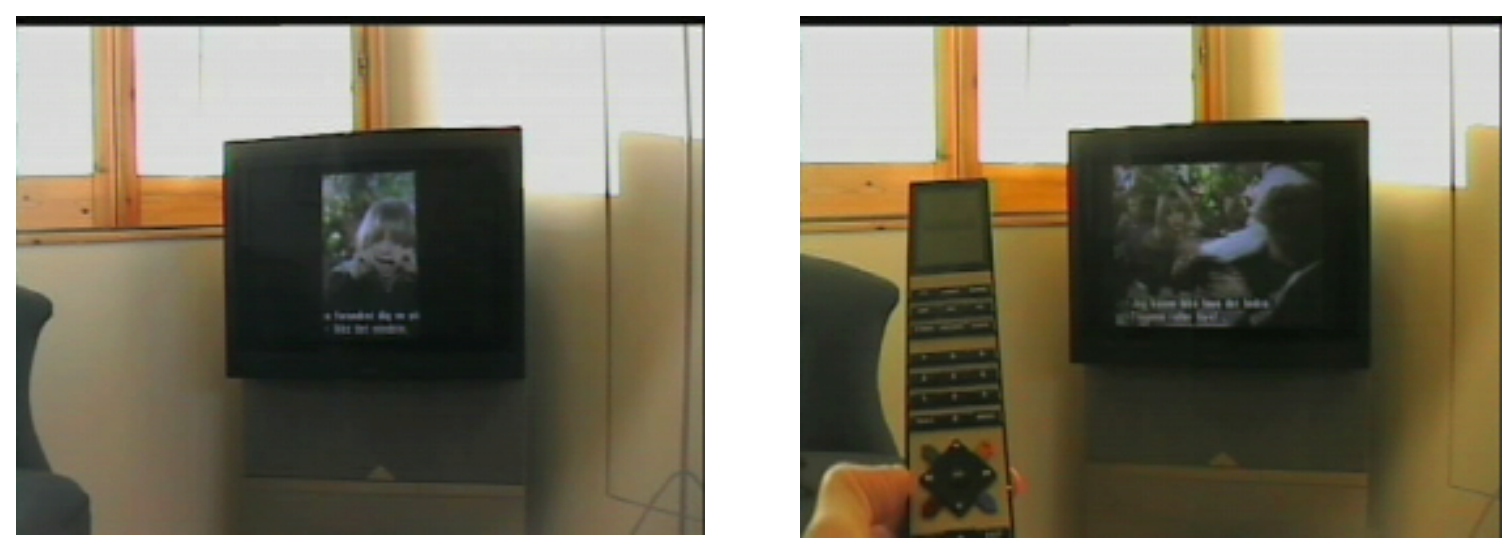

Figure 4.1. The electronic curtains of the Bang \& Olufsen integrated television and video

The metaphor of the cinema experience and a real-life demonstration in the shop trigger their experiences from the cinema. In this way, it provides an overall indication of what it means to watch television using this Bang \& Olufsen product. The cinema experience analogy is also expressed in the product itself, as illustrated in figure 4.1. The electronic curtains is part of the condition artefact, supplying a context for the transformation artefacts in the appearance of the product. As illustrated in figure 4.2, no interaction artefacts have yet come into play in the context of the cinema experience.

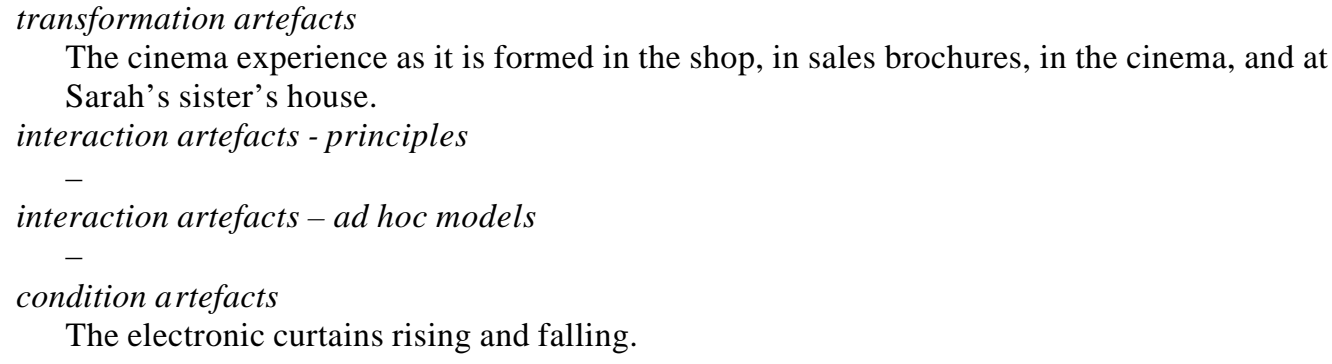

Figure 4.2 Learning artefacts at the time of installation: forming the cinema experience.

\section{One month after delivery: efforts to obtain the cinema experience}

Sarah explains that she primarily uses the remote control from their old television to operate the new television. This works for basic purposes, but does not provide access to the special features of the television, including the cinema experience setup. Sarah is well aware of this, stating that the new remote control "is the future" and that she needs to familiarize herself with it at some point. During this second visit, we ask Sarah about what she would like to do with the new remote control.

Sarah: ... what I can't do now and what I have not learned or asked about or read myself, that is to make the screen ... if I'm watching a video ... to make ... what is it called ... to enlarge or reduce the size of the picture ... I can't do that ... I mean it would take a long time for me to sit and experiment, it would be easier to read the manual, but it would be even easier to ask someone, if there was someone to ask.

(Some discussion about whether Sarah would use the manual or not) 
Sarah: I can operate the video, but there is still the thing about making the picture bigger and smaller and then there is surround sound, too. I have not worked it out ... I know it is (she studies the new remote control in her hand) ... no I don't know ... yes LIST ... I know it has something to do with LIST.

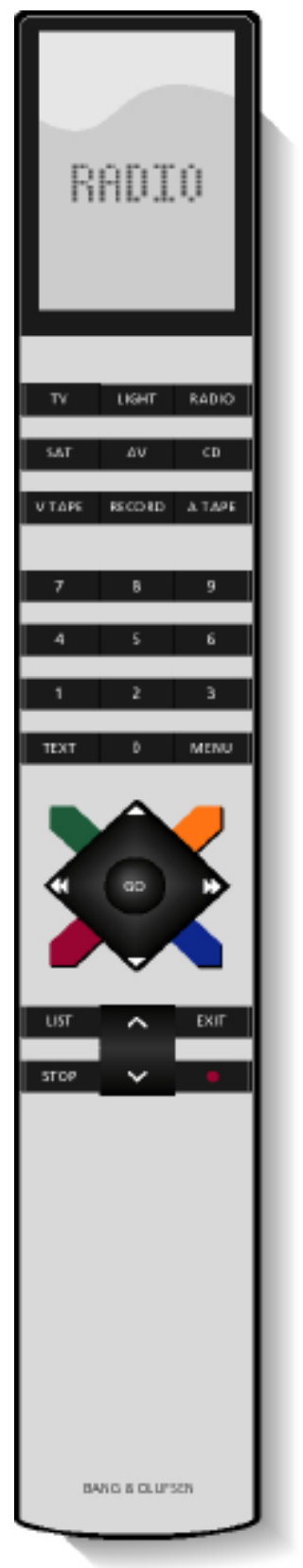

To understand the case, a little background information is necessary. List is the button that shifts between different modes on the remote control. The vision behind the remote is that it should be possible to operate all Bang \& Olufsen devices using this single remote. This means that it is a highly modal remote control, where it is possible to shift modes between the sources tv, cd, video. For each source, the LIST button shifts between modes offering special features like the number of speakers connected and the physical position of the television (it can automatically turn between different angles) etc. Sarah sets out to try to use the new remote control to connect all the loudspeakers to obtain surround sound. She experiments for some time, pressing the LIST button and some other buttons, but eventually she gives up. From conversations with her family, she knows that she needs to do something with the LIST button, but she cannot extrapolate this into a wider context, nor make the connection between the LIST button, the cinema experience and the loudspeakers. "Something to do with LIST" becomes an incomplete how artifact which cannot be connected to the other learning artifacts and which does not take her all the way to establish the cinema experience herself. Figure 4.4 provides an overview of the learning artifacts mediating Sarah's activity.

Figure 4.3 Remote control

transformation artefact

The cinema experience as it is formed in the shop, in sales brochures, in the cinema, and at Sarah's sister's house.

interaction artefacts - principles

$-$

interaction artefacts - ad hoc models

Something to do with the LIST button on the remote control. condition artefacts

The electronic curtains rising and falling.

Figure 4.4 Learning artefacts one month after delivery: efforts to obtain the cinema experience 
During our subsequent discussions with Sarah's husband, Paul, about how he operates the television, Sarah discovers a general interation principle, an interaction artefact, which is of relevance to connecting all the loudspeakers to obtain surround sound.

Paul: Now I would like to have the right size of the picture and the surround sound on. If we start with the size, we do ......

(Paul does this without problems)

Paul: Then, when we want surround sound, we must connect all five loudspeakers. Then we need to go over to what is called "speaker" mode and you do this by pressing LIST .... there we have speaker mode (the text 'speaker' appears in the display of the remote control), then we press number button $5 \ldots$

Question: And you pressed 5 because you remember ...?

Paul: Well there was some logic involved as I know that you have five speakers in surround sound, right?

Sarah: Oooohh, yes of course ... that is a strange kind of logic isn't it! It's so simple really!

In this way, the principle of connecting the loudspeakers by selecting the number of loudspeakers to be connected becomes a general principle of action, i.e. an interaction artefact for Sarah. As she realizes this principle of interaction, she identifies a kind of logic behind the interaction.

\section{Two and a half months after delivery: finally establishing the cinema experience}

Sarah explains that she has now succeeded in connecting all the loudspeakers to obtain surround sound. It turns out that she has accomplished this using the CD player. We ask her to demonstrate to us what she did when she first succeeded. The $\mathrm{CD}$ player works in the same way as the television as regards connecting multiple loudspeakers, the only difference is that the remote control has to be in CD-mode instead of TV. Furthermore, when using the CD player it is only relevant to connect four loudspeakers instead of five - as Paul did when he demonstrated surround sound on the TV - because the one loudspeaker in the television is not connected to the CD player. This challenges the generality of the principle of interaction discovered by Sarah during our previous visit.

Sarah: Then I turned on the CD player. And then I wanted to connect the loudspeakers - all five of them.

Question: What did you do then?

Sarah: Well, then I needed to start by turning up the volume (she turns up the volume) ... and then ... hmm ... (Sarah studies the remote control) ... I put on ... I pressed twice on ... hmm .... on lift ... LIFT! ... and then I pressed number button 4 and now they are on (the surround sound is on).

Question: When you experimented with this yourself, do you remember how you found out that this is the way to do it?

Sarah: Well I recalled that I needed to press .... that LIFT button ... that one I've always remembered ... a few times (actually twice), and then there is nothing to it apart from pressing up to .... you see, I knew we have up to five loudspeakers, right !? ... and then I pressed number button 4 and the lights (on the loudspeakers) turned green (she points to the speakers).

This situation is interesting from a number of perspectives. To start with, when Sarah connects the loudspeakers to obtain surround sound, she starts out by turning up the volume, most probably with the cinema experience as her point of reference. A breakdown occurs as she needs to find the LIST button, with which she is still not confident. This time she refers to it as the LIFT button, suggesting that the term LIST does not mean much to her in the context of establishing the cinema experience. Furthermore, the principle she discovered last time in terms of pressing a number corresponding to the number of loudspeakers has now become operational for her as an interaction artefact. In addition, her previous interaction ad-hoc interaction artefact 
in terms of "something to do with LIST" has now been refined to "press LIST or LIFT a few times". Thus mediated by the following learning artefacts as shown in Figure 4.5, Sarah's efforts to obtain the cinema experience in her living room finally bear fruit.

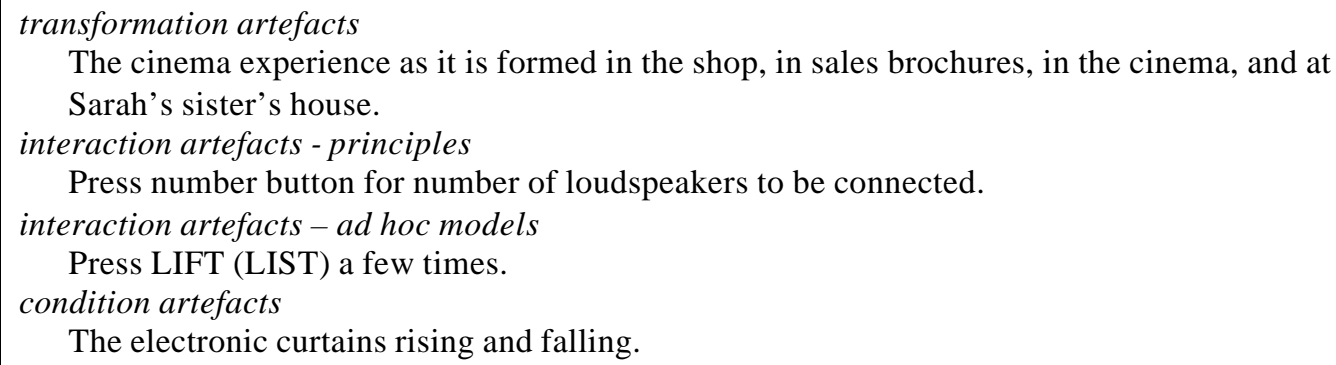

Figure 4.5. Learning artefacts two and a half months after delivery: Finally establishing the cinema experience

Six months after delivery: The cinema experience has turned into the concert experience plus watching movies without glasses

Interestingly, when we visit Sarah and Paul six months after the delivery of their new Bang \& Olufsen system, Sarah's use of surround sound has consolidated into the concert experience. Sarah is now fully familiar with the use of the LIST button, but she primarily uses the surround sound facility when listening to music via the Bang \& Olufsen CD player, which is linked to the rest of the system. She has found out that she does not really enjoy watching movies with surround sound on, as she does not like the sudden, sometimes very loud, sounds - for example, those made by a flying object coming from behind her- as reproduced by the cinema experience. At this time, both Paul and Sarah appreciate the use of the wide screen format, which also form part of the cinema experience, because it enlarges the subtitles with the result that they do not need to wear glasses to read them.

In terms of learning artefacts, Sarah has now, due to the specific circumstances in terms of her needs and preferences, molded the cinema experience into a concert experience, see figure 4.6. The previous interaction artefacts have become refined, and Sarah is generally more confident in the way she handles the remote control. However, she still cannot manage to adjust the format of movies on her own. Paul does this when they watch movies together



Figure 4.6. Learning artefacts 6 months after delivery: The cinema experience has turned into the concert experience

\section{Learning artefacts in use}

As discussed in [P2] Petersen et al. (2002), the remarkable persistence of the cinema experience, which guided Sarah's exploration over a months of use, suggests the 
motivational power of transformation artefacts (the cinema experience) when contextualised in terms of condition artefacts (the electronic curtains). On the other hand, the lack of contextualisation of the cinema experience, in terms of interaction artefacts, suggests why Sarah has problems establishing the cinema experience herself. Thus the above case confirms the principle suggested by Engeström (1990), that artefacts need to be contextualised at all levels. As we saw it in the case of Sarah's use, the principle of contextualisation between the different levels of learning artefacts ensures that transformation artefacts do not just mediate unattainable futures, but that meaningful interaction artefacts also give people a chance to pursue the values and experiences hold out. In this way we can move away from the situation caricatured by Norman (1988) when he concludes a long tale about the frustrations and confusions he had over a pair of swing doors "Pretty doors. Elegant. Probably won a design prize" (ibid, p. 4).

This study therefore suggests that with carefully designed transformation artifacts, use does not need to "start out with bloomin', buzzin' confusion" (Carroll and Mack 1995, p. 699). Instead these transformation artifacts may sow seeds, which users may subsequently develop on the basis of their needs and wishes. As reported in [P2] Petersen et al. (2002), transformation artefacts indeed come into play differently for different people in different situations. E.g. presented with the same new, improved video programming facility Paul was fascinated by technology that offered greater ease of operation and improved recording quality whereas in the other family, Karen, envisioned a new role for herself in operating the technology. She imagined that she would now be able to program the video herself, independently of her husband, who had previously done all the programming. Thus in line with the perspective of Engeström (1990) who argues that a tool always implies more uses than originally intended by the designer, the goal of learning artefacts is not to design for predicted ways of using and adopting the technology. However, as seen in the case of the cinema experience, transformation artifacts may help users identify directions of use along which they wish to set out. Users will then seek their own paths in accordance with their own needs, situation and background.

As discussed in [P2] Petersen et al. (2002), interaction artifacts in the form of general principles support the robustness and consolidation of the interaction. In the example of the cinema experience, Sarah was struggling to establish an understanding of the general interaction principles of the product - the highly modal design of the remote control as controlled by the LIST button, for example. She only made some discoveries during our interview with her husband. Thus in her case, it was not the design itself that revealed to her the principles required. However, once learned, she was able to use this principle in the setup of the CD player. The condition artefacts in the form of the electronic curtains in turn provided the visibility that persistently reminded Sarah of the possibility of the cinema experience.

In the above case, we see how learning artifacts are not static but develop, become modified and fade away over time due to factors both inside and outside the design. Sarah continuously refines her ad-hoc interaction artifact through her exploration of the television. She starts out with a vague idea that in order to connect multiple loudspeakers to obtain surround sound, she needs to do something with the LIST button. Through her exploration of the television, and through overhearing our interview with her husband, she laboriously refines this into the idea that she needs to press LIST a couple of times. 


\section{Learning artefacts and active learning}

The approach of learning artefacts represents a move away from the idea of the user as a passive recipient of a prescriptive model of use as discussed above. As can be seen from the above case, while the cinema experience appeals to Sarah in the first place, over time, she actively explores it, and alters it to the concert experience, which better suits her preferences and life-situation. This case illustrates Robinson's argument that we should move away from overcoming the disparity between design intentions and actual use and view modeling as a way of re-framing rather than prescribing use, and simply acknowledge that people "creatively misuses" technology (Robinson 1991). This is in line with Norman (1999a) who argue that one of the criteria for success is that people are able to use the technology in a way never intended by the designers (Norman 1999a). Wartofsky (1979), Bannon and Robinson (1991), also state that there are no fundamentally true or false representations. In principle, "Anything can be a model of anything else" (Wartofsky 1979, p. 4).

"Representing is something we do ... representations are, paradigmatically, intentional objects" (ibid, p. xxi). Thus the role of learning artefacts in design can be seen as that of framing use. Of providing users with ideas as to what can be obtained with the technology, as worded by Liddle (1996) concerning the role of metaphors. The above case suggests how this framing can indeed serve to motivate people's exploration. It illustrates the importance of supporting the modeling of expectations and actions in order to give people an impression of the potentials and possible roles of the artefacts at hand, knowing that people will find their own ways. Wartofsky (1979) emphasises this active role of people.

\footnotetext{
"The model produces more than it contains ... The purposes that such a model presents, the goals and ideals to which it summons commitment, are not simply 'in it', as lessons learned or as raisins in a cake. They are read out of it by the interpretive and creative genius, the inventiveness of those who respond to it. The model thus generates creative action. How it does this, I think, has not been investigated and is not clearly known" (ibid, p. 145).
}

As elaborated in [P2] Petersen et al. (2002), the case of the cinema experience provides an example of how models support the generation of creative actions in the use of technology.

\section{Learning artefacts and transparency}

As discussed in chapter two, the ideal of transparency has long been a thread in HCI work, but is has also been criticised especially from the perspective of industrial design, e.g. Dunne 1999. The perspective of learning artefacts allows us to revisit this discussion. Based on this framework and in light of the cases of long term use of the B\&O AVANT [P2] Petersen et al. (2002), a hypothesis can be formed regarding the issue of transparency, which was raised in chapter two. Arguably, transformation artefacts should provoke and draw people's attention to the possible zones of development of future uses of the artefacts, thus allowing them to consciously take a stand on and develop their future possibilities. Understood in this way, transformation artefacts should not be transparent, and it is probably here we should find the place for expressing what Dunne (1999) request, namely the "values and ideals about life" hold out by the everyday artefact in question. As discussed in chapter two, Dunne criticises the Human Factors community for seeking to hide these aspects and proposes that industrial designers have something to contribute here. Wartofsky (1979) also emphasises the role of aesthetics in forming tertiary artefacts or in the terminology of learning artefacts: transformation artefacts. But in Wartofsky's words, not that aesthetics has no use. As we saw it in the case of the cinema experience, 
using this as point of reference for television viewing says something about the ideals and vision for the role of the TV in people's lives. Moreover, this transformation artefact served to set expectations, which supported Sarah's learning in use of the everyday artefact over time. Since in the case of everyday artefacts, the fundamental challenge is to get people started (Bærentsen 2000), it is important to support them in investigating the potentials of the technology and create their own visions and horizon of future use. As we have seen, transformation artefacts can play an important role in this respect.

Interaction artefacts mediate our actions and are formed through learning II. Thus they may be constructed either unconsciously on the basis of trial and error or reflexively on the basis of hypothesis testing. Bødker (1991) provides a thorough account of how actions turn into operations as the user gets experience with the task and the artefact. In either of the cases of learning IIa and IIb, then ideally, as the user gains experience, interaction artefacts turn into subconscious condition artefacts, i.e. they become transparent and unnoticed conditions of our handling of the everyday artefact. Condition artefacts in turn are by definition transparent, unnoticed frames of our operations.

\section{Mental models and everyday artefacts}

Work on mental models typically comprise only a subset of the hierarchy of learning artefacts. E.g. Allen (1997) suggests the roles of mental models to be that of predict and explain relations between input and output, corresponding to both to ad-hoc and general interaction artefacts. Norman (1988) uses the example of a false understanding of what different controls on a refrigerator operate on to illustrate a case of a "wrong" mental model. There are two controls and the user assumes that the one controls the freezer part and the other controls the fresh food part, an example of an interaction artefact in the form of a general principle. Really, the controls are interrelated in a more complex way. Thus, as in this typical instance of discussions on mental models, the focus is primarily on the level of interaction artefacts. As in these cases, most work on mental models do not reference the wider motives and activities out of which goals arise and actions are performed.

\section{Towards linking metaphors and mental models}

The vision of the cinema experience adopted and later adapted by Sarah was no coincidence. It was a metaphor, which has been carefully designed by the designers at Bang \& Olufsen. In the above case, we saw how this metaphor came into play in a concrete process of use. Since the role of the metaphor is to see something as something else (Lakoff and Johnson 1980), and provide users with ideas of what can be accomplished with a given artefact (Liddle 1996), they obviously have a role to play as transformation artefacts. The case of the cinema experience illustrates that this may indeed happen, The framework of learning artefacts suggests that metaphors should be represented both in terms of condition artefact, in the means of interaction and in the overall transformation artefacts. As illustrated in [P2] Petersen et al. (2002), the framework of learning artefacts provides means for evaluating the design against the models people form of the everyday artefacts they interact with. Thus in the perspective of learning artefacts, applying metaphors in design is a matter of designing learning artefacts contextualised at all levels, knowing they will support users in forming models and ideas of future use and interaction. These models will inevitably change and adapt through use. Understanding the role of metaphors in the 
perspective of learning artefacts provides a theoretical basis for the recommendations on how to design in terms of metaphors.

\section{Learning artefacts and design}

Based on Engeström's work (1990), in [P2] Petersen et al. (2002), we developed, among others, the following guidelines for designing learning artefacts

- Design learning artefacts at all levels

- Design for coherence among learning artefacts at all levels

One of the implications of these guidelines is that when using metaphors as transformation artefact, the metaphor should be contextualised in the material design of the technology, as the electronic curtains on the AVANT TV contextualises the cinema experience. This is in contrast with Madsen (1994) who argues that the metaphor should not explicitly be incorporated in the design. But it is in line with Norman (1988) who argue that the user's model (corresponding to the level of interaction artefact) should be coherent with the system image, i.e. the visible part of the device (corresponding to condition artefact). Norman, however, does not see the role of these in the wider perspective of the models supporting motives (transformation artefact).

The design for coherence among learning artefacts at al le vels seems to be an important design goal when designing for learning in use. The predominance of the cinema experience as expressed by Sarah suggests that in this case a more task or experience-oriented design of the remote control, i.e. representing interaction artifacts in these terms, could be an interesting path to explore. To express it differently: conflicts between the different levels of artefacts as identified through evaluations of the design constitute openings for design modifications.

This case further suggests that, at least in the case of home appliances, there is potential for designing learning artifacts both in and around the product itself. In the case of Sarah, we see how the processes of learning in use starts even before she starts utilizing the product itself. By the time of installation, Sarah has a rich set of expectations and ideas about the cinema experience from demonstrations in the shop, from sales brochures, from the cinema and from seeing a similar product at her sister's house. She looks forward to the cinema experience.

In the terminology of mental models the relation between design and use is often depicted in terms of the designers' model of the designed artefacts and the users' model of the same. Here the ideal is often described as designers and users having the same model, and, in Norman's words that users' models are wrong when they are not like the designers' (Norman 1988). Again this view reflects that of the user as the passive consumer, of the models pre-packaged by the designers.

Alternatively, in the perspective of users and designers as co-constructors (Buur and Bødker 2000), which this thesis represents, the important thing is that designers and users co-construct learning artefacts. In this way allowing future users to relate the potentials of the technology to their specific life context and then adapt their use according to their wishes, needs and preferences. This view is in line with Liddle (1996), who sees the role of metaphors as providing abstractions users can relate to their jobs. And with Robinson and Bannon (1991), who argue that the role of models in systems design is that of reframing use, rather than providing a true representations of it. They emphasise that the criteria for success of models are whe ther they are useful for certain people, under certain conditions, in certain situations, and not 
whether they are fundamentally true or false. Following this statement learning artefacts, which are also a form of models, can only be assessed in terms of how useful they are in for specific people in specific situations. A position, which is well in line with the general idea that artfacts can only be understood when in use (Bannon \& Bødker 1991).

\section{From mental models to learning artefacts}

This chapter developed a thesis of learning artefacts, as an activity theoretically grounded approach to understand learning in use of everyday artefacts. The framework addresses the following shortcomings of the areas of mental models and metaphors, which are the predominant ways of understanding learning in use in HCI. Most approaches to understanding human mental models assume passive learning, fail to consider the situated nature of human action, hold no account of the underlying motives of the low-level actions typically modeled, and have weak relations to design, including metaphors in design. As an alternative, the framework of learning artefacts is suggested for understanding learning in use and for providing some initial ideas on how to design for it. The chapter revisits the discussion on the ideal of transparency within the field of HCI arguing that part of the interaction, i.e. that supported by transformation artefacts need not be transparent. It further discusses how the framework of learning artefacts allow us to see mental models and metaphors as related phenomena where one affords the other. It is pointed out how the framework of learning artefacts provides the basis for developing theoretically informed guidelines for designing for learning in use. This chapter provides an example of how the use of a complete and functional system can be evaluated using the framework of learning artefacts. The next chapter looks at how to design everyday artefacts. 



\section{Chapter 5}

\section{Designing for learning in use of everyday artefacts}

Having developed the idea of learning artefacts in the previous chapter, and discussed how they come into play in use processes, this chapter focus on the design side asking how we can design for learning in use of everyday artefacts. This effort forms part of abroader interest in moving usability work from evaluation towards more design oriented activities, as undertaken in the BIDI project (Usability Work in Danish Industry), and as reported in [P6] Petersen \& Madsen (1999), Bødker \& Buur (2000), [P7] Bødker et al. 2000, and [P8] Bødker et al. (2001). This chapter starts out discussing the relationship between use and design and it continues with a tentative idea of how the B\&O AVANT can be redesigned in light of the learning artefacts analysis in chapter four. It then presents a number of approaches to maintain a learning perspective in the design of everyday artefact. Finally, it introduces a design cycle for learning in use of everyday artefacts and frames the approaches presented in this thesis herein.

\section{Artefacts as crystallised design practice}

According to activity theory, artifacts are crystallisations of use practices (Bannon \& Bødker 1991, Bærentsen 1989). Over time, human actions turn into operations, and operations in turn often become materialised or crystallised into later generations of the artefact. However, as discussed in the following, artefacts are also in some sense crystallised design practice. In the following, the framework of learning artefacts is used to analyse the specific case of use and design of the B\&O AVANT TV in order to investigate this relation. 
Mirroring the case of long-term use of the Bang \& Olufsen AVANT system in the underlying design process, we can see how the design process is reflected in the artefact and in the use process. As earlier explained, Bang \& Olufsen wants to create one general purpose remote control, with which all their systems can be operated. This vision is understandable from a number of reasons. It provides simplicity of production and it avoids the messy impression of having several remote controls lying around in the house. From a perspective of designing for learning in use however, this vision is more problematic. As we saw in the case of the design of the B\&O AVANT $\mathrm{TV}$, the concept of the cinema experience was well represented in the overall product concept, communicated during sales and installation. It was also contextualised in the physical design of the product, however not in the general-purpose remote control. In the study of long term use, we saw how Sarah had problems relating her interaction with the remote control to the transformation artefact of the cinema experience. The interaction artefacts provided in the design of the remote control did not make reference to the cinema experience. Instead, the means of interaction reference a computer in terms of the hierarchical menu system. Further, the terminology used in the menus does not reference the cinema experience. Thus the transformation artefact of the cinema experiences has not been contextualised in the interaction artefacts of the remote control in the design process at Bang \& Olufsen, and this is indeed reflected in the adoption process of Sarah. If we look at the underlying design process, we can come to understand part of the origin of Sarah's problems.

As stated above, for good reasons, it is part of the overall company policy to have a general-purpose remote control. When the cinema experience was coined it was designed into the physical appearance of the AVANT in terms of the electronic curtains sliding up and down as the TV is turned on and off. In this way the transformation artefact of the cinema experience was contextualised in the condition artefact of the physical design of the television. Subsequently, the interaction design had to be mapped onto the fixed design of the remote control thus making the contextualisation rather problematic because of few openings at this level of the design. In principle though, menu naming or the labels in the display of the remote control could have referred to the cinema experience. Thus we see here how the lack of contextualisation of learning artefacts at all levels of transformation-, interaction and condition is of crucial importance to the long-term learnability of everyday artefacts. This in turn requires good coordination in the design process among designers largely responsible for the transformation and condition artefacts and the engineers and psychologists designing the interaction ensuring that ideas are designed into the artefacts at all levels from the beginning. Thus when Bærentsen (1989) and Bannon \&Bødker (1991) talk about artefacts as crystallised use praxis, wee see how this represents only one side of the story. Artefacts equally crystallise design practice and design intentions as we see it in the case of the cinema experience.

That both design and use shape the artefact is not that surprising, as others have pointed out the close relationship between use and design (Engeström 1987, Bødker 1999). Focusing on expansive learning more generally, that is activity-level learning, Engeström (1987) hypothesises that the cycle of expansive development mirror the methodological cycle of expansive development research. Much of his subsequent work has focussed on developing the methodological cycle of expansive development research aiming to develop work practices in general without a specific focus on the design of technology (e.g. Engeström 1999). Bødker (1999) in turn, interpret Engeström's thesis onto the situation of learning in use and designing for learning in use, arguing that design cannot be separated from use, anymore than use 
can happen independently from design. She argues that design is inherently a coconstruction process determined by both designers and users. With the analysis in terms of learning artefacts discussed above, it is possible to add to Bødker's position emphasising that the real test-bed of this co-construction process is how the designed artefacts support users in their daily life-practice. As illustrated above, the framework of learning artefacts provides a means of evaluating not only the design of the artefact against how it supports use and long-term use, but it also allows us to mirror design problems in the design practice behind.

\section{Towards re-designing the cinema experience}

Now how does the framework of learning artefacts support re-designing the $\mathrm{B} \& \mathrm{O}$ AVANT TV in light of the observations above? In the following a small example is given of how to think about design in this way. As discussed in chapter two, it would be interesting to adopt a more playful and less rationalistic approach to the design of everyday artefacts. Vygotsky's thoughts on play fit well in with the challenge of designing for learning in use. "Play creates a zone of proximal development of the child....the play-development relationship can be compared to the instructiondevelopment relationship, play provides a much wider background for changes in needs and consciousness" (Vygotsky 1978 p. 102). "It is the essence of play that a new relation is created between the field of meaning and the visual field - that is, between situations in thought and real situations" (ibid, p. 104). In [P2] Petersen et al. (2002) and in the previous chapter it is argued that learning artefacts need to be contextualised at all levels. In the following, an example is provided of how adopting Vygotsky's thoughts on play and the lessons on learning artefacts can serve to tentatively redesign the B\&O AVANT. In line with Vygotsky's ideas on creating new relations to the world, the tentative re-design adopts not one metaphor but several relating in different ways to the technology, supported by a set of transformation artefacts pointing to future possibilities. Designed bottom- up, that is organising the existing features in new ways, and adding a few, the B\&O AVANT is designed in terms of three transformation artefacts, The cinema experience, Be your own architect, and The $\mathrm{B} \& \mathrm{O}$ control room.

\section{The cinema experience}

Transformation artefact The cinema experience

Visions / values / experiences: Lean backward, a pleasant experience, relaxation, entertainment, surprise.

Interaction artefacts The cinema chair: as you lean back, the light is dimmed and the curtains slide away, the format of the screen widens etc. (A more pragmatic approach would be to make references to the cinema experience in the remote control).

Condition artefacts The cinema chair, the electronic curtains 


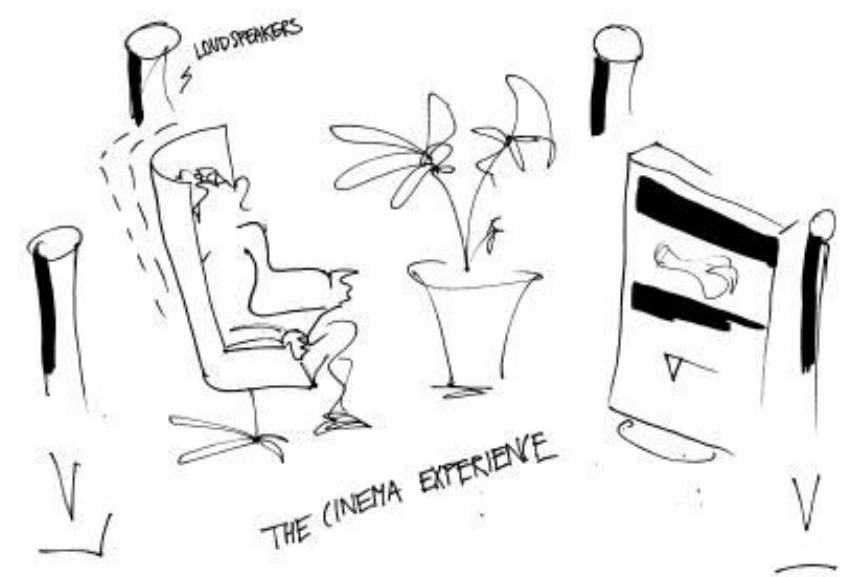

Figure 5.1 The cinema chair. A person leans back in "the cinema chair" in front of the AVANT TV. The light turns dimmed and the movie begins...

\section{Be your own architect}

Transformation artefact Be your own architect Visions / Values / experiences: adaptation to home and situation, furnish with sound and picture, spatial organisation of sound, picture, light embedded in the physical environment.

Interaction artefacts A physical objects that can be manipulated in the home to represent sound and picture. E.g. when you move from the dining table to the sofa you bring the pyramid (center) with you and the TV turns to let you view the picture or the sound moves with you from one room to another.

Condition artefacts $\mathrm{B} \& \mathrm{O}$ look combined with basic building block which represents the tools of an architect's experimental construction of a room / home in the form of blank, basic forms.

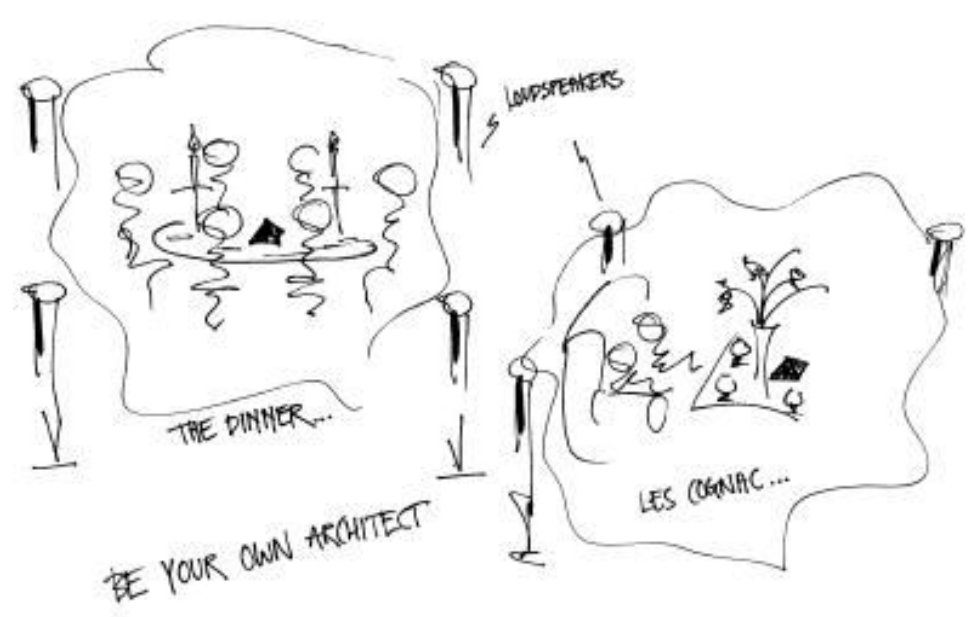

Figure 5.2 Be your own architect. The pyramid represents the center for the sound-picture. It can be moved e.g. from the dining table to the couches after dinner to bring along the optimal sound and cognac experience.... 


\section{The B\&O control room}

Transformation artefact The $\mathrm{B} \& \mathrm{O}$ control room

Visions / values / experiences: efficiency, control, adjusting and controlling a set of parameters, lean forward

Interaction artefacts Computer analogy and control room analogy

Condition artefacts Access from a 'control tower'-remote enabling more advanced manipulation and operation.

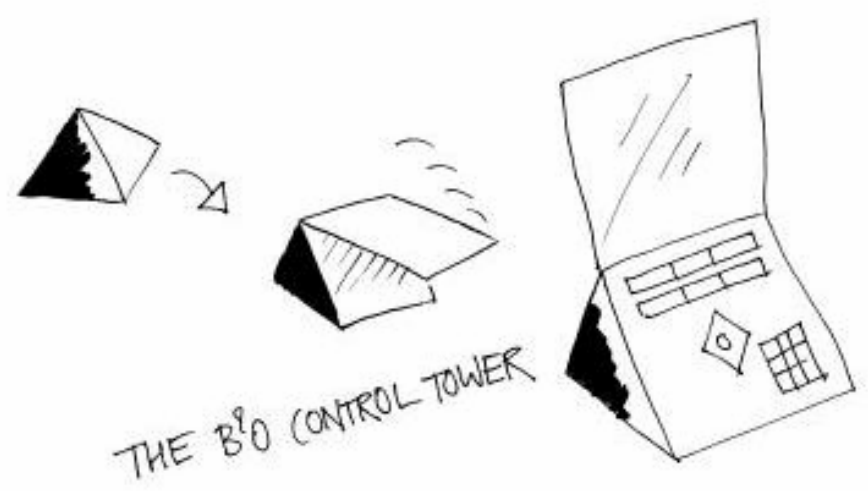

Figure 5.3 The B\&O control tower. The black pyramid can be turned on the side and opened to reveal a display and set of buttons, cursor etc. for programming video recordings, doing more detailed set-up etc.

Now this design proposal is but a very early sketch to illustrate how the idea of learning artefacts can be pursued in the design of the B\&O AVANT television. Indeed it contains several unresolved issues, such as what is the minimal means of interaction necessary in the different situations, e.g. while sitting in the chair and at the dining table, and how should they be supported. While these have not been resolved yet, the approach suggested here is that of supporting the minimal interaction necessary and meaningful in different situations. This is in response to our tours around private houses where the functionality cramming we met on the domestic appliances at times made even basic things impossible to do [P4] Baillie and Petersen (2001). This is also in line with the ideas of others, of not making anything available from anywhere anytime etc. (e.g. Nielsen 2001). The prime purpose of the above design sketch is to illustrate how one can think about creating several zones of proximal development in the design of systems.

This design idea further supports distributed interaction and as such represents a move away from the ideal of Bang \& Olufsen of one integrated remote control offering a neatly tied sofa table with only one remote. Taking up this idea suggests that it would be interesting to pursue the trend of pervasive computing (Mark 1999) into the home sphere too, e.g. through working with interactive walls and rooms ([P8] Bødker et al. (2001), Streitz et al. (1998)). However, this is a subject for future work. As discussed in the following, designing for contextualising learning artefacts at all levels, as attempted in the above design sketches, is also a matter of supporting collaboration in the design process. 


\section{Supporting collaboration in a multidisciplinary design team}

In the interaction design group at $\mathrm{B} \& \mathrm{O}$, called Measure of Pleasure, we find a range of competencies collaborating in the design process including an industrial designer, a psychologist, a software developer and a narrator (Bærentsen and Slavensky 1999). Arguably, also the design of the different types of learning artefacts demands a range of competencies. At $\mathrm{B} \& \mathrm{O}$ the industrial designer has a strong focus on the overall product concept and identity (transformation artefacts) and on how it is represented in the physical appearance of the product (condition artefacts). The psychologist in turn focuses much on how people perceive the means of interaction (interaction artefacts). All this should be seen in light of the technical possibilities understood by the engineers. Thus a perspective on how to design for learning in use implies supporting the collaboration and negotiations among a multidisciplinary design team to ensure that the overall visions comply with the material and visual design as well as the interaction design. It means to support the contextualisation of learning artefacts. This concern has been addressed in a number of ways as part of the BIDI project.

[P6] Petersen \& Madsen (1999) discuss how different physical layouts of the design room support different kinds of collaboration. We found for instance that discussions and negotiations among the competencies are best supported when people face each other in a "lean forward" situation. Further, in light with Schön's view on design as a reflexive conversation with materials (Schön 1983), we identified the importance of having available flexible materials as well as a range of material example technologies and prototypes. In this way people can express their ideas in tangible ways supporting the communication and evaluation among the very diverse group of people. We expanded the concepts of Seeing and Moving, as developed by Schön (ibid), into spectrums, where Moving can be anything from just a verbal expression to material modification and Seeing ranges from visual apprehension to actively experiencing. In light of our studies and experiments with different design settings, we argue that it is important to provide a setting and materials supporting design within the whole ranges of these spectra [P6] Petersen and Madsen (1999). E.g. seeing a remote control can be anything from looking at a picture of a remote control, to holding the remote control in the hand, over to using the remote control to control a TV set or a prototype of a TV set. Thus visual apprehension and verbal expression does not suffice when supporting collaboration in designing everyday artefacts.

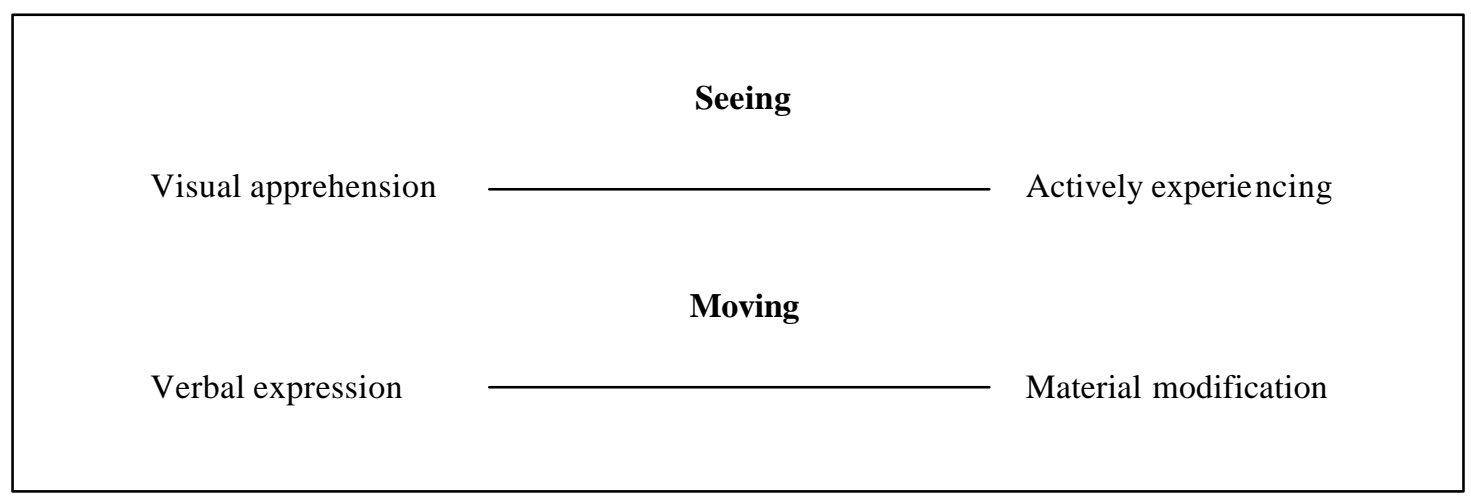

Figure 5.4 Schön's concepts of Seeing and Moving expanded cf. [P6] Petersen and Madsen (1999) 

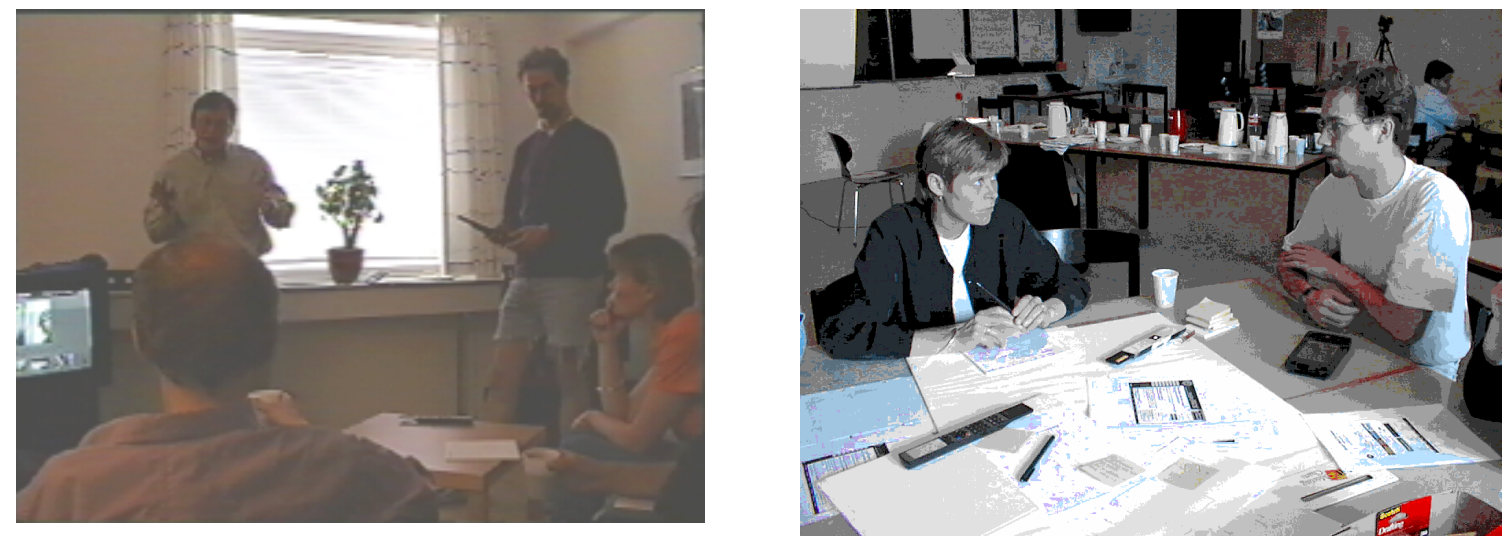

Figure 5.5 Different kinds of seeing and moving at design meetings. The first situation is dominated by Seeing through visual apprehension, whereas the second represents Moving through material modifications.

We further experimented with the idea of stands in the design room, to represent the different voices in the design process and to provide a pool of materials from which to See and Move [P6] Petersen and Madsen (1999).


Figure 5.6 Discussions at different stands in a design workshop

The above ideas have also been expanded to take advantage of emerging pervasive technologies as discussed in [P8] Bødker et al. (2001). Here we focus on integrating interactive wall and table technologies into the physical environment, to support active collaboration in design practice. In line with others (Streitz et al. 1998, Mackay 1998, Moran et al. 1998), we investigate how the physical and technological spaces can support each other. As an example we framed a design meeting supported by an interactive wall and an interactive table around a high table and high stools allowing easy shifts between sitting around the table and jumping up to illustrate ideas on the wall. It was also this concern which led us to focus explicitly on the physical framing of technology in the home, as discussed in chapter two. However, in contrast to the work of Streitz et al. (1998) and Moran et al. (1999) and in line with Mackay (1998), this work seeks to ground technological experiments in practices of everyday life and work, as seen in the following pictures. 


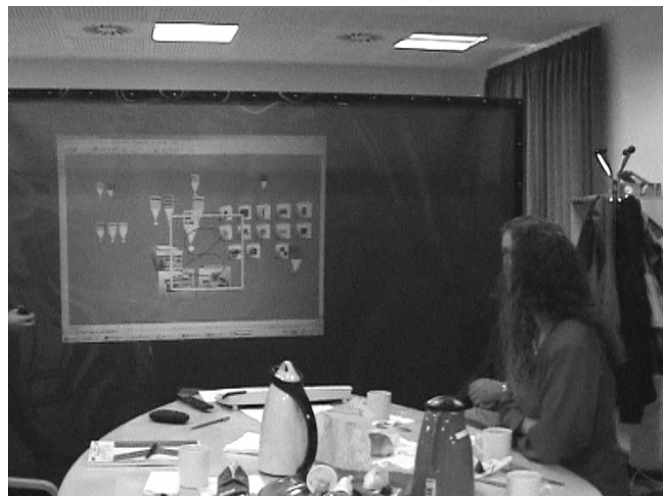

Figure 5.7 The common-meeting scenario of the interactive design collaboratorium

The vision of the common meeting as supported by interactive wall and table technologies was evaluated in a cooperative design workshop, where B\&O interaction designers worked in the experimental setting. This is further discussed in [P8] Bødker et al. (2001). Thus collaboration amongst designers is important in designing for learning in use, but it is also important to consider the role of the users in this respect.

\title{
Creating needs or supporting needs
}

At a first glance, it could look as if designing in terms of learning artefacts implies designing for creating needs rather than supporting needs, which is not well in line with a perspective of user participation in design. Some precautions can serve to resolve this apparent paradox. First it is important to acknowledge that as argued above, artefacts crystallise both use and design, thus as argued by Dunne (1999), we may as well acknowledge that every design holds a set of values. Dunne (ibid) quotes Robinson's criticism of the interest within Human Factors (or the usability community, MGP) to develop products that will not confuse or disappoint. Robinson argues that this approach

\begin{abstract}
"misses the essential connection between the power of objects to affect the way in which the world is seen and the mechanism through which that happens. Paradoxically, user-centredness is not just figuring out how people map things, it absolutely requires recognising that the artefacts people interact with have enormous impact on how we think" (quoted in Dunne 1999, p. 32).
\end{abstract}

Following the original ideals of participatory design (Greenbaum and Kyng 1991, Ehn 1993), the challenge then becomes one of identifying means and methods that allow users to actively engage in the development of future technologies and engage in discussions on the values inherent in the products. One approach to pursue this interest is the design workshops held in private homes as part of this thesis. Here families were engaged in designing future everyday artefacts.

\section{Designing everyday artefacts with families at home}

One way to engage future users in the design of everyday artefacts is to conduct design workshops with families in their homes Baillie et al. (in press), [P5] Petersen and Baillie (2001). We started out by introducing people with technological extremes in order to provoke reactions and thoughts. As discussed in [P7] Bødker et al. (2000) we have found provocations and extremes useful approaches to support creativity in design. We started out the first session with a Technology Tour, discussed in chapter two. We then presented a number of futuristic technological visions and in light of the issues, which arose during the Tour, we asked the family members to discuss how they could or could not fit into their homes. We asked the families to concretise their ideas and visions into mock-ups. As discussed in chapter two, we also focussed 
explicitly on the physical placement of the mock up, asking the users to discuss and place the mock up in the physical context of their home. We finally extracted scenarios from their descriptions.

As argued earlier on, time is an important factor when studying learning in use of everyday artefacts. Thus taking up the idea that cycles of use and design mirror each other (Engeström 1987 and Bødker 1999), we experimented with means of introducing time in the design process. Therefore we left the mock-ups with the families, in the place where they had themselves positioned them and we asked the families to live with them over a period of time. We provided them with post-its and encouraged them to further mould the mock ups, move them, add on any ideas, reflections, critiques etc. as they occurred to in the context of their daily life practice and family life. Our workshop sessions proceeded as illustrated in the figure below.

\begin{tabular}{|l|l|l|l|l|}
\hline & Preparatory Stage & Session 1 & $\begin{array}{l}\text { Inter session } \\
\text { activities }\end{array}$ & Session 2 \\
\hline Focus & $\begin{array}{l}\text { Planning and } \\
\text { collecting families }\end{array}$ & $\begin{array}{l}\text { Investigate } \\
\text { Current } \\
\text { Problems and } \\
\text { Future } \\
\text { Possibilities }\end{array}$ & $\begin{array}{l}\text { Collection of } \\
\text { data } \text { in- } \\
\text { between } \\
\text { sessions }\end{array}$ & $\begin{array}{l}\text { Contextualise } \\
\text { ideas in home } \\
\text { and daily life }\end{array}$ \\
\hline Methods & $\begin{array}{l}\text { Telephoning } \\
\text { families, } \\
\text { gathering } \\
\text { equipment: } \\
\text { stationary, video } \\
\text { camera, tapes. }\end{array}$ & $\begin{array}{l}\text { Tour" } \\
\text { 2. } \\
\text { Representations } \\
\text { of emerging } \\
\text { technologies } \\
\text { 3.Scenarios }\end{array}$ & $\begin{array}{l}\text { Post-it notes } \\
\text { Notes }\end{array}$ & $\begin{array}{l}\text { 1. Informal } \\
\text { interview } \\
\text { 2. Materializing } \\
\text { ideas for future } \\
\text { technologies. }\end{array}$ \\
\hline
\end{tabular}

Table 5.1 Methods and focus for each of the sessions (extract of a figure in Baillie et al (in press).

The idea here is much in line with the use of mock-up in cooperative prototyping (Ehn and Kyng 1991), where systems developers and users cooperate on developing a new design through discussing and simulating use on mock ups, situated in the actual context of use. What is different here is that we ask the users to dwell on the mock up in the context over a prolonged period of time and to materialise their comments and ideas on post-it notes, as they occur to people over time. Our approach shares the idea of gathering information from households over time with the cultural probes idea by Gaver et al. (1999). Gaver et al. (ibid) provide people with different means of communication including disposable cameras and pre-stamped post cards asking provocative questions like "why do we have politicians". However, in their approach, the resulting technology design, is created detached from the context of use, only linked to the community through the post cards and cameras people send. Instead, we have sought to maintain a close collaboration with the users. A session from one of the families serves to illustrate the approach.

After Sue and John have taken us on the technology tour (described in chapter two) they are presented with a number of pictures e.g. "intelligent" microwave oven supporting banking etc, and a number of different technological devices. Following up on earlier discussions Sue mentions the idea of having recipes on a screen in the kitchen. We look at and discuss the use of her own personal recipe book, which her mother got for her. It contains only recipes, which has been tried out and found good. They are written in by hand and personal adaptations are made in this process. We discuss the idea of an electronic version for a while, and Sue is asked to materialise how such a device could look and where in the kitchen it could be. Together, we construct a first, crude representation of recipe support in the kitchen. It contains a 
pen, which allows for annotations and corrections inspired by the process of cooking. We also experiment with the idea of a "flying" representation triggered by a balloon and with having several representations, for when Sue and John are both in the kitchen preparing each their part of the meal. We finally elaborate on the idea of a screen - like device, which Sue argues should be placed lying on the table right next to the stove, as this is where she needs to see the recipes. A number of ideas and discussions come up linking the support for recipes to a family calendar showing when guests are due and also support for a shopping list. The discussions also turned down a number of common ideas on support for the kitchen. Sue found the detailed account of the contents of the fridge uninteresting. Instead she would like to be able to "look into the fridge" while at work preparing the shopping list. When the electronic recipe book is used to support cooking, pictures are not very important. These are more interesting in a situation of recipe surfing, which typically happens as a relaxed situation in a soft chair. As the session finishes, the mock up is left on the table beside the stove, and Sue and John are provided with post-it notes and asked to note down ideas, comments etc. At the next visit, it turns out that the mock up has been moved to a different place in the kitchen. They found that as they start to cook in the kitchen, the place on the table is needed for preparing the food. Thus the mock-up has been moved to the wall next to the fridge. They also suggest that in this place, it serve mainly to guide the cooking of a specific meal. This is not the place to surf for recipes. Sue suggests that its appearance should be fancy and funny, in line with the Allessi products occupying their kitchen. She suggests the form of a silver heart.

It is interesting how even this simple mock up has triggered reflection over time through its very presence. And how trying to live with it provided input for where it should be positioned in the kitchen and thus which role it should take on. The series of design workshops also illustrate how there are a lot of factors, which comes into play in the preparation of meals beyond merely efficiency and optimal fitting between contents of fridge and meals. Care-taking, personalisation, dwell on the process and making the preparation an experience are a few examples as illustrated in the following comments from the workshops.

- When planning a dinner for the family Mrs. Archibald select meals through "using her head" - and prepare meals that she knows the visitors like.

- Sue likes to hand write the best receipts into her personal cookbook, which she got as a gift from her mother.

- Karen would not like to have "optimal" receipts together with remote shopped goods. - "Then every family would have the same thing for dinner. It is all right that things takes time ... you find inspiration when hanging around a bit in the supermarket"

Thus what at first seemed a little odd, in light of these examples, Sue's suggestion of a silver coloured heart as the visual representation of the combined recipe holder and family calendar seems to coin well her ideal cooking experience.

In a second case, we asked people to give their ideas a name. In a case where a mother envisioned an automatic vacuum cleaning system, the family discussed different naming of the system including "the Home Help at Home" and "Suction Sussi". Although they may not make it to the market (and the last could be problematic in the US, as pointed out by the teenage son), shifting focus from the physical and technical realisation and functionality to the overall concept and idea provides more insight into the idea and potential motives for using the future everyday artefact. 


\section{A life-cycle approach to the design of everyday artefacts}

The Technology tours also confirm the idea proposed by Bærentsen (2000) and Clanton (2000) emphasising the need to get users started and focus on first time use, as discussed in chapter two. Sue and John explained how, when they moved into their flat, they were at first unable to turn on the stove to do basic cooking. They had to call the former owner of their flat to ask him how turn it on. They now use this as a party trick. Till now, no one have been able to do it on theirs own. The reason for the irony is obvious. Nobody can perform an apparently extremely simple task, which most adults even have years of experience in. At the other end of the spectrum we find tasks, which needs to be done very rarely, but are never the less essential like changing the batteries of a chord-less phone. Mrs. Archibalds explains how she nearly broke their phone when changing batteries, as she in desperation smashed the handset into the table, after which, by unique luck, the batteries fell into place. We see here how it is important that both first time experiences as well as rare but essential things are part of the concern for learnability of everyday artefacts.

\section{Innovation in design}

Part of designing for learning in use of everyday artefacts is also to design for innovation in use. As reported in [P7] Bødker et al. (2000), we have experimented with a number of approaches for doing this. The "Talk to your TV"-approach is a way of opening up the design space providing a move away from norms for interacting with a television. In this experiment we used a "Wizard of Oz" technique where the participants were asked to perform some tasks assuming they could just talk to the $\mathrm{TV}$, given a scenario to frame their tasks. In this way adopting a playful relationship to the technology in the design phase too. The experiment worked most successfully when we first asked the participants to perform the tasks using the traditional means of interactions; the remote control. Subsequently we asked them to perform tasks just talking to the TV. In this way, the new means of interaction worked as a springboard (Engeström 1987), a "facilitative image, technique or socio-conversational constellation ... misplaced or transplanted from some previous context into a new..." (ibid, p. 287) supporting creativity in design work.

Furthermore, in working with the idea of design workshops [P7] Bødker et al. (2000), [P6] Petersen and Madsen (1999), [P8] Bødker et al. (2001), we have taken the concept of workshop quite literally emphasising that the settings of design should provide an inspiring environment. One approach to support this was in introducing the idea of stands, where each of the competencies involved in the design workshop constructed a stand with their favourite designs and sources of inspiration. The stands were then presented to all the participants in the design workshop providing mutual inspiration. The range of representations at the stands served as sources of inspiration and promoted the different perspectives in the design work. Through having tangible representations, all participants in the meeting were supported in promoting the different perspectives. In this way the different voices were not solely attributable to certain participants but, through the stands, all participants were supported in taking advantage of all perspectives.

\section{A design cycle for learning and living with everyday artefacts}

In [P1] Bødker and Petersen (2000), we devised a design cycle for designing the learnable artefact. The cycle consists of the following phases in iteration:

- Investigate the multiple backgrounds of the users 
- Establish the new instruments

- Support formation of operations

- Consolidate use

In the following, the cycle is briefly described and used to frame the ideas and methods presented throughout this thesis. The concern for everyday artefacts is added to the interest in designing for learning in use. In this way the contributions of this thesis is summarised. No claim is made here, that this thesis provides a complete methodology for designing for learning in use of everyday artefacts. Rather the cycle is used to contextualise the different contributions of this thesis in the process of design. In the following brief descriptions of each phase are provided along with design principles and methodological suggestions emerging from the work of this thesis.

\section{Investigate the multiple backgrounds of the users}

The investigation of the backgrounds of users must focus on their diverse practices and experiences from the variety of artefacts owned and used.

- Technology Tour (Section 2.x and [P5] Petersen and Baillie (2001))

- Analyses of the use of existing artefacts, in terms of learning artefacts (in line with the analysis of the cinema experience reported in chapter four)

\section{Establish the new instruments}

Establish the new instruments consists of threes parts. Establish potential competence is a matter of developing the visions of future possibilities. Establish initial familiarity focus on the grounding of these visions in familiar circumstances and to provide the users with some ideas on where to start. Thus establishing potential competence should have an outset in actual competence. Finally, a microcosmos should be set up where users can explore the formation of activities, actions and operations and we can learn from these explorations in the further design.

\section{a. Establish potential competence}

- Design workshops with users in context e.g. designing for the home in the home. Provide technological provocations and ask to contextualise these in home and practice (chapter five, Baillie et al. (in press), [P4] Baillie and Petersen (2001), [P5] Petersen and Baillie (2001))

- Asking users to name their visions and ideas for new artefacts - what is it called (chapter five)

- Talk to your TV exercise (chapter five, [P7] Bødker et al. (2000)

- Play-perspective on interaction. Relating to things in new and several ways (chapter 2, 3 and five)

- Designing transformation artefacts (chapter four)

\section{b. Establish instruments emphasising initial familiarity}

- Design for pre- use and positive first time experience (chapter three)

- Using Metaphors in design (chapter four)

- Naming technologies: What is it called (chapter five)

- Contextualise transformation artefacts in terms of condition artefacts, triggering possibilities over time and interaction artefacts ensuring that the users can get started (chapter four, [P2] Petersen et al. (2002)). 


\section{c. Establishing a microcosmos}

- Living with mock-ups (chapter five, [P5] Petersen and Baillie (2001))

- Iterative investigations, Explorative inquiry (chapter three, [P3] Kjær et al. (2000))

\section{Support formation of operations}

Supporting formation of operations is an area which is well covered by Bødker (1991) Designing for learning in use of everyday artefacts implies that the operations formed are oriented toward the use process and not towards learning in isolation.

- Contextualise transformation artefacts into interaction artefact and condition artefacts (chapter four [P2] Petersen et al. (2002))

- Hands-on use evaluations ([P3] Kjær et al. (2000)).

Consolidate use

As discussed in [P2] Petersen et al. (2002) general interaction artefacts (or why artefacts in the terminology of [P2]) support the robustness and consolidation of the interaction In the words of the man in one of the $\mathrm{B} \& \mathrm{O}$ families, that is "the logic behind the interaction" ([P2] Petersen et al. (2002)). Also the condition artefacts play a role in this respect as visual triggers possibilities of the artefact.

- Design for use-life cycle (chapter five, [P4] Baillie and Petersen (2001))

- Iterative investigation (chapter three, [P3] Kjær et al. (2000))

- Design general interaction artefacts and condition artefacts to sediment opportunities ([P2] Petersen et al. (2002))

\section{Designing for learning in use of everyday artefacts}

This chapter presented a number of approaches to designing for learning in use of everyday artefacts. It started out further establishing the relation between use and design, and it suggested how the framework of learning artefacts can support evaluations of design against the underlying design practice. Moreover, it establishes collaboration between the different compentencies in design as a central issue, and a number of approaches to supporting this are presented. It concludes with a proposed methodological cycle for designing for learning in use of everyday artefacts and it contextualises the different methods, techniques and concerns raised in this thesis in terms of the cycle. 



\section{Chapter six}

\section{Research methodology}

The work of this thesis continues a tradition of action research (Bødker 1991 and 1999, Ehn 1993, Bardram 1998, Nielsen 2001). As argued by Baskerville (1999), "Action research simultaneously assists in practical problem solving and expands scientific knowledge" (ibid, p. 7). The practical problem sparking off this project is that of how to design Bang \& Olufsen products such that they support the users in learning how to use them. This problem emerged through collaboration with the interaction design group at Bang \& Olufsen.

Understanding the process of learning in use is a new challenge for HCI [P1] Bødker and Petersen (2000). Much HCI research tends to focus on the first hours of use of novice users, and little attention is given to how users become skilled in the use of computer applications over weeks and years (Bannon 1991). As this is a rather new problem for the field, it is hard to know what to look for and indeed how to study the phenomena methodologically. Therefore, it is important to remain open to the situation and not be constrained by pre-determined categories of analysis. Qualitative methods are good for remaining open to the situations, and more over, as argued by Quinn Patton (1980) qualitative methods are well suited to study development processes, since depicting process requires detailed description. Pre- and post-tests do not justice dynamic development processes as they imply a linear, ever upward image of growth and development (ibid). In remaining open in terms of what to look for, the long-term study of TV use was dominated by observations and open-ended inquiry methods. This was a series of site visits, each comprising a kind of snapshot of the situation. As argued by Bødker (1999) on this type of study,

\footnotetext{
"one the one hand, it may not be so easy to understand development from such snapshots, and we run the risk of missing some important steps. On the other hand, it is resource-wise almost impossible to follow such a process more closely than I did, and I would also be running the risk of not seeing the development if I was located in the organisation continuously" (ibid, p. 59).
}

The context of the home poses yet a challenge for this kind of study, namely that simply for issues of privacy, it is not possible to stay on site more continuous ly. 
The qualitative study conducted as part of this thesis fits well in line with the general move of the HCI area from laboratory oriented studies dominated by quantitative methods towards considering use in a broader context through qualitative studies focusing on concrete and particular situations (Bannon 1991, Bertelsen 1998, Kuutti 1996). Qualitative methods provide little background for generalisations, but like quantitative approaches this paradigm also holds criteria for good research. Quinn-Patton (1980) points to triangulation as a way to enhance the quality and credibility of qualitative analyses. Triangulation refers to the phenomenon of land surveying. Knowing a single landmark specifies locations along a line in a direction from the landmark, however knowing a second landmark establishes a single position in the intersection between the two lines of directions. The idea behind triangulation is that every approach and method has its strengths and weaknesses and one approach can never reveal everything. Quinn Patton refers to four types of triangulation, i.e. methods-, data-, theory-, and investigator triangulation. In the study of \&O television usage, methods triangulation is conducted in that people are both observed and interviewed [P5] Kjær et al. (2000). Furthermore, data triangulation (Quinn Patton 1990 ) is done in that the learning processes of two families are followed. There is no systematic theory- nor investigator triangulation. Mackay and Fayard (1997) takes the argumentation of triangulation one step further, arguing that triangulation across the different scientific and design disciplines constituting HCI is the way the obtain more effectiveness of individual results as well as resolving the unproductive debates on who is the most scientific in the field. Arguably, also quantitative data obtained from logging the families' interaction could have provided interesting data on the adoption process in the case of $\mathrm{B} \& \mathrm{O} \mathrm{TV}$ use. Unfortunately, for practical reasons, this was not possible.

In choosing a theoretical basis for addressing the challenges of designing for learning in use of everyday artefacts, activity theory provides a good starting point through its focus on development and mediation. It is a central tenet of activity theory that activities are not static but constantly develop and thus hold a history. Moreover activity theory is object-oriented in that emphasises a focus on the objects of work in a dual sense, namely both in terms of the material objects presented to the mind and senses as well as an end or aim. So the object is both the material given and projections of the anticipated (Engeström 1990). It is exactly these foci which are represented e.g. in the technology tour, where people are asked to present both their technological objects or artefacts, their aims and problems with these and the history of their use and context. The design workshops in people's homes also emphasise the material character of artefacts in that people are asked to materialise their ideas into early mock-ups. The emphasis on mediation and development also comes through in that people are asked to play through scenarios with the early mock-ups and asked to live with them over a period of time. Activity theory fits well in line with the underlying intentions of qualitative methods and action research in that all traditions insist on understanding the world in terms of its rich contextual complexity and they also focus on change processes. These characteristics pervade the choice of studies and experiments in this thesis. In the case of B\&O television usage, giving value to ecological validity over generality, we chose to follow families, in their homes, who had bought their TV sets by themselves regardless of the study reported in this thesis. This allowed us to study the motivations for use as formed in real life situations.

As argued by Engeström (1987), Kaptelinin (1996) and Nardi (1996), activity theory does not offer a set of predictive tools, but rather a conceptual framework, which needs to be conc retised according to the specific object of interest. That is done 
in this thesis through developing the view of learning artefacts for understanding how to design for learning in use of everyday artefacts. Interestingly, Kuutti (1996) argues that within information systems research, a certain consensus has developed that three levels of descriptions are necessary. What distinguishes the framework of learning artefacts, however, is that it is grounded in a theory of human activity, as opposed to many other frameworks lacking a theoretical basis, as pointed out by Kuutti (ibid).

The underlying ideas of participatory design, of moving towards involving users actively in the design of future products, continuously inspire the experiments undertaken as part of this thesis, again representing an established tradition (Greenbaum and Kyng 1991). We collaborated with the interaction design group at Bang \& Olufsen, and held experimental design sessions as part of an ongoing development projects at Bang \& Olufsen. We investigated means of providing users with a voice in design workshops [P8] Bødker et al. (2000) and design workshops were held with families in their private homes [P6] Petersen and Baillie (2001). At times, we were not able to go as far in this direction, as we would have done otherwise, for instance in the design workshop experiment at $\mathrm{B} \& \mathrm{O}$, users were only represented through video clips and quotes and not in reallife. However as argued by Bødker (1999), an action science approach implies double reflexivity, i.e. we demand participation and engagement from the people we work with, but we also have to be engaged and open to the problems of these people and organisations.

However, the focus on B\&O TVs or everyday artefacts challenges the established HCI area in several ways. On a practical level, the area of everyday artefacts has fundamentally different conditions for user participation than workoriented technologies have. Since the 1970s, the Scandinavian countries have manifest by law the right for workers to be heard regarding introduction of new technology (Ehn 1993). The unions have had a central role in organising this democratisation. This is obviously not inherently the case in the design of everyday artefacts. The only inherent vote in this area is through buying. Bjerg (2000) has pointed out this problem with respect to domestic technologies advocating the need to take an oiko-centric perspective in the development of the electronics of private home-life. In Bjerg's view the oikocentric perspective means grounding in the local, particular home and neighbourhood, seen qualitatively, objectively, and subjective from the inside. It means supporting long-term citizen interest through supporting personal expression and reflection. This grounding in the local is also much in line with the need to study artefacts in use in their natural context as voiced by Bannon and Bødker (1991). It is pursued in the work of this thesis through studying long-term use of TVs in private homes and conducting design workshops with families, situated in actual private homes.

While there is a wide agreement on striving for more naturalistic studies in HCI, the pre-dominant focus of the area is still on work-contexts. Grudin (1990a) argues that the computer interface reaches out towards comprising the whole workcontext, but few seems to take up the challenge of the wider move of interactive interfaces into most aspects of everyday life, e.g. the home as exemplified by the B\&O study. A tradition is slowly emerging, e.g. with the home-it conferences (Sloane and van Rijn 2000) and the focus on information appliances (Norman 1999a, Bergman 2000)

Similarly traditions of participatory design have also focussed on co-operation with employees at work places (Greenbaum and Kyng 1991), and activity theory has mainly been applied within the area of HCI to understand and develop work-practices (e.g. Bødker 1991, Bødker 1999, Bertelsen 1998). This is also evident from the 
aspects of activity theory that are well developed within a context of HCI, namely technological mediation, learning and development. However, as discussed in chapter two, interaction with everyday artefacts challenges earlier ideals of HCI e.g. that of transparent interaction. In this thesis a perspective of play is suggested to reveal new aspects of HCI, also based on activity theory. But as evident from the analysis presented in this thesis, these aspects of the theoretical framework are not yet as well developed in an HCI context. Thus the context of the home, as dealt with in this thesis challenges both our means of investigating and understanding use praxis, of our theoretical underpinning as well as our ways to cooperate with future users in design. This thesis provides some reflections in these directions as well as suggestions in terms of the techniques of iterative inquiry and exploratory investigation [P3] Kjær, Madsen and Petersen (2000), cooperative design workshops with families in their homes, and a play-perspective on human-computer interaction.

Regarding concerns on relevance versus rigour, as argued, the work of this thesis is primarily exploratory and thus should be seen as what the name itself suggests, namely as a hypothesis for what it means to design for learning in use of everyday artefacts. Future work should establish a learning perspective as inherent in usability design work with a concern for the characteristics of the new and changing technologies. 


\section{Chapter 7}

\section{Conclusion}

There is a growing concern in the HCI community that something new is needed as part of our understanding of what usability is and of how we practice it (Thomas and Macredie 2002). This thesis offers some suggestions in this direction. Thomas and Macredie (2002) argue, with reference to [P2] Petersen et al. (2002), that one of the challenges for the usability field is that the objects of studies, and so the challenges for design, have changed dramatically over the last years and will change even more radically in the future. Taking the case of the use of a Bang \& Olufsen system as an exemplar situation, this thesis pushes forward the concept of everyday artefacts to grasp some of the characteristics of the new objects we deal with in the area of HCI. The concept of everyday artefacts emphasises a concern for designing selfexplanatory artefacts, for dealing with aesthetics and provocations in design, for designing for shifting degrees of attention, and in the case of domestic technologies to consider the special characteristics of technology use in the household. It proposes play as an interesting perspective human interaction with these objects, and it holds some methodological suggestions on how to address these aspects.

In addition, grounded in activity theory, this thesis suggests a learning perspective on the use of everyday artefacts. This implies moving beyond snapshots of use as a basis for designing and re-designing interactive artefacts, as we often see it in usability practices of today. Taking a perspective of learning in use is a matter of introducing time in design. The perspective emphasises the need to support motivation and pre-use, and to design for positive first time use. Thus in evaluations, we need to look into the zone of proximal development and not only focus on people's present use but also on their potential ones. This means asking different types of questions and this thesis suggests exploratory investigations and iterative inquiry as techniques emphasising a learning perspective. Further, the framework of learning artefacts is one of the central contributions of this thesis. It offers a theoretical basis for understanding how artefacts support learning in use. The framework is a further development of Engeström's (1990) and Wartofsky's (1979) 
contributions. Understanding human-computer interaction in the perspective of learning artefacts implies understanding artefacts beyond the artefact per se, but as carrying with them models of their use, and potentials for a transformed practice including values, ideals and experiences. This thesis offers an example of how the framework of learning artefacts can be used to evaluate existing designs in a learning perspective.

Finally, this thesis provides a number of approaches to the challenge of designing for learning in use of everyday artefacts. One of the tenets here is that the process of design is closely linked to the process of use. The framework of learning artefacts elaborates on the work of others in this respect through pointing out how artefacts can be seen not only as crystallised use, but also as crystallised design. In this perspective, evaluating design is also a matter of evaluating design against the design practice, which produced it. Further it integrates the previously unrelated areas of metaphors and mental models suggesting that these areas are closely inter-linked, where the role of metaphors is to support users in developing models of future use. Further designing for learning in use requires collaboration among a set of competencies in the design process. The thesis reports on a number of approaches to supporting this, including concerns for the physical environment for design sessions. Designing everyday artefacts also implies dealing with new types of users in new environments. This thesis gives examples of design workshops held with families in their homes as one way to address these challenges. In these sessions, time was introduced in the design process in that people were asked to live with early mock-ups for a period of time. In this way early adoption and appropriation were investigated and embedded into the design. To summarise, this thesis offers the following theoretical and practical contributions.

\section{Theoretically}

- It develops and operationalises the framework of learning artefacts based on the work of Engeström (1990) and Wartofsky (1979) with respect to understanding how to design for learning in use of interactive technologies.

- Using this framework, it further develops the perspective on use and design as interrelated, as previously suggested by Engeström (1987) and Bødker (1999), and it points out how evaluations of use is also a matter of evaluating design practice.

- Using the framework of learning artefacts, and provoked by the case of humanTV interaction, it suggests how we may come to broaden our understanding of usability to comprise concerns on aesthetics and non-transparent design.

- A cycle of designing for learning in use is developed, based on the work of Engeström (1987) and others.

\section{Practically}

- It contributes to the methodological toolbox for designing for learning in use of everyday artefacts. Technology tours in private homes, participatory design with families, exploratory investigations and iterative inquiry are examples of techniques developed as part of this thesis.

- It offers a set of design principles for designing everyday artefacts.

- The framework of learning artefacts provides a tool for analysing long-term use, and for evaluating designs against the design practice, which produced it.

This thesis is but a beginning to design for learning in use of everyday artefacts. It posses a hypothesis for what this means and provide some indications of what may be 
fruitful paths to explore in this direction. As such, it provides an excellent starting point for my own future work and hopefully for others too.

\section{Future work}

The proposed design cycle is a merely a hypothesis for designing for learning in use, which needs to be further developed and examined. Equally, the framework of learning artefacts needs to be further operationalised towards supporting a learning perspective in design practice. Particularly the level of transformation artefacts need further development and investigations as this represents a broadened perspective on Human Computer Interaction, which provides room for concerns for aesthetics, and provocative designs. Both these aspects could be investigated through a design project, where also the methodological suggestions would be further tested and elaborated.

Digging into the case of human-TV interaction new aspects of use emerges. These however, needs further investigations in order to be better understood. We only have vague and disparate understandings of how the setting of the home brings in new facets of use. Further engaging families in participatory design is also a challenge, which has only been scarcely addressed till now. 


\section{References}

Albrechtsen, H., Andersen, H. H. K., Bødker, S., and Pejtersen, A. M. (2001) Affordances in Activity Theory and Cognitive Systems Engineering. Work Report, Danish National Center for Human-Machine Interactions.

Allen, R. B. (1997) Mental Models and User Models. In Helander, M., Landauer, T. K. and Prabhu, P. (Eds.) Handbook of Human-Computer Interaction, Second, completely revised edition, Elsevier Science B. V., pp. 49-63.

Baillie, L. and Petersen, M. G. (2001) Emerging Themes in Designing Household Environments. In Proceedings of the OIKOS2001 Workshop, Aarhus University Press, pp. 44-46.

Baillie, L., Benyon, D., Macaulay, C.M. \& Petersen, M. G. (In press) Investigating design issues in household environments.

Bannon, L. (1991) From Human Factors to Human Actors: The Role of Psychology and HumanComputer Interaction Studies in System Design. In Greenbaum, J. \& Kyng, M. (Eds.) Design at Work: Cooperative Design of Computer Systems. Lawrence Erlbaum Associates, pp. 25-44.

Bannon, L. \& Bødker, S. (1991) Beyond the Interface: Encountering Artefacts in Use. In In Carroll, J. M. Designing Interaction. Psychology at the Human-Computer Interface. Cambridge University Press, pp. 227-253.

Bardram, J. E. (1998) Collaboration, Coordination, and Computer Support. An Activity Theoretical Approach to the Design of Computer Supported Cooperative Work. Ph.D. thesis, Aarhus University. Daimi-PB 533.

Bardram, J. E. \& Pedersen, M. B. (1994) Fra Interface til Interaktion [From Interface to Interaction]. Masters thesis, University of Aarhus.

Baskerville, R. L. (1999) Investigating Information Systems with Action Research. In Communications of the Associations of Computing Systems, Volume 2, Article 19, October 1999, pp. 1-32.

Bateson, G. (1972) Steps to an Ecology of Mind. University of Chicago Press.

Baxter, I., and Oatley, K. (1991) Measuring the learnability of spreadsheets in inexperiences users and those with previous spreadsheet experience. In Behaviour and Information Technology, 191, Vol. 10, No. 6, pp. 475-490.

Bergman, E. (Ed) Information Appliances and Beyond. Interaction Design for Consumer Products. Morgan Kaufman Publishers.

Bertelsen, O. W. (1998) Elements of a Theory of Design Artefacts - a contribution to critical systems development research. Ph.D. Thesis, Aarhus University. DAIMI PB-531.

Bertelsen, O. W. (2001) Towards an aesthetic turn in the interface. In Book of Abstracts from the Conference on Activity Theory and Sociocultural Research. September 7-9, 2001, Ronneby, Sweden. pp. 18-19.

Bisgaard, O., Mogensen, P., Nørby, M. and Thomsen, M. (1989) Systemudvikling som larevirksomhed (Systems development as a learning activity) Masters Thesis, University of Aarhus, DAIMI IR -88 .

Blyth, M. (1999) Our Own Devices. In Interactions... nov+dec,1999, ACM Press, pp. 43-45.

Borgholm, T. \& Madsen, K. H. (1999) Cooperative Usability Practices. In Communications of the $A C M$, vol. 42, No. 5, pp. 91-97.

Bowers, J., Button, G., and Sharrock, W. (1995) Workflow from Within and Without: Technology and Cooperative Work on the Print Industry Shopfloor Cooperation and Power. In Proceedings of the Fourth European Conference on Computer Supported Cooperative Work, pp. 51-66.

Brown, J. S. \& Duguid, (1996) Organizational Learning and Communities of Practice. Toward a Unified View of Working, Learning and Innovation. In Cohen, M. D. \& Sproull, L. S. (Eds.) Organizational learning. London, Sage, pp. 58-82.

Buur, J. and Bagger, K. (1999) Replacing Usability Testing with User Dialogue. In Communications of the ACM, vol. 42, No. 5, pp. 63-66.

Buur, J. and Bødker, S. (2000) From Usability Lab to Design Collaboratorium: Reframing Usability Practice. In DIS2000 Designing Interactive Systems: Processes, Practices and Methods. ACM Press pp. 297- 307. 
Bærentsen, K. B. (1989) Mennesker og Maskiner (People and Machines). In Hedegaard, M., Hansen, V. R. \& Thyssen, S. (Eds.) Et Virksomt Liv (An Active Life). Aarhus Universitets Forlag, pp. 142-187.

Bærentsen, K. B. (1998a) Intuitive User Interfaces. For Electronic Mediation of Cultural Experiences. Paper presented at ISCRAT 1998. Aarhus June 7-11.

Bærentsen, K. B. (1998b) Hvordan man får en fjernbetjening til at give mening (How to make a remotecontrol meaningful). Paper presented at the $9^{\text {th }}$ Danish conference on Activity Theory. Røsnæs November 6-8.

Bærentsen, K. B. \& Slavensky, H. (1999) A Contribution to the Design Process. Achieving essential strengths in design, sound, picture, user interaction, and system integration. In Communications of the ACM May 1999, vol. 42, no. 5, pp. 73-77.

Bærentsen, K. B. (2000) Intuitive User Interfaces. In Scandinavian Journal of Information Systems, vol. 12, pp. 29-61.

Bærentsen, K. B. and Trettvik, J. (in press) An Activity Theory Approach to Affordance.

Bødker, S. (1991). Through the Interface - a Human Activity Approach to User Interface Design. Hillsdale, NJ: Lawrence Erlbaum Associates, 1991.

Bødker, S. and Grønbæk, K. (1991) Design in Action: From Prototyping by Demonstration to Cooperative Prototyping. In Greenbaum, J. \& Kyng, M. (Eds.) Design at Work: Cooperative Design of Computer Systems. Lawrence Erlbaum Associates, pp. 197-218.

Bødker, S. (1996) Applying activity theory to video analysis: How to make sense of video data in HCI. In Nardi, B. (Ed.) Context and Conciousness. Activity Theory and Human Computer Interaction, Cambridge: MIT Press, pp. 147-174.

Bødker, S. (1999) Computer Applications as Mediators of Design and Use-developmental perspective. Aarhus University Publication. DAIMI PB - 542.

Bødker, S. \& Petersen, M. G. (2000) Design for Learning in Use. In Scandinavian Journal of Information Systems. 2000, vol. 12, pp. 61-80.

Bødker, S., Nielsen, C. and Petersen, M. G. (2001) Creativity, Cooperation and Interactive Design. In DIS'00 Designing Interactive Systems, New York, 17 - 19 August 2000, ACM Press, pp. 252262.

Bødker, S., Krogh, P. and Petersen, M. G. (2001) Interactive Design Collaboratorium. In Proceedings of Interact2001. ACM Press, pp. 51-58.

Card et al (1980) The Keystroke-Level Model for User Performance Time with Interactive Systems.

Card, S., Moran, T., and Newell, A. (1983) The Psychology of Human-Computer Interaction. Hillsdale NJ. Lawrence Erlbaum Associates.

Carroll, J. M. \& Olson, J. R. (1988) Mental Models in Human-Computer Interaction. In Helander, M. (Ed) Handbook of Human-Computer Interaction, Elsevier Science Publishers, pp. 45-65.

Carroll, J. M. and Mack, R. L. (1995) Learning to Use a Word Processor: By Doing, by Thinking, and by Knowing. In Baecker, R. M., Grudin, Buxton, W. A. S., and Greenberg, S. (Eds.) Readings in Human-Computer Interaction: Toward the Year 2000. Morgan Kaufmann Pbl., pp. 698717.

Carroll, J. M. \& Mack, R. L. (1999) Metaphor, computing systems and active learning. In International Journal of Human-Computer Studies 51, pp. 385-403.

Clanton, C. (2000) Lessons from Game Design. In Bergman, E. (Ed) Information Appliances and Beyond. Interaction Design for Consumer Products. Morgan Kaufman Publishers, pp. 299334.

Cole, M. (1996) Putting Culture in the Middle. In Cultural Psychology - a Once and Future Discipline. The Bellknap Press of Harvard University Press, pp. 116-145.

Davis, D. M. (1997) The Perpetual Novice: An Undervalued Resource in the Age of Experts. In Mind, Culture, and Activity, 4(1), pp. 42-52.

Druin, A., Bederson, B., Boltman, A., Miura, A., Knotts-Callahan, D., and Platt, M. (1999) Children as Our Technology Design Partners. In Duin, A. (Ed) The Design of Children's Technology. Morgan Kaufmann Publishers, Inc. San Fransisco, CA., pp. 51-72.

Dunne, A. (1999) Hertzian Tales. Electronic Products, Aesthetic Experience and Critical Design. RCA CRD Research Publications. 
Ehn, P. and Kyng, M. (1984) A Tool Perspective on Design of Interactive Computer Support for Skilled Workers. In Report of The Seventh Scandinavian Research Seminar of Systemeering IRIS'84, Part I, pp 211-243.

Ehn, P. and Kyng, M. (1991) Cardboard Computers: Mocking it up or Hands-on the Future. In Greenbaum, J. and Kyng, M. (Eds.) Design at Work Cooperative Design of Computer Systems. Lawrence Erlbaum Associates Publishers, pp.169-196.

Ehn, P. (1993) Scandinavian Design: On Participation and Skill. In Schuler, D., and Namioka, A. (Eds.) Participatory Design. Principles and Practices. Lawrence Erlbaum Associates, Publ., pp. 41-78.

Engeström, Y. (1987). Learning by expanding. Helsinki: Orienta-Konsultit.

Engestrom, Y. (1990) When is a Tool? Multiple Meanings of Artifacts in Human Activity. In Learning, Working and Imagining, Helsinki: Orienta-Konsultit, pp. 171-195.

Engeström, Y. (1996) Development as breaking away and opening up: A challenge to Vygotsky and Piaget. In Swiss Journal of Psychology, vol. 55, pp. 126-132.

Engeström, Y. (1999) Introduction. In Engeström, Y. \& Miettinen, R. \& Punamäki, R.(Eds.)Perspectives on Activity Theory. Cambridge University Press.

Erickson, T. (1990) Working with interface metaphors. In Laurel, B. (Ed) The Art of Human-Computer Interface Design, Addison-Weasley, pp. 11-16.

Fein, R. M., Olson, G. M., and Olson, J. M. (1993) A Mental Model Can Help with Learning to Operate a Complex Device. In Proceedings of CHI'93, ACM Press, pp. 157-158.

Floyd, C. (1987) Outline of a Paradigm Change in Software Engineering. In Bjerknes, G., Ehn, P. \& Kyng, M. (Eds.). Computers and Democracy - a Scandinavian Challenge, Aldershot: Avebury, pp. 191-212.

Fogg, B. J. (2000) Pursuasive Technologies and Netsmart Devices. In Bergman, E. (Ed) Information Appliances and Beyond. Interaction Design for Consumer Products. Morgan Kaufman Publishers, pp. 335-360.

Gaver (1991) Technology Affordances. In Proceedings of the CHI'91, ACM Press, pp. 79-84.

Gaver, W. and Dunne, A. (1999) Projected Realities. Conceptual Design for Cultural Effects. In Proceedings of CHI'99, ACM Press, pp. 600-607.

Gaver, W. and Dunne, A. and Pacenti, E. (1999) Cultural Probes. In Interactions January + February pp. 21-29.

Gaver, W. and Martin, H. (2000) Alternatives. In Proceedings of CHI'2000, ACM Press, pp. 209-216.

Go, K., Carroll, J. M. \& Imamiya, A. (2000) Familyware. Communicating with someone you love. In In Sloane, A. \& van Rijn, F. (Eds.) Home Informatics and Telematics: Information, Technology and Society, Boston: Klüwer Academic Publishers, pp. 125-140.

Greenbaum, J. \& Kyng, M. (1991) Design at Work: Cooperative Design of Computer Systems. Lawrence Erlbaum Associates

Grudin, J. (1990a) The computer reaches out: The historical continuity of interface design. In CHI'90 Proceedings, pp. 261268.

Grudin, J. (1990b) Interface. In Proceedings of the Conference on Computer-Supported Cooperative Work 1990, pp. 269-278.

Grønbæk, K., Grudin, J., Bødker, S. \& Bannon, L. (1993) Achieving Cooperative System Design: Shifting From a Product to a Process Focus. In Schuler, D. \& Namioka, A. (Eds.) Participatory Design: Principles and Practices. Lawrence Erlbaum Associates, Publishers, Hillsdale, New Jersey, pp.79-98.

Haakma (1999) Towards Explaining the Behaviours of Novice Users. In Int. J. Human-Computer Studies, 50, 557-570.

Harper, R., Evergeti, V., Hamill, L. and Strain, J. (2001) Paper-mail in the Home of the $21^{\text {st }}$ Century: An analysis of the future of paper-mail and implications for the deisgn of electronic alternatives. In Proceedings of the OIKOS2001 Workshop: Methodological Issues in the Design of Household Technologies, Ebeltoft, Denmark, pp. 73-83.

Hassenzahl, M., Platz, A., Burmester, M. and Lehner, K. (2000) Hedonic and Ergonomic Quality Aspects Determine a Software's Appeal. In Proceedings of CHI 2000, pp. 201-208. 
Henderson, A. (1991) A Development Perspective on Interface, Design, and Theory. In Carroll, J. M. Designing Interaction. Psychology at the Human-Computer Interface. Cambridge University Press, pp. 254-268.

Holtzblatt, K. (1999) Customer Centred Design as Discipline. In Sasse, M. A. and Johnson, C. (Eds.) Human-Computer Interaction - INTERACT'99. IFIP TC. 13. IOS Press, pp. 3-17.

ISO 9241-11 (1998) Ergonomic requirements for office work with visual display terminals (VDTs). Part 11: Guidance on usability. www.iso-standards-international.com/iso-9241-kit9.htm.

-Junestrand, S., and Keijer, U. (2001) Space, Time and Technology. In Proceedings of the Oikos2001 Workshop: Methodological Issues in the Design of Household Technologies. Ebeltoft, Denmark, pp. 62-72.

Kaptelinin, V. (1996) Computer-Mediated Activity: Functional Organs in Social and Developmental contexts. In Nardi, B. (Ed.) Context and Conciousness. Activity Theory and Human Computer Interaction, Cambridge: MIT Press, pp. 45-68.

Karvonen, K. (2000) The Beaty of Simplicity. In Proceedings of CUU'00, Arlington VA, USA. ACM Press, pp. 85-90.

Kjær, A., Madsen, K. H. \& Petersen, M. G. (2000) Methodological challenges in the study of technology use at home. In Sloane, A. \& van Rijn, F. (Eds.) Home Informatics and Telematics: Information, Technology and Society,. Boston: Klüwer Academic Publishers, pp. 45-60.

Kurosu, and Kashimura, (1995) Apparent Usability vs. Inherent Usability. Experimental Analysis of the Determinants of the Apparent Usability. In Proceedings of CHI'95. ACM Press, pp. 292293.

Kuutti, K. (1996) Activity Theory as a Potential Framework for Human-Computer Interaction. In Nardi, B. (Ed.) Context and Consciousness. Activity Theory and Human-Computer Interaction. MIT Press, pp. 17-44.

Kuutti, K. (1999) Small interfaces - a blind spot of the academical HCI community ? In Proceedings of HCI International'99, München, August 20-27.

Lakoff, G. and Johnson, M. (1980) Metaphors we Live by. The University of Chicago Press.

Lanning, M. J. (1998) Delivering Profitable Value. Capstone Publishing Limited.

Laufer, E. A. \& Glick, J. (1996) Expert and novice differences in cognition and activity: A practical work activity. In Engeström, Y. \& Middleton, D. (Eds.) Cognition and Communication at Work. Cambridge University Press, pp. 177-198.

Lave, J. \& Wenger, E. (1991). Situated Learning. Legitemate peripheral participation. Cambridge University Press

Lave, J. (1993) The practice of learning. In Chaiklin, S. \& Lave, J. (Eds.) Understanding practice. Perspectives on activity and context. Cambridge University Press.

Lewis, C. (1986) A Model of Mental Model Construction. In Proceedings of the CHI'86 Conference, ACM Press, pp. 306-313.

Lewis, C., Polson, P., Wharton, C., and Rieman, J. (1990) Testing a Walkthrough Methodology for Theory-Based Design fo Walk-Up-and-Use Interfaces. In Proceedings of CHI'90, ACM Press, pp. 235-242.

Liddle, D. E. Design of the Conceptual Model. In Winograd, T. (Ed) Bringing Design to Software. New York: ACM Press, pp. 17-36.

Mackay, W. E. and Fayard, A. (1997) HCI, Natural Science and Design: A Framework for Triangulation Across Disciplines. In Proceedings of DIS'97 Designing Interactive Systems. ACM Press, pp. 223- 234.

Mackay, W. E. (1998) Augmented Reality: Linking real and virtual worlds. A new Paradigm for interacting with computers. In Proceedings of AVI'98, ACM Conference on Advanced Visual Interfaces, New York. ACM Press.

Madsen, K. H. (1994) A Guide to Metaphorical Design. In Communications of the ACM, vol. 37, No. 12 , pp. 57-62.

Mark, W. (1999) Turning Pervasive Computing into Mediated Spaces. IBM Systems Journal. Vol 38, No. 4 Reprint order No G321-5702. 
Mathiassen, L., Munk-Madsen, A., Nielsen, P. A. and Stage, J. (1997) Object Orienteret Analyse og Design (Object Oriented Analysis and Design). Forlaget Marko (Marko Press), Aalborg, Denmark.

Mogensen, P. (1992) Towards a Provotyping Approach in Systems Development. In Scandinaviand Journal of Information Systems, Vol. 4, pp. 31-53.

Monk, A. (2000) User-Centred Design. The Home use challenge. In Sloane, A. \& van Rijn, F. Home Informatics and Telematics. Information, Technology and Society. Kluwer Academic Publishers, pp. 181-190.

Moran, T. P., Saund, E., van Melle, W., Gujar, A. U., Fishkin, K. P., and Harrison, B. L. (1999) Design and Technology for Collaborage: Collaborative Collages of Information on Physical Walls. In UIST'99.

Nardi, B. (1996) Context and Conciousness. MIT Press.

Negroponte, N. (1995) Being Digital. Hodder and Stoughton Publ.

Nielsen and Molich (1990) Heuristic Evaluation of User Interfaces. In Proceedings of CHI'90, ACM Press, pp. 249-256.

Nielsen, A. C. (2001) Designing to Support Mobile Work with Mobile Devices. Ph.D. Thesis, University of Aarhus.

Norman (1983) Some Observations on Mental Models. In Mental Models. Gentner, D. \& Stevens, A. L. (eds), Lawrence Erlbaum Associates, Hillsdale, N.J..

Norman, D. A. (1988) The Psychology of Everyday Things. Basic Books, Inc., Publishers New York.

Norman, D. A. (1999a) The Invisible Computer. MIT Press.

Norman, D. A. (1999b) Affordance, Conventions, and Design. In interactions...may+june, pp. 38-43.

O’brien, J. \& Rodden, T. (1997) Interactive Systems in Domestic Environments. In DIS'97 Designing Interactive Systems: Processes, Practices, Methods \& Techniques, Amsterdam, The Netherlands, ACM., pp.247-259.

O’Brien, J., Rodden, T., Rouncefield, M., and Hughes, J. (1999) At Home with the Technology: An Ethnographic Study of a Set-Top-Box Trial. In ACM Transactions on Computer-Human Interaction, Vol. 6, No. 3, pp. 282-308.

Payne, S. J. and Green, T. R. G. (1986) Task Action Grammers. In Human-Computer Interaction, 2 , pp. 93-133..

Petersen, M. G. \& Baillie, L. Methodologies for Designing Future Household Technologies. In Proceedings of the Oikos2001 Workshop: Methodological Issues in the Design of Household Technologies. Ebeltoft, Denmark, pp. 47-49.

Polson, P. G. \& Lewis, C. H. (1990) Theory-based design for easily learned interfaces. In Human Computer Interaction, 5, pp. 191-220.

Preece, J., Rogers, Y., Sharp, H., Benyon, D., Holland, S., and Carey, T. (1994) Knowledge and Mental Models. In Human- Computer Interaction, Addison-Wesley, pp. 123-139.

Quinn Patton, M. (1980) Qualitative Evaluation and Research Methods. Sage Publications

Reisner, P. (1990) What is consistency? In Diaper et al. (Eds.) INTERACT'90: Human-Computer Interaction, North-Holland, Amsterdam, The Netherlands, pp. 175-181.

Robinson, M. \& Bannon, L. (1991) Questioning Representations. In Proceedings of ECSCW'91, Amsterdam, Sept 1991, pp. 219-233.

Schön, D. A. (1983) The Reflective Practitioner. How Professionals Think in Actio.n Basic Books Inc.

Shneiderman, B. (1998) Designing the User Interface. Strategies for Effective Human-Computer Interaction. Addison Wesley Longman Inc.

Siegel, D. A. and Dray, S. M. (2001) New Kid on the Block: Marketing Organizations and Interaction Design. In Interactions... march+april, ACM Press, pp. 19-24.

Silverstone, R., Hisch, E. \& Morley, D. (1992) Information and communication technologies and the moral economy of the household. In Consuming Technologies. Media and Information in Domestic Spaces. Routledge. London and New York. pp. 15-31.

Sloane, A. \& van Rijn, F. (Eds.) (2000) Home Informatics and Telematics: Information, Technology and Society,. Boston: Klüwer Academic Publishers. 
Streitz, N. A., Geissler, J. and Holmer, T. (1998) Roomware for Cooperative Buildings: Integrated Design of Architectural Spaces and Information Spaces. In Streitz, N. A., Konomi, S., and Burkhardt, H. (Eds.) Cooperative Buildings. Integrating Information, Organisation and Architecture. Lecture Notes in Computer Science 1370, Springer Verlag, pp. 4-21.

Suchman, L. (1987) Plans and Situated Actions. The Problem of Human Machine Communication. Cambridge University Press.

Tognazzini, B. (1992) Tog on Interface. Apple Computers, Chapter 4, pp. 79-89.

Thackara, J. (2001) The Design Challenge of Pervasive Computing. In interactions May-June 2001, pp. 47-52.

Thomas, P. and Macredie, (2002) Introduction to the New Usability. In ACM Transactions on Computer- Human Interaction (TOCHJ), Vol. 9, issue 2, pp. 69-73.

Tractinsky, N. (1997) Aesthetics and Aparent Usability: Empirically Assessing Cultural and Methodological Issues. In Proceedings of CHI'97, ACM Press, pp. 115-122.

Venkatesh, A. (1996) Computers and Other Interactive Technologies for the Home. In Communications of the ACM, Dec. 1996, Vol. 39, No. 12, pp. 47-54.

Venkatesh, A. and Mazumdar, S. (1999) New Information Technologies in the Home: A Study of Uses, Impacts, and Design Strategies. EDRA Conference(Environmental Design and Research Association), Orlando, Florida, Jun 2-6, 1999.

Vygotsky, L. S. (1978) Mnd in Society. The Development of Higher Psychological Processes. Harvard University Press, Cambridge, Massachusetts.

Wartofsky, M. W. (1979) Models. Dordrecht: D. Reidel Publishing Company, 1979.

Winograd, T. \& Flores, F. (1986) Understanding Computers and Cognition. A New Foundation for Design Addison Wesley Publishing Company. 
Part II

\section{Papers}




\title{
Design for learning in use
}

\author{
Susanne Bødker \\ Marianne Graves Petersen \\ Department of Computer Science, University of Aarhus
}

\begin{abstract}
This paper brings information systems design towards a focus on learning in use. Studying learning in use is a matter of focusing on the development of the designed artefact once the design process is over. Accordingly, designing for learnable artefacts is a matter of understanding and developing use, also when a computer-based artefact has been taken over by users. The paper presents a design-oriented model of the learnable artefact, discusses the possible instruments of learning in use and presents empirical studies that support our design-oriented understanding of the learnable artefact.
\end{abstract}

\section{Keywords:}

Learning in use, integration of use and design, design model

\section{Introduction}

Information systems design does not stop when the design process ends. As people start to use the products they learn, i.e. they go on developing the artefact. This paper brings information systems design towards a focus on learning in use: Designing for learnable artefacts is a matter of understanding and developing use, also once a computer-based artefact has been taken over by users.

Traditionally, information systems design and human-computer interaction/usability studies have focused on snapshots of use. They share a linear thinking where evaluation of usability is a concern only after design and some amount of implementation. As it turns out, use is not static and snapshots of use yield little insight about the developmental aspects of use. Hence, there is an increasing concern, theoretically and practically, for designing computer-based artefacts that are useful, for the advanced user as well as for the first-time novice user, and which support the 
user in this development. And not least, it is a practical concern to include instruments through which the learning of the artefact may be supported in the design. Usability studies, which has traditionally been where the concern for use has been located, is increasingly moving towards integration with design, in iterative processes, where prototypes are developed and tried out by and with users (Buur \& Bødker 2000). The theoretical and empirical work presented in this paper takes such a general development as its starting point and presents a design model that supports the design of artefacts supporting learning in use.

Because the interplay between the computer-based artefact in use, their learning and design are tremendously complex, we will work with an example of an artefact that is much simpler than a traditional information system: a modern TV set. Though there are indeed limitations to such an approach, the paper raises many interesting problems that are valid for a much wider class of computer artefacts.

\section{Learning in use and usability design}

Consider the following example from a usability evaluation at Bang \& Olufsen, a well-known manufacturer of hi-fi equipment. A user is seated in the Bang \& Olufsen testlab which is equipped as a living room. She is carrying out an assignment where she is asked to tune in some channels so as to set up the television set. The user has previously successfully tuned the channels of another Bang \& Olufsen TV, where she discovered an auto-tuning facility (automatic scan and allocation of all traceable channels in the frequency band). In the current situation she expects that the TV supports this same functionality. Accordingly, the user spends a long time searching through the menus in order to find something about auto-tuning. However, despite her expectations, this functionality is not supported by this particular TV set and she eventually gives up tuning in the channels.

This example demonstrates why it is important to focus on learnability in the design of computer artefacts. It illustrates how a user learns through use, and how, in the encounter with the second television, she is actually prevented from using her experiences since nothing on the second TV makes it clear, that this TV was different from the first TV tried out. We see how her expectations are formed from previous experiences, and how the user tries to transfer experiences between artefacts. 
However, the challenge of designing for learning in use is not simple and the example above illustrates some of the design challenges that Bang \& Olufsen is facing concerning the learnable artefact. The overall design philosophy of Bang \& Olufsen is that each product must have its own identity, in its physical appearance as well as in functionality. Given the need for individual product identity, it is not necessarily a solution to change the second TV so as to allow auto-tuning. However, it is necessary to provide ways for the user to understand how the TV set offers itself to be used in a way different from the one known by the user as auto-tuning. And, further to provide means of leading the user in handling the TV set in a different yet more appropriate way (see also Bærentsen, this issue).

Design is further complicated by the fact that an artefact always implies more possible uses than the original operations giving birth to it (Engeström 1990, p. 174). Thus, the presence of a designed artefact does not mechanically determine the way it is actually used and conceived by the users. It is hardly surprising that design changes the artefact being designed. However, use changes the artefact as well, as noted by Engeström (ibid.). This emphasizes the need to look at artefacts-in-use as emerging rather than static. The artefact, at the same time, constrains or disciplines use through the kind of operations it allows the user to form, through the conceptual understanding it offers to the user, through the kind of uses it lends itself to, physically, handling-wise and through the foci that the user is "offered" in or through the artefact (Bødker, 1991, 1999).

Activity theory provides an interesting starting point for designing for learnability by offering a design-oriented framework that accounts for the dynamic nature of artefacts-in-use.

In this paper we first address the issue of design for learning in use through a theoretical exploration of the learnable artefact as seen from the perspective of activity theory. Based on Engeström's work (Engeström 1987, 1990), as well as our earlier work on iterative design (e.g. Bødker \& Grønbæk 1991) this exploration lead us to a design-oriented theory consisting of a combined design model and checklist for designing "the learnable artefact". This design model can be seen as a hypothesis for what it implies to design for learning in use. Subsequently, we report on the early findings from a long-term empirical study of television use, analysed in terms of the activity theoretical framework. Studying learnability of IT-based artefacts is often 
complicated by the complexity of the artefact. In a typical text processing program numerous metaphors are layered over each other, and the actual complexity of menus etc. is fairly big (Beaudouin-Lafon, 2000). In this respect, our Bang \& Olufsen TV set seems much simpler. Finally, we discuss the proposed design model in light of the empirical findings.

\section{The learnable artefact: A theoretical investigation}

Activity theory assumes an asymmetric relation between people and things, in contrast to the proposal of a symmetric relationship offered by cognitive science or various brands of computer science, where computer programs and human behaviours are modelled using the same language and methods. Activity theory places computer applications, along with other artefacts as mediators of human activity (See Bødker (1991)). Through a set of dynamic concepts (activity, action and operation) it makes important features of human endeavours stand out, and makes us focus on the context of use instead of seeing computer use in isolation.

Any (use) activity is both social and motivated. Since artefacts most often mediate several activities, they may usefully be seen as situated in a web of activities. Each activity is conducted through actions of individuals, directed towards an object or another subject. Activity gives meaning to our actions, though actions have their own goals, and the same actions can appear in different activities.

Each action conducted by a human being is implemented through a series of operations. Each operation is connected to the concrete physical or social conditions for conducting the action, and is "triggered" by the specific conditions of the situation. Artefacts, in a human activity framework, have a double character: they are objects in the world around us which we can reflect on, and they mediate our interaction with the world, in which case they are not themselves objects of our activity. In normal use situations our handling of artefacts is done through operations, and is not conscious to us. When we have difficulties with artefacts, the world does not come to a stand-still: Breakdowns lead to actions and operations that "work around" the problems, so that we can carry on.

Artefacts are seen as historical devices reflecting the state of practice up until the time that they are developed. This practice in turn is shaped by the artefacts used 
etc. Artefacts can be characterised as crystallised knowledge which means that operations developed in the use of one generation of technology are later incorporated into the artefact itself in the next. Thus to learn something about the present shape and use of an artefact, a historical analysis of artefacts as well as of practice is important.

Learning in this perspective is a matter of development of operations, actions and activities (and transitions between them) as these developments take place in use, or in dedicated learning activities. Theoretically and practically this learning is a consequence of the interaction of the human beings with the material conditions, with each other, and of the historical development of practice as well as of the individual repertoire of actions and operations. Accordingly we focus on the learning that takes place

- in use of artefacts,

- between users of artefacts and

- in the transfer of experiences that users make between artefacts.

Grudin (1990) rightly points out how computer artefacts-as-seen-from-use, is constituted not only by the software and hardware, but also by the surrounding manuals, teaching, management and support, i.e. human beings as well as material artefacts. This goes for a wider class of artefacts than traditional computer applications, and as Engeström (1990) points out, artefacts are implicitly or explicitly accompanied by models that reflect, and give guidance for their use. Accordingly we have found it useful to look at the artefact as such as well as its surrounding models as instruments of learning. These instruments will be studied further in the following. Hence the learnable artefact not only encompasses the artefact "proper". It further encompasses the models, references to other artefacts, etc. that are part of the web of activities of the users and helps the users get started and develops their use.

In this section we look specifically at the artefact-in-use; how learning takes place in use-in use as situated in a particular context, between users of artefacts, and in the transfer of experiences that users make between artefacts.

\section{Learning in use}

Operations are often transformed actions, i.e. we conduct them consciously as actions in the beginning. Through learning we transform them into operations, but on encountering changed conditions, we may have to reflect on them consciously again, and 
thus make former operations into conscious actions once more. Learning in terms of operations that get formed and break down is one aspect of learning seen from the point of view of activity theory. The transparency of handling the artefact thus achieved, is certainly important. Consequently, transparent interaction is a kind of interaction with focus on only the objects of work, and when breakdowns happen, and the user gets "forced" to shift her attention to the artefact, there is support for bringing back the focus to the objects of work.

Designing transparent interaction is consequently a matter of identifying the objects of work to be focussed on, in or through the artefact, and identifying how these are handled through operations on the artefact and which support the artefact needs to give for this. Bødker (1991) distinguishes between handling aspects and subject/object-directed aspects in order to identify, on the one hand, the aspects of the artefact that supports the development of a repertoire of operations through which the user handles the artefact, and, on the other hand, the support for the development of a repertoire of purposes of use of the artefact.

This repertoire of purposes is a matter of the development of the motives of what we do, and as pointed out by Bardram \& Pedersen (1994), the formation of actions and the moves happening between the levels of actions and activities are equally important for learning, and our understanding of these is far less well developed.

In our case of Bang \& Olufsen television users, it seems that the complex look of the remote control and the invisibility of a range of buttons positioned at the back of the TV get in the way of the formation and operationalisation of actions. In many cases users expected to access functionality via the remote control rather than on the TV itself. This was the case when a user was searching for a button to eject a video tape. In this situation a breakdown occured where the users' focus shifted from the contents of the video to the investigation of the VCR itself, searching for the expected functionality on the remote control. In this situation the user lacked support for the formation of actions, and the TV failed to support the users in developing their expertise in general and their repertoire of operations in particular.

From our studies of television use, we also saw examples of how activities took form. As an example, by the time of the installation of the television in the home of some Bang \& Olufsen costumers, the husband and wife explained excitedly about 
how they were looking forward to obtain the cinema experience with their new television. This expectation of a new experience with their new television (which includes wide screen and surround sound facilities) was coined and demonstrated for the family already in the shop. The cinema experience was then later pursued (and transformed) over time as the family came to use the television in their home.

In order to support learning in use, we need to understand how the learnable artefacts support these processes. Bødker (1991) proposes an understanding of how users develop their repertoires of operations as follows: When operationalisation takes place, it is at first very situation specific, but as the human being meets new conditions, the variation of situations that can be handled by operations is growing. The novice carries out the activity at a very detailed level of actions, each action being consciously planned. With experience, the human being moves toward an operationalised totality. This is achieved through generalisation, operationalisation and abbreviation. The use of an artefact is, if the artefact works well, operationalised. Ideally, learning starts out with actions toward the artefact and ends without those actions.

In the case where the cinema experience formed the initial motive for the users, we saw how, over time, the users insisted on pursuing this experience and we saw how the concept as well as the design of the physical television supported the users in setting out to explore the possibilities of the television in this direction.

Thus, in our interpretation of this, the learnable artefact is becoming transparent to the user, by supporting the development of a repertoire of operations, the formation of high-level actions and of a repertoire of purposes related to the webof-activities in which the artefact is used.

In studying expertise in actual work settings, Laufer \& Glick (1996) talk about noviceness and experteness, where noviceness is characterised by single purposes defined by official norms, single-layered surface relations, and (similar to what Dreyfus \& Dreyfus (1986) point out) detailed actions. Expertness, in contrast, is characterised through handling of several conflicting purposes, where official as well as unofficial norms and personal judgement play a role. Complex, multi-layered social relations and high-level actions are other aspects of expertness. To understand expertness, and, hence, learning beyond the immediate introduction we consequently 
need to understand more about the ways in which learning may be aided through additional instruments and through the social interaction among users.

\section{Learning between users of artefacts}

Learning is fundamentally situated, and socially mediated, as discussed by many authors (Engeström 1987, Lave \& Wenger 1991). Where Vygotsky (Engeström 1987) looks upon the interaction with the more capable peer, helping the learner through the zone of proximal development, Lave \& Wenger (1991) depict learning as legitimate peripheral participation in a community of practice, where novices gradually move from the periphery, through increasing participation, towards the centre of mastering practitioners.

When it comes to learnable TV sets, we see both challenges and potentials in supporting social participation in a community of practice of Bang \& Olufsen users. As of today, the practitioners of Bang \& Olufsen TV sets are globally distributed individuals using their TV sets in their private homes. Accordingly, the peripheral participation in the community of practice of Bang \& Olufsen television users, or easy access to more capable peers is not apparent. Nevertheless, the Bang \& Olufsen sales staff often try to create a community feeling, and this is, as described below, well appreciated by the customers. Indeed, what people often get attracted to and stress as a main reason for buying Bang \& Olufsen is the sense of community that goes with being a customer in a Bang \& Olufsen store, of being invited to certain arrangements etc.

The concern for e.g. Internet connections for TV sets, or combined TV/PC appliances are increasing among television producers including Bang \& Olufsen (Madsen \& Petersen, 1999). Cable TV suppliers offer Internet connections and in general the band-width of Internet connections in the home are increasing. In our opinion this opens perspectives for creating e.g. web sites and communities for Bang \& Olufsen TV users, because these web sites may be integrated with the TV sets in a medium term perspective, rather than an add-on to them. We see this as a way of moving the learning-in-use out of the homes of individuals and as a learning device for Bang \& Olufsen R\&D, usability and sales staff. As illustrated by our example every Bang \& Olufsen TV is delivered to the buyer and installed by Bang \& Olufsen sales staff. Hence, the buyers always get, in principle, a fully functional TV set, and 
this sales staff manages the immediate problems of introduction of the appliance to users. We see a potential for this role to be expanded a great deal more, so that the sales person act as a more capable peer to the new user. A web community with participation of sales staff, is likely to serve as a learning process for users as well as sales staff, and support the kind of community feeling already being created by the sales organisation.

However, this is hardly enough and we need to approach the means of learning in or close to the artefact.

\section{Transfer of experiences between artefacts \\ - instruments of learning in, or close to the artefact}

The fundamentally situated, and socially mediated nature of learning means that we need to be concerned with the context of use, even in situations where there are no immediate peers. Context comes into the picture through the past experiences of the users, and through the meaning that the artefact represents to the user (Bertelsen 1998). As we have seen developed by Engeström, Bertelsen, Bødker and others (e.g. Engeström 1990, Bødker 1999, Bødker \& Christiansen 1997), such experiences may easily be contradictory, and involving, or being derived from contradictory purposes of use.

As an example, working with teletext, a computer-experienced user successfully navigated through the menu structure on the TV set which, with its “computer-look", strongly suggested a hierarchical menu structure that was also perceived by the user. However, as the user got too far down in the menu hierarchy, and relying on previous experiences with computers expected to be able to go one step back in the structure, the user was stuck. After many unsuccessful and inelegant attempts including turning the TV off and on again - a typical work-around - the user finally realised that the "stop" button on the remote control supplied the go-back mechanism she was searching for.

Dwelling a bit further with the computer analogy, we identify the problem that it is unsystematic: Some foci of use stay closely with the computer analogy while others do not. Furthermore, the computer analogy means very different things at the activity- and action level. In terms of activity, it gives connotations of interactivity, or 
perhaps efficiency. On the action level, on the one hand it may lead us to think about settings for volume, luminance etc. But on the other hand it also seems to us that the computer/menu analogy, which seems fundamentally object/action oriented, contradicts with the fundamental capabilities of a TV set, that of processing a stream of pictures and sounds. At the level of operations, the computer analogy allows us to focus on menus as a way of e.g. creating settings of the TV.

In order to look at the instruments of learning in or close to the artefact, we have found it useful to look at the set of models or artefacts developed by (Engestöm 1990). Engeström discusses how these serve different purposes at different times in human learning of the primary artefact, by Engeström called the what artefact.

The first level of learning is close to the forming of operations as described above, through trial use of the what artefact as such. In the second level of learning "the object/outcome is given, and the instrument found through trial and error" (Engeström 1987, p 148), and the how artefacts applied "may be understood as algorithms and rules directly guiding the use and formation of primary [i.e. what] artefacts" (Engeström 1990, p 187). At the next level, the object/outcome is given, and the instrument invented, demanding models that deal with expectations and explanations, models that are constructed based on systematic testing of hypotheses, why artefacts. Where-to artefacts are the imaginative artefacts that help change and recreate the understanding of the human being of the change of the overall activity. As examples of these, Engeström analyses the instruments of medical doctors giving examples of what artefacts: patient's account of the disease, records, examinations; how artefacts: examination procedure, algorithms of computer use; why artefacts: explanatory models of illness, hypotheses, etc. The where-to artefacts in this example is a matter of dealing with the entire understanding of what it means to be a doctor as part of the, in this case, Finnish health care system.

When working with the learnable artefact we must remind ourselves that this does not only encompass the artefact "proper". We may start from the artefact and work to understand the learnable artefact through the what, how, why and where-to artefacts that it encompass. In this way all artefacts can be seen to include (parts of) what, how, why and where-to artefacts and we may design the learnable artefact so as to contain all four in appropriate ways. Starting out from a particular use situation, we may choose to study as well the models, other artefacts, etc. that are part of the 
web of activities of the users that help the users learn about the artefact of interest. This is an alternative perspective by which we can see all of these artefacts as combinations of what, how, why and where-to artefacts. And we can design the wrapping or portable context of the artefact (Brown \& Duguid, 1994), in terms of manuals, checklists etc.

In the world of purchasing and starting to use Bang \& Olufsen TV sets, we have found the following examples of artefacts: What artefacts can be the TV set including the remote control. The manual in turn can act as a how artefact and so can demonstrations of use given by sales staff, and in some cases, the above mentioned computer analogy. Further we have seen how visits to sales rooms and glossy brochures can serve to introduce the level of purpose to users, and thus take on the role as why artefacts. Interestingly, we have found that the where-to artefacts that give indications of why people would want to buy a Bang \& Olufsen TV set often have little to do with better watching of or listening to TV. Rather it is the enrolment into the world of the Bang \& Olufsen family through special arrangements with other Bang \& Olufsen customers that matters.

In line with Engeström (1987), we see unexpected uses as a natural extension of use, as resources for learning rather than 'accidents' and we agree with Béguin and Rabardel (this issue) that such instances are valuable resources for design. Béguin and Rabardel (this issue) develop primarily the interplay between what artefacts and how artefacts, in what they call catacresis. "Catacresis refer to the use of one tool in place of another or to using tools to carry out tasks for which they were not designed. ..(Catacresis are).. an indication of the user's contribution to the development of an instrument and its uses" (Béguin and Rabardel (ibid.)). Part of understanding learnability of artefacts consists of understanding how users' previous experiences can be reused and brought into play when users face new artefacts or problems with handling known artefacts.

Although (Béguin and Rabardel, this issue, Engeström, 1987, 1990) describe the way models of use are constructed for later reuse, neither of these dwell into the details of how these models come into play in concrete situations of use. Furthermore, the notions of why artefacts and where-to artefacts are little developed in the context of development in use of artefacts, whereas they are developed more in the general 
design domain, e.g. through the works of Bisgaard et al (1989), Bertelsen (1994), Bødker \& Christiansen (1997).

We see these general concepts as good starting points, but barely more, for developing a practical approach to designing learnable artefacts, and we find it necessary to move on to develop more practical means of design for such.

\section{Designing the learnable artefact}

In the following section we develop our design-oriented theory of the learnable artefact. This theory focuses on how design may work to uncover instruments of learning and to embed such in the learnable artefact being designed. Coupled with our theoretical investigations we develop a design model for designing the learnable artefact. This model should be seen as a hypothesis, which is further investigated in the next section covering empirical investigations.

Design of learnable artefacts gives a particular focus on design. At the same time our earlier general analyses of the inter-linking of usability matters and design, shows how learnability must be considered in all stages of design. Hence, our concern is to devise a design model that allows (Bødker 1999)

- iteration, as a result of our earlier work on the non-linear nature of design,

- focus on user background and learning in use as the best starting point for design,

- reflecting iterative design and learning-in-use in the product, so that the artefact becomes self-contained to the largest possible extent, i.e. so that it contains, or is "wrapped up" together with models that support learning so as to become a learnable artefact.

We have been seeking inspiration from Engeström's general methodological cycle in providing a methodological cycle that focuses on design of the learnable artefact, rather than on investigating expansive learning in general. Engeström's work on models is an integral part of his quest for expansive learning, and his methodological cycle of expansive development takes us some way in developing a theoretical hypothesis of learning and designing for learnable artefacts. Earlier our way of thinking about design has showed well in line with Engeström's work (See Bisgaard et al 1989, Bødker 1999). Our particular concern for learnability of artefacts is new here. 
However, there are several challenges in the kind of design setting that we look at here:

- Engeström is concerned with expansive learning that changes the fundamental (work) activity of the involved people. When it comes to TV sets, they are a minor part of everyday life, and though TV as such can be said to have revolutionised people's lives, buying a new TV set does not have that characterwhat we are talking about is more likely to be a change of how people handle a new artefact in what is basically the same activity. At the same time, it is useful to think about how these possible use activities may be extended or changed, e.g. so as to include a different perception of why one wants to use a TV, beyond watching TV. E.g. video-on-demand services or Internet integration, may change our ways of understanding why we want a TV-set, and the producers of TV-sets may need to support such changes actively e.g. through advertisement.

- Given the diverse group of users of TV sets these users do not have one, but many different backgrounds needing to be the starting point for learning to/in use. However, this is the case with most artefacts, the main reason for Engeström's (1990) argument that it is necessary to move beyond the personal view of the artefact to understand it.

- Engeström (1987) bases his cycle on the recognition of individuals that their lives need to change. In connection with e.g. TV sets, this is not the case necessarily, though such a need state may be created through active work of advertisement and TV sales people.

In other words, the primary instruments that we are looking for in our attempt to create learnable artefacts are not primarily instruments intending to transcend the use of the artefact as such. Most aspects have to do with the shaping and developing of actions and operations, not activities.

In forming the design model, we further draw upon the work of Bardram and Bertelsen's (1995) design oriented understanding of conditions for transparency, i.e. for supporting learning in use. Interpreting Vygotsky's concept of the zone of proximal development onto the situation of learning in use of IT, Bardram \& Bertelsen (Bardram \& Bertelsen, 1995) insist that the learnable artefact needs to - $\quad$ support development in use, i.e. to embed learning in real, meaningful use situations not as a separate activity, 
- establish an image of the future use - the potential competence of use

- ensure a certain degree of initial familiarity with artefacts and use, with due concern for when the initiation of the learning of something new may usefully be initiated, and to

- set conditions for the formation and operationalisation of actions and in this way support mastering beyond sheer trial and error.

When these claims and Bødker's (1991) aspects of use/foci are looked upon from the perspective of an iterative design model, they are closely connected to Engeström's methodological cycle of expansive development (1987). This model start with the delineation of the phenomenon of interest, the work practice to be changed and the historical and empirical investigation of this. The next stage is the formation of new instruments to make the move towards the new. This phase consist of identification of models, springboards and microcosmos. In the next stage these instruments are applied to carry through the change and this is evaluated.

This general cycle we have confronted with the findings of Bardram \& Bertelsen (1995) as well as our own, leading to a design cycle focussing specifically on the learnable artefact:

1. Investigate the multiple backgrounds of the users. The investigation of the practices of users must focus in parts on their general cultural and most likely diverse practices. And since we are primarily concerned with the handling of artefacts, the variety of artefacts owned and used by the users are of great importance along with how they undertake the types of activities and purposeful actions that we design for. These investigations on the one hand need to be dealt with in an openminded fashion through e.g. field work (Bødker \& Madsen 1998, Nielsen 1998), on the other hand we suggest that it is important that certain questions do get asked regarding the actual competencies of the users, their current needs and experiences with present artefacts. According to Engeström (1987) existing artefacts-in-use should all be analysed as both what, how, why, and where-to artefacts through historical analyses.

2. Establish the new instruments to us consist of three parts;

a. the establishing of the potential competence of future uses including springboards and images helping use to move ahead. This, we propose, involves forming hypotheses about future use, e.g. through use of metaphors 
(Madsen 1994), future workshops (Kensing \& Madsen 1991) exploration of the use of artefacts that have somewhat similar use qualities, confrontation of actual users with images of future use through participatory design techniques (e.g. Bødker \& Christiansen, 1997, Kyng 1995). Designers need help in forming the hypotheses as well as in examining them and including the vision in the learnable artefact.

b. the establishing of instruments to emphasise initial familiarity. Emphasising initial familiarity means establishing reference to the actual competence of the users as well as to the potential one, the possible future use. This may be done in several ways e.g. through use scenarios (Kyng 1995, Bødker in press) and it means to ask questions linking the past to the future and linking use and learning. The designer needs to be concerned with the particular mechanisms supporting learning in use, how they are established, directs use, and develop through learning in use. Again these mechanisms need to be constructed so as to deal with what, how, why, and where-to artefacts. A completed cycle with a microcosm (Engeström 1987) of users to explore the formation and operationalisation of actions is most often necessary, hence 2c. c. establishing of a microcosmos where such instruments may be tried out. This microcosmos is the delimited community of practice where intermediate instruments can be tried out through prototyping, mock-ups, in more or less controlled environments depending on the stage of the design and purpose of the microcosmos. In our experience a microcosmos will in some instances encompass 2-3 users in an artificial, lab-like situation, working with a couple of specific use scenarios in close cooperation with a couple of designers and usability people. In others, real trial use for a limited period of time, in a real use setting constitutes a more useful microcosmos.

3. Support formation and operationalization of actions basically needs to be dealt with through hands-on experience by users, as discussed in (Bødker 1991). In Bødker (1996) a detailed way of analysing the forming of operations and breakdowns of operation in actual use situations is outlined, and e.g. Bødker \& Madsen (1998) discuss how to establish context for prototype evaluations in usability settings. The overall particular concern of the particular focus of this paper is that the operations formed are, if not initially then at the end, use 
operations and not operations pertaining in isolation to the learning activity. This means that the users are able to focus their attention on actual objects of the use activity and not objects that pertain to learning in isolation. We see this stage of the learning as supported by the primary artefact, the what artefact, as well as the how artefact that support the initial development of a repertoire of operations.

4. Consolidate use. Mechanisms to consolidate use could, both figuratively and literally be a matter of removing the scaffolding of the learning in use activity. In accordance with (Newman et al. 1989), we see this not as an act performed by the artefact, but through the cooperative effort of the designer and the actual users, i.e. a process where the designer makes the consolidation possible, but where the user makes the decision of moving to "full-blown" use, if at all. This move can be, but is not always, a matter of stepping out of the learning environment, and is heavily supported by why artefacts supporting reflection in action.

In our model, the stages in the design cycle, and the aspects of the learnable artefact in focus, are in some ways orthogonal. We should be concerned with all aspects of the learnable artefact at all stages of design. At the same time, there is a natural progression of concerns: focus in the investigation of use backgrounds is mainly the existing competence of users, and the questions that we may usefully ask reflect that. As design proceeds, the concerns move along, and in the later stages we are moving towards a primary focus in the handling of the what artefact, focussing on what and how artefacts.

The kinds of questions of interest in the various stages are summarized in table 1. This table is seen as a checklist for design (see Bødker et al, 2000). It has been developed in iteration with our theoretical and empirical work. Checklists, in our proposal (inspired by Bødker \& Christiansen, 1997), are used to present theory and other sorts of research findings in an operational form, to support the role of theory as mediation of the investigation and design process. The initial version of this particular checklist has been developed in iteration with studies of HCI literature on learning, the activity theoretical framing as presented above and a series of design workshops with usability people in three companies and with a groups of HCI students. And in the following we will discuss how it has been used in empirical studies of introductory use in the homes of Bang \& Olufsen customers. 


\section{Consolidate use}

Investigate the multiple

backgrounds of the users

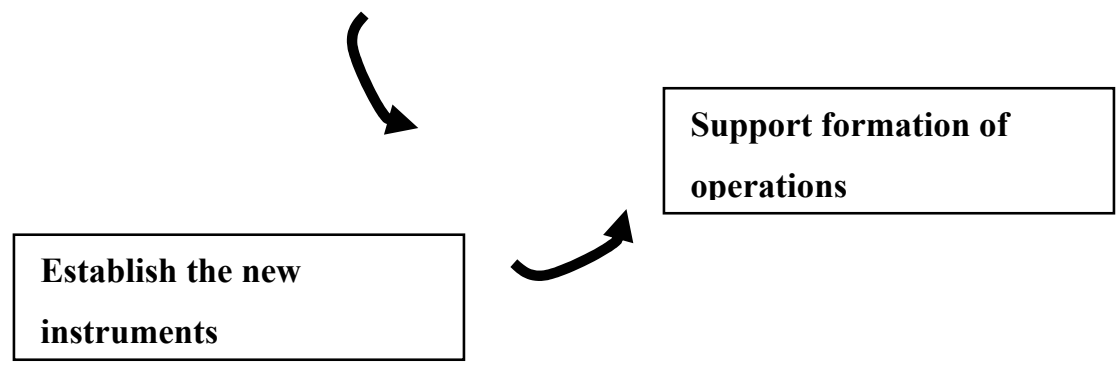

Figure 1. The design cycle for designing the learnable artefact 


\section{Investigate the multiple backgrounds of the} users.

Identify artefacts with similar as well as different handling. (How) does the appliance act in the capacity of what artefacts? how artefacts?

Identify artefacts with similar as well as different purposes. (How) does the appliance act in the capacity of what artefacts? why artefacts?

Identify previous generations of artefacts with similar purposes, and investigate how handling, purposes and contexts of use have developed over history.

Identify previous reasons for purchasing similar artefacts.

Identify additional artefacts of possible future use.

\section{Establish the new instruments}

\section{Establish potential competence}

Looking ahead, the important matter is to identify where-to artefacts. A starting point for this is the above identified present and past artefacts:

Does the artefact propose new possibilities regarding purpose, handling and technological innovation in general?

Where-to artefacts can, however, also be crystallized from other technical and cultural domains (metaphors, science fiction characters, etc.).

\section{Establish initial familiarity}

How to propose to the user what to do with/through the artefact and how?

Support for user to recognize what he or she is doing (why artefacts, where-to artefacts)?

Support for user to recognize similarities and differences to other well-known artefacts, regarding both handling and purposes?

Process of acquiring artefact: introduction in shop, commercials, manuals, etc?

\section{Establish a microcosm}

What is the appropriate group/community of practice in which to evaluate design thus far? What is the status of prototypes, models, etc. with which to evaluate the design?

What is the time scale?

\section{Support formation of operations}

Artefacts that support access to the real objects of the activity (what artefacts) and operationalized handling of the artefact (what and how artefacts).

Support for experimentation, e.g. through "undo"?

Catacresis (supporting existing repertoire of operations to be used with new artefacts, or in new situations)

\section{Consolidate use}

Support for focus on the real objects of the activity, flexible changes between such foci.

No causes of e.g. recurrent breakdowns 


\section{The learnable artefact: An empirical investigation}

In order to investigate the proposed design cycle as well as take some steps towards a practically applicable approach to design for learning in use, we have moved on to study introductory use of Bang \& Olufsen TV sets in people's homes. This study consists of a long term study with recurring visits to the homes of Bang \& Olufsen customers. A study which is in its early stages and of which we report our initial findings. Our approach consists of a combination of interviews, incident questionnaires as well as some hands on sessions all informed by our theoretical work and set up to provide insights into some concrete courses of learning in use in practice.

We have interviewed users by the time of installation of the TV sets in their homes, that is, when people have had an introduction and first demonstration of the TV in the shop, but before they have any hands on experience with operating the TV themselves. The following questions form our discussions with users.

\section{Initial interview}

Investigation into use backgrounds:

- Have you previously owned a similar appliance? - which?

- Which other technical appliances do you own, e.g. computer, video camera other hi-fi equipment?

- Have you previously owned a product by the same producer? which and when? Investigation into potential competence

- Why did you buy this specific TV compared to other TVs?

- What do you expect this TV to offer compared to your earlier TVs and other TVs in general ?

- Can you explain the process that lead to your decision on buying the TV, i.e. what did you learn in the shop, did you hear about the TV or see it demonstrated elsewhere?

- What do you expect the roles of the sales personnel to be during the installation (by the sales personnel) and have you prepared any questions for them in advance?

\section{Figure 2. Interview guide}

Further, as a means for providing some points of reference in the ongoing development process we have developed a questionnaire for users to fill in as they try something new, encounter some problems or in situations which are otherwise 
interesting. We suggested for the users to construct an incident diary using the set of questions, and we intended to use the incidents described as a basis for constructing some use scenarios. The questions fall in two parts. The first section consists of an investigation of the activity. In particular we address the two levels of action and operation, and seek to identify possible contradictions between these levels in the way the television offers itself to the user as opposed to how the user is able to operate the television. The second part addresses the levels of learning as well as the levels of artefacts, i.e. where-to, why etc. artefacts, which come into play in the concrete learning situation.

\section{Questionnaire}

Concerning the activity:

- Briefly describe the characteristics of the situation

- What did you do

- How did you do it

- What did you expect to happen

- What actually happened

What did you learn (tick off relevant cases):

$\square$ You accidentally discovered new features

$\square$ You used a trial and error strategy

$\square$ You got an idea about the way of working of the system and you tested your idea

$\square$ You got a completely revised view of what is offered by your TV

$\square$ Other

What served as means of help in this process on the appliance indicated what I should do

$\square \quad$ I read the manual

$\square \quad$ I used my expectations from

$\square \quad$ I talked to

$\square \quad$ I had heard about from

$\square$ Other

Figure 3. Questionnaire

We have followed up on both the interviews and the questionnaires in our recurring visits in the homes. Based on the information gathered in these ways, we have set up some hands-on session which have allowed us to investigate how different 
artefacts come into play in concrete situations of use.

\section{Experiences from studying introductory use in the home}

Interestingly, we found that in the case of Bang \& Olufsen TV buyers, the where-to artefacts are formed by events and activities surrounding the TV appliance, which are only indirectly related to the design of the TV set itself. Through inviting special customers to events where new products are unveiled, Bang \& Olufsen uses membership of the Bang \& Olufsen society as a where-to artefact to provide an overall indication of what it means to be an owner of a Bang \& Olufsen TV set. To further concretise this feeling of membership of the "Bang \& Olufsen family", Bang \& Olufsen presents other members of the family, e.g. lawyers, politicians, artists and designers together with their explanations of why they have decided on Bang \& Olufsen products in glossy brochures which are given to customers in the special Bang \& Olufsen boutiques. Closer to the design of the TV set itself, you find the introductions to the overall functionality of the television, which are given by specialised sales personnel in the Bang \& Olufsen boutiques. These introductions act as why artefacts and in some cases as where-to artefacts in that they provide the users with expectations as to what they can accomplish with a Bang \& Olufsen TV set and thus justifies why they would want to buy a Bang \& Olufsen TV set. It is interesting to observe that the where-to artefacts may be formed by events only vaguely associated with the TV set itself i.e the what artefact and further that both the where-to and why artefacts in this case come into play before users get any hands on experience using the TV themselves. The cinema experience which the Bang \& Olufsen television owners told about by the time of the installation of their television in their home is an example of a where-to artefact which came into play before the customers had used the television themselves. In terms of designing the learning artefact, our empirical experiences implies that we should explore the potential of designing around the artefact or of designing the wrapping. Furthermore, the importance of the events which precedes the hands-on use experience further emphasises the problems of traditional laboratory studies for studying learnability of designs in that they fail to account for some of the expectations formed around the product in the context of a real life setting.

The analysis of our observations in terms of where-to, why, how and what artefacts further enables us to identify some interesting conflicts in the contextualisation 
between the different artefacts. As described above, the where-to and why artefacts provided for Bang \& Olufsen TV buyers all serve to indicate the luxury and exclusiveness of Bang \& Olufsen TV sets. However, when it comes to the how artefact in the form of a computer metaphor represented by the menu hierarchies and mode of operation using the remote control, the sense of luxury breaks down. Instead the computer metaphor signals efficiency and interactivity in operation, which is not well in line with exclusivity nor the nature of watching television. Thus, we need to be concerned with the contextualisation up- and downwards in designing the different artefacts, in order for the tool with its wrapping to stand out as a coherent tool in the experience of encountering and using it. In this way letting the users' expectations guide them in taking the product into use.

Further the Bang \& Olufsen example points to potential imbalances in the priority between the artefacts at different levels. When we interviewed users at the time of the installation, they expressed a rich set of expectations as to what they would use their new television for including e.g. teletext programming of video, which enables easy programming of video recordings applying a direct manipulation principle. However, when we talked to them one month later, only few had done any programming in this manner. Some had given up, because they encountered problems they could not solve in going through the steps it takes to do the programming. Some of them had completely forgotten about the existence of the feature even though they had been very enthusiastic about it one month earlier. When analysing the case, we find that the Bang \& Olufsen machinery provides a rich set of artefacts on the levels of where-to and why. However, in terms of how artefacts, which serves to support users in moving from expectations to actions, which in this case should have supported them in making use of the teletext programming facility knowing about its existence, the Bang \& Olufsen television often fell through. This example points to the need for careful design of artefacts at all four levels. Further, although we may design around the artefact, this example also emphasises the need for the artefact to trigger the expectations formed elsewhere, i.e. the what artefact must make references to these expectations and remind the user of the presence of the facilities of interest.

Concerning the different methods of inquiry used, our experiences suggest that interviews are useful for providing information on the where-to and why artefacts. The hands-on sessions which followed up on our interviews regarding users expectations 
complemented the interviews well. These hands-on session shed light on the transitions or lack of such from why artefacts level to how and what artefacts. However, the questionnaires did not work the way we intended them to. For various reasons, including the characteristics of the setting where a user sits tired in a late evening watching television, which does not lend itself to filling in questionnaires, the questionnaires were not used and thus did not work as an incident diary. However, the questions comprised in the questionnaire still represents a useful focus for studying learnability in concrete use situations and as such has served as our own agenda when discussing and analysing the hands on use sessions.

Thus a range of methodological approaches, necessary in order to investigate and develop learnable designs, need to be developed further, and has been done so in (Petersen et al., in preparation). Moreover as the example with the questionnaires suggests, these methods need to be developed with respect to the characteristics of the use setting, in this case the home sphere. We will look further at these matters below.

\section{Revisiting the design model}

The design model presented a hypothesis for a design-oriented theory of the learnable artefact. This model is process-oriented regarding design at the same time as it reflects a developmental understanding of use. Our empirical studies have further provided insights, some of which are discussed here (further details in Graves Petersen et al in preparation). These insights point to further challenges to designing for learnability.

First, our studies suggest a complex interplay between the different stages in the development of use. For instance, in one case a commercial for teletext programming of video, which the user had seen even before when he considered buying the TV, played a role as a part of the user's background in that it formed her expectations to the TV, i.e. formed the potential competence. This case emphasises both the special nature of some potential learning instruments and that the quest for learnable artefacts begins long before the establishment of initial familiarity.

Our studies further illustrate the wide range of artefacts which comes into play in these learning situations. As an example, when one user was struggling with connecting multiple loudspeakers as part of a surround sound set up we saw elements from

- the 'cinema experience' she had been explained about in the Bang \& Olufsen boutique, her visit in a real cinema, her visits at her sister's house where they have an 
equivalent system as where-to artefacts,

- an (incomplete) operation principle regarding the remote control which she had intercepted from other members of her household worked as a how artefact, and finally

- the loudspeakers and the remote control as what artefacts.

However, our material also points to considerable individual differences in terms of preferences regarding learning instruments. Where two of the users we studies strongly relied on the manual as a how artefact when establishing initial familiarity and consolidating their use, two others practically refused to consult the manuals, one by principle and the other one in practice. In terms of designing for learnability we have to consider the spectrum of users and make sure that the self-contained artefact or the what artefact at least allows the users to get started and do something, independently of such preferences. Thus although the wrapping, in terms of manuals, checklists etc. can be an important part of the design, we also need to be concerned with the design of the artefact proper, because the wrapping may be neglected by some.

The chosen microcosmos consisted of two families who we intend to follow over a period of at least four months and by the time of writing, we have followed them for a period of three months. Although intensive experimentation happened primarily in the first weeks, and the pace of learning and the interests in the TV set varies significantly among the individuals, we are continuously seeing changes in use and users experimenting with the possibilities of the TV set.

In our studies we have seen examples of how users have consolidated their use through e.g. discovering general principles of operation using the remote control. In the case of the user connecting multiple loudspeakers to obtain surround sound, we see that once she had understood one of the principles of the remote control, namely that it could be set to work in different modes, she was able to connect the loudspeakers repeatedly without problems. In the future, we consider supplementing our studies with visits to families who have owned the same type of television for years to see how their use have consolidated, i.e. which tasks they perform once the hype of the new TV set is truly over.

\section{Conclusions}

Design is a process involving contradictions, choices and trade-offs, rather than one 
where a predefined one best choice exists and can be found. We have seen how, in the range of concerns over learnability, contradictions need to be reconciled. We have seen how what might be the ideal regarding actions may contradict with the ideal regarding operations. Furthermore, learnability issues are certainly just one side of the issues of concern for design. We see no way of devising a reconciliation of these concerns in general; rather the issues must be dealt with in the particular design situation together with the future users.

We have seen how it is important for design to consider more than the physical wrapping of a technical artefact, by focussing on the how, why and where-to artefacts that can supplement or be included in the artefact.

Interestingly, the fact that e.g. TV sets constitute a minor and integral part of the everyday lives of people, has made it very evident that experiences from a number of other everyday artefacts play an important role for usability. The diverse group of users with many different backgrounds adds to this, in contrast to artefacts of work, where a systematic effort of introduction can be expected, and where the variety of backgrounds and experiences of users are largely ignored. In general, we have found it interesting how intrinsically complex the learning situation is for such a simple artefact, and we are convinced that this complexity will increase by many orders of magnitude when we study information systems with much more complex use settings.

We have made good use of the framework of Bardram \& Bertelsen (1995) as a starting point for our concerns. Our empirical material shows that establishing an initial familiarity of the user with the artefact is indeed a very complicated matter. The background of the user in terms of previous uses of a variety of artefacts are linked to the proposed new artefact in non-trivial ways, needing to be considered when designing for initial familiarity. Methodologically, the quest for learnable interfaces starts long before the establishment of initial familiarity. In similar ways, we have been more specific regarding how to establish design for learning in use, and for formation and operationalisation of actions, both more well-known points of concern in our tradition.

The design model forms a specialised version of Engeström's general cycle of expansive learning, targeted towards the challenge of designing learnable artefacts. Indeed, not every design-for-learning-in-use process is potentially a matter of a journey through Engeström's methodological cycle, and we are far from always heading for expansive development in and of use. In practical terms it can be worthwhile to focus 
mainly on the lower levels of learning. At the same time, we have discussed exactly how it is an important concern for usability design to actively consider the conceptual design that will help users understand why they want the new artefact and what place and purpose it will take in the future. Important for our methodological concern here, is that such a reformulation needs to start from the current activity of the users. It cannot be invented from out of "the blue".

Our empirical work has provided examples of what it means to design learnable artefacts. It has illustrated the complexity of this challenge in that we need to design both in and around the product, with respect to-and taking advantage of-the users' background and previous experiences. Our analysis, in terms of where-to, why, how and what artefacts, has suggested that these artefacts may develop to become important tools in designing for learnability.

\section{Acknowledgements}

The work described in this paper has been financed by CIT/CMT through project no. 23, BIDI. Bang \& Olufsen and in particular their usability group is acknowledged for providing a setting, artefacts and enthusiasm for our investigation. Particular acknowledgements goes to Kim Halskov Madsen and Arne Kjær who participated in the planning and execution of the studies of introductory use in homes and to Klaus Bærentsen who generously let us use his video material in our analysis. Olav Bertelsen, Kari Kuutti and Mark Spasser provided many useful comments on earlier drafts of this paper.

\section{References}

Bardram, J. \& Petersen, M.B. (1994). Fra Interface til Interaction [From interface to interaction]. Master thesis, University of Aarhus.

Bardram, J. E. \& Bertelsen, O.W. (1995), Supporting the Development of Transparent Interaction, in Blumenthal, Gornostaev, and Unger (eds.): Human-Computer Interaction. 5th International Conference, EWHCI '95 Moscow, Russia, July 1995. Selected Papers. Berlin: Springer Verlag (LNCS 1015). pp 79-90.

Beaudouin-Lafon, M. (2000). Instrumental Interaction: An interaction model fir designing post- 
WIMP user interfaces, in Turner, T., Szwillus, Czerwinski, M, Paterno, F. CHI 2000 Conference Proceedings, ACM Press, pp. 446-453.

Béguin, P. \& Rabardel, P. (this issue). Designing for instrument-mediated activity, Scandinavian Journal of Information Systems

Bertelsen, O.W. (1994), Fitts' Law as a Design Artefact: A Paradigm Case of Theory in Software Design, in Blumenthal, B., Gornostaev, J., and Unger, C. (eds.) Human-Computer Interaction. 4th International Conference, EWHCI '94 St. Petersburg, Russia, August 1994. Selected Papers, Berlin: Springer Verlag. pp. 11-18.

Bertelsen, O. W. (1998) Elements to a theory of design artefacts: a contribution to critical systems development research, Ph.D.-Thesis, Aarhus University. DAIMI PB-531.

Bisgaard, O., Mogensen, P., Nørby, M., \& Thomsen, M. (1989). Systemudvikling som loerevirksomhed, konflikter som basis for organisationel udvikling [Systems development as a learning activity, conflicts as the origin of organizational development] (DAIMI IR-88). Århus: Aarhus University.

Brown, J. S., \& Duguid, P. (1994). Borderline issues: Social and material aspects of design. Human-Computer Interaction, 9(1), 3-36.

Bærentsen, K. (this issue). Intuitive User Interfaces, Scandinavian Journal of Information Systems

Bødker, S. \& Christiansen, E. (1997). Scenarios as springboards in design. In Bowker, G., Gasser, L., Star, S.L. \& Turner, W. (eds.), Social science research, technical systems and cooperative work, Mahwah, NJ: Erlbaum pp. 217-234.

Bødker, S. \& Halskov Madsen, K. (1998). Context-an active choice in usability work, Interactions, July+August 1998, pp. 17-25.

Bødker, S. (1991). Through the Interface - a Human Activity Approach to User Interface Design. Hillsdale, NJ: Lawrence Erlbaum Associates, 1991.

Bødker, S. (1996). Applying activity theory to video analysis: How to make sense of video data in HCI, in Nardi, B. (ed.). Context and consciousness. Activity theory and human computer interaction, Cambridge: MIT press, pp 147-174.

Bødker, S. (in press). Scenarios in user-centred design - setting the stage for reflection and action. Interacting with Computers, forthcoming.

Bødker, S. (1999). Computer applications as mediators of design and use - a developmental perspective. Doctoral dissertation, Department of Computer Science, University of Aarhus.

Bødker, S., Nielsen, C. \& Graves Petersen, M. (in press). Creativity, cooperation and interactive design, accepted for DIS 2000.

Bødker, S. \& K. Grønbæk (1991). Design in Action: From Prototyping by Demonstration to Cooperative Prototyping. In Greenbaum, J. \& Kyng, M. (Eds.). Design at Work: Cooperative 
Design of Computer Systems. Hillsdale, NJ: Lawrence Erlbaum Associates, pp. 197-218.

Dreyfus, H. L. and Dreyfus, S. D.(1986) Mind over Machine - the power of human intuition and expertise in the era of the computer, Basil Blackwell, Glasgow.

Engeström, Y. (1987). Learning by expanding. Helsinki: Orienta-Konsultit.

Engeström, Y. (1990). Learning Working and Imagining. Twelve Studies in Activity Theory. Helsinki: Orienta-Konsultit.

Kensing, F. \& Madsen, K. H. (1991). Generating Visions: Future Workshops and Metaphorical Design. In Greenbaum, J. \& Kyng, M. (eds), Design at Work: Cooperative Design of Computer Systems. New Jersey, USA: Lawrence Earlbaum Associates, pp. \#\#\#.

Kyng, M. (1995). Creating Contexts for Design. In Carrol, J. (ed.), Scenario-Based Design For Human-Computer Interaction, John Wiley \& Sons, pp. 85-107.

Laufer, E. \& Glick, J. (1996). Expert and novice differences in cognition and activity: a practical work activity. In Engeström, Y. \& Middleton D. (eds.). Cognition and Communication at Work, Cambridge University Press, pp. 177-198.

Lave \& Wenger (1991). Situated learning - Legitimate peripheral participation. Cambridge University Press.

Madsen, K.H. and Petersen M.G. Reflections on three design sessions, Brewster, S. Cawsey, A. and Cockton, G. (eds.) Human-Computer Interaction - INTERACT'99 (Volume II), IFIP, 1999, pp. 185-190.

Madsen, K.H. (1994). A Guide to Metaphorical Design. Communications of the ACM, 37 (12) $57-62$.

Newman, D., Griffin, P. \& Cole, M. (1989). The Contrauction zone: Working for cognitive change in school, Cambridge University Press.

Nielsen, C. (1998). Testing in the Field. Proceedings of APCHI 98, IEEE Press, pp. 285-290.

Petersen, M. G., Madsen, K. H. \& Kjær, A. (in preparation) Towards designing for development in use of domestic technology.

Petersen, M. G. and Halskov M., K. (1999) Supporting Collaboration in Multimedia Design. In Brewster, S., Cawsey, A. \& Cockton, G. (eds.) Human-Computer Interaction - INTERACT'99 (Vol. II), pp. 185-190. 


\title{
The Usability of Everyday Technology \\ - Emerging and Fading Opportunities
}

\author{
MARIANNE GRAVES PETERSEN*, KIM HALSKOV MADSEN, and ARNE KJÆR \\ Aarhus University
}

\begin{abstract}
Current work in the field of usability tends to focus on snapshots of use as the basis for evaluating designs. However, giving due consideration to the fact that everyday use of technology involves a process of evolution, we set out to investigate how the design of the technology may be used to support this. Based on a long-term empirical study of television use in the homes of two families, we illustrate how use continuously develops in a complex interplay between the users' expectations - as they are formed and triggered by the design - and the needs and context of use per se. We analyze the empirical data from the perspective of activity theory. This framework serves to highlight how use develops, and it supports our analysis and discussion about how design, the users' background, previous experience, needs, and the specific context of use supports or hinders the development of use. Moreover, we discuss how the characteristics of the home settings, in which the televisions studied are situated, represent a challenge to usability work. The concluding discussion leads to a set of hypotheses relevant to designers and researchers who wish to tackle some of the aspects of usability of particular importance to development in the use of home technology.
\end{abstract}

Categories and Subject Descriptors: H.5.2 [User Interfaces]: Evaluation/methodology; Input devices and strategies; Training, help, and documentation; J.7 [Computers in other Systems]: Consumer Products.

General Terms: Design, Human Factors.

Additional Key words and Phrases: Development in use, usability, activity theory, design, case study, domestic technology, TV set.

\section{INTRODUCTION}

As new technologies penetrate our lives at an increasing rate, we no longer know what functionality to expect from our refrigerator, our television, our car, our heating control system etc. There is a trend towards product integration and we see an increased complexity of especially domestic technology. Thus our expectations become challenged in the meeting with new products and they are formed and modified as we gain experiences with using the new technology. This exploration does not stop after the first hours or day of use. Our use continuously develops over time, new possibilities emerge and others fade away. Unfortunately, present usability engineering methodologies provide little support in

\footnotetext{
* Marianne Graves Petersen, Department of Computer Science, University of Aarhus, Aabogade 34, DK-8200 Aarhus N, DENMARK, mgraves@daimi.au.dk. Kim Halskov Madsen, Information Science Department, University of Aarhus, Aabogade 34, DK-8200 Aarhus N, DENMARK, halskov@imv.au.dk. Arne Kjær, Information Science Department, University of Aarhus, Aabogade 34, DK-8200 Aarhus N, DENMARK, akjaer@imv.au.dk.
} 
understanding how use develops right from the first meeting with the whole product till we later discover small facets of the technology and more importantly how this development in use may be supported by the design of the technology.

Activity theory provides a solid starting point for implementing designs tailored to supporting development in use by offering a framework that accounts for the dynamic nature of artifacts in use, right from motive formation to the detailled interaction with the material artifact. From the point of view of activity theory, computer applications are artifacts that mediate human activity [Bødker 1991]. In this article, we apply the perspective as developed by Engeström [1990] where artifacts are seen as accompanied by several kinds of learning artifacts, which reflect and provide guidance for the use of the artifact. We use this framework to interpret the processes of use as seen in a case study and we report on some of our findings with regard to what actually happens in the process of system appropriation over time and how the design supports the development in use. The study presented in this article should be seen as a part of a more extensive series of efforts in using human activity theory as a theoretical basis for HCI and design work [Bannon and Bødker 1991; Bødker 1991; Bødker and Petersen (in press); Bardram and Bertelsen 1995; Bardram 1997; Bertelsen 1998; Nardi 1996].

Others have studied development in use, but much of this work has been limited to the area of text editing or other kinds of office work, and much has focused on relatively short studies carried out under laboratory conditions. The work of Carroll and Mack [e.g. Carroll and Mack 1996] is an example of conventional work within this area. This study involved office personnel spending four half days learning to use a word processing application in a laboratory environment. Through their study, Carroll and Mack [ibid] have identified three different learning strategies: learning by doing, learning by thinking and learning by knowing. Some studies of ways of supporting development in use have taken the form of controlled experiments designed to shed light on the optimal design of a specific aspects, e.g. Wiedenbeck's experiments with icons [Widenbeck 1999]. Rieman's studies of exploratory learning in an office environment [Rieman 1996] were carried out in a natural setting covering all available technology but only lasted a period of four days. Draper and Barton [1993] point to the work by Gibson [1986] on affordances in support of learning by exploration. The focus of their study was the first 40 minutes of novices' use of MacPaint.

Our case study, in contrast concerns a long-term study of two families' use of a new television set with an integrated video recorder. This technology represents the trend of product integration and the increasing complexity of domestic technology. We paid our first visit to the families in their homes at the time their new televisions were delivered, and subsequently visited them three times at intervals of approximately one month. With our analysis we seek to move towards an understanding of how the design of technology can support the development in use - thus broadening the scope of usability and design work to encompass the use of interactive technology as it develops dynamically in the context of the home.

The progression of the paper is as follows: firstly, we present the methodological rationale behind our field study followed by an introduction to the concepts of activity theory which form the basis of our subsequent analysis of the development of use. The main body of the article is an analysis of four series of episodes from the field study, which we have found to be particularly successful, problematic, surprising or difficult to relate to. The concluding discussion leads to a set of hypotheses relevant to designers and researchers who share the concerns for supporting development in use in the design of home technology.

\section{METHODOLOGY}

Activity theory emphasizes the fact that artifacts can only be understood when in use [Bannon \& Bødker 1991]. Therefore, we can understand neither use nor artifacts in isolation, and, as a result, we need to 
investigate specific situations involving artifacts in use in order to understand how development in use occurs. However, we face a number of methodological challenges to the study of development in use of everyday artifacts in the context of the home. Our approach to the subject is defined by considerations of privacy issues in particular [O'Brien et al. 1997]. In addition, the fact that a good deal of leisure and home technology is used only sporadically makes it difficult for researchers studying the use of such technology to be in the right place at the right time. The methodological challenge of this study is thus to find ways in which to mirror and condense the families' focus on and interaction with the products in the limited amount of time that was available to us during our visits to their homes.

\subsection{Research methods and rationale}

We wish to study how products with increasing complexity are handled by the users. Especially, we are interested in understanding how the design of interactive technology may support users in developing their use over time. To do this, we need to tackle the process of developing use, rather than concentrating on its results. Consequently, we focus on how users handle the technology, how they learn to use it, and what are the motives that drive the processes.

Further, several investigations have shown the importance of the context of the use of new technology [Greenbaum and Kyng 1991; Kyng \& Mathiassen 1997; Beyer and Holtzblatt. 1998]. To address this we find a qualitative approach to such an investigation extremely relevant. We have used a case study approach, where we have followed the adoption of new television sets by two families over periods of four and six months, respectively. We visited each of the families four times each, in their homes, during the evenings, and at intervals of approximately one month. The frequency of our visits was determined largely by our expectations to the frequency of use of the television sets. Following only two families allowed us to study the adoption processes in depth, given the resources we had. Moreover, due to the demands placed on the Bang \& Olufsen customers, as well as for practical purposes, we had to stop our investigations after studying 6 months of use.

In focusing on how use evolves, we are interested in the process as a whole - i.e. starting from a time before the users even buy the new equipment. The initial phase of this process involves the first motivation, the idea of purchasing a new television, discussions within the families and with friends, and visits to a distributor. The intention of our study was therefore to enter into this process as early as possible. For practical reasons, we became involved in the process at the time when the technician from the store installed the television at the customer's home, at which point we conducted an initial interview concerning the users' reasons for buying the television and their expectations to it. As we were interested in defining the users' motivation for buying the television, the families we followed were Bang \& Olufsen customers who had decided to buy the product in question independently of this study.

A further consequence of our interest in studying the development in use and how design supported this development was our decision to ask open-ended questions which did not disclose any facilities of the technology. We have been inspired by Hammond, [1996], who writes about how to conduct interviews and investigations related to the responses of the interviewee. As a result, rather than systematically providing the users with tasks to perform or with functionalities to try out, we took the users' own actions and explanations, as revealed during the initial interviews, as the basis for the subsequent part of the visits. Subsequently, during each visit, we followed up on the aspects raised by the users by constructing scenario-framed hands-on use sessions [Bødker \& Grønbæk 1991]. This technique has previously - at least in the workplace - proved to be fruitful in establishing situations where users actively cooperate in the design process through assessing existing designs and envisioning future ones [ibid]. We are not aware of others having used this technique before in users' homes. We also experimented with role play as an approach to gaining insight into the users' current understanding 
of the television and its possibilities without influencing the adoption processes. Our study can be seen as a form of iterative investigation seeking to understand the evolution in use by following up on the same use situations as well as investigating new facets of use as they are encountered by the users.

To address the challenge of sporadic use of technology in the home, we developed an incident diary form for the family members to fill in whenever something interesting happened. However, due to a combination of the characteristics of the relaxed and private situation on the sofa in front of the television, the complexity of the specific form, and possibly an insufficient preparation of the users, the form failed to work in this study. See [Kjær et al. 2000] for a more elaborate discussion about this aspect.

Finally, as we were visiting people in their private homes, we restricted both the number and the duration of our visits and were careful in our use of video recording in their homes. Whereas video recording equipment would often be acceptable in a workplace, such technology would be considered much more intrusive in a home setting. We found Mackay's [1995] precautions concerning the use of video extremely relevant also in the home. Due to considerations of respecting private space, we decided only to videotape the situations where we explicitly asked the users to perform some tasks with the technology. See Kjær et al. [2000] for a more detailed discussion of our methodological approaches and experiences.

While others have studied technology in homes, they have most often been driven by motives other than that of designing specific new technology. For instance, most of the papers presented at the early home IT conference concerning home telematics [Rijn and Williams 1988] deal with the social implications of the introduction of various technologies in the household. Although social implications are, to an extent, taken into consideration when designing new technology, we agree with O'Brien et al [1997] that the design of new technology requires more detailed insight than that available from surveys. In order to form a platform for design improvements we need to understand the motives behind the specific instances of use of technology, and we need to gain insight into the actual interaction with the technology. Moreover, it is generally acknowledged from the use of technology at workplaces that great differences may exist between how people talk about their use of technology and how they actually use it. Therefore, rather than choosing a quantitative approach involving a large number of users and centered around a questionnaire, for instance, we have chosen to present our the experiences from a detailed qualitative study. As such, we offer a perspective, which complements much of the other research available within the area of domestic technology.

\subsection{Products and participants}

The product we have studied is a Bang \& Olufsen integrated television and video recorder operated through a single remote control (unit) and as such it represents the trend of product integration. The integrated television and video can be part of a larger linked system, where all audio/video sources are linked together and controlled by the single remote control. The complex functionality offered by the remote control is provided through its different modalities. As an example, after having pressed 'TV' it is the same sequence of key presses that selects channel number 7 as when selecting track number 7 of a compact disque after having pressed 'CD'.

In contrast to other interactive systems that have formed the object of studies of learnability we chose to look at a system which comprises a relatively simple set of metaphors and simple menu structure. This gave us the opportunity of studying the changes in use, and thereby we got an indication of the learning process.

The two families each consist of four members, husband, wife and two children. One family consisted of Paul and Sarah, a middle-aged couple with two adult children, while the other consisted of, John and Karen a younger couple with two small children. While Sarah and Paul had previously owned Bang \& 
Olufsen products and as such were familiar with the company line, John and Karen were new Bang \& Olufsen customers. Both families had just acquired the new Bang \& Olufsen integrated television and video system. In Paul and Sarah's home, this system formed part of a larger system comprising surround sound and other audio-visual technology produced by Bang \& Olufsen. At John and Karen's home the new system was not linked with other technologies.

All the field studies (interviews, etc.) were conducted in Danish which means that quotations etc. in this article are translated into English.

In summary, our case study concerns a long-term study of two families' use of a new integrated television and video recorder. We paid out first visit to the families in their homes at the time when their new televisions were delivered, and subsequently visited them three more times at intervals of approximately one month. During each visit we interviewed the family members and provided scenarios to for hands-on use sessions with the television.

\section{ACTIVITY THEORY AND LEARNING ARTIFACTS}

Bødker [1991] has described how computer applications are successful mediators when they allow users to act through them and maintain a focus on the object of their activity rather than making the artifact itself the focus of their attention. However, breakdown situations inevitably occur when a user is learning to use a new artifact, and the artifact itself comes into focus. This means that creating designs for development in use includes providing support for returning the user's focus to the object(s) of interest.

Through a set of dynamic concepts, activity, action and operation, the framework of activity theory provides a perspective that allows us to discuss how development in use takes place through transitions and formations of these, and it makes us focus on the context of use instead of seeing computer use, for example, in isolation. As artifacts usually mediate several activities, they may be seen as being situated within a web of activities. Each activity is conducted through actions of individuals directed towards an specific object or another subject. Activity is what gives meaning to our actions, although actions may have their own goals and the same actions can appear in different activities. Each action that a human being conducts is implemented through a series of operations. Each operation is connected to the concrete physical or social conditions for conducting the action, and is triggered by the specific conditions of the situation. Operations are often transformed actions, i.e. we consciously conduct them as actions to start with. We transform them into operations by learning, but when the conditions we encounter change, we may have to reflect on them consciously once more, and what were once operations become conscious actions again. Learning in terms of operations that are formed and break down is one aspect of learning seen from the point of view of activity theory.

Artifacts also need to support the development of a repertoire of purposes of use of the artifact. This repertoire of purposes concerns the development of the motives for what we do. As pointed out by Bardram \& Pedersen [1994], the formation of actions and the progression between levels of actions and activity are equally important to the learning process, and our understanding of these is far less well developed.

Furthermore, design in turn is complicated by the fact that an artifact always implies more possible uses than the original operations that led to its creation [Engeström 1990, p. 174]. Thus, the presence of a designed artifact does not determine the way it is actually used and perceived by users. Further, the manuals accompanying a product, i.e. the whole "system image" [Norman 1988] plays a role in forming the users expectations or model of the artifact. This applies to a wider class of artifacts than traditional computer applications and, as Engeström [1990] points out, artifacts are implicitly or explicitly accompanied by models that reflect and provide guidance for their use. Accordingly, we have found it 
useful to look at both the artifact in itself and the models that surround it as learning artifacts, artifacts that will be studied in greater detail in the following sections.

\subsection{Learning artifacts}

Adopting the work by Wartofsky [1979], Engeström [1990] has pointed out that from the perspective of learning artifacts, all artifacts can be seen to include elements of what, how, why and where to artifacts see figure 1. As a result, designing for development in use is a matter of designing artifacts so as to involve all four in appropriate ways. Taking a particular use situation as our starting point, we may also choose to study the models, other artifacts, etc. that form part of the users' web of activities and help users learn about the artifact in question. The different learning artifacts are closely related to the concepts of human activity [Engeström 1987].

\begin{tabular}{|l|l|l|}
\hline Human activity & Learning artifacts & Examples of learning artifacts \\
\hline activity (motive) & where-to artifacts & visions of future use experiences \\
\hline action (goal) & why artifacts & general principles and hypotheses \\
\hline operation (conditions) & how artifacts & ad hoc models \\
\hline
\end{tabular}

Figure 1 Human activity and corresponding learning artifacts.

What artifacts are the artifacts per se with the limitations and conditions inherent in the artifact itself. They are the conditions that frame the formation of the subconscious operations through trial use of the artifact. As an example, the buttons on a remote control can be a what artifact. How and why artifacts deal with the formation of actions and goals. How artifacts are ad hoc models of how to use the actual artifact, the what artifact. Procedural instructions as they are commonly found in instruction manuals can, for instance, work as how artifacts. Such artifacts are not easily transferable to other conditions and situations because they are merely specific instruction offering no ground for understanding why they work. Why artifacts in turn are more general models and principles that offer explanations of how the artifact works. The use of general interaction principles, such as the use of modes on a remote control, is an example of a why artifact. Where to artifacts are the imaginative artifacts, the visions, which help change and redefine a person's understanding of the change in the overall activity. An example of a where to artifact is the desire to experience being in a movie theater when watching television at home. This motive encompasses a vision of changing the existing situation, which makes a difference to the person or persons involved. Where to artifacts are manifestations of the motive of change. They need not manifest collectively, but contain an element of change, which could influence more than an individual person.

Engeström [1990] suggests that these different artifacts are useful in understanding use and development in use. However, Engeström argues that we can never predict how use will develop and that artifacts never predetermine use [ibid]. He uses learning artifacts for developing work practice in 
general without focusing on technological tools in particular. Therefore, in our analysis we extrapolate Engeström's learning artifacts to the situation with which we are concerned, namely the understanding of the development in use of interactive technology.

In the following sections, we present four series of episodes from our case study concerning development of use from the perspective of activity theory. In our approach we have been inspired by the anthropological way of doing field studies. We have made field studies in situ, collected our data (observations, interviews, video recording, etc.), and then we have looked through the material several times, to identify themes of interest from the material itself, rather than from a predefined set of categories. Some of the themes also developed through the interest of the family member, whereas it was coupled to their motive for buying the TV. Further, we have selected episodes that were particularly successful, problematic, or surprising and difficult to tackle. The episodes are: the cinema experience, programming video recordings; sticking to old procedures; programming video recordings: new opportunities; and finally, consistency creating confusion.

\section{THE CINEMA EXPERIENCE}

Sarah is a member of a family that has recently bought an integrated television and video recorder from Bang \& Olufsen. The family previously owned a 10 -year-old Bang \& Olufsen television, so they are familiar with the brand. We analyze how Sarah came to use the new television over a period of six months with special focus on how she pursued the cinema experience offered by the new system.

4.1 Installation: forming the cinema experience

When the product is being installed, Sarah and her husband Paul explain excitedly how they look forward to obtaining what has been labeled a cinema experience in their living room. This experience refers to the possibility of connecting multiple loudspeakers to obtain surround sound and the opportunity to adjust the format of the picture on the screen in order to watch wide-screen movies on a wide screen. This was one of the prime motives for buying the new television set.

Several mediating artifacts play a role in forming both Sarah's and Paul's expectations with respect to the cinema experience at this time, when neither yet has any experience with using the product in their own home. Sarah refers to her visit to the cinema to see "Titanic", as an event that has served to form her expectations regarding the new product. Moreover, she has experienced the same system at her sister's house and in the special Bang \& Olufsen boutique where they bought the television. By using the term cinema experience in their sales brochures and in the sales situation, Bang \& Olufsen introduces the analogy between the television and the cinema, thus making visits to the cinema a point of reference in the encounter with the Bang \& Olufsen television. This analogy is followed up in the design of the actual television. As electronic curtains rise and fall as the television is turned on and off, daily encounters with the television feature a direct reference to the cinema experience (figure 2). 

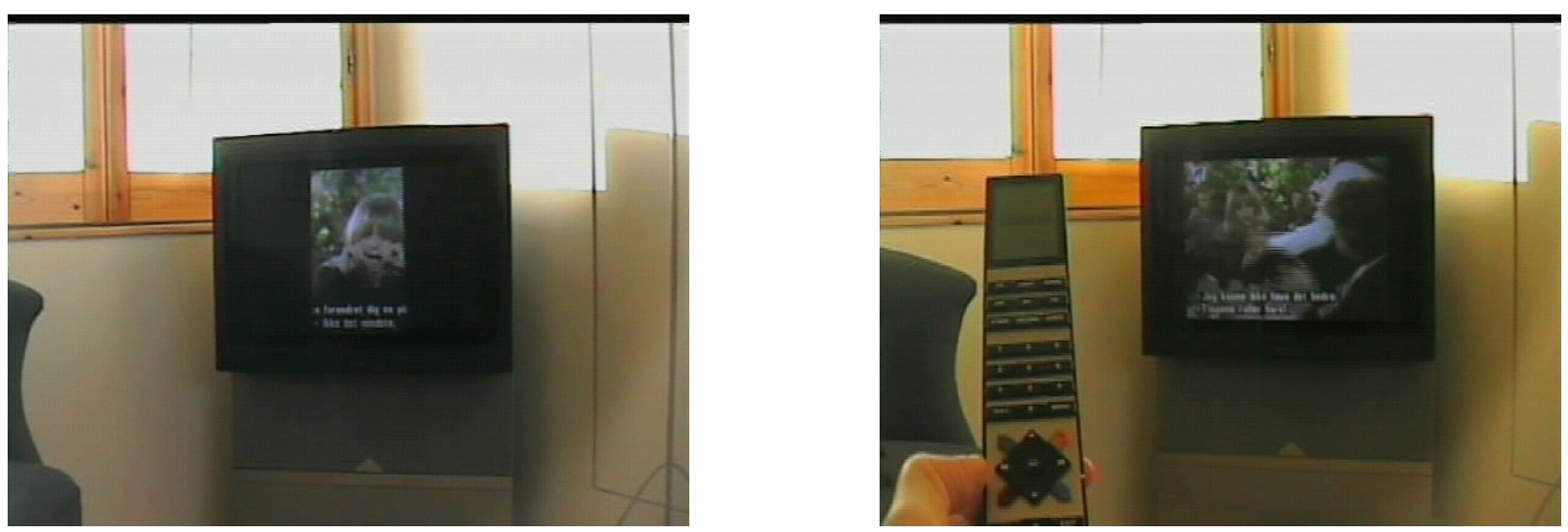

Figure 2. The electronic curtains of the Bang \& Olufsen integrated television and video

In terms of activity theory, the cinema experience as used by Bang \& Olufsen in the sales situation and the sales brochures acts as a where to artifact for Sarah and Paul in that it helps them to envision the new television set providing them with a new kind of experience. The concept of the cinema experience and a real-life demonstration in the shop trigger their experiences elsewhere, e.g. in the cinema. In this way, it provides an overall indication of what it means to watch television using this Bang \& Olufsen product. The cinema experience analogy is also expressed in the product itself, as illustrated in figure 2. The electronic curtains act as a what artifact, supplying a context for the where-to artifacts in the appearance of the product. Thus at this point in time, the cinema experience and the electronic curtains act as where-to and what artifacts in forming Sarah's expectations. As illustrated by "_“ in figure 3, no why and how artifacts have yet come into play in the context of the cinema experience.

where to artifacts
The cinema experience as it is formed in t
why artifacts
-
how artifacts
-
what artifacts
The electronic curtains rising and falling.

Figure 3 Learning artifacts at the time of installation: forming the cinema experience.

4.2 One month after delivery: efforts to obtain the cinema experience

Sarah explains that she primarily uses the remote control from their old television to operate the new television. This works for basic purposes, although it is not possible to use the old remote control to access the special features of the television, including the cinema experience setup. Sarah is well aware of this, stating that the new remote control "is the future" and that she needs to familiarize herself with it at some point. 


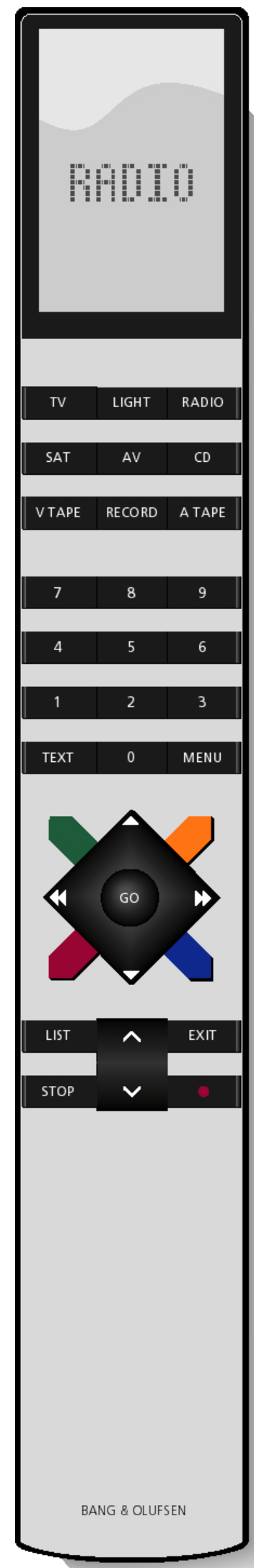

Before detailing how Sarah uses the television at this time, we would like to present a short explanation of some central features of the new remote control, which is illustrated in figure 4. A distinguishing feature of this remote control is that it is highly modal. At the top, there is a display showing the mode selected in this case the television. Moving down the remote control, we find nine buttons whose principal use is to select the source (TV, RADIO, CD, etc.). Further down, we find the number buttons. When the remote control is in television mode (as it is in figure 4), pushing number button ' 5 ' selects TV channel number 5 . Then there are some other buttons that have no bearing on this particular case, and finally, there are six buttons including the LIST button. The LIST button is used to switch the mode of the remote control.

Repeatedly pushing the LIST button scrolls between different modalities. Thus when the remote control is in speaker mode (with the word SPEAKER shown in the display of the remote control), pushing number button 5 would result in turning on the 5 loudspeakers to obtain surround sound. 
During this second visit, we ask Sarah about what she would like to do with the new remote control.

Sarah: ... what I can't do now and what I have not learned or asked about or read myself, that is to make the screen ... if I'm watching a video ... to make ... what is it called ... to enlarge or reduce the size of the picture ... I can't do that ... I mean it would take a long time for me to sit and experiment, it would be easier to read the manual, but it would be even easier to ask someone, if there was someone to ask.

[Some discussion about whether Sarah would use the manual or not]

Question: Are there any other things that you would like to do with the new remote control?

Sarah: I can operate the video, but there is still the thing about making the picture bigger and smaller and then there is surround sound, too. I have not worked it out ... I know it is [she studies the new remote control in her hand] ... no I don't know ... yes LIST ... I know it has something to do with LIST.

Sarah sets out to try to use the new remote control to connect all the loudspeakers to obtain surround sound. She experiments for some time, pushing the LIST button and some other buttons, but eventually she gives up. However, as she is experimenting, she accidentally succeeds in finding a way to manipulate the size of the picture. From conversations with her family, she knows that she needs to do something with the LIST button, but she cannot extrapolate this into a wider context, nor make the connection between the LIST button, the cinema experience and the loudspeakers. "Something to do with LIST" becomes an incomplete how artifact which cannot be connected to the other learning artifacts. Figure 5 provides an overview of the learning artifacts active for Sarah at this time.

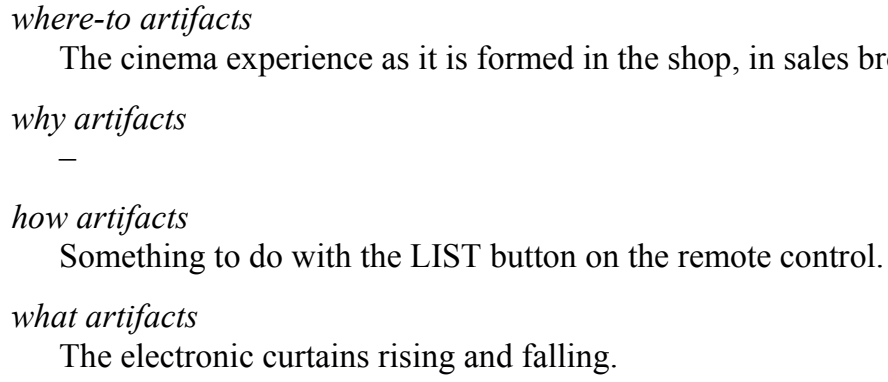

why artifacts

how artifacts

Something to do with the LIST button on the remote control.

what artifacts

The electronic curtains rising and falling.

The cinema experience as it is formed in the shop, in sales brochures, in the cinema, and at Sarah's sister's house.

Figure 5 Learning artifacts one month after delivery: efforts to obtain the cinema experience

During our subsequent discussions with Sarah's husband, Paul, about how he operates the television, Sarah discovers a principle of action, a new learning artifact, which is of relevance to connecting all the loudspeakers to obtain surround sound.

Paul: Now I would like to have the right size of the picture and the surround sound on. If we start with the size, we do .....

[Paul does this without problems]

Paul: Then, when we want surround sound, we must connect all five loudspeakers. Then we need to go over to what is called "speaker" mode and you do this by pressing LIST .... there we have speaker mode [the text 'speaker' appears in the display of the remote control], then we press number button $5 \ldots$

Question: And you pressed 5 because you remember ...?

Paul: Well there was some logic involved as I know that you have five speakers in surround sound, right?

Sarah: Oooohh, yes of course ... that is a strange kind of logic isn't it! It's so simple really!

In this way, the principle of connecting the loudspeakers by selecting the number of loudspeakers to be connected becomes a why artifact for Sarah. As she realizes this general principle of interaction, she identifies a kind of logic behind the interaction. However, according to activity theory, a tool only unfolds in use and Sarah still needs to employ this learning artifact herself before it becomes active for her. She has accomplished this by the time of our next visit. 


\subsection{Two and a half months after delivery: finally establishing the cinema experience}

Sarah proudly explains that she has now succeeded in connecting all the loudspeakers to obtain surround sound. It turns out that she has accomplished this using the CD player. We ask her to demonstrate to us what she did when she first succeeded. The CD player works in the same way as the television as regards connecting multiple loudspeakers, the only difference is that the $\mathrm{CD}$ has to be selected as the source (see figure 4) instead of the TV. Furthermore, when using the CD player it is only relevant to connect four loudspeakers instead of five - as Paul did when he demonstrated surround sound on the TV - because the loudspeaker in the television is not connected to the CD player. This challenges the generality of the principle of interaction discovered by Sarah as a why artifact during our previous visit. Sarah: Then I turned on the CD player. And then I wanted to connect the loudspeakers - all five of them.

Question: What did you do then?

Sarah: Well, then I needed to start by turning up the volume [she turns up the volume] ... and then ... hmm ... [Sarah studies the remote control] ... I put on ... I pressed twice on ... hmm .... on lift ... LIFT! ... and then I pressed number button 4 and now they are on [the surround sound is on].

Question: When you experimented with this yourself, do you remember how you found out that this is the way to do it?

Sarah: Well I recalled that I needed to press .... that LIFT button ... that one I've always remembered ... a few times [actually twice], and then there is nothing to it apart from pressing up to .... you see, I knew we have up to five loudspeakers, right !? ... and then I pressed number button 4 and the lights [on the loudspeakers] turned green [she points to the speakers].

This situation is interesting from a number of perspectives. To start with, when Sarah connects the loudspeakers to obtain surround sound, she starts out by turning up the volume - most probably with the cinema experience as her point of reference for her action. A breakdown occurs as she needs to find the LIST button, with which she is still not confident. This time she refers to it as the LIFT button, perhaps indicating that the term LIST does not mean anything to her. Furthermore, the principle she discovered last time in terms of pressing a number corresponding to the number of loudspeakers has now become operational for her as a why artifact. In addition, her previous how artifact in terms of "something to do with LIST" has now been refined to "press LIST or LIFT a few times". Thus mediated by the following learning artifacts in shown in Figure 6, Sarah's efforts to obtain the cinema experience in her living room finally bear fruit.

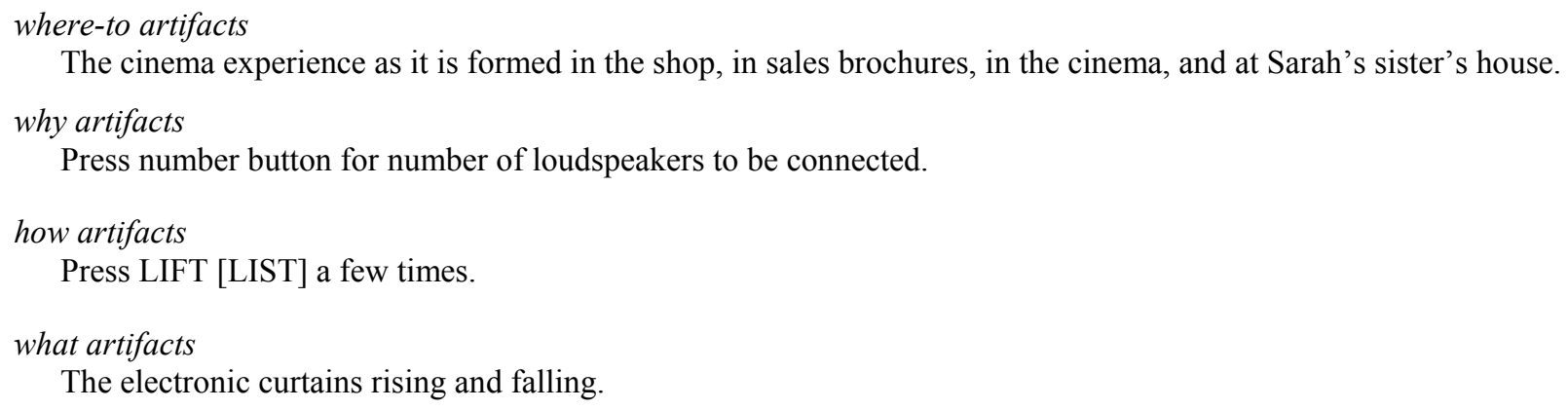

The cinema experience as it is formed in the shop, in sales brochures, in the cinema, and at Sarah's sister's house.

The electronic curtains rising and falling.

Figure 6. Learning artifacts 2 months after delivery: finally establishing the cinema experience

4.4 Six months after delivery : the cinema experience has turned into the concert experience plus watching movies without glasses

Interestingly, when we visit Sarah and Paul six months after the delivery of their new Bang \& Olufsen system, Sarah's use of surround sound has consolidated into a concert experience. Sarah is now fully familiar with the use of the LIST button, but she primarily uses the surround sound facility when listening to music via the Bang \& Olufsen CD player, which is linked to the rest of the system. She has 
found out that she does not really enjoy watching movies with surround sound on, as she does not like the sudden, sometimes very loud, sounds - for example, those made by a flying object coming from behind her- as reproduced by the cinema experience. At this time, both Paul and Sarah appreciate the use of the wide screen format, which also formed part of the cinema experience, because it enlarges the subtitles with the result that they do not need to wear glasses to read them.

In terms of learning artifacts, Sarah has now, due to the specific circumstances in terms of her needs and preferences, molded the cinema experience into a concert experience, see figure 7 . The previous why and how learning artifacts have become refined, and Sarah is generally more confident in the way she handles the remote control. However, she still cannot manage to adjust the format of movies on her own. Paul does this when they are watching movies together.

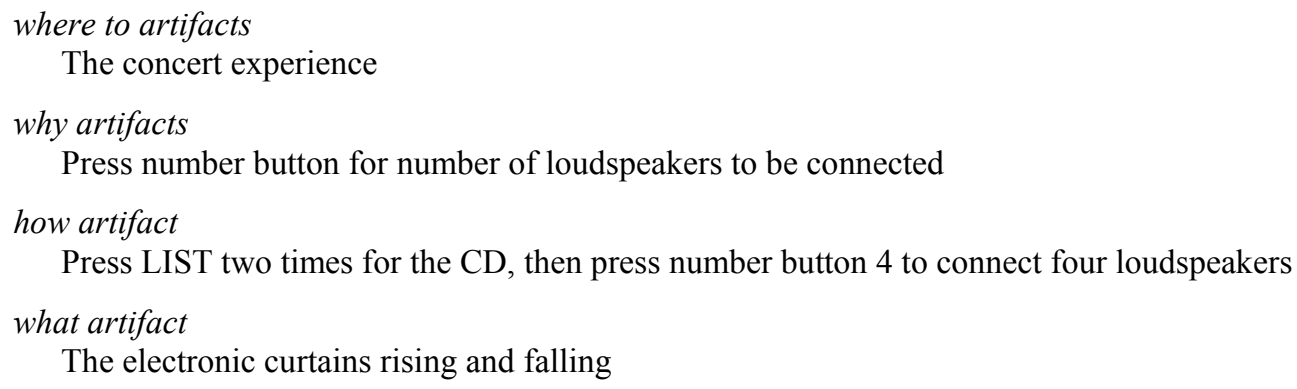

Figure 7. Learning artifacts 6 months after delivery: the cinema experience has turned into the concert experience

We find that the experiences revealed by this series of episodes point in the direction of a number of implications for designing home appliances to support development in use. In this case, we saw how the concept of the cinema experience, as it was formed in the shop, in sales brochures and triggered by the physical design of the television guided Sarah's exploration of the Bang \& Olufsen television. During her two-and-a-half month struggle to obtain the cinema experience, she repeatedly referred to this vision of future use as the point of reference in her exploration of the television set.

In her exploration, Sarah particularly focuses on how to adjust the size of the picture and how to obtain surround sound as the next steps in her process of learning to use the new television. Arguably, the television contains other functions that are also highly relevant to her way of using the television. As an example, Sarah explains that she uses teletext a lot, especially to see weather forecasts. Thus the opportunity to access frequently used teletext pages directly would be a useful functionality for her - an opportunity that the television set provides. However, she is not aware of this option and the television does not remind her of its presence.

Interestingly, Sarah had some specific expectations to the things she wanted to do with her new television even before the time of installation, i.e. before she had interacted with the television herself. In this case, this was largely due to the learning artifacts in terms of where to artifacts introduced during the sales situation through the presentation of the concept and the real-life demonstration of the cinema experience in the shop. Moreover, it was also referred to in the sales brochures. Thus in creating designs to encourage learning through use of home appliances which users buy themselves, this case points to the potential in designing learning artifacts which come into play even before the users lay their hands on the product.

Furthermore, the cinema experience presented in the sales situation was elegantly referenced in the what artifact of the electronic curtains which act as a constant reminder of the vision of the cinema experience to be pursued by the user 
Our analysis also suggests that one reason for Sarah's problems in obtaining the cinema experience was the lack of support for her interaction with the product in her search for the cinema experience. There was limited support in her progressing from expectations towards accomplishment. Nothing in the design of the remote control or its display supported her in making the connections required to achieve the expected experience.

Furthermore, this case exemplified Engeström's argument [1987] that the design of artifacts does not prescribe use. As we saw in the example of Sarah's learning progression, artifacts will indeed always be modified and shaped through use, possibly in ways unanticipated by the designers and, as our case clearly illustrates, also unanticipated by users. This case suggests that by designing where to artifacts, we may motivate users to set out to explore the new technology, and, as this case demonstrates, users will then mold their use of the artifact (the television in this case) with respect to their specific preferences, needs and context.

Notably, it is the flexible design of the link system, linking the different hi-fi technologies in Paul and Sarah's house together, that allows Sarah to find new ways of using the system, having realized that she does not like the cinema experience after all.

\section{PROGRAMMING VIDEO RECORDINGS - STICKING TO OLD PROCEDURES}

The second series of episodes concerns programming video recordings.

5.1 The Installation: easier programming of the video using teletext

When the television is installed in their house, Paul explains that he expects it to become easier to program video recording due to the integration of the television and the video recorder in their new Bang \& Olufsen system. Paul explains that he has learned from the demonstration in the shop as well as from brochures that all you need to do is to highlight the appropriate program in the teletext display. If the program is delayed, the system will automatically adjust the recording time.

In terms of learning artifacts, the demonstrations of the improved integration between the television and the video exemplified in terms of using teletext to program video recordings leads Paul to expect that the system will be easier to operate due to improved communication between the television and video. He is thus supported in forming a general vision of future use, a where to artifact, covering the overall expectation of a more integrated system. Finally, the physical appearance of the television, in terms of the integration, acts as a what artifact, signaling improved integration and communication between the television and the video recorder. The way the television comes into play for Paul at this time is summarized in figure 8.

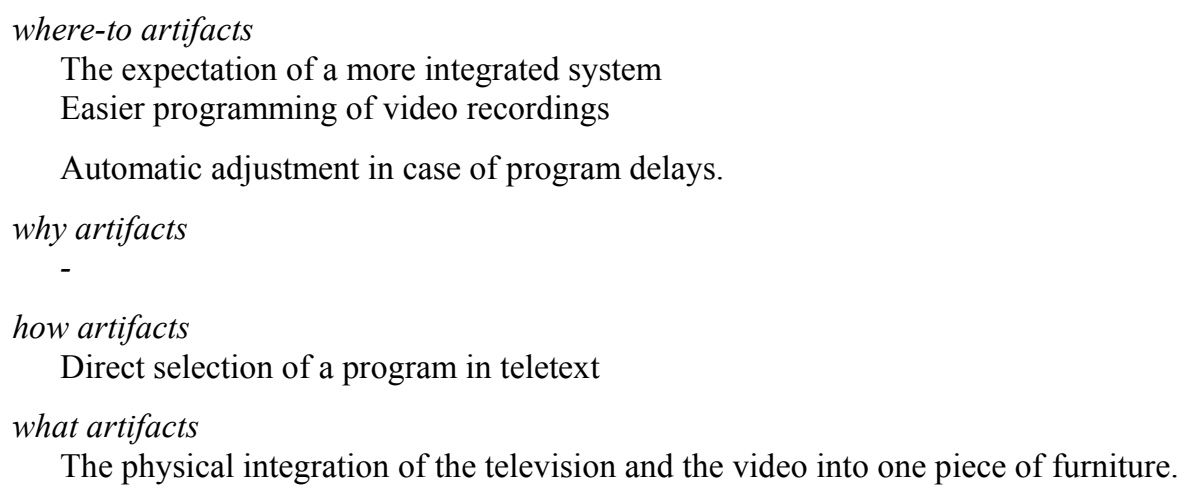

The physical integration of the television and the video into one piece of furniture.

Figure 8 Learning artifacts at the time of installation: easier programming of the video using teletext 
One month after the delivery of the new television set, Paul still programs the video using the conventional approach of specifying the channel and the planned start and stop times for the program in which he is interested. When asked why he is still doing it this way, he replies that this is the way he used to do it on his old system. Talking to him about this issue, it actually seems that he has forgotten the existence of the new way of programming the video. As Paul is specifying the start and stop times for the program, the television displays a reminder of the alternative programming strategy offered by the system in the form of a textual reference: "Press MENU for teletext programming" at the bottom of the bar in which he is working, see figure 9. However, it seems that Paul does not notice this reference, and it certainly does not cause him to change his strategy.

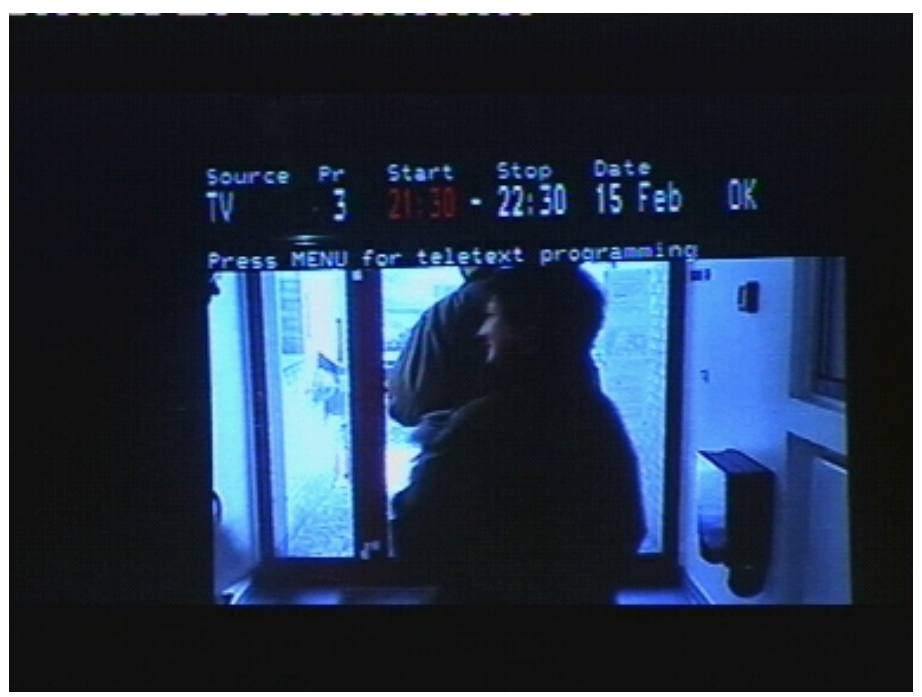

Figure 9 The conventional video programming menu on the television.

Thus the learning artifacts in play at the time of the installation of the television - i.e. those suggesting this overall vision of a new way of programming the video - are not active for Paul in his use of the television at this time. Instead, he draws upon his experiences from their previous video recorder, which come into play as a why artifact in this case, due to their generality and transferability between different products. However, Paul also has to learn to use the new remote control (it is late summer, and the weather has been so fine that they have not been watching much television). In fact, he has not yet used the option of programming a recording at this time, when he is still learning to "handle" the remote control. The physical design of the new remote control differs from the old one, and he is "fumbling" with the registration of the start and stop time. He uses his understanding from the old system (as a why artifact) to guide him through the process of programming on the new system. At the same time, he is experiencing the difference at the physical level (what artifact) as regards both the shape of the new remote control and the way in which the different elements are displayed on the screen, see figure 10. 


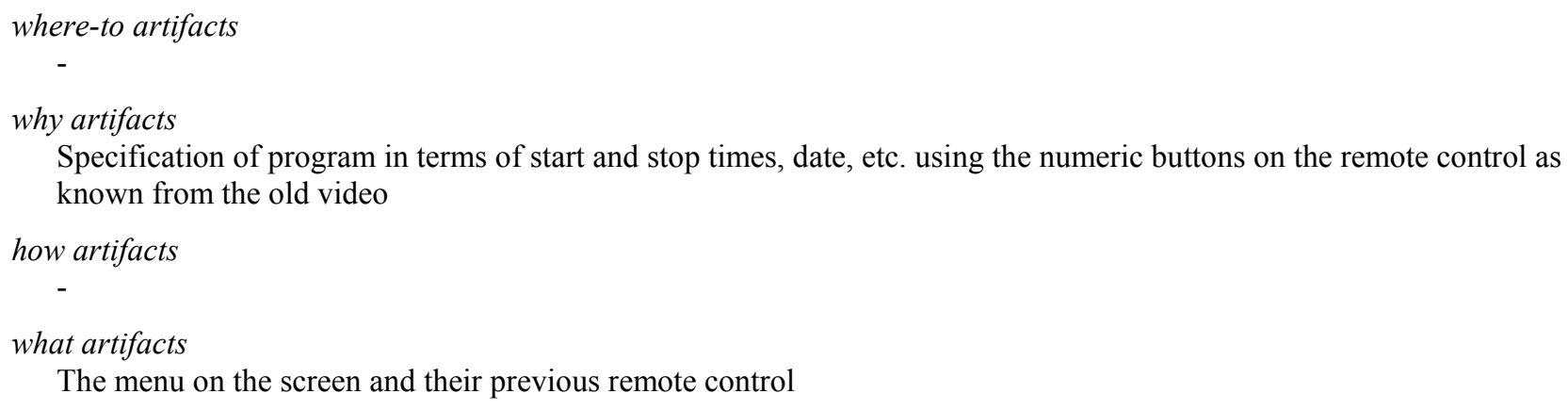

The menu on the screen and their previous remote control

Figure 10 Learning artifacts one month after delivery: conventional video programming

\subsection{Two and a half months after delivery: still programming the video in the conventional way}

After two and a half months Paul still uses the programming strategy he knows from their previous television. Again, he achieves the task but the way he is handling the situation illustrates that he is not very familiar with programming recordings. He focuses on the remote control and its relationship to what happens on the screen. Interestingly, at one point he accesses teletext to find the right start and stop times to specify in the conventional menu-based programming process, but not even the teletext display is sufficient to remind him of the presence of the teletext programming facility. As such, no change appears to have occurred since the previous visit in how the television acts in terms of learning artifacts.

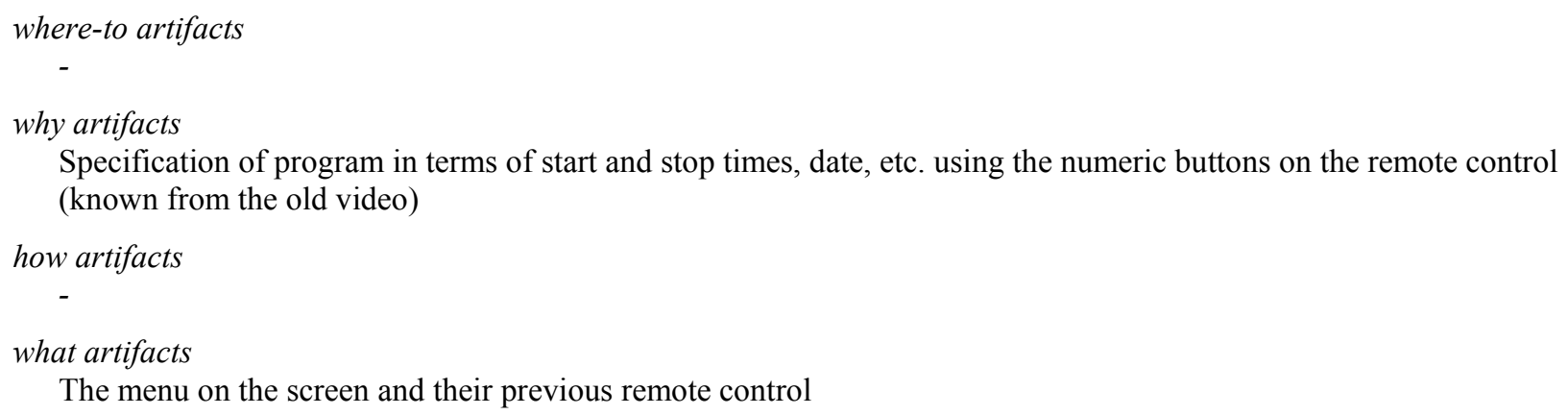

Figure 11 Learning artifacts two and a half months after delivery: still programming the video in the conventional way

\subsection{Six months after delivery: remembering the new facility but not using it}

At the final visit, Paul is still applying the conventional strategy of video programming. When asked whether he can think of a different way to program the video, he now mentions the teletext programming facility. He argues that since the other, more conventional strategy was mentioned first in the manual, this has been his preferred approach. Besides, he was familiar with this process from their previous video recorder. When we asked Paul to program a recording using the teletext programming facility, he has problems completing it and eventually gives up. Sarah, Paul's wife, explains that during the six months they have owned the television, they have used the programming facility approximately four times. They have typically used it when they have been going out, and there were problems with the recordings on every occasion, resulting in parts of the movie or show being cut. Ironically, Paul continues to argue that one of the advantages of teletext programming, apart from the fact that it is easier to use, is its automatic adjustment of recordings in the event of programs being delayed. This 
means that if he had used this programming strategy, the quality of the recordings would presumably have been better.

We see several possible explanations to this paradox. First of all, the design itself does not contain any reminders in terms of what artifacts that appeal to Paul and trigger his knowledge of this easier way of programming the video recorder (where to artifact). Apparently, the what artifact of the integration between the television and video is not specific nor strong enough in terms of reminding Paul of the availability of this possibility.

Secondly, the textual reminder in the menu bar (the how artifact, see figure 9) does not have any effect on Paul - partly because it is written in English and partly because it does not address the goal that Paul is seeking to achieve when this reminder is displayed. This means that the learning artifacts in play at the time of the installation of their television, which suggested the new possibilities offered by this system, are not sufficiently attractive for Paul to exploit this way of operating the new system. Moreover, teletext programming is generally somewhat concealed in the present design of the television.

Thirdly, when Paul is trying to program a recording, the challenge he faces involves not only learning a new way of doing this, but also handling the new remote control. Again, there is nothing in the general purpose remote control, nor in the menus on the television that comes into play in the form of how and what learning artifacts to follow up on Paul's initial expectations which were supported by where to and what artifacts.

Fourthly, the situations in which Paul has programmed the video to record have typically been a little stressful. In most cases, they have just dressed up to go out and then a few minutes before they leave they suddenly remember that there is a program they would like to record, and so Paul rushes into the living room to program the video. In such situations there is no incentive to experiment with new ways of accomplishing tasks, and the speed of operation becomes the critical factor. Thus the complexity of the learning artifact needs to be designed with respect to the characteristics of the use situation in which the learning artifact should come into play.

A final factor concerns Paul's need to deal with the programming of video recordings. As it is primarily Sarah who wishes to watch the movies afterwards, Paul has no direct incentive to spend time investigating how to make use of the new, improved programming facility. The lack of exploitation of the new facility even after six months of use and the problems Paul and Sarah have experienced are probably due to a combination of - and complex interplay between - the above-mentioned factors.

\section{PROGRAMMING VIDEO RECORDINGS - NEW OPPORTUNITIES}

The third series of episodes concerns the programming of video recordings as it unfolds in the case of the second family.

6.1 Installation: a new "division of labor" in the family

At the time of the installation, Karen explains that she is looking forward to being able to program the video on her own. Previously, this has always been her husband's "job". Her expectations stem primarily from the shop, where she was very impressed by the demonstration of the teletext programming facility. This demonstration acted as a where to artifact in allowing Karen to envision a new role for herself in the use of the television set within the family, see figure 12. 
where to artifacts

Demonstration of teletext programming facility in the shop allowing Karen to envision her own improved potential with the television -i.e. being able to program the video on her own.

why artifacts

$-$

how artifacts

Programming a recording by selecting a program directly from the teletext display

what artifacts

Figure 12 Learning artifacts at the time of installation: a new "division of labor" in the family

6.2 One month after the installation: successful programming of video but no need

Karen has not been in a situation where she needed to program a recording since the time of installation. However, she still remembers the presence of the facility and when asked to program a recording, she programs the video using teletext without any significant problems. She explains that she remembers the demonstration in the shop, which showed her that she needed to press the MENU button on the remote control twice (see fig. 4) to display access the "highlight programming bar", which is a precondition for being able to indicate a recording. This instruction becomes an ad hoc how artifact for Karen in that she remembers this instruction without being able to position it in a more general interaction principle, see figure 13.

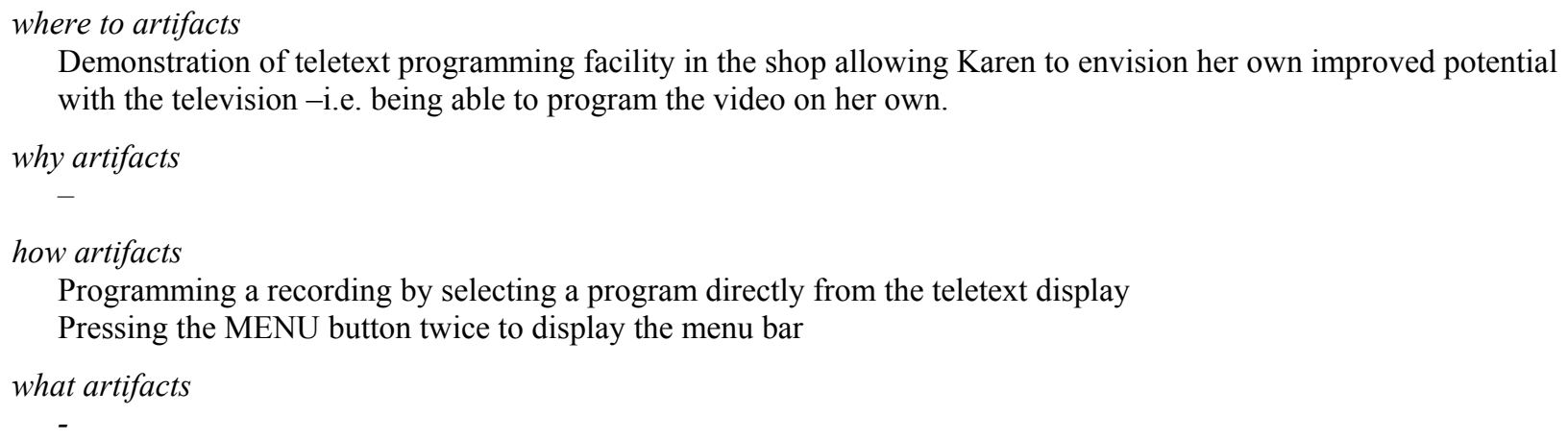

Figure 13 Learning artifacts one month after installation: successful programming of video but no need

\subsection{Two and a half months after delivery: fading opportunities}

Once again, we ask Karen to participate in a scenario that involves her programming a recording. Karen still remembers that she can use teletext to program the video, but she no longer recalls exactly how to accomplish this. In some way, the previous how artifact has faded and there is nothing in the design to remind her of how to do this, see figure 14. The only way to access the information required is to consult the manual. However, Karen never uses the manual on principle. She believes that "the technology should simply work". Finally, her husband guides her through the task, but even here, there is no recognition or consolidation of the approach she uses. 


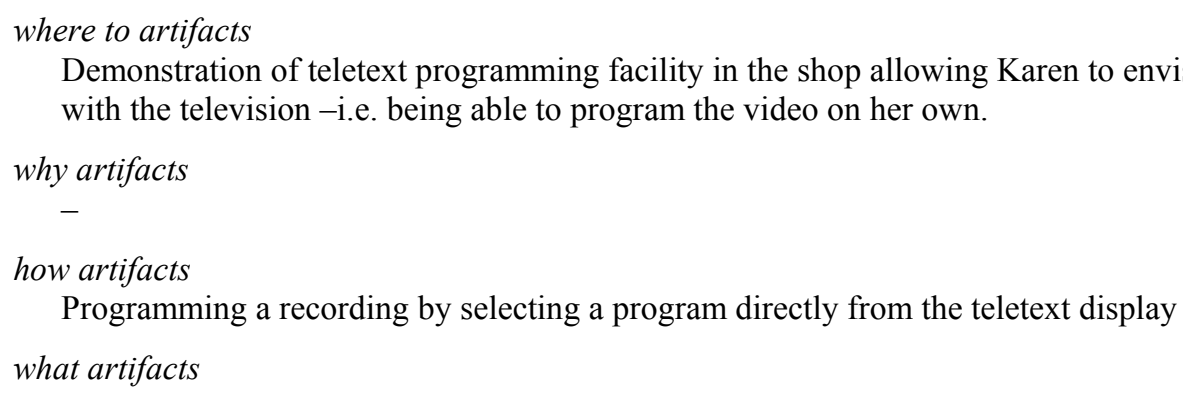

Figure 14 Learning artifacts two and a half months after installation: fading opportunities

\subsection{Four months after delivery: need for video programming but lost opportunity}

After four months of use, the time has come for either Karen or her husband John to record the Christmas series on show every day in December, which their children like to watch over and over again. Karen therefore makes recordings rather frequently during this period of time. However, as she still does not remember how to use the teletext programming facility, she ends up making direct recordings manually by pressing the "record" button when she remembers to. This results in her taping a lot of superfluous recordings between the daily shows.

Again we see a number of factors interacting in a complex manner and exacerbating the problems Karen experiences. Interestingly, Karen still remembers the presence of the facility, but again, she seem to experience problems with performing the actions involving the system. An interpretation in terms of learning artifacts could be that Karen is lacking a why artifact. As such artifacts are by nature more general than how artifacts, they may prove to be more robust and less prone to fading away as easily as in this situation. Moreover, when Karen was struggling to find the way to use the teletext display to program a recording, there was no visible reminder on the television itself to guide her through the process. As Karen does not use manuals on principle, she was stuck in this situation.

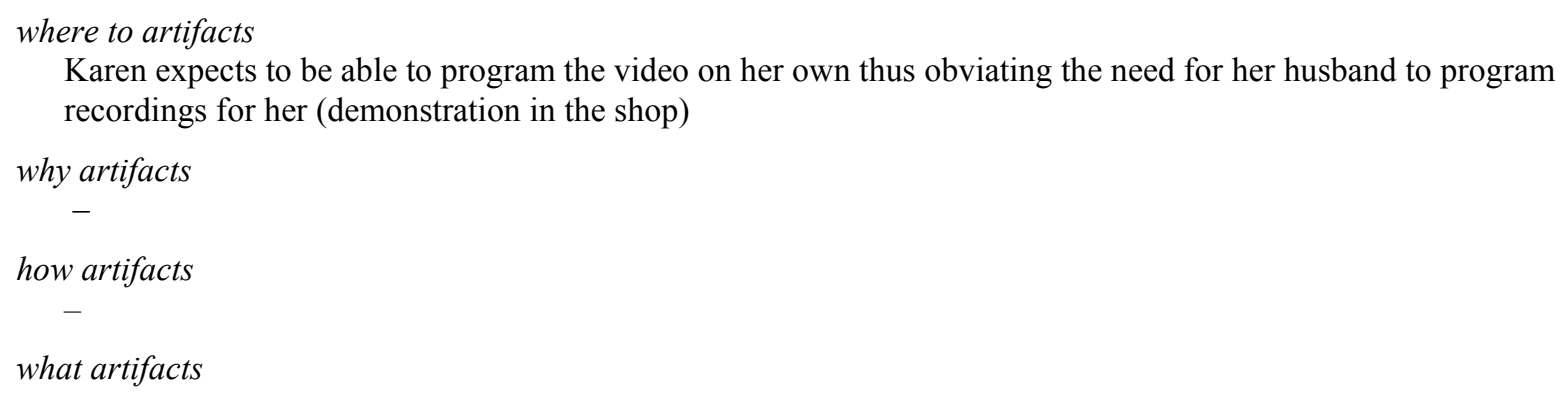

Figure 15 Learning artifacts four months after installation: need for video programming but lost opportunity

This example further highlights the need for designing with respect to the frequency of use of a facility. In the early stages of use, Karen did not use the video programming facility very often. However, after a period of use, when she suddenly had an incentive to program the video, she no longer remembered to "press MENU twice". Had this been an action she had performed daily, she probably would not have forgotten it despite the fact that it lacked a relation to the purpose of her action or to any why or where to artifacts active in this situation. 


\section{CONSISTENCY CREATING CONFUSION}

During the second visit to John and Karen, John states that something about the way the teletext programming works confuses him. From the demonstration in the shop, he expects feedback in the form of programmed start and stop times for the recording once the programming has been completed, but this feedback never appears. The problem here is that John confuses two items in a menu with one another (TIMER RECORD and TIMER PLAY, see figure 1).

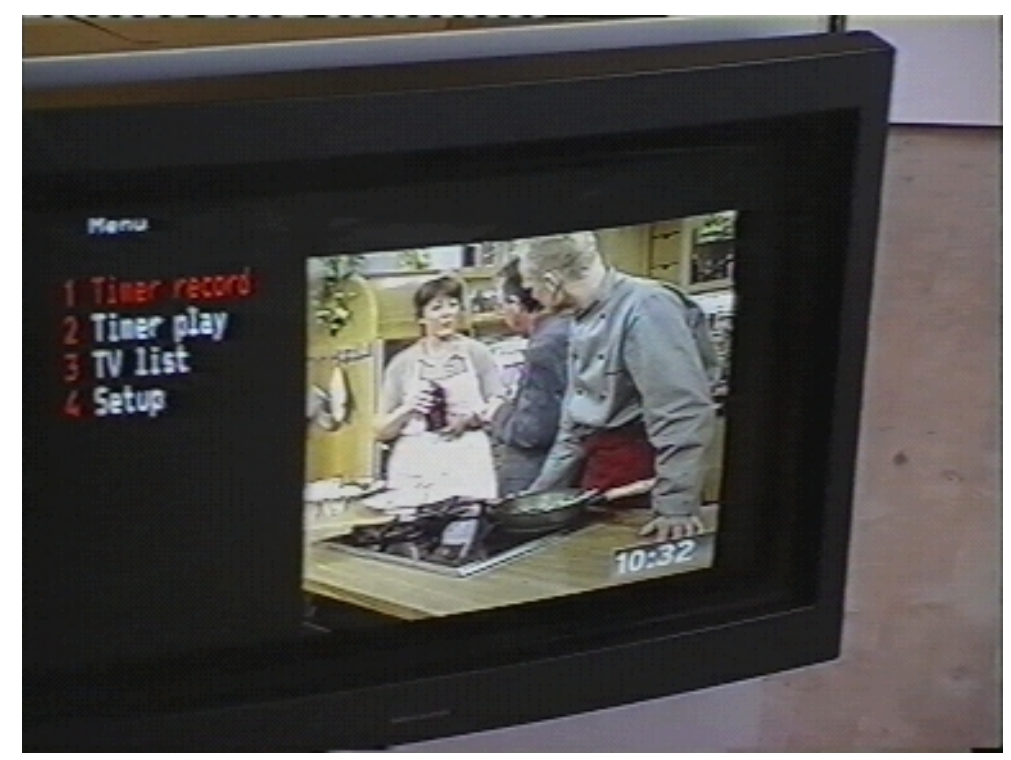

Figure 16 The main menu of the Bang \& Olufsen integrated television and video

On our fourth visit, we return to the discussion of TIMER PLAY and TIMER RECORD, this time revealing the difference to John. John explains that he has vague memories of reading about the option of programming the television to turn itself on and off at specific times in the manual around the time when they purchased the television. However, he never pursued this theme. No aspect of the television reminded them of its presence since the term TIMER PLAY never worked as a learning artifact for them.

\section{THE NATURE OF LEARNING ARTIFACTS}

Before discussing the implications of experiences from our case study for the design of domestic technology, we would like to point out the limitations of our study. The generality of experiences from this case study should be seen in light of the specific domain of home appliances and the limited number of families visited, and of episodes discussed above. The following conclusions and discussions should therefore be seen as hypotheses for what may constitute important factors in creating designs for development in use.

8.1 Where to artifacts as guides for development in use

In our empirical study, we saw several examples of how the design, when it came into play as a where to artifact, served as a guide and triggered the users' exploration of the television. In the story about the cinema experience, we saw how the concept of the cinema experience - as it was formed in the shop and triggered by the form of the physical design of the television - guided Sarah's exploration of the Bang \& Olufsen television. During her two and a half months of efforts to access the cinema experience, she repeatedly termed it her point of reference in her exploration of the television. Our study therefore suggests that with carefully designed where to artifacts, use does not need to "start out with bloomin', 
buzzin' confusion" [Carroll and Mack 1995, p. 699]. Instead these where to artifacts may sow seeds which users may subsequently develop on the basis of their needs and wishes.

In the stories about how the facility of programming the video came into play in the two families, we see that, depending on the background, adoption process and life-situation of the users, the same design worked in quite different ways as a where to artifact in terms of motivation and visions of future use. Whereas Paul was fascinated by technology that offered greater ease of operation and improved recording quality via teletext programming of the video, Karen, when presented with the same facility, envisioned a new role for herself in operating the technology. She imagined that she would now be able to program the video herself, independently of her husband, who had previously done all the programming.

These two cases also differ with regard to use over time. To start with, Karen actually managed to use the new facility, but for reasons which we will discuss below, this ability faded with the passing of time. Paul, on the other hand, spoke excitedly about the facility in the beginning, but never actually managed to make use of this facility during the six months of the survey. In these cases, the design of the system in terms of the integration of the television and video recorder into one system, and the radical new way of programming the video worked well as a where to artifact. The subsequent disappearance of the awareness of and the ability to use the opportunity seems to stem from other factors as discussed below.

This case study thus makes clear how positioning where to artifacts in context allows us to consider expectations of more emotional and visionary character than is conventionally considered in cognitively inspired usability evaluations. These are typically more concerned with how the design of the technology actually supports the goals of the users (the action level cf. figure 1) [Kaptelinin 1996]. Furthermore, as argued by Engeström [1990], the long-term projection into the future offered by the perspective of where-to artifacts is not normally considered part of system design. In this study we point out how the long-term development of use is also an important matter for understanding the usability of a product.

Interestingly, our study suggests that where-to artifacts may be a powerful resource in creating designs for development in use in that it helps users identify their motivation for using an appliance, and it may thus encourage people to explore the capabilities of a product in specific directions. We believe that by analyzing and designing in terms of where to artifacts, we may answer some of the criticism presented Blyth [1999] and others. Blyth [ibid] argues that "designers tend to think about consumers in a rather narrow way. They are strongly inclined to see consumers as economic entities with clearly definable needs. Instead, in the words of the sociologist Bourdieu, designers ought to think of themselves as 'cultural intermediaries' - playing an active role in attaching to products particular meanings and lifestyles with which consumers will identify" [ibid, p. 44]. As we have seen, people begin using appliances in different ways, depending on how they identify and see themselves in the visions stimulated by the product. For instance, Karen saw an opportunity for herself in her perceived ability to program the video on her own, whereas Sarah, with her background and experience with technology, did not see a role for herself in this respect. Thus we find that the actual use of the technology occurs via a complex interplay between the design of the technology, the users' background, previous experience, their needs and goals, etc. In line with Engeström [1990], we do not believe that the final goal should be to design for predicted ways of using and adopting the technology, nor do we hope that this will be the case. However, we find that the design of where to artifacts helps users to identify directions of use along which they wish to set out, or in Blyth's words "with which they identify". Users will then inevitably find their own paths in accordance with their own needs, situation and background. 
Nevertheless, this is not the whole story. Our case study reveals that users still have problems in achieving their expectations in spite of successful where to artifacts. The framework of activity theory provides a basis for discussing why this happens, in that it provides a perspective which relates the discussion on where to artifacts with regard to more detailed aspects of the interactive design and physical design of the technology through the why, how and what artifacts. This is discussed in the following section.

\subsection{Why artifacts provide robustness and consolidation of the interaction}

Our study points to the fact that on the one hand, why artifacts support the robustness and consolidation of the interaction. In the example of the cinema experience, we saw how Sarah was struggling to establish an understanding of the general interaction principles of the product - the highly modal design of the remote control, for example - and how she made some discoveries during our interview with her husband. Thus in her case, it was not the design itself that revealed to her the principles she required. In the cases of video programming, we see a striking absence of why artifacts. In Karen's situation, her ability to program the video diminishes, and after two and a half months she is unable to use the teletext display to program the video despite her need to do so. Our analysis suggests that part of the explanation of this is that the previous how artifact "press MENU twice" has faded away in her use of the TV, and there is no general principle in the form of why artifacts nor any other immediate clues in terms of what or how artifacts to support her in re-constructing this artifact. In contrast to this situation, when Sarah was asked to discuss how she would connect surround sound in the case of the television (even though she primarily used this feature with the CD player) she was able to infer from the general why artifact "press the number button for the number of loudspeakers required" that she needed to press number button 5 to connecting surround sound for the television (where the TV loudspeaker was included). This contrasts with pressing number button 4 in the case of the CD player. Similarly, when Sarah had identified the general principle of the modality of the remote control, and had established that the current mode was always indicated in the display on the remote control, she was able correct her own behavior. This happened in a situation where Sarah wanted to connect the loudspeakers and her first attempt was unsuccessful. She tried once more, looking at the display to ensure that she had accessed the correct mode - and this time she succeeded.

These studies thus suggest that why artifacts in the form of general interaction principles - or, in Paul's words: "the logic behind" - strengthens and consolidates the users' way of operating the technology. However, creating designs for these artifacts represents something of a challenge. Consistency in design could be one approach, although, with our interest in the development in use, we need to understand how people actually identify these consistencies in order to understand how we can use design to support this process. Our study revealed the fact that those who referred extensively to the manual often identified why artifacts in this way. As an example, Paul identified the principle of "press the number button for the number of loudspeakers required" in this way. A second approach to designing why artifacts involves making the visual layout of the screens in sub-menus consistent. However, in some cases this resulted in the users erroneously perceiving themselves as doing one thing while they were really doing something very different. This happened in the final series of episodes reported, when John programmed the television to turn on and off at specific times, while he actually thought that he was programming the video to record during a certain period.

8.3 How artifacts providing ad hoc guidance

Viewing the mediation of the Bang \& Olufsen television in terms of how artifacts, we find that the names of the menus - which could potentially act as how artifacts - often fails to come into play as such. One example of this is John's confusion between TIMER RECORD, which allows users to program the 
video to record at specific time intervals, and TIMER PLAY which provides a facility for programming the television to start and stop at certain times. We saw other examples where designed how artifacts, e.g. small help prompts, were overlooked or not perceived as meaningful in the situations for which they were intended. This happened in the case of Paul who continued to program the video in the conventional way, even though a message appeared on the screen reminding him of the opportunity to program the video using teletext (See figure 9).

\subsection{What artifacts materializing learning artifacts}

The role of a television in terms of what artifacts is the story of how the television restricts the interaction, and how it physically meets the user. Our experiences suggest the importance of learning artifacts to be materialized as what artifacts. In the case of the cinema experience, the where to artifact presented in the sales situation was elegantly referenced in the what artifact - through the electronic curtains which acted as a daily reminder of the vision of the cinema experience to be pursued by the user, see figure 2. However, we also found examples where missing what artifacts may play a role in eliminating intentions. For instance, when, during our second visit, we talked to Paul about the feature of programming the video using teletext to which he and Sarah had referred at the time the new television was installed, it turned out that at that time he did not recall the existence of this option. In terms of artifacts, this possibility was referred to only vaguely as a what artifact through the physical integration of the television and the video into one product. However, this abstract representation and expectation of "easier programming of the video" was possibly too abstract to act as a trigger for the option of programming the video using teletext. Thus our study suggests that when learning artifacts are placed in context and materialized specifically as what artifacts, which can act as a visible reminder, they become points of reference in the process of development of use.

\section{IMPLICATIONS FOR DESIGN}

\subsection{The design of learning artifacts at all levels}

When establishing the four kinds of artifacts - where to, why, how and what artifacts - Engeström [1990] argues that the context of artifacts should be positioned both upwards and downwards in such a way that they are represented in all four forms. In adopting these artifacts as learning artifacts for analyzing how development in use is supported by the design of technology, our experiences suggest that a similar recommendation seems appropriate in this area. From analyzing our study we can see why Sarah has problems accomplishing the task of turning on the loudspeakers in the surround sound system to establish a surround sound experience, since she lacks some learning artifacts on the intermediary why and how levels. Only when we created a somewhat artificial situation, where we ask her husband to explain how he does the same task did Sarah discover an essential why artifact which later enables her to successfully reach her goal. Our analysis suggest that this, in some respects simple interaction principle of pressing a number for the number of loudspeakers required, is not intuitive to Sarah. The design itself does not help Sarah to understand it, and Paul, her husband, only knows it because he read about it in the manual.

A further example of this is revealed in Karen programming her video via teletext. To start with, she has no problems with this process, but as time passes the how artifact "press MENU twice" - which enabled her to accomplish the task - diminishes, and as nothing in the television itself (a what artifact) nor any general design principles, (a why artifact) are active for Karen in her use, there is no firm foundation for her ability to exploit the new facility and we see it fading away over time.

As we see it, the challenge is thus to design learning artifacts at all levels and preferably as close to the product and the sales situation as possible. In the cases of Sarah and Karen, we never saw any evidence that they consulted the manual and used this as a learning artifact. 
In addition, our study provides some indication that the interplay and contradictions between the different levels of artifacts may contain openings for design or for re-design. Ideally, coherence between the artifacts at the different levels would support the users in embodying learning artifacts at all levels. In episode 1 we saw that there was no way in which Sarah could establish a reference between the cinema experience and the LIST button on the remote control in the form of why or how artifacts. Thus in Engeström's terms [1990] positioning artifacts in context at different levels seems to be an important design goal when designing for learning by use. The predominance of the cinema experience as expressed by Sarah suggests that in our case a more task or experience-oriented design of the remote control, i.e. representing why and how artifacts in these terms, could be an interesting path to explore. To express it differently: conflicts between the different levels as identified through evaluations of the design constitute openings for design modifications.

Another example was revealed in episode 4, where John misunderstands the differences between programming TIMER PLAY and TIMER RECORD. This may be explained by the use of a foreign language, but there may be another explanation. On the one hand, the interaction is designed in a way that allows the user to program a video recording and to program a start time for the television in the same way. There is consistency in the design of the interaction, in that the same principle is used in the two situations. However, we also see that John may need some kind of reference to tell him that he has accessed the wrong mode or part of the menu. He needs some indication of the difference. Actually, he does remark that something is different, but this difference is not strong enough to make him to investigate whether something is wrong or not. In relation to our discussion, the problem may be that he needs a stronger what artifact indicating the difference between these two functions. The point in relation to design is that consistency in the design of how and why artifacts is appropriate, but there should also be references marking the differences at the what level.

\subsection{The transformation of artifacts}

In the cases described above, we see how learning artifacts are not static but develop, become modified and fade away over time due to factors both inside and outside the design.

In the example of Karen, when her how artifact "Press MENU twice" was removed from its context, it faded away as it was hard to relate to any of the other learning artifacts of this situation. Furthermore, since she had no need for this facility to start with, she used it very rarely. Paul's initial vision of the easier way of programming video recordings also faded away over time, probably because of a combination of limited need and limited reminders, in terms of what artifacts, of the presence of the facility. In the cinema experience example, Sarah continuously refines her how artifact through her exploration of the television. She starts out with a vague idea that in order to connect multiple loudspeakers to obtain surround sound, she needs to do something with the LIST button. Through her exploration of the television, and through overhearing our interview with her husband, she laboriously refines this into the idea that she needs to press LIST a couple of times.

As argued previously, our goal is not to prescribe use nor development in use through design. In our study we saw examples of how use, although being triggered by the visions expressed in the design and the sales situation, actually ended up as something totally different once the vision was realized and adopted into the context of the specific users and their needs and in the specific settings of use.

We saw an example of this in the case of Sarah's initial expectations of the cinema experience finally transforming into a concert experience. It is important to note that the transformation of the cinema experience into a concert experience in this situation was made possible only by the flexibility of the interlinked technology of their home, i.e. the surround sound equipment that could be used with both the 
television and the CD player. As pointed out by O'Brien and colleagues [1999], flexibility of technology is an important design criterion for domestic technology. This case confirms this finding and also suggests that in the interest of supporting the learnability of domestic technology, it is important that the design of the technology offer itself to the user - in the form of visions of future use - as where to artifacts, which users may react upon, identify with, discard, or pursue and mold according to their specific situations, interests and needs.

\subsection{The context of learning in use}

In addition, our case study points to the importance of considering the context of learning in use. It is not enough to be motivated to learn: users have to be in a situation where the conditions support its occurrence. As an example, we heard about Sarah, who learned how to access the surround sound feature by using the CD player. Sarah states that she uses the manual if there is something she needs to find out, but when visiting the family we have not seen her use it nor have we heard her talk about using it in specific situations. What we found was that she was driven by her motivation to hear music. Having learned a principle of interaction from her husband, she used this general principle one afternoon to find out how to obtain surround sound from the CD player. Sarah was in a situation where she had the time to experiment and explore the technology on her own.

In the case of Paul programming the video recorder, he still used the "old procedure", and although he is aware of the teletext programming option, he does not use it. His wife explains that he typically has to program the video when he is in a hurry, on the point of leaving the house to visit friends, for example. Paul's strategy for learning new ways of using the television typically involves reading the manual. He reads the manual and follows the processes described. Naturally, he does not have the time to do this when he is about to leave the house, but why does he not learn it some other time? An explanation could be that he is not motivated. Part of the explanation is that it is Sarah who wishes to see the program being recorded, but she does not set out to record it herself. Her unwillingness to do this outweighs the fact that the recordings have been incomplete all four times Paul has programmed the recorder on the new television.

In another case, which we have not reported in this article, John describes a situation where he comes home from work and one of this children shows him a teletext feature that allows users to recall predefined teletext pages. He investigates how he can program the system to open on predefined pages. He sits in the sofa, reads in the manual and finds out how to do it. He takes the time he needs.

One point of this discussion may be that learning by use is more likely to occur if it is driven by motivation (an active where to artifact). Another could be that learning by use is not always possible. If users are under pressure of any kind, they will handle the situation in a way they think they know. This is particularly the case if the preferred learning strategy is reading the manual, as in this case users have to arrange a situation for detached learning.

The implications of these aspects for design is that designers should reflect upon which learning strategies different designs support as well as the connection to the potential situation of use.

9.5 Learning artifacts both in and around the product

In conclusion, our study suggests that, at least in the case of home appliances, there is potential for designing learning artifacts both in and around the product itself. Our study points to how the process of development in use starts even before users start utilizing the product itself, provided that the resources for design outside the artifact per se are exploited as they are in the case of the Bang \& Olufsen television we studied. We have seen how, at the time the product was installed, the users already had some specific expectations of the things they wanted to do with their new Bang \& Olufsen system. Sarah looked forward to the cinema experience, Karen envisioned being able to program the video 
independently of her husband, and Paul was looking forward to exploiting the easier way of programming the video and to watching movies in wide screen format with surround sound. These expectations were largely due to the learning artifacts in terms of the where to artifacts introduced in the sales situation through the language used and experiences provided, to which the sales brochures also referred. Furthermore, the manual played a role in supporting two of the four users in achieving the experiences they chose to pursue.

Thus in creating designs for appliances which users buy themselves, there is potential in designing learning artifacts which come into play even before the users lay their hands on the product, through considering the presentation and demonstration in the shop, through the design of sales brochures, and through the design of manuals. When well designed, the learning artifacts are followed up and referenced by the design of the technology itself, creating coherence which provide the users with an image of the experiences available through the new technology, and allows users to pursue their own paths of development in the use of domestic technology.

\section{CONCLUSION}

In the particular setting studied we have documented how a technological artifact like a TV set is appropriated and how the use of technology involves a process of evolution. We have highlighted how learning artifacts guide development in use and how artifacts may consolidate use of technologies in different ways. Moreover, we have demonstrated how activity theory may be productive in terms of formulating a set of design recommendations including the notion of designing different kinds of learning artifacts as part of designing a technology. These artifacts need to be coherent and designed with respect to the context and we need to be aware of the resources outside of the product itself when designing for development in use.

In work-contexts of technology use it is generally acknowledged that use changes, though often only slowly, and it seems obvious to conducts similar studies like the one we have conducted in workplace settings in order to find better ways of supporting development in use. Many of the characteristics of home IT, for instance being shared and being integrated parts of physical devises with unique kinds of interfaces, is becoming important characteristics of IT at workplaces, in particular when we move outside of the office environment. Given for instance the privacy issue of the home, the specific methodological approach will most likely be different in a work place context but many of the issues concerning development in use will be similar.

When it comes to products for the mass consumer market, like interactive TV and Internet appliances, it is particular important to consider the motivational factors as reflected by 'where to' artifacts, not in isolation, but in conjunction with way people may interact with the technology, including the physical form of the product. The concept of motivation refers in this context to the reason to buy a product in terms of the user need it fulfils. Our study suggests that one product fulfils several and different needs and that motivations are created and modified through extended use beyond the messages communicated through marketing and sale. This nature of motivation and product identity seems to be new to some strands of marketing. The implications of this are worth studying in the future.

New usability issues are emerging for the design of a vast range of novel technologies - e.g. handheld devices, technologies with embedded software, mechatronic products (i.e. integral mechanical and electronic products) and game machines - which all challenges how to support development in use. We suggest an awareness of the physical characteristics, the interaction principles and the motivational factors of these new technologies, as illuminated by the categories of learning artifacts presented in this article, as the way to move usability from design for snapshots of use to design for development in use. 


\section{ACKNOWLEDGEMENTS}

The work presented here is sponsored by CIT/CMT through grant no. 23 and in part by The Danish Research Councils grant no 9600869 (The Staging of Virtual 3D Spaces). We wish to thank Bang \& Olufsen for their support and interest in the study and Susanne Bødker, Ellen Christiansen and the anonymous reviewers for their comments on the paper and finally, we thank in particular the families who contributed with their time and engagement.

\section{REFERENCES}

BANNON, L., AND BØDKER, S. 1991. Encountering Artifacts in Use. In Designing Interaction, Psychology at the Human-Computer Interface, J. M. CARROLL, Ed. Cambridge University Press, 227253.

BARDRAM, J. E. AND PEDERSEN, M. B. 1994. Fra Interface til Interaktion [From Interface to Interaction] Masters thesis, University of Aarhus.

BARDRAM, J. E., AND BERTELSEN, O.W. 1995. Supporting the Development of Transparent Interaction. In Human-Computer Interaction. 5th International Conference, EWHCI '95 Moscow, Russia, July 1995, B. BLUMENTHAL, J. GORNOSTAEV AND C. UNGER, Eds. Selected Papers. Berlin: Springer Verlag (LNCS 1015), 79-90.

BARDRAM, J. E. 1997. Plans as situated action: An activity theory approach to workflow systems. In The Proceedings of the Fifth European Conference on Computer Supported Cooperative Work, J. A. HUGHES, W. PRINZ, T. RODDEN, AND K. SCHMIDT, Eds. Kluwer Academic Publishers, 17-32.

BERTELSEN, O. W. 1998. Elements of a Theory of Design Artifacts: a Contribution to Critical Systems Development Research. Ph.D. Thesis, Aarhus University. DAIMI PB-531.

BEYER, H., AND HOLTZBLATT, K. 1998. Contextual Design, Defining Customer-Centered Systems. San Francisco: Morgan Kaufmann Publishers.

BLYTH, M. 1999. Our Own Devices. Interactions 6, 43 - 45.

BØDKER, S. 1991. Through the Interface - a Human Activity Approach to User Interface Design. Hillsdale, NJ: Lawrence Erlbaum Associates.

BØDKER, S., AND GRØNBÆK, K. 1991. Design in Action: From Prototyping by Demonstrations to Cooperative Prototyping. In Design at Work:Cooperative Design of Computer Systems, J.

GREENBAUM AND M. KYNG, Eds. Hillsdale, N.J.: Lawrence Erlbaum Associates, 197-219.

BØDKER, S., AND PETERSEN, M. G. 2000. Designing for learning in use. Scandinavian Journal of Information Systems 12, 61-81.

CARROLL, J. M., AND MACK, R. L. 1995. Learning to Use a Word Processor: By Doing, by Thinking and by Knowing. In Readings in Human-Computer Interaction: Toward the Year 2000, R. M. Baecker, J. Grudin, W. A. S. Buxton, AND S. Greenberg, Eds. Morgan Kaufmann Pbl, 698-717.

DRAPER, S. W., AND BARTON, S. B. 1993. Learning by Exploration, and Affordance Bugs. In Proceedings of ACM INTERCHI'93 Conference on Human Factors in Computing Systems Short Papers Talks: A Kaleidoscope of HCI, ACM Press, 75-76.

ENGESTRÖM, Y. 1987. Learning by Expanding. Helsinki: Orienta-Konsultit.

ENGESTROM, Y. 1990. When is a Tool? Multiple Meanings of Artifacts in Human Activity. In Learning, Working and Imagining, Helsinki: Orienta-Konsultit, 171-195. 
GIBSON, J. J. 1986. The Ecological Approach to Visual Perception. Lawrence Erlbaum, Hillsdale.

GREENBAUM, J. AND KYNG, M., Eds.1991. Design at Work:Cooperative Design of Computer Systems. Hillsdale, N.J.: Lawrence Erlbaum Associates.

HAMMOND, S. A. 1996. The Thin Book of Appreciative Inquiry, Kodiak Consulting, Plano, Texas.

KAPTELININ, V. 1996. Acticity Theory: Implications for Human Computer Interaction. In Context and Conciuousness, B. NARDI, Ed. MIT Press, 45-68.

KJÆR, A., MADSEN, K. H. AND PETERSEN, M. G. 2000. Methodological challenges in the study of technology use at home. In Home Informatics and Telematics: Information, Technology and Society, A. SLOANE AND F. VAN RIJN, Eds. Boston: Klüwer Academic Publishers, 45-60.

KYNG, M. AND MATHIASSEN, L. Eds 1997. Computers in Context. Cambridge MIT Press.

MACKAY, W. E. 1995. Ethics, Lies and Video. In Proceedings of the CHI 95 human factors in computing systems, ACM Press, 253-254.

NARDI, B., Ed 1996. Context and Conciousness. MIT Press.

NORMAN, D. A. 1988 The Psychology of Everyday Things. Basic Books, Inc., Publishers New York.

O'BRIEN, J., RODDEN, T., ROUNCEFIELD, M., AND HUGHES, J. 1999. At Home with the Technology: An Ethnographic Study of a Set-TopBox Trial. In ACM Transactions on Computer-Human Interaction 6(3), 282-308.

O’BRIEN, J., AND RODDEN, T. 1997. Interactive Systems in Domestic Environments. In Designing Interactive Systems, DIS '97. Amsterdam, The Netherlands, ACM Press, 247-259.

RIEMAN, J. 1996. A Field Study of Exploratory Learning Strategies In ACM Transactions on Computer-Human Interaction 3(3), 189-218.

RIJN, F. VAN AND R. WILLIAMS Eds. 1988. Concerning Home Telematics. Amsterdam: NorthHolland.

WARTOFSKY, M. W. 1979. Perception, representation and the forms of action: Towards an historical epistomology. In Models, Dordrecht: D. Reidel Publishing Company, 1979. 188-210.

WIEDENBECK, S. 1999. Empirical studies of human interfaces - The use of icons and labels in an end user application program: An empirical study of learning and retention. In Behaviour and Information Technology 18(2), 68-82. 


\title{
METHODOLOGICAL CHALLENGES IN THE STUDY OF TECHNOLOGY USE AT HOME
}

\author{
Arne Kjaer \\ Information and Media Science \\ Aarhus University \\ Niels Julesgade 84 \\ DK-8200 Aarhus N \\ akjaer@imv.au.dk
}

\author{
Kim Halskov Madsen \\ Information and Media Science \\ Aarhus University \\ Aabogade 34 \\ DK-8200 Aarhus N \\ halskov@imv.au.dk
}

\author{
Marianne Graves Petersen \\ Computer Science Dep. \\ Aarhus University \\ Aabogade 34 \\ DK-8200 Aarhus N \\ mgraves@daimi.au.dk
}

\begin{abstract}
Based on the planning and conduction of a longitudinal field study of the use of television sets in the homes of two families, we discuss how approaches like field studies, which are otherwise well established when designing for work practices, become questionable when transferred to a home setting where the issue of privacy is prevalent. The fairly sporadic operation of a TV set poses additional methodological challenges. Furthermore, we point out how our general concern of designing for development in use becomes even more relevant with the introduction of interactive technology in the home sphere. We report on our experiences from using different approaches for studying how use develops in the home. The approaches applied include: hands-on in context, incident diaries, scenarios, iterative and explorative investigation, and role playing.
\end{abstract}

Keywords: Home IT, television set, field study, qualitative methods, development in use.

\section{NEW CHALLENGES}

There is a growing concern within the area of Human Computer Interaction (HCI) that the spreading of interactive technology into all aspects of everyday life, including private homes, offers new challenges for the design of home IT $[15,19]$. When designing interactive technology for workplaces, field studies are among the prevailing approaches for establishing an understanding of the practice and context in which the future design will exist, and furthermore for identifying requirements for the technology being developed [2,9]. However, when conducting field studies of the use of information technology in a private home setting, issues such as privacy and sporadic use call for a revision of the way this field is approached. In this article we address some of the methodological challenges of conducting field work and studying how use evolves in a home setting. We are particularly interested in how use develops and how this is supported by design, an issue which is underdeveloped within the area of HCI [6]. This issue becomes even more important when designing home IT since, unlike at the workplace, there is most often no formal training involved in getting to know the technology at home. This means the user relies even more on the design itself to get started using the product as well as to take advantage of more advanced features over time. Moreover, the sporadic use of technologydepending not only on the situation of the family, but also on the season and the weather-and the particular kind of social situation in which the technology is used, offers additional methodological challenges.

Our discussion of the methodological challenges in the domain of home IT is based on a longitudinal study of two families' use of a new television set. The product we have studied is an integrated television and video recorder from Bang \& Olufsen, which may be regarded as representing the trend of increasing integration between different products. The two families each consist of four members: husband, wife, and two children. In one family the parents are middle aged with two grown-up children, in the other the parents are younger with two small children. While one of the families has previously owned Bang \& Olufsen products and is thus familiar with the company line, the other family is a new customer in the Bang \& Olufsen shop. We first visited the families in their homes 
when their new televisions were delivered. Subsequently, we visited them three times, at intervals of approximately one month. On each visit we interviewed the family members and provided scenarios [7] to frame some hands-on use sessions with the television. We will describe the methods used and the rationale behind our choice in greater depth in the main body of the article. We discuss some general challenges when conducting field studies in private homes with a particular focus on sporadic use and with an interest in understanding the nature of use as it evolves over time.

While others have studied technology in homes, they have most often been driven by different motives than that of designing some specific new technology. For instance, at the early home IT conference, concerning home telematics [21], most of the papers deal with the social implications of the introduction of various technology in the household. Although social implications form part of the considerations in designing new technology, we agree with O'Brien et al. [19] that what we need when designing new technology is more detailed insight than what is obtained from surveys. In order to form a platform for design improvements we need to understand the motives behind the specific instances of technology use, and we need to gain insight at the level of the actual interaction with the technology. Moreover, it is generally acknowledged from the use of technology at workplaces that there may be great discrepancies between how people talk about their use of technology and how they actually use the technology. Therefore, rather than using a quantitative approach involving a large number of users and using, for instance, a questionnaire, we argue for the need for a detailed qualitative study.

Ultimately, our research interest is the design of technology and how this design may support the user in developing his or her use. But before getting there, we must strive for a detailed understanding of technology use at the expense of a general and context-independent knowledge about technology use. Since we wish to investigate development in use as it happens in a real-life context, we need to extend the study over a longer period of time.

\section{METHODOLOGICAL CHALLENGES IN THE HOME}

Studying technology use in the home poses some special challenges as compared to our wellestablished practice doing this at the workplace. In the following, we discuss in particular how our relationships with users change once we enter their homes, and how we need to revise some of our methods. Secondly, we address the challenge of capturing sporadic use, which is prevalent in the case of users watching television.

\section{The relationships with users in their homes}

When studying use of home IT, establishing contact with the users is more difficult or at least different from other IT use contexts. In establishing the initial contact with users at a workplace, we normally make an arrangement with the management. However, in this situation, no manager is in charge of the users. Secondly, constructing as well as capturing collaborative sessions with the users in context is different in homes as opposed to the workplace.

In our study we established the first contact with our families through the shop in which the users bought their television sets. We did consider lending out television sets to some friends and studying their use of them. In the project we are collaborating with Bang \& Olufsen, which produces the equipment and lent us the products we studied. It would thus have been an easy option to lend out these televisions. We abandoned this idea, however, because our acquaintances would know too much about the aim of the investigation, and we could imagine how they would purposefully set out to examine the different functionalities. Besides, we wished to study development in use, and for this purpose the motivation behind buying the product influences how people start using the product, and since we wished to study this process we were careful not to set up artificial situations in this respect. In the study we contacted the customers after they had decided to buy their new television set but before it got delivered. 
Choosing to visit users who from the start had no interest or any direct incentive in participating in our study and receiving visits from us in their precious spare time in their private homes placed limitations on how much of their time we could take up. We restricted our study to four visits, each lasting oneand-a-half hours in the evening, because they were busy at work during the day. This approach is in line with other studies, e.g. O'brien et al. [19], who conducted three evening visits in families' homes "adopting a pragmatic as opposed to ethnomethodologically purist stance" [19, p.252]. This is however in contrast to what we have done in workplace situations, where workshops with users have often taken up a full working day, sometimes even more.

Furthermore, at work it is the manager who in the end decides what technology is to be used and whether employees should participate in a research project. Our families have had the possibility not to participate-when first asked, but also after each of our visits, they were offered the option of interrupting ther participation. We found that the limited number of visits as well as the fact that the users volunteered their time in this case resulted in careful participation by the users throughout the course of the study.

Once the initial contact with the users was established the study could start. In respect to the recording of these activities, we find that extra caution must be taken in the home as compared to the workplace. An example is the recording of video in private homes. Videotaping people is generally considered to be a very productive way of acquiring knowledge about work practice and use of technology [23], but it is also a rather sensitive issue. Mackay [18] has explained some of the general precautions that need to be taken when recording and subsequently using video to analyze users' interaction with technology so that misuse of the video material is avoided. The use of a camera is intrusive in the workplace and even more so in people's private homes. Thus, when entering the home we must carefully consider the extent to which we can use videotaping. Moreover, there are practical and aesthetic problems posed by situating a camera in homes. Whereas video recording equipment would often be an acceptable addition to a workplace, such technology could certainly ruin the interior of a living room. Wishing to respect the private sphere we were entering, we ended up videotaping only the hands-on situations of the users. The interviews were not videotaped. We told the users beforehand how we would use the tapes and we received their permission.

Afterwards, when analyzing the development in use, the video tapes have been of great support in giving us the possibility to review what actually happened in specific situations. On the other hand, our experience was that even our presence in the homes was from the outset an awkward situation that required a great deal of caution from our side in regard to how to behave. This situation was different from corresponding situations at workplaces, which after all are far more public spaces than what we meet in homes. Recording with the camera in the homes only made this situation come to a head. Thus, in homes we face the trade-off between obtaining a comprehensive record and respecting the privacy of the home setting. In homes we need to be even more careful with recording video. Mackay's [18] precautions are therefore also extremely relevant in the home setting.

\section{Capturing sporadic use}

The use of television is sporadic on several levels. First, the amount of use depends largely on the time of the year, and even on the weather. Though it sounds banal, this has implications for the planning of a field study. For instance, one of the families had their television installed in the middle of their summer vacation, and since the weather turned out to be really nice during that period of time, they had not used the television very much by the time we returned to them one month later. Secondly, watching television is a task which involves a limited amount of interaction most of the time. In our families, the daily use of television only covers limited interaction. The television is often turned on just after dinner and left on for the rest of the evening, with the parents of the family sometimes falling asleep in front of the television and waking up in the middle of the night, turning the TV off and wandering to bed. Clearly, studying the interaction taking place in a natural situation involves staying with a family in very private situations over long periods of time, which is problematic for ethical as well as practical reasons. While use is sporadic, the times, where the families try out new functionalities is even more rare and there is no way of predicting when this happen. Thus the 
challenge of our study was thus to find means to mirror and condense the families' focuses and interactions with the product in the limited amount of time we had available during our visits in their homes. The means should somehow bridge the gap between the naturally occuring use and the point in time we met the families. In designing our approach we considered how others have approached related challenges.

Diaries have been used for different purposes and in different forms to construct a record of people's activities in the absence of a designer or an evaluator. Baxter [1] used diaries to capture events of learning in a laboratory test of the learnability of spreadsheets and Rieman [20] constructed a diary form to capture learning in the use of technology in general at a workplace. Further, the area of remote usability testing offers some suggestions in this situation. Critical incident reports [8] and combined automated logging and critical incident reports [12] are examples of this. In these examples, only Rieman [20] has studied the naturally occurring use of technology. In the rest of the examples, constructed tasks were provided for the users to perform while filling in the diary.

Inspired by Baxter's notion of an incident diary [1], we constructed our own incident diary to focus on learning incidents and interesting events. We expected the selection of particularly interesting incidents to minimize the users' effort, because we would not disturb them too much in their private, relaxed situations at home. Secondly, we were interested in studying the naturally occurring events in the houses, since our focus was to study development in use and thus we were careful not to shape the users' expectations or to guide them in certain directions.

We considered asking the users to construct a video diary inspired by Blomberg et al [3], who used video to document the work practice at a law office revolving around the use of documents in a file cabinet. Since the file cabinet was only used infrequently and for short periods at a time, they made the arrangement with the lawyer, that whenever he used the file cabinet he turned on a video camera placed in his office. A similar idea could be introduced to users in homes: Mounting a camera in their living room for, say, 14 days or 1 month, and whenever they use the remote control for something besides turning the television on and off or changing channels, they turn the camera on. Whether users in homes will participate in such an experiment remains to be tested. We decided not to set up this kind of study due to our skepticism concerning the intimacy of the situations potentially being recorded in the home setting as well as to the practical arrangements involved.

We also considered using automatic logging of the users' interaction with the television. Rosson [22] and Kay \& Thomas [13] have used this approach in the case of users' learning to use a word processor and Kaasgard [12] has applied this technique to the evaluation of web-pages of which the users are widely distributed physically, potentially situated in the ir homes. Obviously, this technique would be applicable and not very intrusive in the home setting. In the end we abandoned it, partly due to technical obstacles. It is an approach we would consider using in the future; however, in consonance with others [12]. We find that this approach cannot stand on its own since it does not reveal the motivation and rationale behind the larger activities of the users nor the context in which the logged key-strokes take place. Quantitative accounts of number of incidents as we have seen in some cases [13] are not very informative on their own, particularly not when our aim is to understand how to design new technology. In addition, we are concerned with the trend of moving away from the users rather than approaching in direct collaboration; which some of the work on remote usability testing represent. In our case, we would have found it interesting to use the logging as a supplement to our approach of user-driven hands-on use sessions to reconstruct the details of interesting events discovered in close collaboration with the users.

Instead, we decided to develop a paper-based incident diary. Although our work is in line with other studies, e.g. Rieman [20], we have a particular focus on how use develops in the home over a period of time. Thus, we constructed our own specialized form in response to the characteristics of our specific study. 


\section{Concerning the activity:}

? Briefly describe the characteristics of the situation

?hat did you do?

? How did you do it?

? What did you expect to happen?

? What actually happened?

Figure 1 . The incident diary form.
What did you learn? (check relevant cases):

\& You accidentally discovered new features

25 You used a trial-and-error strategy

es You formed an idea about how

the system works and you tested your idea

25 You completely revised your view of what the television has to offer

2s Other

\section{What served as means of help in this process?}

should do on the appliance indicated what I

2. I read the manual

I I used my expectations from

I talked to

I had heard about ___ from

es Other

The diary was to be used by the user immediately after trying out a new functionality or using a known functionality in another way. The idea was not to register in detail what actually happened; the diary was to serve as a reminder. Receiving the users' diaries before our visits, we intended to use them in planning the following visit. Furthermore, during our visits, the diaries were to be used as a starting point for reenacting the situation. This use is different from any of the other diary studies we have come across, where diaries are either supplemented by interviews [20] or automatic logging [12].

However, it turned out that in our case the users did not use the diaries to any great extent. First, they found them difficult to fill in. We had asked the users to rethink - to the best of their ability — what they had done, why they did so, and how it turned out. Discussing this with the users, we found that they had difficulties in remembering what they actually did, also just after it had happened. However, our form is only a subset of the critical incident reports [8] which have worked successfully in a constructed laboratory setting. Thus, the problems we experienced may also be due to the nature of the home setting in which the diary was to be completed in our study. In using televisions at home, users are not interested in completing forms, but most often they want to relax in front of the ir televisions. At rare occasions, they may discuss with other family members how to operate the television. Further, with our visits every one month, there were not many reminders for the users of the ongoing study and thus for the presence of the diary form.

Based on this study it is hard to conclude whether the diary failed due to the characteristics of the relaxed and private situation on the sofa in front of the television, to the complexity of the specific form, or to insufficient preparation of the users. Nevertheless, our experiences suggest that what may be useful approaches to diary studies in constructed or work based-situations may not prove useful in longitudinal studies in the home. Further investigations within the home sphere are necessary to shed more light on this.

In order to gain an understanding of how the users used the television and the problems they encountered along the way, we established situations where the users demonstrated for us literally, with their hands on the television and the remote control, what had happened in interesting and critical situations. In our work in the area of cooperative design [10], this has previously turned out to be a very useful technique, at least in the workplace, to establish situations where users actively cooperate in the design process through assessing existing designs and envisioning future ones [9]. We are not 
aware of others having used such techniques before in the homes of users. As we shall argue in the following, this turned out to be a very useful technique, also in the home.

We set up scenario-framed hands-on use sessions which took as their starting point the users' own reasons for buying the new television set, also covering things they would like to change in respect to how they used their former television. On the first visit, these issues were brought to light through interviews. Subsequently, on each visit we followed up on the themes raised by the users by constructing scenario-framed hands-on use sessions, and we interviewed the users about things they had learned or tried out in the meantime which could be followed up on immediately as well as during the next visit.

The following is an example taken from one of our visits to one of the families. It involves the turning facility of the television, whereby a small motor in the television allows the user, using the remote control, to make the television turn to either side so that the television can easily be turned from facing the sofa section to, for instance, the dining table. On our first visit in the family-let's call the parents Mary and John-Mary had explained how she really looked forward to exploiting this turning facility so that the television could easily be turned and the children would not stumble on the cords on the floor. Returning one month later, we followed up on this issue, asking them about whether the television had fulfilled their expectations in this respect. In response to this they first argued that it certainly had. We then presented them with a short scenario in which they are ready to have dinner and want to watch the news while eating their meal. John then acted out how he would turn the television; interestingly, John got up, moved a big plant which was situated right next to the television in their living room, physically dragged the television away from the corner wall by which it stood, and then grabbed the remote control to turn the television towards the dining table. Mary commented cheerfully that she was not able to do this because the television was too heavy. On our later visits they had moved the television so that the plant was no longer in the way and the TV could be turned more easily. However, they still had not found the perfect place for the television and from time to time John still physically adjusted the television, attempting to find a better place for it.

This example emphasizes the value of studies in context, also when we design for the home. The problem of finding the right position for the television in the physical configuration similar to John and Mary's, where the television is positioned in a corner in the living room, would not have been identified in a laboratory situation, where the room would be arranged around the television, giving it a more "optimal" position. Furthermore, this situation illustrates the value of having users act out the situations, since this provides a much more detailed insight into how the television actually performs in its different roles and situations in the home.

\section{STUDYING EVERYDAY EVOLUTION OF USE IN THE HOME}

Traditionally, when studying usability within the field of Human Computer Interaction, we have focused on snapshots of use rather than on how use evolves in the everyday use of technology [6]. We do so whether it is in a laboratory setting or on location, and whether it is in a naturally occuring situation or as some kind of scenario framed activity.

Our long-term research interest is the design of learnable technology, in this case a television set. We are concerned with how the design of the technology can support the users in evolving their use through using the technology. We have different reasons for this research interest, and for why it is particularly important to study how use evolves in the home. First, in homes users of television are not "forced" to use the television in the same way as users in a workplace where the management has decided to buy some equipment. There are no demands from the context to use a television. People are primarily motivated to use the television to have an experience and possibly because they spent money on the product. Furthermore, as opposed to technology in workplaces, there is no tradition for formalized training or education in using home technology. On the contrary, from a salesman's point of view, there is an incentive to make the technology look as simple to use as possible, leaving the users with even greater problems when learning to operate their television set. Bang \& Olufsen is 
aware of this problem and they have asked their sales personnel to guide the users through the operation of their products already when the users are looking at them in the shop. Despite this, we saw incidents where the sales personnel quickly rushed through the different functionalities of the television upon delivery, showing how easy it is to operate. Finally, the social situation is different in homes than at workplaces. Lave and Wenger, [17], among others, have pointed out how learning often occurs through what they term 'legitimate peripheral participation,' which comprises the notion that users gradually become practitioners of a certain practice - in this case the practice of using a television set-through watching and collaborating with more capable peers. However, in the use of televisions at home, most often only the family acts as a community of practice. In addition, on rare occasions friends or the distributor can act as more capable peers.

Hence, because of the special characteristics of the home in terms of the lack of enforcement to use the technology, the lack of formal training in using technology as well as few more capable peers present in the home, users who want to use home technology relies to a large extend of the design itself to support them in getting to use the technology as well as supporting the everyday evolvement in use over time. Thus, in order to design technology that support users in evolving their use, we need to understand how use evolves in the home. Methodologically, it is therefore a challenge to capture the learning process of the user. The challenges behind these questions are thus the following: how to study the use without introducing the possibilities and functionality which the users have not seen themselves, and how to capture the ongoing development in use. In the following, we describe how we have approached these challenges.

\section{Capturing early evolution}

We designed our study with a focus on the everyday evolution of use. This focus had consequences for the course of the study as well as for the methods we used in collecting data in the field study. First of all, we chose to enter the use process at the earliest possible stage. This allowed us to study how the users initially adopted the television set as well as the further development of the use. The process starts even before the users buy the new equipment; it starts with the idea of a new television, with discussions in the families and with friends and others, and with some visits to a distributor. We did not have the opportunity to deal with this part of the process. The owner of the shop-quite naturally - gave top priority to selling his products and did not want to have the sale situation disturbed by people from outside, i.e. researchers. Thus, in this case as early as possible meant by delivery of the products to the homes. The distributor made the initial arrangement with the users, and we accompanied the salesmen when they set up the televisions. Methodologically, this first meeting served several purposes. The project was presented for the family in our own words, and we asked for their agreement to participate; we saw how the salesman introduced the television to the customer, and we conducted an initial interview concerning the users' reasons for buying the television and their expectations from the television. Taking their expectations as our starting point, we basically used three different techniques in order to study the development process: iterative investigation, explorative inquiry, and role playing.

\section{Iterative investigation}

Our initial interview was crucial because it identified some of the reasons why the users bought the television set, which we took as our point of departure. For instance, for one of the families a central aspect was the possibility to get surround sound from the television set. So at the first meeting after participating in the installation of the television set, we asked about this. It turned out that the wife of the family had problems turning the surround sound on and we asked her to demonstrate how she would attempt to do so. On the next visit, we followed up on this by asking whether she had used the surround sound facility, and asked her again to demonstrate how she handled the problem in a handson scenario. By following up on the same use situation from one visit to the next our approach had the quality of an iterative investigation. 
Having users act out situations with concrete demonstrations using the technology turned out to be very useful, not only for understanding the general use of the technology in the home, but also for studying evolution of use. In contrast to this, others have interviewed people about which general strategies they use when they approach and adopt new technology [20]. However, based on our experience, questionable results are often obtained from this, instead we would argue that it is important to discuss specific experiences with users and refrain from asking users to make generalizations about their behavior. The following example from our study illustrates how we have done this.

In one of our families, the woman—we can call her Sarah—-had problems turning on multiple loudspeakers together with other parts of their hi-fi equipment to obtain a surround-sound effect with their television. Right from the beginning, Sarah was very motivated to achieve this surround-sound effect in their living room; however, on our second visit, she was still not able to accomplish this on her own. We asked her about how she would approach this task and what sources of help she would seek, and she explained with great conviction how she would consult the manual to find out what to do. She even praised the structure of the manual, arguing that it was very easy to use. When we returned one month later, she had found out through experimentation and exploration how to switch on the loudspeakers, and she was very proud. We asked her to demonstrate how she had accomplished this and she demonstrated to us how she did it now, explaining what had confused her the first times in respect to how she did it now. Interestingly, when we asked about the role of the manual in her discovery, she explained that she had not used the manual at all in this situation. She now argued that "when you want it to work, and if you are alone one day... and there is something you want to watch ... then you become stubborn and start to experiment, because you do not have any other options..... oh, you do have the manual, but before you get started flipping through that, the movie has already started." Although this general explanation probably should not be taken at face value either, we can ascertain that in this specific situation it was certainly not the manual that helped Sarah accomplish her task, despite her earlier praise of the manual as a tool in this respect.

\section{Explorative inquiry}

Our way of approaching the users in the study was generally characterized by asking open-ended questions, a method that was particularly important in our objective to study the evolution of use, where it is crucial to avoid asking questions which disclose the facilities of the technology. So, for instance, we would ask "Have you tried any new things since our last visit?" rather than asking "Have you used teletext programming?"

Within the area of therapy it is crucial that the clients themselves formulate their problems. In order to support this process it is crucial to ask questions offering the client the possibility to formulate his or her own view of the situation without searching for a specific answer. We were inspired by Hammond [11], who writes about how to make interviews and investigations that link to what the person says. In keeping with the focus for the study, we had a whole range of issues related to evolution in use. But rather than systematically going through them on each visit, we listened to what the family members said and used that as the platform for the subsequent part of the visit. So when we asked the family about new things they had tried, we asked them how they became aware of the functionality, how they tried it out the first time, and whether they used some kind of support such as a manual, other people, and so forth.

\section{Role play}

We experimented with role play as an approach to gaining insight into the users' current understanding of the television and its possibilities without influencing the adoption processes. For example, we wanted to know whether the users had made any use of the television as an alarm clock, using the facility which allows them to program the television to start and stop at certain times. It could be tempting just to ask them about this, but in doing so, we would have pointed out this 
possibility in the television. Since we were interested in studying the process of how users discover and start to use different facilities, we did not want to disturb this process. In order to avoid this, we set up a role play. The idea was that the family should imagine that we, i.e. the researchers, were friends who had come to visit them and were in the process of buying a new television set. Therefore, we would like the family members to show us their television and explain to us - as their friendswhat aspects of the television they would recommend and if there was anything annoying about their television. Again, this was an attempt to ask very open-ended questions and to engage the users in active cooperation.

Once again, it turned out to be a good idea to ask open-ended questions. What happened in the role play, though, was different from our expectations. We had expected the users to make more references to the fancy features of the operational aspects of the television, but, interestingly, the level of the explanations varied significantly among the different individuals. For example, while one of the users praised the appearance and aesthetics of the television, saying how it fit well in their home, another focused much more on how easy it was to use teletext to program their video to record, which for him was an important feature of the television. Thus, this approach turned out to be useful in allowing the users to describe in their own words how they perceived their television and to emphasize the aspects that were particularly interesting for them, with direct reference to the television and demonstrating what they meant. The role play surprised us as a means to understand more fundamentally the different roles the television played in the different families and for the different individuals.

\section{CONCLUSION}

In devising a way to study technology use in homes with a particular focus on how use develops, we have experimented with various approaches. In light of our experiences from a longitudinal study of television use in the home, we have reflected upon the applicability of the methods tried out.

Our study suggests that diary studies may be problematic for longitudinal studies in the home, where users are not reminded of the ongoing study and are concerned with other things such as relaxing or even sleeping in front of the television. However, more studies are needed to explore this issue further. Our lack of experience as well the specific diary form in our study may also have been critical factors that left the diaries practically unused.

In contrast, participatory design techniques with hands-on demonstrations of use turned out to be fruitful in work settings as well as in the home for understanding the details of how people interact with technology as well as how their use develops the means that support this. By relying on how people explain how they learned to operate the technology in question through active demonstrations and with references to their actions, more reliable and interesting accounts are obtained than those that can be obtained through interviews where the users are asked to provide generalized characterizations of how they deal with technology in the home.

Development in use was successfully studied by starting out with the expectations of the users, revealed through qualitative interviews, by the time of the installation of their new televisions. In subsequent visits followed up on these expectations as well as addressed new themes, as they were raised by the users. We experimented with a set of techniques to study the development process including iterative investigation, explorative inquiry and role play.

\section{ACKNOWLEDGEMENTS}

The research project Usability in Danish Industry is sponsored by The Danish National Center for IT Research through grant no. 23. In addition, this research have been supported by The Danish Research Councils grant no 9600869 (The Staging of Virtual 3D Spaces). We would like to thank our two families for their contribution to the study and Bang \& Olufsen for their help in establishing the contact with the families. 


\section{REFERENCES}

1. Baxter, I. \& Oatley, K. (1991) "Measuring the learnability of spreadsheets in inexperienced users and those with previous spreadsheet experience". In Behaviour \& Information Technology, Vol. 10, No. 6, pp. 475-490.

2. Blomberg, J., Giacomi, J., Mosher, A., Swenton-wall, P. (1993): Etnographic Field Methods and Their Relation to Design, in: Schuler, D., Namioka, A. (ed.): Participatory Design: Principles and Practices, Hillsdale: Lawrence Earlbaum Associates, pp. 123 - 155.

3. Blomberg, J., Suchman, L. \& Trigg, R. (1994): Reflections on a work-oriented design project. In Trigg, R., Anderson, S. \& Dykstra-Erickson, E. (eds.): PDC'94 Proceedings, pp. 99- 109.

4. Brown \& Duguid (1991) “Organizational Learning and Communities-of-Practice. Towards a Unified View of Learning, Working and Innovation”. In Organisational Science, Vol. 2, no.1.

5. Bødker, S. (1999). "Scenarios in user-centred design - setting the stage for reflection and action. Hawaii International Conference on System Sciences 32.

6. Bødker, S. \& Petersen, M. G. (to appear in Scandinavian Journal of Information Systems) Designing for learning in use.

7. Carroll, J. M. (ed) (1995) Scenario-Based Design - Envisioning Work and Technology in System Development John Wiley \& Sons, Inc.

8. Castillo, J. C., Hartson, H. R. \& Hix, D. (1998) "Remote Usability Evaluation: Can Users Report Their Own Critical Incidents ?" In Proceedings of the CHI 98 summary conference on CHI 98 summary: human factors in computing systems 1998, ACM Press, pp. 253-254.

9. Ehn, P. \& Kyng, M. (1991) "Cardboard Computers: Mocking-it-up or Hands-on the Future” in Greenbaum, J. \& Kyng, M. (eds.) Design at Work:Cooperative Design of Computer Systems. Hills dale, N.J.: Lawrence Erlbaum Associates, pp. 169- 196.

10. Greenbaum, J. \& Kyng, M. (eds.)(1991). Design at Work:Cooperative Design of Computer Systems. Hills dale, N.J.: Lawrence Erlbaum Associates.

11. Hammond, Sue A.: The Thin Book of Appreciative Inquiry, Kodiak Consulting, Texas, 1996.

12. Kaasgaard, K., Myhlendorph, T., Snitker, T. \& Sørensen, H. E. (1999) "Remote Usability Testing of a Web Site Information Architecture: Testing for a Dollar a Day”. In Sasse, M. A. \& Johnson, C. (eds.), Human-Computer Interaction-INTERACT '99. IOS Press, pp. 443- 450.

13. Kay, J. \& Thomas, R. C. (1995) "Studying Long-Term System Use”. In Communications of the ACM, July, Vol. 38, No. 7, ACM Press, pp. 61-69.

14. Kraut, R. (1996) "The Internet at Home" (Introduction to special issue). In Communications of the ACM, December 1996, Vol. 39, No. 12, ACM Press, pp. 32-35.

15. Kuutti, K. (1999) "Small Interfaces - a blind spot of the academical HCI community?" In Proceedings of HCI International '99. München, August 20-27, 1999.

16. Kyng, M. (1995) “Creating Contexts for Design”. In Carroll, J. M. (Ed.), Scenario-based design. Envisioning work and technology in system development. Wiley, New York, NY, pp. 85-108.

17. Lave, J. \& Wenger, E. (1991). Situated Learning. Legitemate peripheral participation. Cambridge University Press.

18. Mackay, W. E. (1995). "Ethics, Lies and Video" in Proceedings of the CHI 95 human factors in computing systems, ACM Press, pp. 138-145.

19. O'brien, J. \& Rodden, T. (1997) Interactive Systems in Domestic Environments. In DIS '97 Designing Interactive

20. Systems: Processes, Practices, Methods, \& Techniques, Amsterdam, The Netherlands, ACM., p.247-259.

21. Rieman, J. (1996) “A Field Study of Exploratory Learning Strategies”. In ACM Transactions on Computer-Human Interaction, Vol.3, No. 3, September 1996, pp. 189-218. 
22. Rijn, F. van \& R. Williams (eds) (1988). Concerning Home Telematics: Proceedingsof the IFIP TC9 Conference on Social Implications of Home Interactive Telematics ;Amsterdam24-27 June. Elsevier Science Publishers.

23. Rosson (1983) "Experiences in Text Editing" in Proceedings of the CHI 83: human factors in computing systems, ACM Press, pp. 171-175.

24. Suchman, L. A. \& Trigg, R. H. (1991) "Understanding Practice: Video as a Medium for Reflection and Design”. In Greenbaum, J. \& Kyng, M. (eds.) Design at Work: Cooperative Design of Computer Systems. Hills dale, N.J.: Lawrence Erlbaum Associates, pp. 65-89. 


\section{Emerging Themes in Designing Future Household Technologies}

Lynne Baillie

School of Computing

Napier University

219 Colinton Road

Edinburgh

Scotland
Marianne Graves Petersen

Computer Science Department

University of Aarhus

Abogade 34

DK-8200 Aarhus N

Denmark

\section{Introduction}

To date, contributions from the field of Human-Computer Interaction have primarily focused on a task-oriented environment. Hughes et al (1998) commented that many designers are merely migrating existing approaches to design, which focus on work environments, into the home. We need to assess users, modes of interaction with existing domestic devices and re-evaluate our techniques and methods in response to this move from the office to the home.

This paper will report on a series of recent studies, which were carried out in people's homes in Denmark and Scotland. The aim of the study was to understand how people operate and use home-oriented information and communication technologies. This paper discusses some of the early findings from these studies.

\section{Method}

We embarked on a series of workshops, which employed the following approaches: hands-on in context, scenarios, post-it notes, mock-ups and a technology tour (Petersen \& Baillie 2001). We used video and audio tapes as well as note-taking to capture the data. The field notes have been analysed, looking for certain themes in the data. The emerging themes are efficiency, device lifecycle, context, cramming, and unused devices.

\section{When efficiency becomes less important}

The material indicates that technology does not always need to be as efficient as possible. For example one of our participants $(S)$ was still willing to use a tape recorder that was only partially working because it was portable and the parts that did work worked in a good enough way.

This is an excerpt of a discussion with the mother of one of the families about an old tape recorder.

$S$ : I have got this umm... tape and radio but I am afraid only the radio works now.

$R$ : Right

$S:$ As you can see it has seen better days

$R$ : Why have you still got it?

$S$ : Well it comes in handy when I am moving round the house doing different things, the other one (she points to the new music system in the corner) has to stay where it is.

Another of our participants $(B)$, preferred to write out recipes by long-hand, even though it would have been more 'efficient' to type the information into a computer. 
Thus people were still willing to use technology that was only partially working and were willing to carry out tasks in an inefficient way if it achieved a more personally desired result.

\section{Design for use-lifecycle}

The findings indicate that we need a life-cycle approach to the design of technologies in the home. There are tasks that are rarely carried out but are essential to the running of a technology. This was the case when $(E)$ had to change the batteries in her phone: the phone had instructions as to where the positive and negative symbols should be facing on the phone but no instructions as to how to insert or place the batteries, therefore $(E)$ spent several frustrating hours trying to fix the phone only to find that when she threw the phone down in disgust the batteries slipped into place.

When a person runs into difficulty when using a technology in the home there is often no expert to call. We therefore argue that essential, but rare, events should be well supported by the design, and should be part of the concern for the usability of home devices.

\section{Design for context}

Although it is often said that we should design for context, this does not always seem to happen with home technology. Frustration was expressed by the families over for example how troublsesome it is to clean certain items, timers which were not robust enough to live in the kitchen they were intended for, the lack of mobility of devices reflecting the flexibility of the home, and conflicts over use.

We found that by being in context and surrounded by the families' technologies discussion about the use of these technologies came easily, as people would come across an item while taking you on a tour of their homes and explain the reason for the item being in that particular location. This in turn helped us to bring about discussions about the technology and its use, this helped us particularly in the area of technologies which where no longer in use.

\section{Avoid functionality cramming}

An interesting discovery was that several of the technologies in the home had been crammed with functionality that was never used. For example, we found that even though two of the families had ovens that could be programmed in several ways e.g. to start and stop at certain time, to cook at varying temperatures, they did not use these facilities. We found with one of the two families that even though there were ten different types of wash cycles on their washing machine they only ever used three of the programs. It is interesting to note that sometimes a product with fewer features might be more usable, more functional, and superior for the needs of the user. It can been seen from these findings that we should be wary of adding extra functionality without a clear idea of the actual needs of the user and the way they use the technology.

\section{Unused devices}

One of the most unusual aspects we found in the home relates to devices that are left unused and some of the reasons for this. One family $(C)$ had a brand new PC, printer and scanner, but did not use either the printer or the scanner. When asked why this 
was, both of the children replied that they had not ever felt the need to use it, and when pressed said that they did not even know how to use it. Another example of an unused device is of a device bought by the $(L)$ family. This family had paid more for one type of games console over another because of its extra functionality e.g. the Internet and e-mail, however, the e-mail systems interface was so unusable, in their opinion, that they abandoned the system and went to a cyber café instead.

\section{Conclusion}

In this paper, we have highlighted certain themes found during the sessions involving families in the home. By using the different techniques employed we managed to gather a rich set of data on the use of technologies in the home and the life cycle of a product.

\section{References}

Hughes, J., O’Brien, J., and Rodden, T. (1998). Understanding technology in domestic environments: Lessons for cooperative buildings. Cobuild'98, Springer-Verlag, Vienna, Austria.

Petersen, M.G., Baillie, L. (2001). Methodologies for Designing Future Household Technologies. Oikos2001, Aarhus University Press, Aarhus, Denmark 


\section{Methodologies for Designing Future Household Technologies}

\author{
Marianne Graves Petersen \\ Computer Science Department \\ University of Aarhus \\ Abogade 34 \\ DK-8200 Aarhus N \\ Denmark
}

\author{
Lynne Baillie \\ School of Computing \\ Napier University \\ 219 Colinton Road \\ Edinburgh \\ Scotland
}

The majority of recent approaches to design of interactive technology have been developed for work environments. However, with technology migrating into the home, we need to consider the methodological challenges and opportunities in the home environment with respect to tools and methods for design of household technology. At present a number of studies of the use of household technologies have been conducted (O’Brien \& Rodden, 1997., Stolzoff et al. 2000, Kjær et al. 2000 ). However, few have looked into tools and methods specifically for the design of future household technologies.

We have in the past used design workshops as a way of establishing creative and collaborative settings for design (Petersen \& Madsen 1998; Buur \& Bødker 2000; Bødker et al. 2000). We have also conducted studies of use of household technology (Kjær et al. 2000), and designed technology for the home (Baillie \& Benyon 2000). In this work we draw upon the experiences from the domestic ${ }^{1}$ environment in framing the approaches for designing technology with families in their homes.

We engaged with eight different families in Scotland and Denmark and set up three successive sessions in each family with approximately three weeks in-between the sessions. The families cover a spectrum ranging from the family with two children aged seven and twelve to a single 80 years old woman. Each session lasted approximately one and a half hours and took place in the homes of the families. The sessions were run using the same format in Scotland and Denmark except for the final workshop, which had a slightly different format in Denmark, where all the families met in one workshop session outside of the homes. Venkatesh \& Mazumdar (1999) proposed that we should conceptualise the household in terms of "Home As Living Space", consisting of three key 'spaces': the social space, the technological space, and the physical space. We aimed in our sessions to focus on all three of these household spaces. In our first session we decided to focus initially but not exclusively on what Venkatesh and Mazumdar termed 'The Technological Space', which represents the nature of the technological environment within the household.

As illustrated in the following table, the focus of the sessions developed through the course of the engagement with the families.

\begin{tabular}{|l|l|l|l|}
\hline & Session 1 & Session 2 & Session 3 \\
\hline Foci & $\begin{array}{l}\text { Investigate Current Problems } \\
\text { and Future Possibilities }\end{array}$ & $\begin{array}{l}\text { Contextualise ideas in home } \\
\text { and daily life }\end{array}$ & $\begin{array}{l}\text { Discussion, Critique and } \\
\text { Iteration }\end{array}$ \\
\hline Means & $\begin{array}{l}\text { "Technology Tour" } \\
\text { Representations of emerging } \\
\text { technologies } \\
\text { Materialising ideas for future } \\
\text { technologies }\end{array}$ & $\begin{array}{l}\text { Elaborating and Constructing } \\
\text { Prototypes and Scenarios. } \\
\text { Positioning the technology } \\
\text { physically in the home }\end{array}$ & $\begin{array}{l}\text { Sharing ideas across families } \\
\text { Modifying and elaborating on } \\
\text { proposals. }\end{array}$ \\
\hline
\end{tabular}

Table 1. The Foci and Means in the three sessions held in each family

\footnotetext{
${ }^{1}$ Although we prefer to use the word household, sometimes the word 'domestic' seems more apt.
} 
In our approach, we took advantage of the richness of the home environment (O'Brien \& Rodden, 1997; Stolzoff et. al. 2000), and we were careful to engage all the members of the families. In the following section, we reflect on our experiences from the first and second sessions.

\section{Technology Tours and stories}

Several researchers have pointed out how the way the technology is integrated in the physical and social organisation of the house provides useful clues of understanding the use of these technologies (O'Brien \& Rodden, 1997; Stolzoff et. al. 2000). Thus we maintained this focus in the technology tours of the first session through asking the families to take us on a tour of their homes. In these rounds we asked about possible conflicts in ownership of space (O'Brien \& Rodden, 1997; Venkatesh, 1996) as well as the history, flexibility and motivation for the physical organisation. We further asked them to describe problematic situations they had experienced with the technology and we asked people to show us how they used the technology.

We got particularly interesting accounts in this way, when people started to tell stories (Brown \& Duguid, 1996). The stories are records of particular incidents, and "they are built in response to the particulars of breakdown" (ibid, p. 65). For example John's story about the first time they used the stove. John and Susanne were about to cook dinner, but they could not work out how to turn on the stove. Puzzled by the complexity of this simple operation, they finally gave up, called the previous owner of the flat, and got him to tell them how to turn on the oven. Subsequently, they have several times used this as a "party trick", asking people to turn on the stove, having a laugh as it turns out each time that people cannot accomplish this on their own. The stories are valuable in that they "are repositories of accumulated wisdom" (ibid, p. 66) or in Venkatesh and Mazumdar's (1999) terms they provide accounts of both the social, physical and technological space of the situation, thus providing holistic accounts of the event.

\section{Representations of future services}

Through the technology tour and the discussion on emerging technologies, most often some ideas arose for new devices, that the members of the families would be interested in having. The participants were asked to materialise their suggestions in the form of preliminary representations of future services and to discuss where they envisioned the new device would be located. We asked them to leave the representation in the proposed place until the next workshop.

\section{Post-its and Notes}

We had earlier experimented with little success with short questionnaires as a way of gaining insights into interesting cases of technology use in between visits (Kjaer et al. 2000). We felt that we needed a new way of capturing data in-between visits we therefore decided to leave some blank post-its with the participants. We encouraged the participants to write any comments on the drawings or post-its and stick them onto an existing device or their newly drawn device. When we returned for the next workshop session, some of the participants had been moving the mock up around their house, for instance a recipe service had been moved from the table besides the stove to hanging on the wall because of the lack of space in the daily work in the kitchen. Some had added extra facilities they would like on post-its. We had hoped that by doing this we would generate new scenarios, leave triggers, and gain an insight into the home. The combination of the drawings, card-board mock-ups, and the blank post-its turned out to be a success. 


\section{Designing with families}

As argued by Druin (1999), we need to take into account who are the users of the technologies we are designing. While Druin's work concentrate on designing technology with children, in this work, we have sought to engage whole families, since the users of domestic technologies are families.

\section{References}

Baillie, L., Benyon, D (2000) Designing and Evaluating a User Interface for a Home Convergence Technology. IFIP W.G. 9.3. Home-Oriented Informatics and Telematics (HOIT) International Working Conference.

Brown, J. S. \& Duguid, (1996) Organizational Learning and Communities of Practice. Toward a Unified View of Working, Learning and Innovation. In Cohen, M. D. \& Sproull, L. S. (eds.) Organizational learning. London, Sage, pp. 58-82.

Buur, J. \& Bødker, S(2000) From Usability Lab to "Design Collaboratorium" Reframing Usability Practice. In DIS’2000 Designing Interactive Systems. ACM Press, pp.297- 307.

Bødker, S., Nielsen, A. C. \& Petersen, M. G. (2000) Creativity, Cooperation and Interactive Design. In DIS'2000 Designing Interactive Systems ACM Press, pp.252-262.

Druin, A. (1999) Cooperative Inquiry: Developing New Technologies for Children with Children. In CHI'99. ACM Press, pp. 592-599.

Kjaer, A., Madsen, K.H., Petersen, M.G. (2000) Methodological Challenges in the Study of Technology Use at Home. IFIP W.G. 9.3. Home-Oriented Informatics and Telematics (HOIT) International Working Conference.

O’brien, J. \& Rodden,.T. (1997) Interactive Systems in Domestic Environments. In DIS'97 Designing Interactive Systems ACM Press, pp. 247-259.

Petersen, M. G. \& Madsen, K. H. (1999) Supporting Collaboration in Multimedia Design. In Brewster, S., Cawsey, A. \& Cockton, G. (eds) Interact'99, vol. II, pp. 185-190.

Stolzoff, N. C., Shih, E. C. \& Venkatesh, A. (2000) The Home of the Future: An Ethnographic Study of New Information Technologies in the Home. Project NOAH report, http://www.crito.uci.edu/noah/paper/hof.pdf, printed october 2000.

Venkatesh, A. (1996) Computers and other Interactive Technologies for the Home. In Communications of the ACM 39(12), pp. 47-54.

Venkatesh, A. (1999) New Information Technologies in the Home: A Study of Uses, Impacts and Design Strategies. Presented at EDRA Environmental Design and Research Conference, Orlando, Florida, June 2-6, 1999. 


\title{
Supporting Collaboration in Multimedia Design
}

\author{
Marianne Graves Petersen \& Kim Halskov Madsen
}

\author{
interMedia, Aarhus University \\ Åbogade 34, DK 8200 Århus N, Denmark \\ +4589425651 \\ mgraves@daimi.au.dk, halskov@imv.au.dk
}

\begin{abstract}
Using the development project of the integrated television and PC concept of Bang \& Olufsen, as the setting for experimenting with different ways of organising design sessions, this paper addresses the issue of how collaboration between designers is mediated by design materials and use of physical space. Based on an analysis of two design meetings, which represent rather different strategies for applying design materials and physical space, we provide recommendations on how these means can support collaboration in a multi-disciplinary team of designers. The main recommendations include to use a diverse set of flexible design materials for supporting communication and exploration of design ideas among the designers. Further, we provide examples of how the way people are physically organised may influence their engagement in discussions and modifications of design proposals.
\end{abstract}

Keywords: the design process, collaboration, materials, physical space, TV and PC integration

\section{INTRODUCTION}

The emergence of multimedia technology poses new challenges for designers of interactive systems. The competencies needed in the design process can no longer be covered by designers with a uniform background. Thus we see software engineers working together with for instance anthropologists, psychologists and communications design people when designing multimedia products. In the BIDI project (Brugbarhedsarbejde I Dansk Industri, Eng. Usability work in Danish industry), we work with developing methods and settings that allow for these very different perspectives to be integrated in the development process. This involves experimenting with new forms of participation as well as identifying tools that support collaboration and synthesis amongst different disciplines. Starting from an analysis of two specific design sessions of quite different nature, this paper describes how collaboration between designers is mediated by design materials, and how the dynamic of a design sessions also depends on the use of physical space in which the setting is situated.
The specific development project, which provided the setting for experimenting with design practice, was the development process of Bang \& Olufsen's PC-TV living room. Bang \& Olufsen is a major Danish hi-fi manufacturer and one of the commercial partners in the BIDI project. The vision of $P C-T V$ living room is to provide users of a traditional television with access to PC functionality and applications when seated in the sofa in the living room. Bang \& Olufsen have already developed the counterpart product of PC-TV living room, the $P C-T V$ office, which allows users to watch television or listen to radio or $\mathrm{CDs}$, from the computer. The products exploit the BeoLink ${ }^{\circledR}$ concept of Bang \& Olufsen which allows audio and video devices to share services, such that for instance a person from one room can select and listen to a track from a CD loaded in the $\mathrm{CD}$ player placed in another room. The technology is multimedia in the sense that it is the integration of a mass media and the computer as a media, rather than in the sense of combination of picture, sound and text. 
As the platform for our analysis we apply the work of D. Schön (1983, 1988 \& 1992). Through his exploration of how reflection and action are intimately connected in the world of practitioners, Schön provides a valuable perspective on design practice. His notion of design as a reflective conversation with materials supports our analysis of the role of materials in the design process. We have found it productive for the purpose of our analysis to expand his theoretical framework concerning the number of people involved, the materials available, and his notion of seeing and moving. In addition we have added a concern for the role of physical space.

\section{THE SET UP OF THE TWO DESIGN SESSIONS}

The empirical basis for our analysis consists of the first design meeting in the PC-TV living room project and a workshop conducted as part of the project three weeks later. In the following, we will term the two sessions the 'meeting' and the 'workshop' respectively. The total number of people involved in the two sessions was 14; 10 of them participated in the meeting and 12 of them in the workshop. Participating in the meeting were five people from the usability group, three from the multimedia department, one from the communications department, and one person from our research group. Participating in the workshop were four people from the usability group, two from the multimedia department, one from the communications department, two from the other industrial partners of BIDI, and three people from our research group, whose main responsibility was to organise the event. The people involved represented expertise from a broad range of domains, including software engineering, psychology, anthropology, aesthetics design, communication, and multimedia.

\subsection{The meeting}

At this first design meeting, the first prototype of the $P C-T V$ living room was presented by the multimedia department, for the usability group to comment on it. The goal of the meeting was to start a process where people with different competencies would comment on the technological initiative in the form of a prototype and hereby provide recommendations for how the prototype should be modified to form an improved version. The only design representation available at the session was a prototype of the PC-TV living room, which was set up with access to two different kinds of web sites - a local newspaper and a European art museum. In addition a page with favourite links and a button panel had been designed. The meeting started off by a demonstration of the prototype by the manager of the multimedia department, followed by a discussion between multimedia developers and usability people on a wide variety of issues concerning the design of the PC-
TV living room. The meeting took place in a room equipped as a three piece suite, where the people from the usability group were comfortably seated in sofas while discussing the prototype.

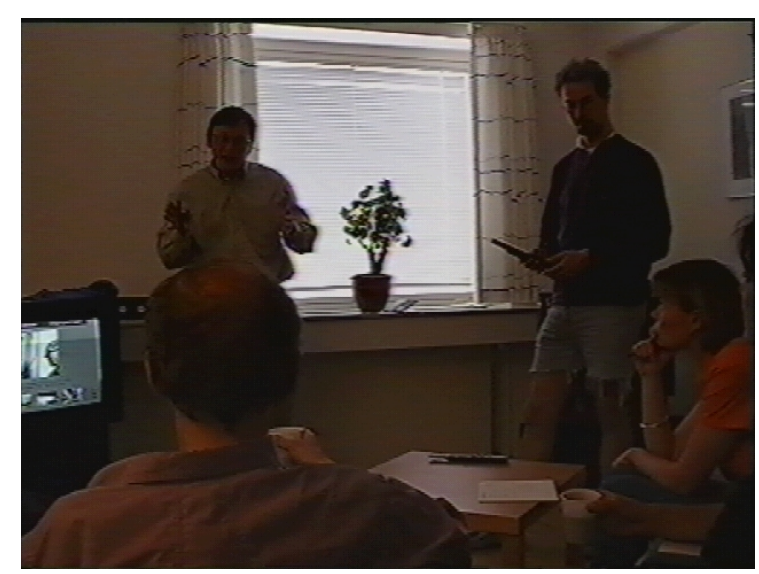

Figure 1 The meeting

\subsection{The workshop}

The goal of the workshop was to further develop the design concept of the PC-TV living room. The workshop took place in a room equipped with products and prototypes of relevance to the PC- TV living room. Moreover, video was shown from a previously conducted workshop with users concerning the design of the PC-TV living room. The workshop started out with the participants split in two multidisciplinary teams who in turn visited different stands which presented products and prototypes related to the PC-TV living room and a video which presented highlights and key-issues from the workshop with users. At the stands, design dilemmas and statements from users were presented on posters on the wall, and the participants were asked to comment on these and summarise their discussions on post-it notes. Based on the discussions held in this first round, two specific design issues were chosen which the two groups should then work on. Each team was asked to produce their design solution in a tangible form, for instance as a paper prototype. The idea was that after approximately half an hour, the two groups presented each their design proposal for the other team, and then swapped design topics. For the second round a team could either start from scratch or start out from what the other team had produced.

Whereas people had been standing while discussing posters and prototypes, during the latter part of this session they were seated around a table. At their disposition were various design materials including pens, paper in various sizes, Scotch tape, Post Its, etc. In addition, screen dumps from the current prototype of PC-TV living room were available. 


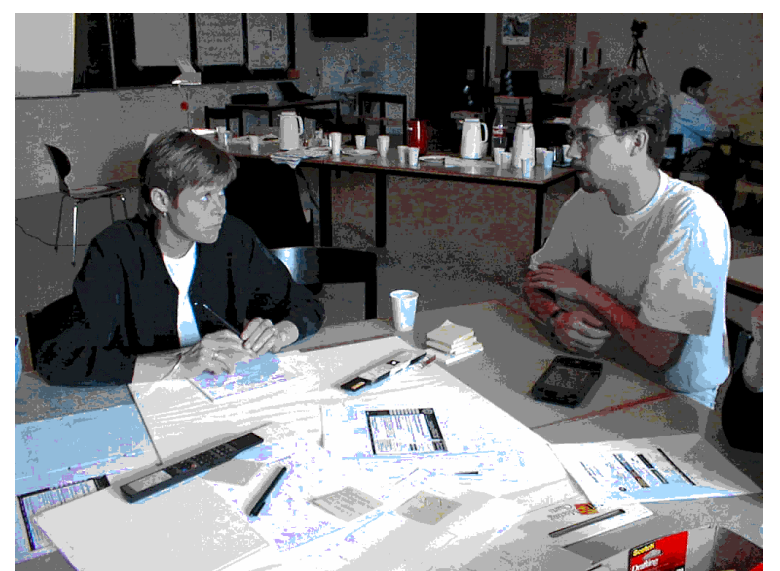

Figure 2 The workshop

\section{ANALYSING DESIGN AS A REFLECTIVE CONVERSATION WITH DESIGN MATERIALS}

In order to analyse the strengths and weaknesses of the two design sessions, we apply the framework of Schön (1983, 1988 \& 1992), who sees design as a reflective conversations with design materials. According to Schön, design is a kind of experimentation that consists in reflective 'conversation' with materials. The interaction with materials is a conversation between the designer and the materials in a metaphorical sense. For instance when "working in some visual medium (...) the designer sees what is 'there' in some representation (...), draws in relation to it, sees what has been drawn, thereby informing further designing" (Schön 1992 p. 135). Keeping with the metaphor, the materials talk back to the designer, which guides further moves and the process becomes one where the designer sees, moves while taking account of previously unanticipated result of his moves, and sees again (Schön 1983 p. 158). The design representations are virtual worlds, which may facilitate experimentation at low risk and cost by eliminating or inhibiting constraints of the built world (Ibid. pp. 157-8). "But the virtual world of drawing can function reliably as a context for experiments only insofar as the results can be transferred to the built world" (Ibid. p. 159).

Although we base our analysis on the work of Schön, we have found it necessary to expand his framework as regards the number of designers, the range of design materials and finally we have sought to clarify his terms of seeing and moving, such that an analysis of a specific design session is enabled.

The prototypical design case reported by Schön involves one designer. One of the widely used examples in his work is about a student of architecture who makes and reflects on a series of sketches of building layout (Schön 1983 p. 76-104). Though the design situation also includes a master designer he does not include the interaction between the student and the master designer as subject for his analysis. Our case involves several people and in our analysis we have found it important to incorporate a concern for the collaboration between them. In Schön's general discussions of design he puts great emphasis on the role of design materials, for instance by discussing how the designer works selectively in different media or materials experimenting with different aspects of his design. Having originally been concerned with the design practice of architects, he has quite naturally primarily been concerned with material like paper, wood, and cardboard. However, in our case, a number of different kinds of material are being used in addition to various kinds of pens and paper: Software prototypes of for instance the $P C-T V$ living room, hardware prototypes of for instance a remote control with tracker ball, prints of screen images, pictures of products, posters, and Post Its.

The terms seeing and moving are by Schön used in a fairly loose way and we have found it productive to use them in a little bit more accurate way. We use the term moving in two different ways: 1A) in the sense that somebody says something, which moves the design ahead $2 \mathrm{~A}$ ) in the sense that a design representation in some material is being modified. Similarly we distinguish between two kinds seeing: 1B) in the sense of visual apprehension of for instance a design sketch or listening to what some one else says, and 2B) in the sense of actively experiencing how it would be, for instance, to apply a certain interaction principle by trying out a prototype. That is, we make the following distinctions:
A) Moving:
1. Verbal expression
2. Material modification
B) Seeing:
1. Visual apprehension
2. Actively experiencing

Visual apprehension and actively experiencing is not a dichotomy but rather the two end points of a continuum as illustrated by the following list of ways of seeing a remote control:

1. looking at a picture of a remote control

2. looking at a remote control

3. holding the remote control in the hand

4. holding the remote control in the hand and imagining how it would be to use it, for instance by pushing the buttons

5. using the remote control to control a TV set or a prototype of a TV set

\section{TWO FORMS OF COLLABORATION IN DESIGN}


The two sessions were quite different with respect to the way collaboration was supported.

\subsection{Brainstorm at the meeting}

The nature of the meeting was most of all a brainstorm of problems to be considered in the future work on designing the PC living room product. Numerous issues were touched upon, inspired by the prototype presented at the session, ranging from aspects of functionality to aesthetic concerns regarding the graphical appearance of the PC-TV living room. However, most of these issues were left standing alone and were not elaborated on by the rest of the participants. This loose coherence among moves taken at the meeting was partly due to the limited and inflexible materials available at the session. The hardware and software used for implementing the prototype did not support the creation of alternative design solutions - not to mention on the spot experiments.

In terms of moving, the session represented only verbal moves, that is the list of topics raised during the session were not documented in any way, except for some sporadic notes produced by the head of the multimedia department in his private notebook. Again no materials were available for documenting the reflections and observation, thus many of the rich and valuable comments produced at the meeting was in jeopardy of being lost in relation to future work. Though we in general would argue in favour of having strong coherence between statements and contributions from different participants, a session like the meeting where a number of issues are raised, is important as well - in particular in the early phase of a design process. What seems to be needed are better ways for materialising the moves while at the same time maintaining the dynamics of raising a number of issues within a short time frame. Elements of Future Workshops, (Jungk \& Müllert 1987) could be an important source of inspiration here. A Future Workshop is a way of organising a meeting where the goal is to handle a complex problematic situation but has also been applied in design, see for instance (Kensing \& Madsen 1991). Parts of a Future Workshop is conducted according to a set of rules which include formulating and writing short statements on posters on the wall where the speaking time is restricted to 30 seconds to make it easier for all participants to raise their voice. Another principle at this particular part of the process is that there is no need for rational arguments for points raised.

As regards seeing, the prototype was at the meeting experienced in the sense of literal visual apprehension and only on rare occasions did anybody actively experience the prototype by using the remote control. The main exception being the manager of the multimedia department who gave the introduction to the prototype. The fact that the participants of the session were seated as a fairly large group in front of the TV may to some extend account for the lack of interest in trying out the prototype. In retrospect, minor changes to the set-up of the meeting could have supported more active ways of seeing than what actually took place. By having ten people sharing one prototype to a large extend prevented active exploration from taking place. Either more prototypes or some short sessions with minor groups exploring the prototype could have provided a better background for the discussions taking place in this session. Further an awareness of the importance of active exploration could have been reflected in the agenda such that participants were encouraged or asked to actively try out the prototype.

\subsection{The co-operative workshop}

Compared to the set up of the meeting, the setting of the workshop turned out to support more collaboration between the designers in a form where the contributions of the participants complemented each other rather than being isolated, undocumented statements. However, given the experiences from the workshop, we see room for improvements of this type of design work too. As an example of the collaborative nature of the workshop consider how one group explored ways of using the remote control for navigating among the hot spots on an internet page viewed on a TV-set in the living room. In this case, the designers started out from the idea of using the arrow keys on the remote control to direct the position of a cursor on the screen. The initial idea was investigated in series of seeing and moving which involved the use of both the remote control at hand, some screen dumps from the present prototype, pens and paper. The screen dumps facilitated in a very productive manner on the spot experimentation as people were able point to the screendump and not least to add modifications to the screen dump using various materials including post its and pens. Further separate notes were produced on paper for later reference.

Thus the collaborative nature seen at the workshop can be attributed to several aspects of the organisation of the event. By asking the participants to solve a specific design task, and by providing them with flexible materials such as screen dumps on paper, pens and postits, the designers were to a larger extent able to relate to each others comments thus supporting coherence among seeing and moving. Further, the participants used the materials for expressing their ideas in a tangible way, which in conjunction with the fact that the participants were seated in a small group around a table, made the implications of the design proposal easier to explain and build upon among the participants. 


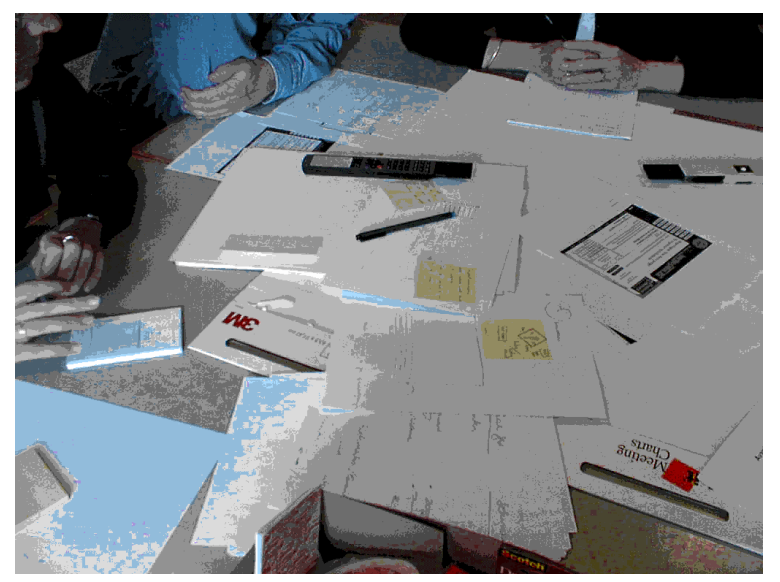

Figure 3 Materials at the workshop

In the workshop, the materials like screen dumps, to a large extent supported seeing in the terms of active exploration when used to play through scenarios of future use. But this setting also turned out to be problematic in other respects. First of all, it was a problem that the design solutions were only tried out actively in one specific case, i.e. on one specific webpage and that the setting did not support an awareness of the limitations of the material. For instance, what would be a good navigation form on a page with few links positioned vertically on one side of the page, may not be a useful navigation form in a case with many links evenly distributed all over the web-page. Obviously, more example materials in terms of print out of web pages would help overcome this limitation. Further, seeing representations in the form of paper prototypes, as was the case in the workshop, raises the issue of whether the experiences from seeing a design representation is in accordance with seeing a corresponding real life implementation of the representation. Obviously this is not the case with respect to the aesthetic experience of a design presented on a piece of paper, which is of great importance in the case of Bang \& Olufsen products. Thus although paper based materials are useful due to the flexibility and modifiability they offer, they are limited with respect to especially their realism regarding aesthetics.

At the workshop, we used the physical space as one of the means of setting up a productive workshop, but this is still an area with room for improvements. One of our experiences was that material from the posters on the walls presenting design dilemmas and users' statements was only used a little during the later design discussions, which might be due to the fact that the session took place in a rather large room. Karat and Bennett (1991) suggest to use a room large enough for two to eight people and small enough so that all walls are nearby. Another general guideline pointed out by Karat and Bennett (1991) is to use each of the walls in the room for separate design issues similar to that we had a stand in three of the four corners. Several designers and researchers, for instance Beyer \& Holtzblatt, K. (1998), have pointed out the value of having a design room available throughout the design process as a way of keeping design ideas and reflection accessible for everybody involved throughout the process.

In terms of the different ways of seeing, the meeting and the workshop represent each their ends of the spectrum ranging from pure visual apprehension to actively experiencing. At the meeting, in which one prototype was mainly demonstrated for the designers by the head of the multimedia department and only few of the meeting participants actually tried out the prototype themselves. At the other extreme, we have the workshop in which the paper screen dumps were actively used to play through future scenarios of use and where the participants in turn took the existing remote control in their hand and played through a use-session using the remote as a dummy remote control. This served to provide each designer with an impression of how the design would come into play in future use situations and thus provided the designers with a basis for the next moves. Given the positive experiences from the workshop in terms of iterations and coherence of discussions, we argue that it is crucial that the designers actively try out design representations at design meetings. This is very much in line with the Scandinavian design tradition, (Greenbaum \& Kyng 1993), where it is argued design proposals in the form of mock ups or prototypes support the collaboration between designers and users. However, given the insights gained in this study we argue that such techniques are also useful in a setting where multiple designers with different backgrounds need to collaborate.

\section{GUIDELINES}

We summarise our experiences from analysing the two forms of design practice in the following set of guidelines.

\section{Supporting collaboration in multimedia design work}

- make available a diverse set of materials to support communication and reflection among the participants;

- flexible materials can support cohesion among seeing and moving;

- the layout of the room may be used as a means of creating dynamic and interactive sessions;

- asking the participants to solve a specific design task within a certain time limit may stimulate productivity;

- use the agenda to balance out brain storming and 
elaboration of design ideas.

Support active hands on experience

- adjust the number of participants to the number of prototypes available;

- put active exploration on the agenda of the design session;

- make sure that people are seated in a way which encourage trying out prototypes;

- use design scenarios to stimulate trying out prototypes in an active way;

- consider how to pay respect to the aesthetic qualities;

\section{Support experimentation}

- provide flexible materials like screen dumps, post its and pens, to support the creation of alternative design solutions;

- use example date, like screen dumps, to facilitate on the spot experimentation;

- be aware of the limitations of the example material

Ideas for possible design materials

- pens

- paper

- cardboard

- post-it notes

- $\quad$ screen dumps

- posters

- mock-ups

- prototypes

- video

- $\quad$ previously developed products

\section{ACKNOWLEDGEMENTS}

The research project Usability in Danish Industry is sponsored by The Danish National Center for IT Research through grant no. 23. We would like to thank Bang and Olufsen for their active participation in both seeing and moving. We would like to thank Susanne Bødker for her comments on an earlier version of this article.

\section{REFERENCES}

Beyer, H. \& Holtzblatt, K. (1998): Contextual Design, Defining Customer-Centered Systems. San Francisco: Morgan Kaufmann Publishers.

Greenbaum, J. and Kyng, M. (1991): Design at Work: Cooperative Design of Computer Systems. Lawrence Erlbaum Associates.

Jungk, R. \& Müllert, N. (1987): Future workshops: How to create a desirable future. London, UK: Institute of Social Invention.

Karat, J. and Bennett, J. L. (1991): Working within the Design Process: Supporting Effective and Efficient Design. In Designing Interaction: Psychology at the Human-Computer Interface. Carroll, J. M. (ed).

Kensing, F. \& Madsen, K.H.: Generating Visions: Future Workshops and Metaphors, in Greenbaum, J. \& Kyng, M.: Design at Work, Lawrence Earlbaum 1991 (155-168).

Schön, D. (1983): The Reflective Practitioner. New York: Basic Books.

Schön, D. (1988): Designing: Rules, types and worlds. Design studies, vol. 9 no 3 July 1988.

Schön, D. (1992): Kinds of seeing and their role in design. Design studies, vol. 13 no 2 April 1992. 


\title{
Creativity, cooperation and interactive design
}

\author{
Susanne Bødker, Christina Nielsen, Marianne Graves Petersen \\ Department of Computer Science \\ University of Aarhus \\ +4589425630 \\ bodker,sorsha,mgraves@intermedia.au.dk
}

\begin{abstract}
This paper focuses on ways and means of stimulating idea generation in collaborative situations involving designers, engineers, software developers, users and usability people. Particularly, we investigate into tools of design, i.e. tools used in design to get ideas for a new interactive application and its use.

Based on different studies from a research project that we have been involved with over the past three years, we present specific examples of such tools and discuss how they inform design. We frame this discussion through the following (theoretical) considerations: a concern for the past and the present in informing design; for theoretical inspiration as a source of inspiration, and for making extremes and multiple voices play a role in innovation.
\end{abstract}

These considerations are used to structure and discuss the examples, illustrating how it is important for such tools to be concrete, tangible and even caricatured.

\section{Keywords}

Tools for idea generation, cooperative, iterative design

\section{INTRODUCTION}

Many design methods suggest that something new, i.e. the new computer application, arises from a stepwise process describing first e.g. the existing physical system, then the existing logical one, followed by the changed logical one and ending with the changed physical one [15]. A first reaction to this is that it is difficult to imagine that something creatively new should come out of a stepwise derivation process from the existing. At the same time we do not subscribe to the idea that creative design is a matter of the individual designer's genius or a strike of lightening, a characterization that seems predominant e.g. in industrial design and architecture of today. Instead, this paper will focus on the systematic and deliberate attempts to create a new design that transcends the current practice of the users, at the same time as it is based on this practice, as well as on the knowledge and skills of designers, engineers, software developers, and usability people. Our experiences stem from the design of a wide range of products: from software to industrial components and TV-sets (see also [4]). Some of these experiences date to earlier projects (e.g.
[9]) whereas the examples that we are discussing stem from a project that we have been involved with for the past three year regarding the development of usability design.

Bødker \& Buur in [4] coin the term design collaboratorium to talk about the overall methodological results from this project. The design collaboratorium is a design approach that creates an open physical and organizational space where designers, engineers, users and usability professionals meet and work along side each other. At the same time the design collaboratorium make use of eventdriven ways of working known from participatory design [8]. This paper focuses on ways and means of stimulating idea generation in the design collaboratorium or similar collaborative design situations.

In our way of thinking, design, be this of computer systems or other sorts of appliances, is an iterative process, involving the active participation of users and of professional designers, engineers and usability people. Hence, design is co-operative. We have earlier discussed how it is of vital importance for designers to understand use so as to build artifacts to support and develop use [6, 7], and how it is essential for users to get hands-on experiences with mockups and prototypes to participate actively in design [12]. It is furthermore important to work systematically to get new ideas to further the design [9]. Because creating something new in design is neither a matter of a stepwise refinement of a description of the existing situation, nor of a hierarchical decomposition of complex problems into solvable ones, new interactive applications must be designed and explored in an iterative process. What we focus on in this paper, are the tools for getting new ideas in cooperative, iterative design.

\section{TOOLS FOR GETTING NEW IDEAS}

In the remainder of this section we will outline our sources of inspiration for the particular analysis that are to come.

$[9,13]$ argue that tools for thinking ahead, for supporting creativity, is an area which still needs development. It is necessary to understand more about where these tools come from and how they might be used in a systematic and purposeful design activity, and not just at random.

These tools are not detached from the history and present tools of design, neither are they detached from the history and present activities of work, that are designed for. Engeström's [16] notion of springboard, a "facilitative 
image, technique or socio-conversational constellation ... misplaced or transplanted from some previous context into a new..." (p. 287), has been important when looking at which technical and social/use-oriented constructions serve usefully as springboards in design. The idea is to move away from stepwise derivations to ways of rethinking the whole of the new activity or parts of it in different, yet very concrete, ways. From a similar way of thinking both Schön [25] and Madsen [20] talks about seeing something as something else, and Madsen [20] proposes using the dissimilarities in two referents of a metaphor as the source for creating something new (by seeing e.g. a library as a meeting place and a warehouse.).

We propose to look for things and notions that in similar ways help us see, or rather do, something in new and different ways in the context of use. Reminding the reader of the need for cooperation and hands-on experience, such tools need to support action as well as reflection [13]. They are furthermore, as Bertelsen [2] discusses, placed in a boundary zone, where the different practices of designers, engineers, usability people and users meet. In order to support cooperation, they must, accordingly, be boundary artifacts, as Bertelsen [2] calls them with reference to Star's [26] boundary objects. They must in some ways support the joint action and reflection, at the same time as the serve action and reflection of each of the involved groups in their activities.

\section{The past, the present and the future}

Computer applications and other technical artifacts should, like any other artifact be seen as historical devices that reflect the state of practice up until the time that they are developed [1]. Thus, to learn something about the present shape and use of a particular artifact, a historical analysis of artifacts as well as of practice is important. Furthermore, to find inspiration for future artifacts, the past generations of technology are informative, we propose. The history, however, is not just an absolute and given thing, and history does not only concern the past. [9] seeks inspiration in [24]. Mogensen, [21] develops his Heidegger-inspired understanding in a similar fashion, to emphasize the relation between the past, the present and the future. The key point is that we are dealing with both experience and expectation as soon as we start researching a practice, and as soon as we e.g. introduce a prototype. Fundamentally, we cannot design from understanding the artifacts alone. Neither can we understand the artifacts only from understanding use as it is carried out "here and now". In this sense, we need to go further, and e.g. Carroll's [14] "taskartifact" cycle (as discussed in [1]).

For our purpose of finding tools that point ahead, we are suggesting that past generations of technology may inform innovation well.

Theory as a possible source of inspiration

Bertelsen [3] makes a thorough analysis of how theory in general, and Fitt's law in particular may appropriately be seen as a design artifact. Morgan [22] uses organizational theories as metaphors for diagnostic readings of an organization, and for what he calls imaginizing, which is basically designing or re-designing organizations. "One of the major strengths of the different metaphors explored in this book is that they open numerous avenues for the ways in which we attempt to organize practice. " (p. 335). Interestingly, Morgan suggests a place for theory, and not just for a collection of random metaphors. Furthermore, he uses the effect of theories contradicting each other as a means of creating openings for innovation.

$[9,10]$ proposes to use theoretical checklists as input to CSCW design, an area that we have explored further as regards learning in use (see below). They similarly make use of the contradictions created through systematic application of particular perspectives as a way of pointing ahead.

For our purpose of this paper, the question is how to operationalize theories so as to inform design.

\section{The present points ahead}

We are assuming that the starting point of creative design is some amount of understanding of use, achieved through a combination of more or less systematic field work and participatory design. It is necessary to capture this understanding, to reduce the empirical situations to manageable dimensions as well as to clarify and complete the situations (See e.g. $[9,17]$ ). The issue of concern here is how this understanding can be used to point ahead.

[13] discusses how scenarios can be used in this effort. Making scenarios is a creative process: they are hypotheses, or qualified guesses about the artifact [9]. They serve to open the dialogue about future possibilities and current constraints. [13] proposes that we have to work with work situations and scenarios as constructions meant to stage acting in the future or to reflect on and illustrate problems with this action. Selecting and "cutting" the right situations out of many hours of video and observation material is in itself a construction process where the new is constructed, rather than a reproduction of the existing. What is gained from the real situations is mainly the richness of detail that makes them useful triggers of thoughts.

This paper will discuss further how to "design" present situations so as to serve design.

\section{The right tool for the job, extremes and multiple voices}

There is much more to a good scenario than choosing a characteristic work situation. Depending on the state of the prototype that one is dealing with and of the objective in terms of purpose of the design situation and scope of the prototype as regards to what aspects of work it may support, it pays off to be very selective [13]. [9] proposes that representations are containers of ideas, rather than some sort of mapping of an existing or future situation or artifact. This suggests that we need to focus more on a 
variety of representations that support different purposes and perspectives in the design activity.

Overemphasizing distinguishing features makes the point more easily understandable for participants. It gives a better effect to create caricatures instead of such that are nuanced. [9, 13] develop the notion of plus and minus scenarios as one way of driving particular features to the extreme, instead of evening out between the useful and the non-useful, or instead of aiming for a neutral scenario. [13] argues that it is much easier for users and whoever else is going to relate to the scenarios to assess things when they see full-blown consequences than when the implications go a bit in all sorts of directions. Not that they "believe" in the caricatures, indeed they don't, but it is just much easier to use ones common sense judgement when confronted with a number of extremes, than when judging based on some kind of "middle ground".

As mentioned, Morgan [22] uses the theoretical perspectives in a manner where they may at time contradict each other, and he, Engeström [16] and other have argued that this is actually where the openings are for creative innovation. Similarly, [9] propose to use the checklists to support contradiction and dialogue. The checklists were consciously organized to let different perspectives talk to each other.

[2] discusses how design takes place in a boundary zone where heterogeneous practices meet to create the new, emphasizing the multi-voiced nature of design. Engeström [16], and along with him Bertelsen [2], talks about heteroglossia, or multi-voicedness as a way of letting different voices participate in the creation of the new. Engeström's [16] notion of multi-voicedness deserves mentioning as a perspective on bringing the voices of various groups together, constructively, in design/development of a new work activity. [13] gives various suggestions to how scenarios, anchored in specific use/work situations may be used to support bringing these voices forth.

In the present paper we illustrate and discuss how to choose the right tools, in terms of constellations of scenarios, prototypes, etc. for the design activity in question. We will further illustrate how we have made use of extremes and supported the multiple voices of the particular design activities that we are dealing with.

\section{Tools develop}

Just as any other tools, the design tools that we present and discuss here develop in use, in the particular setting in which they are used. This has consequence, for us, as well as for any reader who might want to use some of these ideas in their own settings. We hope that presenting our own development process to the reader, we will leave ways open for further development of the tools, rather than stigmatizing the reader in a "does it work or not" choice.

\section{THE EMPIRICAL EXAMPLES}

The empirical material that we present and use in the following comes out of a project that we have been involved with for the past three years. We have been collaborating with the usability departments of Bang \& Olufsen A/S, Danfoss A/S, and Kommunedata, in an action oriented research project that aimed to develop the work practices of usability [4]. The three involved companies do their work rather differently, and work with different products ranging from computer software to hi-fi equipment and thermostats. Common to them, however, is that during our joint project they have been moving out of the lab and into the field ([7,19]). They have committed themselves to collaborating with users as well as with designers and engineers, and they have moved from doing evaluation of products to doing design together with these other groups [4].

Our attempt to move usability from evaluation to collaborative design has taken many experimental forms, and this paper will focus on only one of these, the development of cooperative, tangible tools for creation of ideas.

The remainder of the paper is structured as two sets of examples from two projects in two of the three companies. These examples will shed light on the theoretical issues above and lead to a concluding discussion of the possibilities and constraints of such tools.

\section{THE PC-TV LIVING ROOM}

The project framing this case was the development of a Bang \& Olufsen PC-TV living room. The vision was to provide users of a traditional television set with access to PC functionality and applications when seated in the sofa in the living room. The total number of people involved in the project was around 10, half from the usability group, half from the multimedia department, and one from the communications department. From this case, we look at three interlinked design activities, that involved us as researchers as well as Bang \& Olufsen usability designers and engineers, and to some extent the users. These activities are: "Talk to your TV", using workshop-stands and the construction and use of learning checklists.

\section{Talk to your TV}

In this activity we enrolled a small number of users (2 individual sessions and one session with 2 users together) and asked them to do two things together with us:

a. to find some information using the tele-text and remote control of TV-set provided by us. An example scenario dealt with how to find out about the weather in Sidney in connection with a trip there.

b. to find the same information "talking to the TV". We used a transparent "Wizard of Oz" technology, in that somebody in the room would actually press the relevant buttons on the remote control to get what was requested. In 
other words, we created an open and flexible prototype out of an existing TV-set.

Some users were proficient users of tele-text and some not, which we believed to be a strength because we wanted to get as many ideas as possible regarding the interaction with the tele-text. All users were also proficient WWW-users. This became apparent through a lot of comments and ideas. The users produced a number of ideas of interest to design. Some of these had to do with sequentiality of sub-pages, some with the overall structuring of the search, some with ways of stepping back, and of retrieving previously used pages, and some had to do with the lay-out of the remote control.

We found that through choosing an extreme, futuristic interaction modality in $b$, the users were provoked to think beyond existing possibilities both in terms of technical aspects and in terms of design. This happened especially when $b$ followed $a$. We experimented some with the order of $a$. and b., to investigate which setup stimulated creative ideas the most. We found when we started out with $b$, the users were quite restricted by existing limitations due to their familiarity with the existing design. When $b$ followed a however, it stood as a contrast to the limitations of the existing design, and thus worked better as a springboard for the users in generating ideas beyond the existing design.

The scenarios were used to form an overall "story-line", which turned out to be a good idea. However, we used the same scenarios, that were rooted in the current tele-text functionality, in both $a$ and $b$. In retrospect we should probably have chosen two different sets of scenarios for the two sessions, and have made some more directed towards possible future functionality.

We edited a videotape that presented the innovative design ideas which came up in the "talk to your TV" activity. We presented this to the Bang \& Olufsen group as a source of inspiration for the design of the PC-TV living room and as an example of how users can contribute with creative ideas for design. Through this material, we sharpened the "voice of the users" not based on any claim of representativity, but as a source of potentially interesting design ideas. The video recordings of these experiments were a useful basis for being selective, emphasizing particular problems or situations when editing the video. The recordings are fictions in more than one sense: First of all, the original use experiments were constructions and nothing that could be called real use. Secondly, they were digested by us into a story that we wanted to tell. The main criteria for selecting what we wanted to tell was to overemphasize distinguishing features, so as to make the point more easily understandable for participants. In accordance with our earlier work [13], we found it much more effective to create simulations that are caricatures instead of such that are nuanced. Further, the story of this material is not any more "true" and objective, by virtue of having been recorded on video. The design ideas developed by a group of designers such as in this case, still ultimately need to be tried out in real use situations in order to prove their worth. And the way we use video material in this case provide no way around that.

The "Talk to your TV" project investigated futuristic interaction modalities as springboards $[9,16]$ for users in generating design ideas. The experiences from "Talk to your TV" illustrate how we can create the new, inspired by the existing, once the setup of the confrontation between users and the technology is carefully considered. Moreover, the project exemplifies how something fruitful comes out in the meeting between contrasts, in this case the different interaction modalities. Finally, this initiative formed part of our contribution to move usability work from evaluation to co-design through experimenting with settings that support users in their role as creative partners in the design process. We did not set up the "Talk to your TV" sessions to extract a representative voice of the users that we could present to designers. Neither did this project focus on actual user involvement, field work and capture of real work situations, nor with other possible ways for designers, engineers and usability people to cooperate. Rather these simulations are constructions made with a purpose, in this case to illustrate alternative solutions regarding fundamental issues of HCI as outlined above.

In our experience, supporting user participation by giving them means for externalizing their design ideas by providing materials for sketching and modeling as ideas show up would be a valuable extension to the experiment. In this way the users could develop their ideas a little further and express their ideas in more tangible ways.

Further, we see some potential in using the video more actively in the session, e.g. through working with the video recorded in the first part of the session in cooperation with the users as the basis for elaborating or developing on the design ideas expressed.

\section{Workshop stands}

As part of the design of Bang \& Olufsen PC-TV living room we arranged a design workshop [18] where different stands served to inspire the design work as described in the following. A group of people from the usability group, the multimedia department, the communications department and researchers met in a room equipped with products and prototypes of relevance to the PC-TV living room. In order to prepare the workshop, the different competencies in the project had been asked to prepare a stand each presenting what was in a sense their favorite related products or prototypes. The participants split in two multidisciplinary teams who in turn visited the stands.

The stands were: The voice of the users presented by the researchers, the prototypes of the technicians, and the products of the designers. 


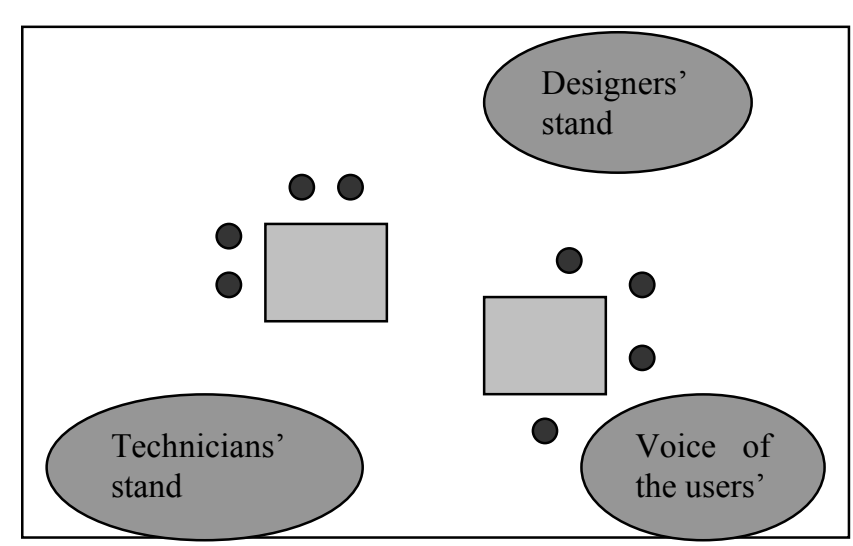

Figure 1 The layout of the design workshop room.

At the stand presenting the voice of the users, the video clips from the "talk to your TV" experiment were presented. The clips were supplemented with posters capturing the design ideas envisioned by the users. Together the video and the posters provided tangible means [27] for the discussions in the group of designers, engineers and usability people. However, we believe that had the video clips been shortened, from 10 minutes e.g. into 2-3 two-minutes sessions they would have been even more useful for this purpose. The technicians' stand displayed a wide variety of prototypes including various prototypes of remote controls. Finally, the designers presented an earlier product named the PC-TV office, which is the counterpart of the PC-TV living room, in that it brings the TV functionality to the PC for use in the office. At the stands of both the technicians and the designers were also posters capturing design rationale and design dilemmas of relevance to the design of the PC-TV living room.

In the first round of the workshop, the participants were in groups asked to take a round in the room, visiting the stands. At each stand they were asked to comment on the issues raised at each stand and to capture their discussions on post-it notes.

Based on the discussions held in this first round, two specific design issues were chosen for the two groups to work on. Each team was asked to produce their design solution in a tangible form, for instance as a paper prototype. After half an hour, each group presented their design proposal for the other team, and then swapped design topics. For the second round a team could either start from scratch or start out from what the other team had produced. At their disposition were various design materials including pens, paper, Scotch tape, post-its, etc. In addition, screen dumps from the current prototype of the PC-TV living room were available.



Figure 2 discussions around posters at the designers' stand.

The range of representations at the stands served as sources of inspiration and promoted the different perspectives in the design work. Through having tangible representations, all participants in the meeting were supported in promoting the different perspectives. In this way the different voices were not solely attritbutable to certain participants but, through the stands, all participants were supported in taking advantage of all perspectives.

For instance, when discussing how to provide access to web pages on a Bang \& Olufsen television, in particular how the navigation should be supported using a remote control, one of the participants in the workshop walked up and grabbed one of the early prototypes at the technicians' stand. He brought it to his group and acted out how he envisioned a design solution. Subsequently, one of the other participants requested the prototype and demonstrated a slightly modified version of this first suggestion. In this way, the discussion carried on for a while with the different parties supplementing and contrasting each other using the prototype from the stand as an important point of reference.

The material at the stands also made reference to the historical development of Bang \& Olufsen products. This in turn was fruitful since the old products served as a source of inspiration in the development of the new product. To illustrate this, the PC-TV office product that was presented at the designers' stand had been developed before the PC-TV living room project started. This product allows users to watch television on their PC. At several occasions the PC-TV office was referenced in the discussion on how to design the PC-TV living room. In this way, on the discussions about whether there should be some sort of menu-bar to access Internet functionality on the PC-TV living room, the remote control representation on the PC version was references as a source of inspiration both positively and negatively. Positively, in the sense that 
the living room product could be inspired by the office version such that they both had the special Bang \& Olufsen expression and both appeared to be part of the company line. At the same time the PC-TV office product served to emphasize the contrast to the PC-TV living room in that the two products are designed for very different use situations and each need to have their own identity. Hence, through having earlier products available for direct reference, the workshop participants were offered inspiration for the design both in terms of supporting continuity as of taking up new challenges in design.

The workshop described was set up for a single day event and the stands were removed by the end of the day. An interesting extension to this approach is to permanently equip design rooms with stands or with a rich set of representations, products, prototypes and statements, which as described above allow designers to be inspired from both looking back and looking ahead when designing new products. At this very moment Bang \& Olufsen is working on designing their own design workshop room inspired by these thoughts.

\section{Learning checklists}

In order to explore how to design more learnable, or selfexplanatory interfaces for the TVs so as to inform Bang \& Olufsen TV design in general (see also [5]), and the PC-TV living room in particular we undertook a study of HCI literature about learning, and tried to operationalize these in checklists [9].

The development of the learning checklists has been an iterative process where we (the researchers) created an initial version based on literature studies. This version was used in a design workshop with the entire project and in a similar workshop with a group of multi-media students. After iteration the checklists tried out in the PC-TV [11]. It is this use that will be focussed on in the following.

We developed four checklists, each focusing on particular areas of relevance for our study of learning of a particular artifact:

- questions of artifact/user interface

- questions of errors

- questions of differences between novices and experts

- questions of use/learning context

The number and headings of the checklists more than anything reflect areas focused on and insights to be gained from textbooks and scientific papers. Obviously these lists (For examples from the list see figure 3) were not allinclusive and they were a consequence of choices we made together with the usability people, regarding what would be useful in these particular analysis and design situations. Our idea was that the checklists could be used for focusing empirical investigations of learning in use as well as for reflecting on possible hypotheses and design solutions.
We have analyzed a number of trial use situations of TV sets. The use situations all deal with one or both of two Bang \& Olufsen TV sets that are handlingwise quite distinct. We were given two TV sets for exploration, and notes were made regarding usability issues as the two TV sets were gaining increased use.

The analysis of the empirical material was indeed post-hoc as regards the design of the two particular TV sets. In particular, we looked at five interesting situations of trial use, where some problem occurred that could be related to the relation between the user's background and the design of the particular artifact, or to forming and consolidation of operations.

These analyses were used to further inspire the design of the PC-TV living room, which includes a more complex interface than the "plain" TV.

Our experiences from this can be summarized in the following:

- analyzing use background is design in that it is necessary to make choices regarding which use backgrounds and relevant artifacts to focus on (see further discussion in [21]).

- in order to look ahead and identify potential competence of the users it is as useful to focus on metaphors and artifacts that are different from the one being designed as it is to focus on such which have similarities.

- confrontation of perspectives was informative for design. Using the checklists emphasizes the important point that one cannot necessarily accommodate for all concerns at once, and that these contradictory concerns needs to be considered in the specific design.

To actually design the learnable PC-TV is a long step from this analysis. However, the checklists helped in shedding light on where or what the users learn from, and what analogies are of importance (both positively and negatively), and where learnability issues collide. We are continuing to fuse these findings into our discussions with Bang \&Olufsen.

The learning checklists have been thoroughly restructured in their continued use, and in our ongoing theoretical elaboration. This process is described in [11]. 


\section{Investigation of artifact/user interface}

1. Does the artifact allow for inspection of the result physically, "outside" the artifact? If not, how well will the later end-result be represented in the artifact? (is what you see what you get?)

2. Does the artifact allow for experiments, e.g. through undo? How does the artifact support the user in getting "back on track" after a breakdown in handling the artifact?

4. Does the artifact invite users to use experiences from other artifacts?

5. How extensive is the set of menus or commands? can the user be cut off from the use of certain parts of menus or commands, either through pre-defines settings or by his or her own choice?

\section{Investigation of errors}

The overall hypothesis is that all users err, as part of their exploratory use of an artifact, but that e.g. novices and experts may err in different ways.

1. Is the error conceptual/bound to a misunderstanding, or operational/bound to the handling of the artifact?

3. Does the error result in a breakdown in relation to the handling of the artifact or to an object of scrutiny, or is the error seen through a work-around?

4. Does the error relate to the user's understanding of/ acting in the domain of work, the particular artifact, or technology in a wider sense?

Investigation of differences between novices and experts

1. Does the user approach the artifact as neutral observer, wanting to investigate the artifact, or does she just start doing the job?

2. Does the user apply external theories or a repertoire of flexible strategies?

4. Can the user handle multiple, conflicting purposes of work or only one?

Investigation of use/learning context

2. Which materials are used for what and how is the artifact applied in relation to these materials and

\section{USING INTERACTION PERSPECTIVES TO TRIGGER IDEAS}

Basis for the second example was a design project at Danfoss. The User Centered Design Group at Danfoss and a group of researchers from Aarhus University were undertaking a study of work at a combined district heating and power plant. The overall aim of this project was twofold: to investigate into the need for and consequently possible uses of portable/handheld technology in the plant; and to utilize and develop methods for usability work in the field.

The field study was done over several rounds with 3-8 people from the research group spending several days in the plant following different workers in groups of two with video cameras [23]. This video was analyzed and a small number of key situations were transcribed as the starting point for further design considerations. These transcripts of dialogue between workers in the plant, pictures of the setting, and the actual snippets of video constituted the work situation descriptions in this example.

The field study and video analysis provided us with a greater understanding of the work taking place in a process setting like a combined heating and power plant, and pointed out some areas in which mobile technology could be introduced to support their work practices.

\section{The Museum workshop}

As a parallel event to further our understanding of what constitutes a process environment and act as a source of inspiration, a workshop was held at the Danfoss museum. On display at the museum is virtually every kind of component ever produced at Danfoss and the tour through it shows the development of the company tied into the story of Mads Clausen, the man who founded Danfoss. The aim of this workshop was to sketchingly chart the development in Danfoss components, the technology and interaction concepts, as well as the development in the organization ('the Danfoss company sprit', or how Danfoss saw itself), and through the unfolding of the history find new inspiration for design.

In working with the development in technology and interaction concepts, we considered the role of technology in the society at particular points in time, illustrated by the science-fiction literature of that time (inspired [28]). With this timeline, we classified the interaction styles used in the components in relation to the technology view of the specific point in time, and created three character types to exemplify these.

\section{Design principles}

The generation of these characters triggered the idea of using interaction perspectives in a much more structured way as tools for creativity.

Basis for our effort was the four theoretical interaction perspectives (tool, media, system and dialogue partner) described in [12]. Briefly described, the four perspectives map out the basic relations between humans and artifacts as follows. In the Tool perspective, humans use tools to work on material (in analogy to how we use a hammer). In the System perspective, humans and machines are regarded the same type of components, i.e. the human are reduced to the 'language' of the machine. The Media perspective emphasizes humans interacting with humans through machines (seeing "undisturbed, direct communication as an ideal). Finally, in the Dialogue Partner perspective the 
human's interaction with the machine analogous to a dialogue between humans, i.e. using natural language.

Based on these theoretical constructs, four 'design perspectives' were created as two-page posters with the original, abstract description of the interaction perspective on the right-hand side and a character description to the left-hand side, focusing on his or her use of technology, which served as an exemplification of the perspective. Inspired by our work at the museum workshop, we chose characters originating from the science fiction literature and films, which also served the purpose of making them easily recognizable. We chose Flash Gordon as the personification of the Tool perspective, Spock for the System perspective, The Nethacker (based on various characters from William Gibson's universe) for the Media perspective, and the ship computer 'Mother' on the starship Nostromo (from Ridley Scott's film 'Alien') for the Dialogue Partner perspective. We see these perspective/character pairs as a tool for sketching a 'design space' for the further exploration of the setting. The future scenarios and designs we created with them as brainstorming devices enabled us to look at the same setting, use description or problem from different perspectives. Utilizing theoretical constructs like the four original interaction perspectives in relation to a character enabled us to exemplify the strong and weak points by imposing them on a scenario in which the character could act. The theoretical description worked as a backdrop to consolidate the characters' behavior.

Furthermore, the coupling of perspective and character gave the participants a concrete anchor into the concepts. We experienced repeatedly that when using the perspective/character pairs, participants would refer to how the character would act in a given situation, rather than how the given perspective would apply, thus considering the concepts within the interaction perspectives as the characters' behavioral patterns. This is hardly surprising because the characters provided a very effective means of relating the abstract concepts to the concrete example of work. It stresses the value of providing good exemplification when working with interaction perspectives to inter-link the abstract and the concrete.

The historical frame, which initially inspired the choice of characters, showed itself as a double-edged sword. We realized that our choices of characters had some unintended negative effects: the sci-fi characters were too fixed within a certain time period, e.g. Flash Gordon made the Tool perspective seem 'old' or outmoded, a limitation which is not inherent in the original theoretical tool perspective. We want to maintain the recognizability of the characters without stigmatizing them by grounding them in a specific, historical context, which we seek to remedy in a later version of the perspective/character pairs.
Furthermore, it was difficult to find already defined characters whose 'personality' fits the perspectives fully. E.g. as regards 'Mother', they do not use normal language to communicate with it in the film but a complex command language and a standard screen and keyboard! However, our only plausible alternative, 'Hal', the ship computer from Stanley Kubric and Arthur C. Clarke's "2001 - A Space Odyssey" seemed to have to many negative connotations attached for it to be used constructively. Some of our characters were simply inappropriate for the concepts they were meant to exemplify.

Following the recommendations from [9] to use extremes to make a point, we plan to extend each of the four perspectives with a 'good guy' and a 'bad guy' description of them to juxtapose their positive and negative aspects. The positive and negative connotations associated with each perspective provide a more detailed image of the possibilities and limitations of them, and serve the purpose of distinguishing the individual design perspective even further from the rest.

\section{Using work scenarios to anchor perspectives}

At a second inspiration workshop, a group of interaction designers, industrial designers, HCI researchers, usability engineers and psychologists from Danfoss, Kommunedata, Bang \& Olufsen and Aarhus University was gathered to work with the first version of the design perspectives in relation to work at the combined heating and power plant. These were immediately nicknamed 'Flash Gordon and friends'. The participants were handed a small number of work situation descriptions. They watched video from the field study at the plant, and were asked to explore design possibilities for a portable piece of equipment from the point of view of the four design perspectives, one perspective in each of four groups. It is in this context essential to note that the work situations used in this workshop were not chosen at random from the vast quantities of video material from the field study, but situations carefully selected because they illustrated circumstances within which mobile technology might support the work [13].

The groups created scenarios based on the work situation description to situate their thinking about possible ways of interaction in this setting - where would the media perspective, emphasizing communication between people in the plant, head? Or, with the tool perspective, which tools would be needed, and for what purposes? The groups were further asked to present their design scenarios by acting them out, and obviously this was easier for some groups 
than for others. In particular, one group came up with a futuristic design scenario with negotiating sludge-tanks, and for them the specific dialogue of the original use setting was of little use. However, all groups found scenarios to be a useful way of relating possible interaction designs to what actually happens in the plant, despite the very selective work situations.

We found that the restrictions inherent in working with one specific work situation description and one specific design perspective actually helped define the boundaries and create a common ground on which the participants could use their individual experiences and backgrounds in the negotiation of the design. This 'boundary zone' [2] was first defined through the negotiation between the participants of how the assignment should be understood and affronted. Later it served as a collaborative design space as the participants started sketching design ideas for the future scenario on paper and with simple props like pipe cleaners and plastic cups, elaborating on some and discarding others.

The choice of using the same work situation description across the groups rather than choosing work situation to fit the individual deign perspectives provided means of comparing the resulting design scenarios. Furthermore, the use of sci-fi characters, which are arguably caricatures, for the different types of interaction exaggerated the differences between the different perspectives, which made them easier to juxtapose and assess.

The intended outcome of this workshop was not to generate specific design solutions but rather to inspire and aid the process of generating new ideas for regarding mobile support for work at a combined heating and power plant. We see the use of caricatures in the design perspectives as an important tool in achieving this goal. Because the design perspectives quite clearly did not provide realistic views of the world, it was also clear for all participants that their utilization did not yield the solution to a design problem but rather the unfolding of a design space.

\section{CONCLUSIONS}

We have described and discussed a number of tools and how they support creativity in design. Common to them is that they support, and are developed to support, cooperation in design. Cooperation both at the level where they support meetings in the boundary zone of the overlapping practices of design, and at the level where they are part of cooperative activities in design. They help provide tangible artifacts that the groups of designers, users and usability people can get their hands on and explore in these cooperative activities. They provide input to these sessions, and they are part of shaping the results. And though we talk about creativity, and about what is really thinking tools [9], the results of using these are very concrete and support the next iteration in the iterative design loop.
The proposed tools are different, and none of them serve all purposes equally well. In the following we discuss the described tools from the point of view of how they support our initial theoretical points.

\section{The past, the present and the future}

Using the past to inform design has taken various forms in our work: The Danfoss museum is certainly one, where the relationship between the form and appearance of products were considered in relation to general stylistic trends, pointing ahead (See also [28]). However, as we point out, it is important not to make these past styles appear oldfashioned, if they are to serve design constructively.

In the Bang \& Olufsen example, the stands explicitly served for particular groups to extract the positive aspects of a particular past product, and confront these with the future product. In both the learning checklist analysis, and the "talk to your TV" example, people made references to past artifacts that they were reminded of, for good or bad, for reasons of similarity or difference. The latter is an important concern that has come out of our present work: That the past does not only inform design as regards the good sides, it is equally, though perhaps less constructively, informative regarding the less attractive sides.

\section{Theory as a possible source of inspiration}

The checklists and interaction perspectives are two different ways of operationalizing theory. Through the personification, etc, the interaction perspectives seem much more readily available for being acted out and explored. This does not mean the checklists could immediately be given the same "flavor", simply because the questions they ask are not as coherent and clear-cut.

However, both of the types of operationalizations have been used, and are useful for confronting particular sets of concerns in a particular design.

\section{The present points ahead}

The TV sets in use give useful design ideas. In the "Talk to your TV" example it was clear that by starting with the present, well known use, the users were inspired to think ahead, when asked to talk to their TV. In contrast, when they were asked to talk first, they were much more trapped in the present, perhaps in demonstrating that they knew what tele-text was about. And, as discussed, through the analysis of the present, we are already shaping the future. The present day products which were presented at the stands also acted at tangible means in support of design in the Bang \& Olufsen workshop as in other examples we have seen [8].

Using transcribed situation out of use turned out to be a very useful basis for designers to explore the consequences of the interaction perspectives. The anchoring in the actual use made the designers fly, with both feet on the ground, and it was possible to discuss implications of the design choices, without this being pure speculation. 
We find that what is useful overall in these examples, is that the references to the present are concrete and quite specific.

\section{The right tool for the job, extremes and multiple voices}

The right tool for the job, in our analysis, is one that gives a concrete, and often tangible focus, perhaps oversimplifying matters a bit, so as to illustrate extremes. We have made good use of clear-cutting perspectives, be these in terms of particular perspectives of certain groups as in the Bang \& Olufsen stands, or through opening up a broad design space with the different interface modalities in the "talk to your TV" example. We have developed theorydriven extremes as with the interaction perspectives, and we are in general proposing to work with extremes in terms of plusses and minuses, good guys and bad guys.

It is equally important to keep confronting these perspectives, however, and not to go off in any one direction. This is indeed why the meeting of perspectives through cooperation of people in workshops is very important for the whole of the creative design process.

\section{Tools develop}

As we have illustrated the proposed tools for creativity are in continuous development. It is essential to continuously confront the tools with the particular design situations that one is designing for, and with the ongoing accumulation of experiences in these particular design activities.

\section{ACKNOWLEDGMENTS}

The project "Usability work in Danish industry" is sponsored by CIT/CMT through grant \# 23.

We thank all the BIDI-participants for their contributions; Pernille Marqvardsen, Kim Halskov Madsen, and Thea Borgholm for their contribution to the work presented here.

\section{REFERENCES}

1. Bannon, L. \& Bødker, S. Beyond the Interface, Encountering Artifacts in Use. In Carroll, J. (Ed.). Designing Interaction: Psychological Theory of the Human-Computer Interface. Cambridge University Press, pp. 227-253, 1991.

2. Bertelsen, O. W. Elements to a theory of design artefacts: a contribution to critical systems development research, Ph.D.-Thesis, Aarhus University. DAIMI PB-531, 1998.

3. Bertelsen, O.W. Fitts' Law as a Design Artefact: A Paradigm Case of Theory in Software Design. In Blumenthal, B., Gornostaev, J. \& Unger, C. (Eds.). Human-Computer Interaction. 4th International Conference, EWHCI '94 St. Petersburg, Russia, August 1994. Selected Papers, Berlin: Springer Verlag, pp. 1118, 1994.

4. Buur, J. \& Bødker, S. From usability lab to "design collaboratorium": Reframing usability practice, paper submitted to DIS 2000.
5. Bærentsen, K. Intuitive User Interfaces, paper in review for Scandinavian Journal of Information Systems

6. Bødker, S. Ehn, P., Kammersgaard, J., Kyng, M., \& Y. Sundblad. A Utopian Experience, Bjerknes, G., Ehn, P. \& Kyng, M., (Eds.). Computers and Democracy - a Scandinavian Challenge, Aldershot, UK: Avebury, pp. 251-278, 1987.

7. Bødker, S. and Halskov Madsen, K. Context - an active choice in usability work, Interactions, July+August 1998, pp. 17-25.

8. Bødker, S. \& K. Grønbæk Design in Action: From Prototyping by Demonstration to Cooperative Prototyping. In Greenbaum, J. \& Kyng, M. (Eds.). Design at Work: Cooperative Design of Computer Systems. Hillsdale, NJ: Lawrence Erlbaum Associates, 1991pp. 197-218.

9. Bødker, S. and Christiansen, E. Scenarios as springboards in design. In Bowker, G., Gasser, L., Star, S. L. and Turner, W. (eds.). Social science research, technical systems and cooperative work, Mahwah, NJ: Erlbaum, 1997 pp. 217-234.

10. Bødker, S. E. Christiansen, M. Thüring, "A conceptual toolbox for designing CSCW applications", COOP '95, International Workshop on the Design of Cooperative Systems, (pp. 266-284), Juan-les-Pins, January 1995

11. Bødker, S \& Petersen M.G. Design for learning in use, paper in review for Scandinavian Journal of Information Systems.

12. Bødker, S. Through the Interface - a Human Activity Approach to User Interface Design. Hillsdale, NJ: Lawrence Erlbaum Associates 1991.

13. Bødker, S. Scenarios in user-centred design - setting the stage for reflection and action. Hawaii International Conference on System Sciences 32. CD-ROM. Version to appear in Interacting with Computers, 1999

14. Carroll, J. M., Kellogg, W.A. \& Rosson, M. B. The task-artifact cycle. In Carroll, J. M. (ed.) Designing Interaction: Psychology at the Human-Computer Interface, New York: Cambridge University Press, 1991, pp. 74-102.

15. Coad, P. \& Yourdon, E. Object-Oriented Analysis. Englewood Cliffs, NJ: Prentice Hall, 1990

16. Engeström, Y. Learning by expanding. OrientaKonsultit, Helsinki, 1987.

17. Kyng, M. Creating Contexts for Design. In Carroll, J. M. (Ed.), Scenario-based design. Envisioning work and technology in system development (pp. 85-108). New York, NY: Wiley 1995.

18. Madsen, K.H. and Petersen M.G. Reflections on three design sessions, Brewster, S. Cawsey, A. and Cockton, G. (eds.) Human-Computer Interaction - INTERACT'99 (Volume II), IFIP, 1999, pp. 185-190. 
19. Madsen K.H. and Borgholm, T. Cooperative Usability Practices. Communications of the ACM, 42, 5, May 1999, pp. 91-97.

20. Madsen, K.H. A Guide to Metaphorical Design. Communications of the ACM, 37 (12) 1994, 57-62.

21. Mogensen, P. Challenging Practice: an Approach to Cooperative Analysis, Ph.D. thesis, Aarhus University: DAIMI PB-465, 1994.

22. Morgan, G. Images of organization, Beverly Hills CA: SAGE, 1987.

23. Nielsen, C. Testing in the Field. Proceedings of APCHI 98, IEEE Press, 1998, pp. 285-290.

24. Ricoeur, P. Time and Narrative (Volume 3). Chicago: The University of Chicago Press, 1988.

25. Schön D. A. The Reflective Practitioner-How Professionals Think in Action, Basic Books, New York, 1983.
26. Star, S. L. The structure of ill-structured solutions: boundary objects and heterogeneous distributed problem solving. In Gasser, L. \& Huhns, M. (eds.) Distributed artificial intelligence, vol. 2, London: Pitman, 1989, pp. 37-54.

27. Trigg, R., Bødker, S. \& Grønbæk, K. A Video-based Analysis of the Cooperative Prototyping Process. Scandinavian Journal of Information Systems 1991, vol. 3, pp. 63-86.

28. Øritsland, T.A. A Theory of Discursive Interaction Design. Mapping the development of quality and style in man machine interaction, Doctoral Thesis, Norwegian University of Science and Technology, Department of Product Design Engineering, Trondheim 1999 


\title{
The interactive design collaboratorium
}

\author{
Susanne Bødker*, Peter Krogh\#, Marianne Graves Petersen* \\ *Department of Computer Science and Center for Human-Machine Interaction, \\ University of Aarhus, Aabogade 34, DK-8200 Aarhus N \\ \# Aarhus School of Architecture, Danish Center for Integrated Design, DK-8000 \\ Århus C
}

bodker, pkrogh,mgraves@daimi.au.dk

\begin{abstract}
This paper reports on an experimental process in which a prototype was developed of an interactive design collaboratorium, in cooperation with a group of usability designers. In a longterm research cooperation, this usability group has changed its work practice in order to work in the design collaboratorium. The design collaboratorium was developed to move usability design away from a lab towards an open physical and organizational space where designers, users and engineers meet and collaborate, or work alongside each other. The cooperation between researchers and the usability group has resulted in practical experimentation in projects and in experimental design of an experimental design collaboratorium employing electronic whiteboards, 3D design documentation, etc. This experimental prototype has been evaluated in cooperative workshops. We report on the results of this evaluation.
\end{abstract}

Keywords: Interactive design rooms, usability design practices, cooperative design

\section{Background}

The design collaboratorium is an approach to usability design where the focus is on involvement of usability concerns early in design, concern for actual use rather than what is re-produceable in a lab, and for collaboration between the competencies of design and usability. The design collaboratorium has been developed (Buur \& Bødker, 2000, Madsen \& Borgholm, 1999) through practical experimentation in projects in three companies. One of these companies was Bang \& Olufsen whose usability design work we focus on in the following. In cooperation with researchers, this usability design group has done an experimental implementation of aspects of the design collaboratorium. Studies of this implementation have been the basis for informing an experimental design of an interactive design collaboratorium prototype, employing electronic whiteboards, 3D design documentation, etc. This experimental prototype has been evaluated in cooperative workshops. We report on the results of this evaluation, and discuss requirements for the further design of interactive design room technology.

The vision of the design collaboratorium covers the following themes (Buur \& Bødker, 2000):
It accumulates design knowledge. To serve as a reminder of important aspects of the design complex, the design collaboratorium contains places for summing up the various phases of design. It reflects the history of the project, the history of use, the history of the product line, etc.

It reflects the use context, both to constantly remind the design team of the people and the environment for which they design, and to make it easier for users, when invited to participate, to engage their tacit knowledge.

It inspires innovation by being equipped with artifacts and illustrations pointing out new directions either related to the work domain in question or unrelated to provoke contrast.

It supports open and closed cooperation between changing constellations of participants. People can enter and exit at will or in coordinated manners. A place where things may be left behind is a place to come back to. Doors can be closed when the participants decide so, and open to new participants when that is the choice.

\subsection{Research approach and related work}

The work on the interactive design collaboratorium draws upon experience and techniques from a number of different fields: Collaborative Virtual Environments (Churchill \& Snowdon, 1998), Human-Computer 
Interaction and usability practice (Madsen \& Borgholm 1999), and Computer Supported Cooperative Work (Schmidt \& Bannon, 1992).

Specifically, this work draws upon and expands on a number of studies of design rooms (Karat \& Bennet, 1991, Madsen \& Graves Petersen, 1999) and design spaces (e.g. Büscher et al., 2000), by focusing on the development of a particular design practice, supported by interactive technologies.

Technologically, we have been inspired by interactive room technologies (e.g. Streitz et al., 1999), electronic meeting environments, (e.g. Pedersen et al., 1993), and whiteboard-based interaction, (e.g. Rekimoto, 1998). In contrast to many of these designs, our interactive design room draws from a longterm empirical study (Buur \& Bødker, 2000, Madsen \& Graves Petersen, 1999) as well as from the particular problems of the current ways of working in the specific case. We explore the usefulness of recent technological gadgets, and this paper shows how questions arising out of the particular empirical case can inform general problems of interactive design rooms.

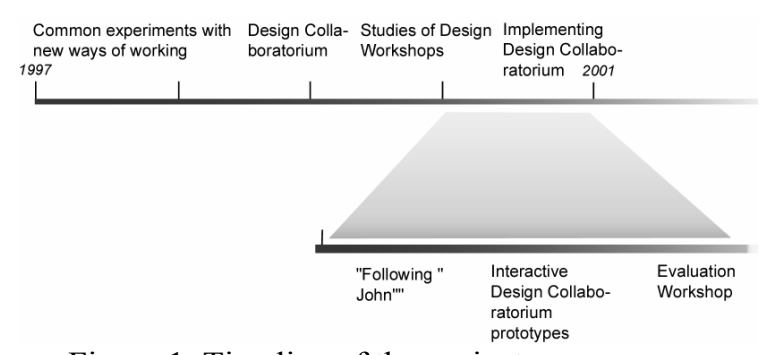

Figure 1. Timeline of the project

\subsection{Structure of paper}

The paper tells the story of a development involving empirical studies of a particular usability design practice (selected from a large body of work conducted over the last 4 years, supplemented with specific studies, see Figure 1), theoretical elaboration of findings, design proposals utilizing recent wall, portable and interaction technology, and design workshops in which the design prototypes were evaluated together with users. Obviously we have been very selective in telling this story, and other pieces of the story have been reported on elsewhere (e.g. Buur \& Bødker, 2000, Madsen \& Graves Petersen, 1999, Büscher et al., 2000). We have chosen to structure the paper so as to reflect the steps in the development process, and accordingly it is focussed on: the design collaboratorium idea, the experimental implementation, the inspiration that we got from this setting in designing the interactive design collaboratorium, the presentation of the design/prototype, and an account of the evaluation of this prototype in a work- shop with the practitioners. We conclude with a set of requirements for the interactive design collaboratorium.

\section{Bang \& Olufsen}

Bang \& Olufsen is a manufacturer of integrated video and audio products linked in a small network allowing the products to share services. The products are primarily installed in private homes. The usability work is linked to the design concept phase and the group is responsible for the interaction design quality of all Bang $\&$ Olufsen products. The work has been characterized by a high degree of division of work and qualifications: industrial designers design, engineers build prototypes, and the psychologist does the testing (Bærentsen \& Slavensky, 1999). The main point of coordination between these groups was meetings where all groups would contribute to the discussion of prototypes. Users have primarily been brought into the evaluation process in tests, and the results of these tests have been fed back to designers and engineers in meetings.

\section{Experimental implementation of the design collaboratorium}

The usability design group at Bang \& Olufsen has chosen to experimentally implement the design collaboratorium by rearranging their use of space. In the following, we discuss the problems and potentials of the present work practice of the group, as it unfolds in and around the central meeting room, with respect to the visions of the design collaboratorium.

The group has basically created a workshop in the classical sense: a joint room where people can cooperate or work alongside each other. The room is the physical framing of workshops with users, usability evaluation sessions, meetings, and work activities of smaller groups of usability professionals, designers, and engineers; in parallel or interleaved with each other. Thus the room is used extensively by all group members, and serves a series of purposes. The room is equipped with a number of whiteboards of varying sizes. Further, it holds prototypes of earlier and present projects. The layout of the room has a traditional meeting table with whiteboards on the surrounding walls and prototypes positioned on shelves on the walls (see Figure 2).

We have followed one person-John-on his job for 3 days. John is project coordinator at the usability design group. As a project coordinator his job is to monitor and supervise the various design projects initiated by the group. On his job, John is in continuous personal contact with many people, both at Bang \& Olufsen and 
from other companies i.e. subcontractors and external designers.

During the days when John was observed, we saw how he worked both in and outside the common room. The following characteristic work situations suggest the spectrum of different settings.

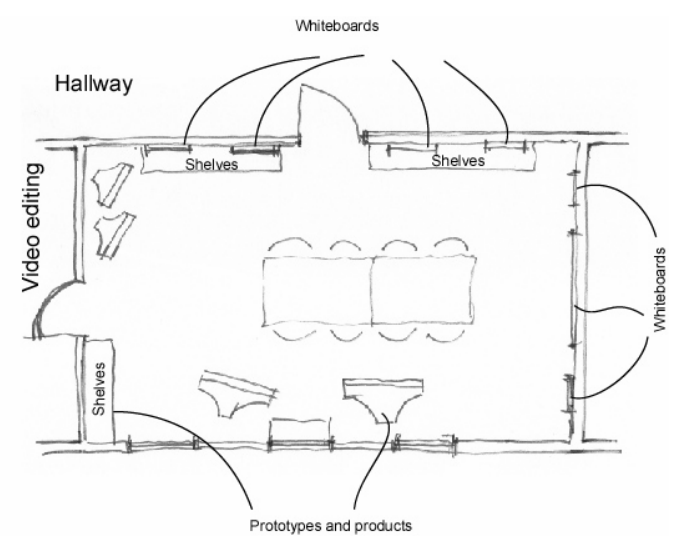

Figure 2. The design collaboratorium room

\section{Situation 1- the common meeting}

Common meetings are formal meetings with very different and varying agendas ranging from deciding on holiday plans through status reports of design projects to intense brainstorming sessions. These sessions involve the entire usability design group, and they typically take place in the design collaboratorium. Decisions are partly materialized in the participants' personal notebooks and partly written down on the whiteboards in the room.

\section{Situation 2 - the design meeting}

Design activities takes place in offices or production areas with the purpose of furthering the design process. John and collaborators make joint sketches and develop prototypes based on ideas developed in earlier brainstorm meetings, or they discuss problems with the implementation of design decisions. This type of work relies heavily on knowledge of the intentions and design decisions made in earlier meetings, e.g. after a brainstorm session. John and other participants of these design meetings carry this information around as personal notes if materialized at all, and the information is passed on verbally to the implementors.

\section{Situation 3 - spontaneous encounters}

Spontaneous encounters with colleagues in hallways or in offices. These typically involve two to three persons discussing implementation problems and design issues. Such discussions are rarely captured in any formal way.

These work situations are characterized by a high degree of verbal interaction. Little is done to capture design decisions made in any shared form (pictures or notes) except for on whiteboards when available. When discussions or decisions are captured, they are typically recorded in personal notebooks.

\section{Key findings from current practice}

The findings from following John and from other studies of the design collaboratorium at Bang \& Olufsen are summarized through the headings of the four initial requirements of the design collaboratorium idea.

\subsection{Accumulation of design knowledge}

The present implementation of the design collaboratorium at Bang \& Olufsen accumulates design knowledge in different forms:

In the design collaboratorium the presence of prototypes from present and previous projects serves to support an awareness in the group of ongoing projects. Exemplar previous products provide a sense of history of the company line. The design knowledge in the group is summarized in a set of principles for good interface design, which are kept an A3 sheet of paper, pinned on one of the boards in the room, annotated with notes on a small whiteboard.

After a common meeting in the design collaboratorium all the whiteboards were covered with notes from a brainstorm. Minutes were produced from the meeting. Due to the quality of the brainstorm, however, it was decided that the whiteboards were to be left untouched for a week to inspire the people working on the project in their further work and to serve as a reference for an external designer, who was due to arrive later. Accordingly none of the whiteboards could be used for a week. While the whiteboards worked well during the brainstorm, i.e. they were used as point of reference and annotated during the discussions, the choice of leaving them untouched for a week severely limited the usefulness of the design collaboratorium for the purpose of other projects during that period.

Secondly, the usefulness of the notes was limited by the trivial fact that they were only available in this specific room. Thus spontaneous encounters in hallways and design activities in other locations, discussing the same project, could not benefit from this resource.

Thirdly, the extent of the use of whiteboards and other means of shared sketching and note-taking both in and outside of the present design collaboratorium room varied. During some events nothing was noted down, whereas during others, all the boards were covered with notes and drawings capturing ideas, thoughts and proposals. As an example, a project kick-off meeting produced a number of ideas which were not materialized in any form. Indeed the meeting was very 
productive in forming visions and scenarios of future use of the product in question. However, since these ideas and visions were not recorded, the prototype developer, who had not been present at the meeting, could not benefit from the discussion and lacked inspiration and a starting point for initial design of prototypes.

Hence, the present setting does not have the flexibility for supporting shifts between events on different projects during the day, while preserving continuity on the individual design projects. The lack of materialization in the design process constitutes an additional obstacle for the accumulation of design knowledge within and across projects.

In the various design situations we have observed, most often very few personal notes are taken. In some cases it is only when the process reaches the state where prototypes are produced that the design decisions made during the design process get materialized (see also Madsen \& Graves Petersen, 1999).

\subsection{Inspiring innovation}

In our previous work on the design collaboratorium, we have outlined essential elements in supporting creativity in cooperative design work (Bødker et al., 2000). We point out how past and present products and stylistic trends can serve to inspire innovation in future products. In the present implementation of the design collaboratorium, the presence of present and past Bang \& Olufsen prototypes as well as competitors' products are brought into the discussions and thus inform the design of the future. Further, a team member is working to develop a set of principles for interaction design based on psychological theories, in this way making theory a possible source of inspiration in design work.

(Madsen \& Graves Petersen, 1999) pointed out how the flexibility of the design materials, and the physical organization of the room are important elements in supporting cooperation in design. Although the design collaboratorium holds prototypes of various forms, there are most often very few flexible, low tech materials like screendumps, pictures, post-it notes, posters etc. available. The prototypes cannot be modified on the spot and the lack of flexible materials makes it hard for the participants to materialize the discussions in a common form and to create a common ground for a continued discussion.

\subsection{Reflecting use context}

The context of use of Bang \& Olufsen products is represented by a full scale living room which acts as test facility. Although this living room is located near the design collaboratorium, it is not a part of it at present. This separation continues because the tests are carried out by one member of the group and the experiences are brought into the group mainly by this person. The longterm vision is that the test room should be connected to the design collaboratorium through a video-connection so that the group can share experiences from the tests as a direct part of the design work (Madsen \& Borgholm, 1999).

\subsection{Cooperation between changing constellations of participants}

As we see from following John, he cooperates with many people during his working day. He shifts between larger, preplanned meetings, and smaller ones, some of which are more ad hoc.

In planned meetings, it sometimes happens that participants bring artifacts to mediate the discussion. Often meetings take unexpected turns and the participants either have to continue without relevant artifacts or alternatively leave the meeting to pick up the needed materials. As an example, the agenda of the aforementioned project kick-off meeting did not include a brainstorm, but was rather intended to resolve areas of responsibility among the groups with respect to this new specific project. Hence the prototype designer was missing, along with means of capturing the discussions for him.

Even though John was aware of the fact that he may later need to talk to the prototype designer, he often has no documentation of the process to bring along, and accordingly the lack of material outcome is indeed a severe problem, also when the constellations of participants changes.

In situations where the design collaboratorium room has been left untouched and notes taken, it would in some instances be useful for him to bring his new collaborators into the room, and in this way recapture the discussion. In other cases this is not possible, even when the room is left unchanged. In these cases, it is important for him to decide which notes to take and which documentation in general to bring away from the meeting.

Even when John has a plan of people to talk to in a given day, he often meet people in the hall, and it is difficult for John to anticipate whom he may end up working with, where and when. Accordingly John may need to carry vast quantities of notes and documentation around in a regular working day. This is unrealistic, and most often not done.

\section{The interactive design collaboratorium}

In order to address some of the challenges and conflicts in present design work, as identified above, we have 
prototyped an augmented environment for design work - an interactive design collaboratorium.

We have developed a room-sized prototype combined with a concept for how information and materials can be brought in and out of the room, and for shift between private and shared forms of information and materials. The room has interactive walls with rear projections, serving as enhanced whiteboards. It further contains a designer's workbench with a projection in the tabletop showing the projected workspaces either in 2D or $3 \mathrm{D}$. The prototypes takes advantage of the Open Hypermedia application "Manufaktur" (Büscher et al 1999) as interface in the prototypes. This interface provides a link structure that supports users working with "live" documents and objects in a 3D environment where "workspaces" are used as a structuring mechanism.

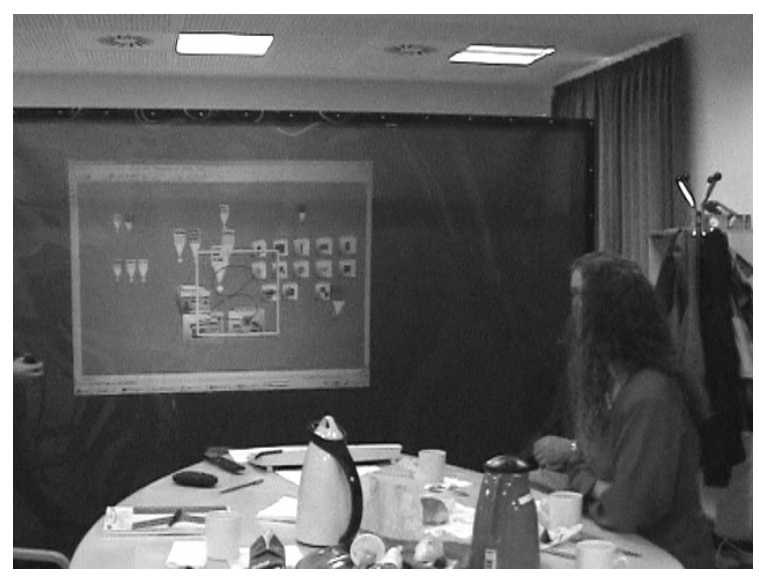

Figure 3. The interactive design collaboratorium

Furthermore the application supports annotations. All interaction with the prototype applies an IR-pen and a wireless keyboard.

Through palmtops users can bring electronic link structures to and from the room, to be accessed on the palmtop or on walls and boards elsewhere. Objects can be moved between walls, the table and the personal palmtop.

The following scenarios were used in exploring how the interactive design collaboratoruim would support and change the work in the usability design group. They match the 3 situations from John's work described earlier.

\section{Scenario 1}

The common room is equipped with projection walls, an elevated meeting table and high stools. The group discusses holiday plans displayed on an interactive boards projected on the walls. The group moves on to brainstorm regarding a new project. The outcome of the brainstorm is added to the displayed workspace by taking notes, as on a whiteboard and additionally attaching these notes to the displayed documents. The interactive boards are used to sketch visions. While elaborating on the common ideas, each person also seeks to relate the visions to the parts they are responsible for. At some point, the implementation coordinator uses her palmtop to drag a list of component specifications onto the common board. She reminds everybody of the limitations of the components, and John makes a note on the board to check the recent developments in specifications. He does that by walking to the board and writing an annotation on the specifications list. In order to develop some use scenarios, they look at pictures of past design, and agree on a couple that they want to keep as reminders for the continuation. John drags these to the current collection of documents, using the IR-pen. The scenarios get adjusted in light of the comment and the meeting ends up with a set of sketches of future scenarios on the boards. The technician drags the most problematic scenarios, as seen from her perspective, to her personal "to do" list. As the room is left, a snapshot of the walls is saved by John.

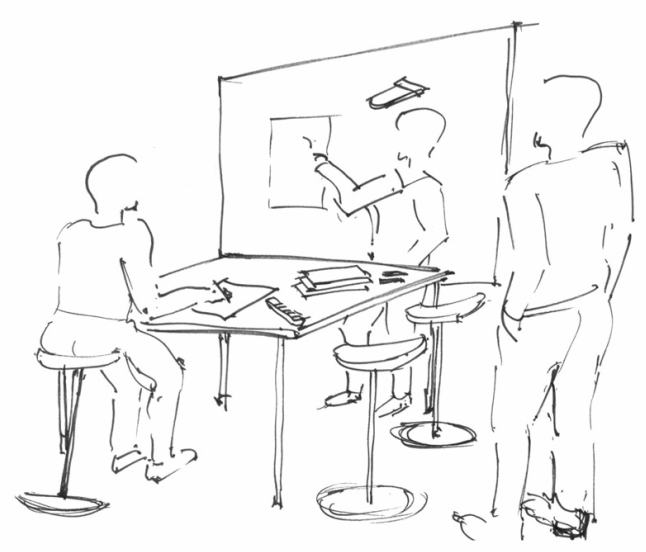

Figure 4. Scenario 1 - the common meeting 


\section{Scenario 2}

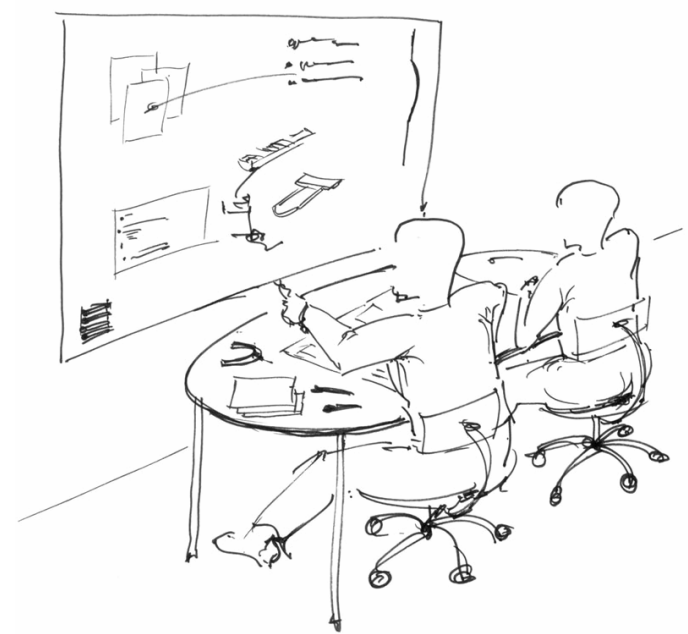

Figure 5. Scenario 2 - the design session

When John later meets with the prototype developer, Brian, he uses his palmtop to drag the snapshot from the brainstorm meeting to Brian's office board. Brian's office is equipped with a projection board and a designer's workbench table. John explains the visions and ideas which came up during the meeting. Brian asks questions and together they start sketching the prototype on the designer's workbench. They choose to look at one of the previous products in $3 \mathrm{D}$ to find out if it can be used as the basis for an early prototype. They retrieve a number of design documents that specify the menu structure of this past product, and they discuss if the prototype could be based on this same structure. Brian sketches a couple of alternatives as simple drawings directly on the workbench. John needs to leave, and Brian continue to work on the collection of documents.

\section{Scenario 3}

On his way to the next meeting, John passes his boss' office. Andrew, the boss, calls him in and points to his board, where a snapshot is projected. He tells John the latest news from a recent meeting. During this meeting they have come up with a suggestion which Andrew finds questionable and he asks John for advice. The problem reminds John of a discussions he has attended earlier in the day. Using his palmtop, he retrieves the relevant document from the brainstorm meeting and drags it to Andrews' workspace. Andrew keeps the new sketch on his board for further thoughts and discussions.

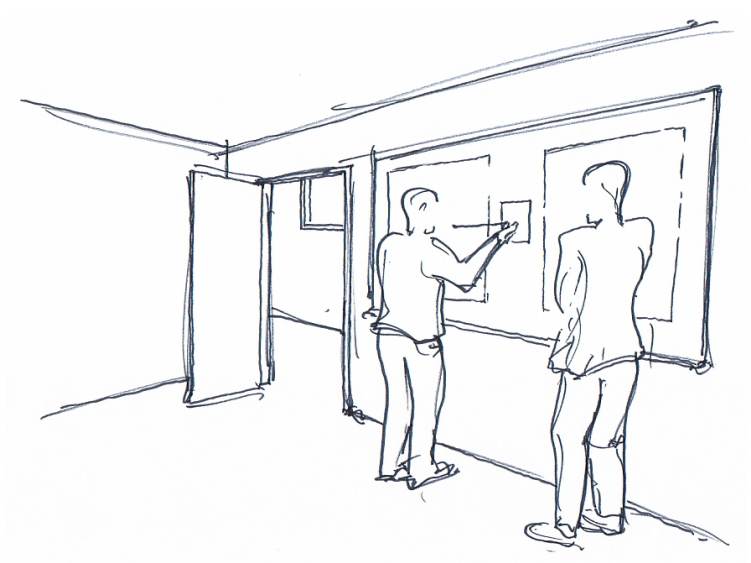

Figure 6. Scenario 3 - the ad hoc meeting

\section{Evaluation with users}

We evaluated scenarios 1 and 2 through a cooperative design workshop with the usability design group, whereas we have not yet evaluated scenario 3 . Basically, the group held two of their scheduled meetings, reflecting scenarios 1 and 2, in the interactive design collaboratorium rather than at home. Project material had been incorporated in the prototypes in advance.

Working with scenario 1 , the group of 5 people was to initiate a brainstorming session based on an electronic version of their own documents and make annotations capturing ideas and new connections between documents. The result of this session was to be used in the next setting, addressing scenario 2 . This scenario added the designer's workbench to the arrangement and included only two participants. The task was to refine and specialize the outcome of the brainstorm session.

Notes and documents were used extensively in both sessions to underpin issues raised in the discussions and to qualify design ideas. In this type of use, the participants tended to want to shuffle around documents by hand and gestures, whereas when drawing and writing the use of a pen-like physical device seemed more desirable.

Having the pool of project documents available at hand was seen as a powerful resource. It happened several times that participants opened new documents during the discussion to illustrate their opinions or to remind them selves of e.g. technical specifications or of strategic product scenarios. They argued that without this support, they would typically not have bothered to find the material, since the only alternative would be to leave the meeting to pick up material.

The lack of a personal notebook was seen as a problem in both settings. Writing in the notebook is 
often seen to signify to others that "this" is recorded and will be taken care of. The participants also requested an easy way of making personal notes public, e.g. by dragging them to the common space.

The physical setting in session 1 with extended stools, around a high positioned table was intended to encourage a lively activity and get everybody to step up to the wall. Apart from being puzzled by the novel arrangement of stools, table and wall at the beginning of the workshop, the participants adopted the setting fast and most of them went up to the wall to note down issues.

In session 2, the need for easy shifting of materials between the wall and the designer's workbench was identified. By intuition the designers placed the document they expected to modify on the tabletop, rather than on the wall. However, one of the documents placed on the wall ended up being central in their discussion, and they did not know how to move it to the tabletop for easy modification.

\section{Requirements of the interactive design collaboratorium}

The field studies and prototype experiments point to a number of issues of consequence to our future work. First of all, we clearly identify the need for different ways of accumulating design knowledge:

\section{Snapshots}

To support the accumulation of design knowledge in individual design projects, the interactive design collaboratorium must provide a way of capturing snapshots of design meetings for later re-use. These snapshots must maintain the spatial layout of the documents to make it easy to reconstruct the document space for a subsequent meeting, or for the individual designer to return to earlier ideas and decisions.

\section{Collections}

As a different way of supporting the accumulation of design knowledge and inspire innovation, the interactive design collaboratorium must support individuals in selecting and saving (e.g. by transferring to the palmtop) the collection of documents that they need to keep or bring. Furthermore, such collections can be used by groups e.g. as a way of saving a collection of good ideas for later inspirational purposes or as a reflection of a particular use context.

\section{Locales}

Locales is a concept that deals with our concern for the physical organization of the room. It augments the concern for the spatial arrangement of documents by addressing the equally important physical objects and documents of the design situation. We make no assumption that a digital environment is better than physical objects and documents. Accordingly it is important that the interactive design collaboratorium supports the handling of physical artefacts, and at a later stage, that these can be tagged and traced as part of the set-up of the interactive design collaboratorium.

We have experimented with snapshots and collections and with ways of tagging and tracing physical objects. We have, however, not yet invented the magic wand that put the physical objects back in their place as part of the re-launching of a snapshot.

In our experience, saving e.g. the outcome of a design meeting is not a matter of saving everything. Rather we propose that saving the outcome of a meeting involves some amount of thought and cleaning up, so that whatever is saved, is saved with a concern for possible future uses. The case shows that the various design meetings and sessions involve ever-changing constellations of collaborators, and hence that new people will be expected to "join" the design documentation in many parts of the process.

The case also illustrates how the primary concern must be with supporting people in actually creating joint design manifestations in the process, before there is anything (beyond spoken words) to share.

The requirements of the design collaboratorium can now be addressed in terms of "how to do it":

\section{It accumulates design knowledge}

The case shows how we need different types of support for accumulation of design knowledge (snapshots, collections and locales).

\section{It reflects the use context}

At present, the test facility living room is not well integrated in the design collaboratorium. We see a number of ways of resolving this. The test room could be equipped with interactive walls and meetings could be held in the room, or the proposed video connection could be projected into the interactive workspace. Collections of images and documents of the use context is an additional possibility.

\section{It inspires innovation}

Personal collections play a role in inspiring innovation in that they provide means for the participants to present materials from their discipline and experience. Group collections similarly can evolve over themes like e.g. competitor products or a company "museum", and thus inspire the process.

The awareness created through persistent checklists and traces from other projects also serves to inspire innovation. 
It supports open and closed cooperation between changing constellations of participants

The changing constellations of participants throughout a project, reinforces the need for materialization in terms of snapshots and collections.

Awareness of other participants is important. E.g. writing something in a notebook is an act of taking responsibility, and hence, not all writing is interesting for the substance as much as for the act. Accordingly, it is necessary to provide support for note-taking on the palmtop as alternative to writing on the board.

At a larger scale, leaving objects, checklists, etc. behind in the common room is a way of creating awareness between groups and projects, of what each other are doing. In the interactive design collaboratorium, this means that there is a need for persistent documents and objects, for things to be left behind, once a project meeting is wrapped up and saved.

One possibility is that certain areas and boards are reserved for e.g. inspiration rooms, where potentially relevant objects can be dragged whenever convenient. This is a way of using the spatial organization of the room without interfering with the actual working area of any particular project.

The research further poses additional requirements to the interactive design collaboratorium:

\section{It supports mobility}

Though Bang \& Olufsen has built a design collaboratorium room, many design activities take place outside this room. Hence design activities take place in many physical locations, some ad hoc, and some in other locations that have a particular purpose, e.g. the test lab.

In the present case, everybody made use of personal notebooks to record and carry the thoughts and ideas that they found of use. And John in many instances prepared his trip around the building by collecting documents that he thought would be needed. Despite this, he often had not brought what he needed. The palmtop solution helps him bring more stuff along as links to documents, to project on walls and boards in various places. Hence, snapshots and collections and not just of individual documents must be moveable.

It integrates the physical organization and the digital materials

In scenario 1, the spatial arrangement of digital documents and annotations were successfully supported by the physical organization of the room in terms of extended stools making it easy for participants to move to the wall to contribute to the materialization of design ideas.

Locales is a further concept that deals with our concern for the physical organization of the room.
An interesting prospect that we haven't yet dealt with is that of other locales than the common room. E.g. a meeting in the test room could put other requirements on the constellation of physical and virtual objects, and constellations could be kept to support later configurations of the room, where e.g. particular documents have been changed in between.

Based on a long-term cooperation with the usability design group at Bang \& Olufsen we have further developed the vision of the design collaboratorium to take advantage of interactive room technologies. We have framed our findings in the concept of the interactive design collaboratorium, and in a set of requirements for this. We see this contribution as an important step in informing our own future experiments with interactive rooms, as well as valuable in informing general problems of interactive design rooms.

\section{Acknowledgement}

The interactive design collaboratorium has been developed by a large group of people in the iRoom project. Astrid Søndergaard has been closely involved with the case study. We would like to thank Henning Slavensky, Karsten Moesgaard and the usability design group at Bang and Olufsen for their contribution to our research. The project has been sponsored by CIT (BIDI and Pervasive computing), by the Centers for HumanMachine Interaction and for Integrated Design. Kaj Grønbæk and Polle Zellweger have provided us with many useful comments.

\section{References}

Buur, J. \& Bødker, S. (2000). From usability lab to "design collaboratorium". Reframing usability practice. DIS 2000 conference proceedings. ACM, pp. 297-307

Büscher, M., Mogensen, P., Shapiro, D. \& Wagner, I. (1999). The Manufaktur: Supporting Work Practice in (Landscape) Architecture. Proc. The Sixth European Conference on Computer Supported Cooperative Work, Kluwer Academic Press, Copenhagen, Denmark, 21-40

Büscher,, M., Christensen, M., Grønbæk, K., Krogh, P., Mogensen, P., Shapiro, D. \& Ørbæk, P. (2000) Collaborative augmented reality environments: integrating VR working materials, and distributed work spaces; Proceedings of the third international conference on Collaborative virtual environments, pp. 47-56

Bødker, S., Graves Petersen, M. \& Nielsen, C. (2000). Creativity, cooperation and interactive design. DIS 2000 conference proceedings. ACM, pp. 252-261 
Churchill, E. \& Snowdon, D. (1998) Collaborative Virtual Environments: an introductory review of issues and systems. Virtual Reality: Research, Development and Application

Karat, J. \& Bennett, J. (1991) Using scenarios in design meetings, A case study example. In Karat, J. (ed.). Taking software design seriously: Practical techniques for human-computer interaction design, Boston: Academic Press, pp. 63-94

Madsen K.H. and Borgholm, T. (1999). Cooperative Usability Practices. CACM, 42, 5, pp. 91-97

Madsen, K.H. \& Petersen M.G. Supporting collaboration in multi-media design, Brewster, S. Cawsey, A. \& Cockton, G. (eds.)(1999). Human-Computer Interaction INTERACT'99, IFIP, pp 185-190
Pedersen, E., McCall, K.., Moran, T. \& Halasz, F. (1993). Tivoli: an electronic whiteboard for informal workgroup meetings. Proceedings of the conference on Human factors in computing systems, ACM pp. 391-398

Rekimoto, J.(1998) A multiple device approach for supporting whiteboard-based interaction. Proceedings of the conference on Human factors in computing systems, pp. 344-351

Schmidt, K. \& Bannon, L. (1992). Taking CSCW Seriously: Supporting Articulation Work. CSCW Journal, 1(1), 7-40

Streitz, N., Geissler, J., Holmer, T., Konomi, S., MullerTomfelde, C., Reischl, W., Rexroth, P., Seitz, P., \& Steinmetz, P. (1999). i-LAND: An Interactive Landscape for Creativity and Innovation Collaborative and Multimedia Systems. Proceedings of the conference on Human factors in computing systems, ACM, pp.120-127 